\title{
The organization of the substrate of proprioception in the elbow region of the rat
}

Citation for published version (APA):

van der Wal, J. C. (1988). The organization of the substrate of proprioception in the elbow region of the rat. [Doctoral Thesis, Maastricht University]. Rijksuniversiteit Limburg.

https://doi.org/10.26481/dis.19881216jw

Document status and date:

Published: 01/01/1988

DOI:

10.26481/dis.19881216jw

Document Version:

Publisher's PDF, also known as Version of record

\section{Please check the document version of this publication:}

- A submitted manuscript is the version of the article upon submission and before peer-review. There can be important differences between the submitted version and the official published version of record.

People interested in the research are advised to contact the author for the final version of the publication, or visit the DOI to the publisher's website.

- The final author version and the galley proof are versions of the publication after peer review.

- The final published version features the final layout of the paper including the volume, issue and page numbers.

Link to publication

\footnotetext{
General rights rights.

- You may freely distribute the URL identifying the publication in the public portal. please follow below link for the End User Agreement:

www.umlib.nl/taverne-license

Take down policy

If you believe that this document breaches copyright please contact us at:

repository@maastrichtuniversity.nl

providing details and we will investigate your claim.
}

Copyright and moral rights for the publications made accessible in the public portal are retained by the authors and/or other copyright owners and it is a condition of accessing publications that users recognise and abide by the legal requirements associated with these

- Users may download and print one copy of any publication from the public portal for the purpose of private study or research.

- You may not further distribute the material or use it for any profit-making activity or commercial gain

If the publication is distributed under the terms of Article $25 \mathrm{fa}$ of the Dutch Copyright Act, indicated by the "Taverne" license above, 
THE ORGANIZATION OF THE SUBSTRATE OF PROPRIOCEPTION IN

THE ELBOW REGION OF THE RAT 



\section{THE ORGANIZATION OF THE SUBSTRATE OF PROPRIOCEPTION IN \\ THE ELBOW REGION OF THE RAT}

\section{PROEFSCHRIFT}

ter verkrijging van de graad van doctor

aan de Rijksuniversiteit Limburg te Maastricht, op gezag van de Rector Magnificus, Prof. Dr. F.I.M. Bonke,

volgens het besluit van het College van Dekanen.

in het openbaar te verdedigen op vrijdag 16 december 1988

om 16.00 uur

door

\section{JACOB CORNELIS VAN DER WAL}

geboren op 17 februari 1947 te Maarsseveen 
Promotor: Proff. Dr. J. Drukker

Co-promotor: Dr. H. van Mameren

Beoordelingscommissie:

Prof. Dr. F. Spaans, Rijksuniversiteit Limburg (voorzitter)

Prof. Dr. J.L. Dubbeldam, Rijksuniversiteit Leiden

Prof. Dr. F. ten Hoor, Rijksuniversiteit Limburg

Prof. Dr. P.E. Voorhoeve, Universiteit van Amsterdam

Prof. Dr. G.J. van de Vusse, Rijksuniversiteit Limburg

Colofon:

tekeningen/grafische vormgeving

H. Rensema

opmaak

J. Beursgens

$H$. Rensema

correctie vertaling

M. Drukker-Boxman

druk

Krips Repro B.V. Meppel 
Was ist das Schwerste van allem?

Was dir das leichteste dünket:

mit den Augen zu sehen,

was vor den Augen liegt.

\section{GOETHE}

ftekst op de wand van de microscopiezaal van het Anatomisch Instituut van de Universiteit van Hamburg) 
De uitgave van dit proefschrift werd mede mogelijk gemaakt door financiële steun van de Stichting Het Remmert Adriaan Laan Fonds en van de Nederlandse organisatie voor zuiver-wetenschappelijk onderzoek Z.W.O.

(C) 1988 No part of this book may be reproduced in any form, by print, photoprint, microfilm or any other means, without written permission from the author. 


\section{Table of Contents}

\section{Chapter 1}

Introduction

\section{Chapter 2}

\section{Materials and methods}

$\begin{array}{ll}\text { Contents } & 19\end{array}$

$\begin{array}{ll}\text { Summary } & 19\end{array}$

2.1 Microscopical techniques 20

2.1.1 Acetylcholinesterase in toto staining method 20

2.1.2 Formaldehyde Induced Fluorescence (F.I.F.) 20

2.1.3 Silver impregnation method according to Holmes 21

2.1.4 Silwer impregnation method according to Spaethe 21

2.1.5 Ultramicroscopical techniques and staining method according to 21 Laczko and Levai

2.2 Techniques for three-dimensional representation and quantification 23

2.2 .1 Dissection 23

2.2.2 Three-dimensional reconstruction 24

2.2.2.1 Preparation (plastic embedding and Trichrome staining) 24

2.2.2.2 Plotting and drawing methods 26

2.2.2.3 Three-dimensional reconstruction of the substrate of proprioception 27

2.2.3 Quantification of the substrate of proprioception 28

\section{Chapter 3}

Architecture of muscular and connective tissue in the lateral cubital region

\section{Contents}

Surmmary

3.1 Muscular and skeletal tissue structures in the lateral cubital and antebrachial region (definitions and nomenclature)

3.2 Architecture of regular dense collagenous connective tissue (in relation to the architecture of muscular tissue) 41

3.2.1 Superficial muscle compartments and connective tissue layers

3.2.2 Deep muscle compartments and connective tissue layers

3.3 Architecture of muscular and connective tissue in the lateral cubital region (integral description)

3.4 Discussion

3.5 Conclusions

3.6 Some characteristic transwerse sections of the cubital and antebrachial region (Appendix) 
Chapter 4

Quantitative parameters of the morphological substrate of proprioception

$\begin{array}{llr} & \text { Contents } & 65 \\ & \text { Summary } & 65 \\ 4.1 & \text { Introduction } & 66 \\ 4.2 & \text { Results } & 67 \\ 4.3 & \text { Discussion } & 73 \\ 4.4 & \text { Conclusions } & 77\end{array}$

\section{Chapter 5}

Proprioceptive substrate related to the proximal connective tissue apparatus

Contents

Summary

5.1 Introduction

80

52 Materials

80

53 Results

5.3.1 Nervous tissue elements related to the superficial muscle compartment walls

5.3.2 Nervous tissue elements related to the supinator muscle compartment walls

5.4 Discussion

5.5 Conclusions

\section{Chapter 6}

Muscle spindles and golgi tendon organs in relation to the architecture of muscular and connective tissue

$\begin{array}{ll}\text { Contents } & 105\end{array}$

Summary $\quad 105$

6.1 Introduction $\quad 106$

$\begin{array}{lll}6.2 & \text { Results } & 108\end{array}$

6.2.1 Occurrence of muscle spindlles and GTO's per muscle area 109

6.2.2 Occurrence of muscle spindlle/GTO zones considered regionally 129

6.3 Discussion $\quad 132$

6.4 Conclusions 139 
Chapter 7

Substrate of proprioception related to the periskeletal connective tissue

Contents

141

Summary

141

7.1 Introduction

7.2 Materials

7.3 Results

7.3.1 Nerve elements in the periosteal connective tissue

7.3.2 Pacinian corpuscles

7.4 Discussion

7.5 Conclusions

\section{Chapter 8}

Final discussion and general conclusions

\section{Chapter 9}

References

Chapter 10

Summary 175

Samenvatting

Nawoord 


\section{LEGEND OF ABBREVIATIONS AND SYMBOLS AS USED IN TEXT AND FIGURES}

\begin{tabular}{|c|c|c|}
\hline $\begin{array}{l}\text { Abbute- } \\
\text { viation } \\
\text { (Text) }\end{array}$ & $\begin{array}{l}\text { Symbol } \\
\text { (Figs) }\end{array}$ & MAME OF THE STRUCTURE \\
\hline & & MUSCULAR TISSUE STRUCTURES \\
\hline & & SUPERFICIAL EXTENSOR MUSCLES \\
\hline $\mathrm{ECU}$ & 1 & Extensor carpi ulnaris muscle \\
\hline ECU.hum. & 1.1 & $\begin{array}{l}\text { Part of ECU indirectly attached to the lateral humeral } \\
\text { epicondyle (humeral head) }\end{array}$ \\
\hline ECU.uln. & 1.2 & Part of ECU mainly attached to the ulna (ulnar head) \\
\hline EDL & 2 & Extensor digitorum lateralis muscle \\
\hline $\mathrm{EDC}$ & 3 & Extensor digitorum communis muscle \\
\hline $\mathrm{ECR}$ & 4 & Extensor carpi radialis muscle \\
\hline ECR.br. & 4.1 & Extensor carpi radialis brevis muscle \\
\hline ECR.10. & 4.2 & $\begin{array}{l}\text { Extensor carpi radialis longus muscle } \\
\text { DEEP EXTENSOR MUSCLES }\end{array}$ \\
\hline EDP & 5 & Extensor digiti primi muscle \\
\hline EDP.uln. & 5.1 & Part of EDP attached to the ulnar bone (ulnar head) \\
\hline EDP.rad. & 5.2 & Part of EDP attached to the radial bone (radial head) \\
\hline EI & 6 & Extensor indicis muscle \\
\hline SUP & 7 & $\begin{array}{l}\text { Supinator muscle } \\
\text { OTHER EXTENSOR MUSCLES }\end{array}$ \\
\hline TR & 8 & Triceps muscle \\
\hline TR.10. & 8.1 & Long head of triceps muscle (caput longum) \\
\hline TR.lat. & 8.2 & Lateral head of triceps muscle (caput laterale) \\
\hline TR.med. & 8.3 & Medial head of triceps muscle (caput mediale) \\
\hline $\mathrm{ANC}$ & 9 & $\begin{array}{l}\text { Anconeus muscle } \\
\text { FLEXOR MUSCLES }\end{array}$ \\
\hline BIC & 10 & Biceps brachii muscle \\
\hline BRA & 11 & Brachialis muscle \\
\hline FLEX & 12 & Antebrachial flexor muscles \\
\hline
\end{tabular}

\section{CONNECTIVE TISSUE STRUCTURES}

$\begin{array}{ll}\text { ecu/edl } & a \\ \text { ecu/edl.u } & \text { a.a } \\ \text { ecu/edl.l } & \text { a.b } \\ \text { ecu/edl. } & \text { a.c } \\ \text { edl/edc } & \text { b } \\ \text { edc/ect } & c \\ \text { ext.fas. } & \text { d }\end{array}$

Layers between ECU and EDL muscles

Part of ecu/edl to which muscle fascicles of ECU and ANC insert - including floor layer of ECU compartment Part of ecu/edl to which muscle fascicles of EDL insert Intramuscular distal prolongation of ecu/edl.u Intermuscular layer (septum) between EDL and EDC Intermuscular layer (septum) between EDC and ECR Superficial antebrachial (fascial) layer constituted by outer compartment walls of the superficial extensor muscles (and of the triceps muscle) 


$\begin{array}{ll}\begin{array}{l}\text { ret.ol. } \\ \text { (tr.fas.) }\end{array} & \text { d.a } \\ \text { s.s. } & \mathrm{e} \\ \text { s.s.im. } & \text { e.e } \\ \text { l.c.uln. } & \mathrm{f} \\ \text { l.c.rad. } & \mathrm{g} \\ \text { d.c.com. } & \mathrm{h} \\ \text { ct.com. } & \mathrm{k} \\ & \\ \text { edp/ei. } & \mathrm{m} \\ \text { zo.areol. } & \mathrm{n} \\ & \\ \text { zo.int. } & \mathrm{o} \\ & \\ & \\ \text { m.i. } & \mathrm{p} \\ \text { per.uln. } & \mathrm{q} . \mathrm{a} \\ \text { per.rad.. } & \mathrm{q} . \mathrm{b} \\ \text { t.* } & \mathrm{t.*}\end{array}$

Part of ext.fas. constituted by outer compartment walls of the lateral and medial head of the triceps muscle (lateral olecranal retimaculum)

Supinator septum - connective tissue layer, part of the outer wall of the supinator muscle compartment Intramuscular extension of supinator septum Ulnar division of lateral collateral connective tissue layer Radial division of lateral collaterall connective tissue layer Deep common connective tissue layer formed by proximal fusion of s.s., l.c.uln. and l.c.rad.

Common layer formed by proximal fusion of d.c.com. with compartment walls of the superficial extensor muscles Connective tissue layer (septum) between EDP and EI Zone of loose areolar connective tissue on the (outer) superficial side of d.c.com.

Intermediate zone of connective tissue between the distal edge of os.sup. $(=\mathrm{D})$ and the proximal border of the supinator muscular tissue mass Interosseous membrane Periosteal layer of the ulnar bone Periosteal layer of the radial bone

Tendon of * (follows abbreviation or symbol of muscle)

\section{OSSEOUS STRUCTURES}

hum. A cap.hum. A.A tr.hum. A.B ep.lat. A.C cr.sup. A.D ulln. B ol.uln. $\quad$ B.A cr.uln. B.B rad. $\quad C$ tub.rad. C.A cap.rad. C.B colirad. C.C os.sup. D

Humeral bone (Humerus)

Humeral capituilum (Capitulum humeri)

Humeral trochlea (Trochlea humeri)

Lateral humeral epicondyle (Epicondylus lateralis)

Lateral supracondylar crest of humerus (Crista supracondylaris)

Ulnar bone (Ulna)

Olecranal process (Olecranon)

Ulnar crest (dorsolateral ridge on ulnar shaft and olecranon)

Radial bone (Radius)

Radial tuberosity (Tuberositas radii)

Head of the Radial bone (Caput radii)

Neck of the Radial bone (Collum radii)

Supinator (sesamoid) bone in d.c.com. (Os supinatoris)

\section{NERVOUS STRUCTURES}

$\begin{array}{ll}\text { Pl.supf. } & \text { I } \\ \text { Pl.prof. } & \text { II } \\ \text { N.Rad. } & \text { III } \\ \text { R.prof. } & \text { IV }\end{array}$

Nerve plexus in ext.fas. "Plexus superficialis"

Nerve plexus in zo.areol. "Plexus profundus"

Radial nerve (n. radialis)

Deep branch of Radial nerve (r.profundus) 


\section{CHAPTER 1}

\section{INTRODUCTION}

Proprioception is the process of conscious and subconscious sensoring of joint position or motion. The morphological substrate of proprioception - encapsulated or unencapsulated mechanosensitive sensory nerve endings (mechanoreceptors) and related afferent neurons - is considered to provide the centripetal information needed for the control of locomotion or for the maintenance of posture. In general such mechanoreceptors are reported to occur as muscle receptors or joint receptors (Barker, 1974). Muscle receptors are mechanoreceptors present in the muscles, including auxilliary structures like tendons and fasciae: muscle spindles and Golgi tendon organs are the best known types of muscle receptors. Joint receptors are considered to be situated in joint capsules and related structures. The latter category consists of several types, usually ordered according to (ultra)-structure of the receptor itself, to physiological features, type of afferent nerve fiber and other parameters (Gardner, 1950; Skoglund, 1956;
Barnettet al., 1961; Polacek, 1966; Freeman and Wyke, 1967a, 1967b; Skoglund, 1973; Halata et al., 1975; O'Connor and Gonzales 1979; Malinovsky, 1986). In table 1.1 the types and characteristics of some mechanoreceptors are listed according to O'Connor and Gonzales (1979), based on Freeman and Wyke (1967a, 1967b).

Untill recently the concept prevailed that joint receptors play the leading role in the processes of monitoring joint position or movement for purpose of stataesthesis and kinaesthesis, while muscle receptors are relegated to motor functions that operate at a subconscious or reflex level (For review: McCloskey, 1.978 and Matthews, 1981, 1982, Gandevia, 1983).

This concept is nowadays challenged by results of physiological investigations (Burgess and Clark, 1969; Goodwin et al., 1972, Clark and Burgess, 1975; Grigg, 1976; Grigg and Greenspan, 1977; McCloskey, 1978 and Tracey, 1978, 1979, Gandevia, 1983) suggesting that also muscle spindle afferents can

Table 1.1

\begin{tabular}{|c|c|c|c|c|c|}
\hline Type & $\begin{array}{l}\text { Shape and major } \\
\text { structural } \\
\text { characteristics }\end{array}$ & \begin{tabular}{|} 
Average \\
size \\
$(\mu \mathrm{m})$
\end{tabular} & $\begin{array}{l}\text { Diameter } \\
\text { parent } \\
\text { merve }(\mu \mathrm{m})\end{array}$ & $\begin{array}{l}\text { Fhysiological } \\
\text { characteristics }\end{array}$ & $\begin{array}{l}\text { Common } \\
\text { eponyms }\end{array}$ \\
\hline I & $\begin{array}{l}\text { Globular or oval. } \\
\text { Thin capsule } \\
\text { enclosing } \\
\text { fine arborizing } \\
\text { nerve filaments }\end{array}$ & $\begin{array}{r}100 \\
x \\
40\end{array}$ & $5-8$ & $\begin{array}{l}\text { low threshold, } \\
\text { slowly adapting } \\
\text { mechanoreceptor }\end{array}$ & $\begin{array}{l}\text { Ruffini, } \\
\text { Golgi- } \\
\text { Mazzoni, } \\
\text { Meissner, } \\
\text { Spray }\end{array}$ \\
\hline II & $\begin{array}{l}\text { Cylindrical or } \\
\text { conical. Single } \\
\text { axis cylinder } \\
\text { surnounded by } \\
\text { laminated capsule }\end{array}$ & $\begin{array}{c}280 \\
\times \\
120\end{array}$ & $8-12$ & $\begin{array}{l}\text { low threshold, } \\
\text { rapidly adapting } \\
\text { mechanoreceptor }\end{array}$ & $\begin{array}{l}\text { Pacinian, } \\
\text { Paciniform } \\
\text { Vater- } \\
\text { Pacinian, } \\
\text { Pacini }\end{array}$ \\
\hline III & $\begin{array}{l}\text { Fusiform. Thin } \\
\text { capsule around } \\
\text { coarse artorizing } \\
\text { nerve filaments }\end{array}$ & $\begin{array}{c}600 \\
x \\
100\end{array}$ & $13-17$ & $\begin{array}{l}\text { high threshold, } \\
\text { very slowly } \\
\text { adapting } \\
\text { mechanoreceptor }\end{array}$ & $\begin{array}{l}\text { Golgi, } \\
\text { Golgi- } \\
\text { Mazzoni }\end{array}$ \\
\hline
\end{tabular}


contribute to human kinaesthesis. Clinical observations in patients, who retained their kinaesthesis after complete surgical removal or interruption of joint capsules (endoprostheses) and experiments that tested position-sensing abilities following selective anaesthesia of joint capsules in wivo (Goodwin et al. 1972; Cross and McCloskey, 1973; Clark, 1975; Grigg et al., 1973) provided further evidence that muscle spindles (and mechanoreceptors of the skin) also contribute to kinaesthesia (McCloskey, 1978; Millar, 1979; Halata et al., 1985).

On the other hand Ferrell $(1980,1985$, 1988), Ferrell et al. (1986, 1987), Wood and Ferrell (1985) and Baxendale and Ferrell (1987), conclude from their experiments on position sense in human interphalangeal and knee joints, that joint receptors are of importance for the perception of joint movement. It is stated that those receptors only react at the extremes of joint position, acting as "limit detectors"' (Ferrell, 1987). Several authors also mention that the discharge of articular receptors is limited to the positions which significantly stress the joint capsule, in which positions the capsule and related structures are thought to be strained passively (Skoglund, 1973; McCloskey, 1978; Tracey, 1978, 1980; Rossi and Rossi, 1985). Others make it plausible that muscle afferents provide the substrate of mid and/ or full range receptor activity, present in recordings from articular nerves (Grigg, 1975, 1976; Clark and Burgess, 1975; Mclntyre et al., 1978; Ferrell, 1980; Rossi and Grigg, 1982; Rossi and Rossi, 1985).

Abrahams (1982), Richmond and Abrahams $(1975,1979)$ and Richmond and Bakker (1982) describe in the neck region of the cat a variety of sensory endings in so-called "non-articular" connective tissue. They suggest to attribute a more important role in neck proprioception than generally assumed (a.o. Freeman and Wyke, 1967a, $1967 \mathrm{~b}$; Wyke, 1967, 1979), to substrate of mechanoreception that is not situated directly within or near joint capsules. Similar findings are reported by Strasmann and $\mathrm{Ha}$ lata (1988) for the periarticular elbow re- gion in Monodelphis. In summary, it can be stated that the exact identification of the mechanosensitive substrate involved in sensoring joint position and movement has not been established yet. It is questioned whether the localisation of the various kinds of such substrate indeed is restricted to certain constituents of the locomotor apparatus.

Distinction between muscle afferents and articular afferents is implicitly based on the anatomical concept that (peri)articular regular dense collagenous connective tissue structures and muscular tissue structures are organized in parallel to each other along the joint. Most textbooks on anatomy (a.o. Williams and Warwick, 1980) are based on the view, that the collagenous connective tissue structures -joint capsule with reinforcing ligaments etc-- run mainly from bone to bone (continuous with the periosteum of the articulating bones), while muscles - with adnexa as tendons, aponeuroses, epimysial sheaths etc. - are also thought to cross ower the joint, being attached to other areas of the bones. The usual method of dissecting the locomotor apparatus actually is based on this principle and is thought to distinguish between these two types of structures. Usually it is assumed that ligaments as well as muscles contribute to the integrity and stability of a synovial joint. These two constituents of the locomotor apparatus are thought to function more or less in parallel and separately: the former with only passive possibilities to resist stresses, the latter with active (i.e adjustable) stress resisting qualities. In physiological studies (as cited above) to identify the substrate of the perception of joint position or movement and of related stresses, the concept of an in parallell and separate functioning of joint capsule and ligament receptors on the one hand and muscle receptors on the other hand, is challenged on functional arguments. It is not seen however that the anatomical concept of in-parallel and separate organization is abandoned or questioned by these authors.

As to the human elbow joint, the point of 
view about muscular and connective tissue architecture as mentioned above has been challenged however by experiments as performed by Van Mameren (v.Mameren, 1983; Drukker et al., 1983a). The reaction forces resulting from the forces of the biceps and brachioradialis muscle activity ánd an applied external load in a simulation model of the human elbow joint, were calculated. Only a small difference in magnitude and position of these forces was measured between simulations with an intact capsule (including ligaments) and simulations with the capsule sectioned. These findings suggested that in the region of the human elbow joint, passive conveying of tensile stresses does not occur through capsular ligaments alone. Therefore the architecture of the muscular and regular dense collagenous connective tissue in the lateral elbow region in man was investigated. It was concluded that an anatomical basis for the classification of ligaments (apart from muscles), which run from bone to bone, is not valid (v.Mameren et al. 1983; Drukker et al., 1983b, 1983c; v.Mameren and Drukker, 1984).

In those studies a dissection method has been proposed that does not make a distinction between morphological entities like muscles or ligaments, as in classical dissection by removal or splitting of connective tissue. The alternative method proposed is based on separating the two types of tissue of different consistency and of different mechanical qualities i.e. the tissues of the muscle belly (muscular and loose connective tissue) and the complementary remaining regular dense collagenous connective tissue. In this way the elements that can resist stresses actively by varying (adjusting) their length, are separated from the elements to which they are attached and that are only able to resist stresses passively (i.e. with fixed length). This implies that the elements with only passive stress resisting qualities are kept: particularly continuities in the regular dense collagenous connective tissue are spared in this way. This may lead to the preservation of a possibly existing coherent apparatus of such tissue in a given joint te- gion. A descriptional method as suggested here, in fact also deals with the connective tissue as the matrix in which the other main types of tissue of the locomotor system, i.e. skeletal tissues (bone and cartilage), muscular and nervous tissue, are taken up. This copes with the observation that during the development of the locomotor system, the elements differentiate within a matrix of embryonal and foetal connective tissue (mesenchym) which also has potencies to develop independently (cf. Jacob and Christ, 1980; Christ et al. 1983; Christ and Jacob, 1986).

The dissections of Van Mameren and Drukker (1984) gave impetus to the idea that most regular dense collagenous structures in the lateral cubital region actually are continuations of collagenous connective tissue walls of muscle compartments. Only a few collagenous fibers appeared to run from bone to bone. In fact, capsular ligaments like lateral collateral ligament and anular ligament do not exist, or at least cannot be described as separate entities (v.Mameren, 1981; Drukker et al., 1983a-c). A complex apparatus exists in the proximal part of the region, consisting of layers of regular dense collagenous connective tissue converging to the lateral humeral epicondyle and obviously playing an important role in the conveying of tensile stresses.

From these findings Van Mameren and Drukker (1984) postulated that a distinction between morphological entities that transmit force actively and passively (muscles and ligaments) actually has no basis in the anatomy of joints and periarticular structures. As an alternative they state the existence of one system operative in promoting the integrity and stability of a joint, which is morphologically represented by units built up from (regular dense collagenous) connective and muscular tissue, organized in an in-series situation, with variable (adjustable) length and tension. Such units are able to transmit tensille stresses around the joint under static 'as well as under dynamic circumstances. In this view not only alteration 
of joint position produces tension in iuxtaarticular collagenous connective tissue, but. in wivo different tracts of connective tissue can be brought (and kept) under tension and therefore may convey tensile stresses -, dependent on which muscle fascicles are active. Since in the proximal lateral cubitall region the muscle compartment walls are considered as the stress-conveying structures and in the distal extension the "intra"-muscular tendons are considered as such, not the muscles per se are the (actively adjustable) stress-conveying units. Areas of muscular tissue organized in series and between a distal tendon and a component of the proximall collagenous connective tissue apparatus, function as such units. Peters (1988) performed in vitro studies on specimens of the connective tissue septum between extensor digitorum muscle and extensor carpi radialis brevis muscle in the human forearm. He found that different parts of this (proximal) septum are loaded when different (distal) tendons of extensor digitorum muscle are loaded. This seems to affirm the aforementioned notion. Moreover, it has proven to be feasible to formulate a numerical model which predicts the mechanical behaviour of such collagenous membranes (Roddeman et al., 1987a, 1987b; Roddeman, 1988)

The question may be put whether the way in which the architectural and functional relation between muscular and regular dense collagenous connective tissue is defined, has implications for the functional interpretation of occurrence and distribution of the morphological substrate of proprioception in a joint region. The assumption of an inseries organization of muscular and collagenous connective tissue instead of an inparallel organization, strongly influences the view, which areas may be considered to be most "strategic" for substrate of mechanoreception, since deformation or other mechanical stimuli are thought to be the basis for stimulation of such substrate. Besides localisation of mechanosensitive nerve endings within the muscle compartment walls and other components of a pres- umed connective tissue apparatus, such substrate may also be hypothesized to occur in the transitional areas between the regular dense collagenous connective tissue and (inserting) muscle fascicles. After all, deformation is expected to take place in the transition between those two complementary Lissues of the locomotor apparatus with different consistency and mechanical qualities. Similar considerations hold for the transitionall areas between muscular and collagenous connective tissue on the one hand and skeletal tissue on the other hand.

This results in the question if, and to what extent there exists a correlation between the architecture of the muscular and connective tissue and the spatial distribution ("architecture") of the morphological substrate of proprioception.

It is hypothesized that functional interpretation of the occurrence and distribution of the morphological substrate of proprioception has to be based on the spatial relation of the substrate with the architecture of muscular and regular dense collagenous connective tissue regarded as organized and functioning as one stability system.

In this view, muscular activity may not only influence the condition of putative mechano-sensitive substrate within an area of muscular tissue, but also of the mechanoreceptors that are arranged within or adjoining the passive (peri)articular collagenous connective tissue structures organized in series with it. This also has implications for the aforementioned discussion about the contribution of so-called joint receptors respectively muscle receptors to the process of joint position sense and joint movement sense, which regards the outcome of physiological experiments and clinical observations.

Therefor insight into the exact architectural and spatial relationship between muscular and collagenous connective tissue on the one hand and the morphological substrate of proprioception on the other hand is required. Also the structural and physiological properties of the present mechanore- 
ceptors have to be taken into account. A prerequisite for testing this hypothesis is:

- an integral description of the architecture of the muscular and connective tissue in a joint area based on the principles as discussed above, combined with:

- a complete description of the three-dimensional arrangement of all the possible (and detectable) substrate of proprioception present.

We chose to study the lateral cubital and antebrachial region of the rat, because the architectural features in the human lateral elbow region can be described and functionally interpreted as regards their role in the guiding of forces (v.Mameren, 1981; Drukker et al, 1983a-c; v.Mameren and Drukker, 1984). Since an integral description of the morphological substrate of proprioception in man is complicated, the choice was made to study the aforementioned relationship in the elbow region of a (histotechnically) accessible animal as the laboratory rat. Moreover, the choice of an experimental animal provides the possibility of an animal model in which the hypothesized correlation might be studied further.

Prerequisite is a description of the architecture of the muscular and connective tissue based on the issues mentioned above to establish the use of the lateral cubital region of the rat as a model for the in-series organization of the muscular and regular dense collagenous connective tissue in a joint region.

\section{Contents (and plan of action)}

For this study not only techniques were demanded that enable histological recognition of the various types of mechanosensitive substrate, but also techniques for threedimensional representation of the architecture of the muscular and connective tissue as well as of the morphological substrate of proprioception. The materials and methods applied for both purposes will first be described in chapter 2.
Chapter 3 describes the results as to the architecture of the muscular and connective tissue structures as revealed by dissection and by computerized three-dimensional reconstruction of serial sections of complete forelegs embedded in a polyester resin.

For the description of the spatial distribution of the morphological substrate of proprioception it was necessary to clarify our definitions of the various types of mechanoreceptors. Criteria concerning internal structure and function of the receptors are taken into account that are discussed by Polacek (1966), Freeman and Wyke (1967a, 1967b), Wyke (1967) and O'Connor and Gonzales (1979). In table 1.2 the definitions of mechanoreceptors are listed as we will apply them in this study.

In chapter 4 quantitative data about the occurrence and distribution of mechanoreceptors are given. This is done in order to compare the substrate under consideration with data available in literature. Moreover, it seems worthwile to reestimate the usually applied quantitative parameters for the occurrence and distribution of mechanoreceptors, in relation to the concept of the inseries organization of muscular and regular dense collagenous connective tissue.

The occurrence and distribution of the preterminal nervous tissue elements that appeared to be present within the regular dense collagenous connective tissue structures and related terminals in the transitional area between those connective structures and adjoining muscular tissue, are described in chapter 5 . It includes the description of encapsulated nerve endings (like lamellated corpuscles) and unencapsulated free nerve endings present in and adjacent to some components of the connective tissue apparatus in the joint region.

In chapter 6 the results are given of our investigations into occurrence and distribution of mechanosensitive terminals in the complementary constituent of the locomotor apparatus i.e. the muscular tissue. This mainly concerns the spatial distribution of muscle spindles and Golgi tendon organs in the muscular tissue of the region respective- 
Dy in the transitional areas between muscular tissue and regular dense collagenous connective tissue structures (including distall tendinous connective tissue).

Chapter 7 will deal with the occurrence of nervous tissue elements adjacent to the skeletal tissue components of the antebrachial region. This includes the description of $\mathrm{Pa}$ cinian corpuscles that - though not strictly situated in the studied region - may be considered substrate for proprioceptive input evoked by movements or stresses that are induced by, or conveyed by ellements of the locomotor apparatus in the lateral cubital and antebrachial region.

In chapter 8 an integrated description of all the morphological substrate of proprioception in its (functional) relation to the architecture of the muscular and connective tissue, will be given. Finally, the results and conclusions will be discussed to answer the central issues of this study as put forward in the generall introduction.

Table 1.2

\begin{tabular}{|c|c|c|}
\hline Free nerve ending & FNE & $\begin{array}{l}\text { Unencapsulated nerve ending } \\
\text { (chapter 5) }\end{array}$ \\
\hline collgil terdon organ & GIO & $\begin{array}{l}\text { Type III-ending, present in } \\
\text { transition zone between muscular } \\
\text { and connective tissue (chapter 6) }\end{array}$ \\
\hline $\begin{array}{l}\text { Lamellated compuscle } \\
\text { (or: Pacini compuscle) }\end{array}$ & $\mathbb{L C}$ & $\begin{array}{l}\text { Type II-ending, with a } 2 \text { to } 5 \\
\text { layered capsule and less than } \\
100 \text { m length (chapter 5) }\end{array}$ \\
\hline Muscle spindle & MS & $\begin{array}{l}\text { Sensory ending with encapsulated } \\
\text { intrafusal muscle fibers } \\
\text { (chapter } 6 \text { ). }\end{array}$ \\
\hline Pacinian corpuscle & $\mathbf{P C}$ & $\begin{array}{l}\text { Type II-ending, with up to } 30 \\
\text { layered capsule and more than } \\
100 \text { m length and diameter } \\
\text { (chapter } 7 \text { ) }\end{array}$ \\
\hline Ruffini conouscle & $\mathbf{R C}$ & Tume T-endina (chanter 5 ) \\
\hline
\end{tabular}




\section{CHAPTER 2}

\section{MATERIALS AND METHODS}

\section{Contents}

2.1 Microscopical techniques

2.1.1 Acetyllcholinesterase in toto staining method

2.1.2 Formaldehyde Induced Fluorescence (F.I.F.)

2.1.3 Silver impregnation method according to Holmes

2.1.4 Silver impregnation method according to Spaethe

2.1.5 Ultramicroscopical techniques and staining method according to Laczko and Levai

2.2 Techniques for three-dimensional representation and quantification

2.2.1 Dissection

2.2.2 Three-dimensional reconstruction

2.2.2.1 Preparation (plastic embedding and Trichrome staining)

2.2.2.2 Plotting and drawing methods

2.2.2.3 Three-dimensional reconstruction of the substrate of proprioception

2.2.3. Quantification of the substrate of proprioception

\section{Summary}

Standard methods for the mesoscopic, light- and electron-microscopic identification of nerve structures in situ, are summed up first (par. 2.1). Next, the applied method to dissect regular dense collagenous connective tissue structures is described (par. 2.2.1). Then an elaborate description is given of the techniques applied to obtain three-dimensional representations of the afferent nerve fibers and their endings in relation to the constituents of the locomotor apparatus (par. 2.2.2). Finally the methods used for quantification of the occurrence of mechanoreceptors are described (par. 2.2.3). All methods described here, are applied to the forelegs of young adult ( 12 weeks old) white laboratory rats (Lewis strain). 


\subsubsection{Acetylcholinesterase in toto staining method}

For staining of nervous tissue elements in toto, a modification of the histochemical acetylcholinesterase method of Karnovsky and Roots (1964) as developed by Baljet and Drukker (1975) was used. This method was applied to:

-20 specimens of the proximal collagenous connective tissue apparatus taken out separately - in toto as well as divided into separate components -.

- 10 specimens of the foreleg in which collagenous connective tissue structures were left in situ after careful removal of muscular tissue.

- 10 specimens of the foreleg in which muscular and connective tissue were left in situ in various stages of dissection.

Most of the foreleg specimens in which this method was applied to the collagenous connective tissue in situ, coincided with the specimens used for dissection studies (par. 2.2.1).

The animals were brought under aether anaesthesia. After laparotomy a cannula was inserted into the abdominal aorta up to the level of the descending thoracic aorta. Then perfusion was carried out with $150-200 \mathrm{ml}$ saline solution containing 150 T.R.U. hyaluronidase per $500 \mathrm{ml} 0.9 \% \mathrm{NaCl}$ solution (Hyason $^{\circ}$, Organon), by means of an electric perfusion pump (injection speed about 50 cc per $2 \mathrm{~min}$.). Perfusion with this medium promotes the effect of the acetylcholinesterase in toto staining (Baljet and Drukker, 1975). Fixation was performed by perfusion with $200-250 \mathrm{ml}$ sucrose-formaldehyde solution buffered with sodium-cacody- late (M 160.0, pH 7.4) of $4^{\circ} \mathrm{C}$ (Holt et al., 1959), after which the specimens were postfixed for 24 hours in the same medium at $4^{\circ}$ C. Next, they were rinsed for 24 hours in 0.22 $M$ sucrose in $0.05 \mathrm{M}$ sodium-cacodylate buffer ( $\mathrm{pH}$ 6.0) at $4^{\circ} \mathrm{C}$ (Holt et al. 1959) and stored in the same medium. For in toto staining the specimens were incubated in the medium described by Karnovsky and Roots (1964) to demonstrate cholinesterases. The media were adjusted to the $\mathrm{pH}$ required (5.6) before incubation. Incubation occurred at $37^{\circ} \mathrm{C}$ for periods of 2 hours, after which the medium was renewed. The course of the reaction was followed by direct observation. In most cases, four times renewal of the medium proved to be adequate. When staining was still considered insufficient, an overnight period of incubation at room temperature was added. After completion of the reaction the specimens were rinsed in doubly distilled water and dehydrated in a series of glycerin/water mixtures of increasing glycerin content and stored in pure glycerin.

The specimens with collagenous connective tissue structures left in situ were studied under a stereo-microscope (ZEISS OPMI 6-F). Specimens of collagenous connective tissue layers taken out separately (particularly specimens of the superficial antebrachial fascia), were mounted on object glasses with a thin film of gelatine-formol (Pearse, 1968) dried for 14 hours at $37^{\circ} \mathrm{C}$ and cleared in xylene. Then coverslips were mounted with Entellan.

\subsubsection{Formaldehyde Induced Fluorescence (F.I.F.)}

According to the procedure described by Falck et al. (1962) four rats were injected intraperitoneally with a sympathicomimeticum: one rat with $100 \mathrm{mg} 1-\mathrm{DOPA} / \mathrm{kg}$ body weight, a second rat with $200 \mathrm{mg}$ l-DOPA/kg body weight, a third rat with $300 \mathrm{mg}$ niala- mide/kg body weight and a fourth rat with a mixture of 1-DOPA $(200 \mathrm{mg} / \mathrm{kg})$ and nialamide $(300 \mathrm{mg} / \mathrm{kg})$. After 3.5 to 4 hours the animals were sacrificed. The connective tissue layer concerned, was dissected free and divided into several parts. The tissue 
specimens were mounted on an object glass and dried by means of a hot air blower ( 60 to 90 minutes). Then the specimens were submitted to paraformaldehyde vapor in an exsiccator at $60^{\circ} \mathrm{C}$ for one hour at a relative humidity of $50 \%\left(50 \% \mathrm{H}_{2} \mathrm{SO}_{4}\right)$.

As control, a part of the mesenterium of the experimental animals was taken out and treated with the same procedure. Moreover the same connective tissue structures of an- other rat were processed without previous treatment of the animal.

Half of the specimens was mounted immediately after this procedure with coverslips and studied under a fluorescence microscope. The remaining specimens were either counter-stained with toluidine blue or processed for acetylcholinesterase in toro before microscopical examination.

\subsubsection{Silver impregnation method according to Holmes}

Five adult rats were brought under aether anaesthesia and sacrificed. Immediately post mortem various components of the proximal collagenous connective tissue apparatus were taken out separately, some of them with attached muscle fascicles in- cluded. The specimens were fixed for 24 hours in $10 \%$ formaline solution at $4^{\circ} \mathrm{C}$. After routine dehydration and embedding in paraffin, serial sections were cut of $15 \mu \mathrm{m}$ and impregnated with $\mathrm{AgNO}_{3}$ (Drury and Wallington, 1980).

\subsubsection{Silver impregnation method according to Spaethe.}

Two animals were fixed by means of intracardially applied perfusion with Bouin's fixative $\left(4^{\circ} \mathrm{C}\right)$. Blocks containing muscular and connective tissue, were taken out (see par. 5.2) and processed for dehydration and paraffin embedding. Thereafter the specimens were sectioned serially $(7 \mu \mathrm{m})$ and stained with $\mathrm{AgNO}_{3}$ according to the method described by Spaethe (1984).

\subsubsection{Ultramicroscopical techniques and staining method according to Laczko and Levai.}

Six adult animals were perfused intracardially with $6 \%$ glutaraldehyde, buffered in $0.1 \mathrm{M}$ sodium-phosphate buffer. Selected blocks of tissue taken out (see par. 5.2) were left for two hours in the same fixative at $4^{\circ}$ $\mathrm{C}$ and then transferred to $1.0 \% \mathrm{OsO}_{4}$ in 0.1 M sodium-phosphate buffer containing $1 \%$ sucrose, again at $4^{\circ} \mathrm{C}$. After dehydration, the specimens were embedded in EPON
812 according to the method of Luft (1961). Semi-thin sections ( $1 \mu \mathrm{m})$ were stained according to Laczko and Levai (1975).

Consecutive ultra-thin sections of $60 \mathrm{~nm}$ thickness were obtained by means of the "Ultracut" ultramicrotome (Reichert), contrasted with $1 \%$ uranyl citrate and $1 \%$ lead citrate (Reynolds, 1963) and examined in a Philips 300 electron microscope. 

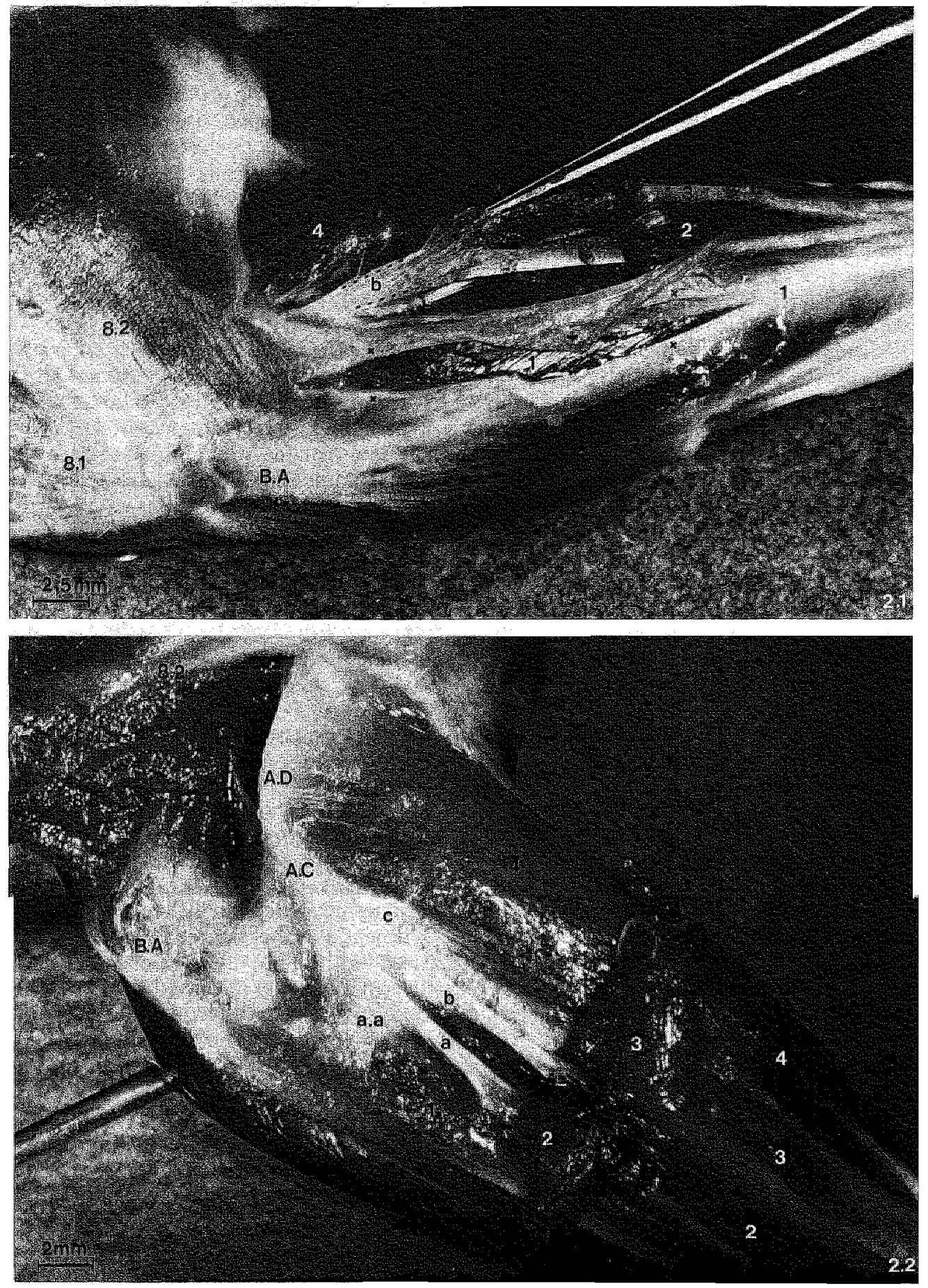


\subsection{Techniques for three-dimensional representation and quantification}

\subsubsection{Dissection}

Macroscopical dissection was performed in the forelegs of ten unfixed animals and of ten animals fixed with Holt fixation fluid (par. 2.1.1). Part of the dissected specimens were processed for acetylcholinesterase in toto staining ("par. 2,1.1).

Dissection of the lateral elbow region was carried out under a stereo microscope (ZEISS OPMI 6-F), according to the alternative dissection method as expressed in chapter 1 (v.Mameren and Drukker, 1984). In general, dissection was started - after removal of the skin and subcutaneous tissue - by longitudinal incisions of the collagenous connective tissue layer forming the outer wall of a given muscle compartment. Next, muscle fascicles attached to the inner side of the walls of such a muscle compartment were separated from them by means of blunt or (if necessary) careful sharp dissection. In this way the muscular tissue mass of the so-called muscle belly could be dissected out of its collagenous connective tissue compartment. By this procedure the architecture of the (regular dense collagenous) connective tissue remained intact as much as possible and it was avoided to create artificial, sharply cut boundaries in the collagenous connective tissue apparatus, where there is actually continuity. Thus distinction was made on the basis of difference between the types of tissue present, not on the basis of distinguishing muscles and ligaments as morphological entities.

Some characteristic stages of the dissection are shown in figure 2.1 and 2.2 .

\section{Figure 2.1}

Lateral aspect of the right foreleg (fixed specimen). The outer wall of the muscle compartment of the ECU muscle (1) is opened by a longitudinal incision $(x x)$. The outer muscle compartment wall of the EDL muscle (2) is also opened and partly folded aside ( + ) after dissection of the muscle fascicles inserting to it. The distal portion of the EDL muscle belly is left in situ (2). The proximal muscle fascicles of the adjacent EDC muscle are dissected out of its compartment, with the distal part of this muscle also left in situ (3). The intermuscular connectiwe tissue layer presented in this way $(\cdots,-\cdots)$ is hell by a pair of tweezers.

\section{Figure 2.2}

Lateral aspect of the right foreleg (fixed specimen). The medial and lateral heads of the triceps muscle are dissected from the humeral bone and folded aside (8.2 and 8.3). The antebrachial superficial fascial connective tissue has been removed. The muscle fascicles of the EDL (2) and EDC (3) muscles are dissected from the related muscle compartment walls and are folded in distal direction, showing the intermuscular parts of the muscle compartment walls ( $\mathrm{a}, \mathrm{b}$ and $\mathrm{c}$ ). The muscle fascicles of the ECR muscle are leftin situ, still attached to the liayer between this muscle and adjacent EDC muscle (c). The proximal extension of the floor layer of the ECU (1) muscle compartment ( $\left.a_{0} a\right)$ is left in sifu after dissection of the ECU muscle fascicles inserting to this layer. 


\subsubsection{Threedimensional reconstruction}

\subsubsection{Preparation (plastic embedding and Trichrome staining)}

Following conditions were considered to be minimal prerequisites for three-dimensional reconstruction of the architecture of the various constituents of the locomotor apparatus as well as of the spatial distribution of the morphological substrate of proprioception:

- minimal shrinkage (and other artefacts) in order to retain the original architectural and spatial relations as much as possible.

- serial sections of foreleg specimens embedded in toto (including the skeletal tissue elements).

- an embedding medium that easily permits application of strict reference marks which should be displayed well in the sections serving as reference points for the 3D-reconstruction procedure.

- at the microscopical level a histological quality of the sections such as to enable discrimination and/or classification of different types of mechanoreceptors as well as clear demarcation between muscular and connective tissue.

In our department there is a lot of expertise as to embedding of macroscopical specimens (and slices of specimens) in polyester resin (Lataster and v.Mameren, 1983; Lataster et al., 1984). This medium provides the possibility to place reference marks in position easily. Also de-calcification - involving shrinkage of the specimen - can be avoided, because of the hardness of the medium. This procedure however included a step of impregnation with Wintergreen oil (methyl-salicylate) in order to "clear" particularly connective tissue structures i.e. to enhance their visibility (Spalteholz, 1914). In our study this step was omitted and the specimen was embedded in the resin directly after dehydration with styrene as interphase medium.

\section{Fixation}

Fifteen rats were prepared for histological study 3D-reconstruction by means of fixation perfusion (par. 2.1.1).

Ten rats were fixed with Holt fixative medium. Five animals were perfused with $10 \%$ formaline solution after pre-perfusion with $0.9 \% \mathrm{NaCl}$ solution $\left(4^{\circ} \mathrm{C}\right)$. This was done in order to test the possible interaction between fixative medium and polyester resin as to penetration and hardening of the resin. No striking differences could however be seen in section quality or impregnation rate. The shrinkage seemed to be slightly stronger in the formaldehyde fixed specimens.

After perfusion the skin was removed and both extremities were separated from the trunc. Then the complete forelegs were postfixed for at least one day in excessive fixative medium at $4^{\circ} \mathrm{C}$.

\section{Dehydration and preembedding}

After washing in running tap water, the specimen was dehydrated in graded series of ethanol:

$\begin{array}{lll}\text { ethanol } & 70 \% & \text { 1 day } \\ \text { ethanol } & 90 \% & 2 \text { days } \\ \text { ethanol } & 100 \% & 3 \text { days }\end{array}$

To promote impregnation of the polyester resin, the uncatalysed polyester was introduced into the specimen via a series of mixtures of styrene with uncatalysed resin in the sequence as demonstrated in table 2.3 .

These steps were carried out in a vacuum exsiccator placed in a refrigerator $\left(4^{\circ} \mathrm{C}\right)$ in order to promote impregnation of the mixture and evaporation of the ethanol and styrene components. Step 5 was carried out for 3 days in vacuo. Longer evaporation of styrene caused too low a viscosity of the medium. 


\begin{tabular}{|llll|}
\hline 1. styrene $100 \%$ & & 1 day \\
2. uncatalysed polyester resin: styrene & $1: 3$ & 1 day \\
3. uncatalysed polyester resin : styrene & $1: 1$ & 1 day \\
4. uncatalysed polyester resin : styrene & $3: 1$ & 1 day \\
5. uncatalysed polyester resin $100 \%$ & & 1 week \\
\hline
\end{tabular}

\section{Embedding}

The proximal pole of the foreleg specimen (shoulder girdle) was put into a small amount of Plasticine (artificial clay) and fixed to the bottom of a mould of kautschuk material. In this way the foreleg specimen stood upright in the kautschuk container. Then catalysed polyester resin was poured into the mould in consecutive layers of 1.0 to $1.5 \mathrm{~cm}$ with intervals of about 12 hours. This was done in order to avoid development of too much heat and to avoid air bubbles. For the same reasons the resin was precooled and evacuated before pouring, in a vacuum exsiccator at $4^{\circ} \mathrm{C}$. The interval of 12 hours allowed to pour the next layer upon the previous one, while the latter was still hardening. This promoted the sticking together of the layers, which prevents breaking of the block during the cutting procedure. About 5 layers were required to embed the specimen completely. Finally, the resin block was left to harden for at least 1 month - optimal period 2 months - at room temperature (no evacuation).

\section{Cutting}

After removal of the kautschuk mould, the block was trimmed with the surface to be sectioned, as parallel as possible to the transverse plane of the embedded foreleg. Two parallel grooves perpendicular to the plane of sectioning were carved on two sides of the remaining block, for the purpose of creating reference marks. The grooves were filled with Technovit 3040 , which procedure should prevent deformation during cutting. The block was cut in sections of $15 \mu \mathrm{m}$ on a LKB multirange microtome. The knife was introduced to one of the angles of the plas- tic block, which prevented too abrupt immediate loading of the microtome knife. Each tenth section was fixed with adhesive tape before cutting - to prevent deformation and loss of material - and was sampled.

\section{Staining}

Next the sections were mounted onto a microscope slide together with the adhesive tape by pouring some catalysed polyester resin out over the section and microscope slide and mounting the section with the tape directed to the surface of the glass. Then the section (still fixed to the tape) was covered with a Hostaphan-sheet and pressed to the glass surface with a rolling-pin. The resin was allowed to harden overnight, after which the sections were stained with a Trichrome dye:

- 7 min.Weigert A and B (equal parts, *)

- Rinsing in aqua dest.

- $8 \mathrm{~min}$.Tungstophosphoric acid $5 \%$

- Rinsing in aqua dest.

- 8 min.Mixture of Aniline Blue acid/ Acid Fuchsin / Orange G (**)

- Rinsing in aqua dest.

(*) Romeis, 1968.

(*) $8 \mathrm{ml}$ glacial acetic acid was added to 0.5 gram water-soluble Anilline Blue and 2 gram Orange $\mathrm{G}$ in $100 \mathrm{ml}$ aqua dest. The mixture was heated untill boiling. Filtration was carried out after cooling down. Next 1 gram Acid Fuchsin was added. The mixture was shortly heated untill boilling and filtered after cooling down.

The staining procedure was concluded with immersion in Thionine - buffered with acetic acid (M 0.1) and sodium-acetate (M 
acetic acid (M 0.1) and sodium-acetate ( $M$ 0.1) at $\mathrm{pH} 4.5$ - for 4 minutes, after which the sections were rinsed in aqua dest. Next they were left to dry to the open air. Finally a cover slip was mounted with a layer of catalysed polyester resin. After an overnight period of hardening the specimens were ready for inspection.

Muscular tissue (yellow-orange stained) could be clearly distinguished from the blue to purple appearance of connective tissue. Thick collagenous connective tissue structures showed a tendency to stain brightly orange in their central core. This sometimes caused difficulty in distinguishing it from cartilaginous tissue. Bony tissue stained brightly blue and could be distinguished well from the purple blue of the connective tissue.The clear colour difference between (endo- and perimysial) connective tissue and muscle fibers promoted the discrimination of muscle spindles (particularly their

\subsubsection{Plotting and drawing methods}

First the sections were copied on sheets by means of projection (magnified about 20 times) with a Kindermann AV 100 slide projector with the frame container adapted to contain microscope slides. As reference points the angles of two of the grooves carved into the polyester block were used. They were clearly distinguishable in the sections because of a difference in light diffraction between the polyester resin and the Technovit in the grooves.

In the initial phase of this study threedimensional graphic reconstructions from these line drawings were made by hand. This was carried out by means of a drawing instrument that produces graphic reconstructions in quasi-perspective (Tinkelenberg, 1979).

Later on, the reconstruction procedure was computerized. The reconstruction program needed was developed by J. Beursgens. The outlines of the various structures and elements in the section and the reference points were digitally fed into a MINC PDP polar ends) from adjacent muscular tissue (Lennartson, 1980a). The recognition of Golgi tendon organs (GTO's) was somewhat more difficult because of their relatively high amount of collagenous connective tissue. This made them not easily distinguishable from the collagenous connective tissue structures related to them. In most cases however, brigthly yellow staining nervous tissue elements within these organs supported their classification. Pacinian corpuscles were clearly distinguishable by their blue staining lamellae around a yellow staining axis cylinder.

After selection based on histological quality, eventually eight foreleg specimens were processed through the complete procedure of embedding and 3D-reconstruction i.e. six specimens fixed with Holt fixative (code: A1, A2, B1, B2, C1 and C2) and two fixed with formaline (code: Z1 and Z2). There was an even distribution of right and left forelegs.

$11 / 73$ computer by means of a digitizer (Summagraphics ID series). In an orthonormal coordinate system every point of the outlines has an $X$ and $Y$ coordinate (from the digitizer) and a Z-coordinate based on the distance between the sections (taking into account a magnification factor). The point distance could be varied from 0.2 . maximal resolution - to $2 \mathrm{~mm}$ (v.Mameren et al., 1984, 1985).

A drawing program run on the same PDP $11 / 73$ computer visualized the drawings on a Tektronix 4111 screen or a Tektronix 4662 plotter ( 8 colours). In this drawing program it was possible to select:

- an "eye-position" from any given point in the system.

- an "eye-direction" to a point of interest in the object to be reconstructed.

- an adjustable optic angle, when a given "eye-position" was chosen. This means a tele or a wide angle effect.

Moreover, the size of the drawing could be adjusted on the screen by local zoom and 
pan functions.

Since the technique did not provide a "hidden line $e^{\text {st }}$ possibility, the plotted threedimensional line drawings were redrawn on transparant paper, only representing the outlines visible from the chosen point of view. Finally, definitive graphic refinement and plastic representation was performed by the medical artist ( $H$. Rensema). In a later phase of this study a drawing program was developed by means of which the threedimensional graphic reconstruction was presented directly with "hidden line" on a colour screen (Beursgens et al., 1987). By means of a hard copy device the reconstruction drawings could be reproduced directly from the screen. This procedure was applied to the reconstructions of the muscle spindle/GTO zones in chapter 6 (figures

\subsection{0 to 6.11).}

The fact that structures of less than $2 \mathrm{~mm}$ in thickness (in the camera lucida drawing) can not be reconstructed forms a noteworthy limitation of this procedure. In that case the chosen point distance of $0.5 \mathrm{~mm}$. necessary by the given circumference measures of the skeletal, muscular and connective tissue structures - interferes with the procedure of closing the contours. Therefore particularly flat structures of less than 75 to $100 \mu \mathrm{m}$ can not be reconstructed. This means that for instance neither the thin distal (or proximal) continuations of the collagenous connective tissue layers are represented in the reconstruction drawings nor the main part of the antebrachial superfical (fascial) connective tissue layer.

\subsubsection{Three-dimensional reconstruction of the substrate of proprioception}

In three specimens embedded in plastic in toto (B2, C1 and Z2), the positions of the mechanoreceptors were plotted in the camera lucida drawings that already were made for 3D-reconstruction of the architecture of muscular and connective tissue. Those data were also digitally fed into the computer. The relatively large diameters of Golgi tendon organs (GTO's) and Pacinian corpuscles made it possible to draw the outlines of those structures (point distance 0.2 $\mathrm{mm}$ ). As to the muscle spindles, both the poles and the equator of the capsule were indicated by dots. The computerized drawing program represented the spindlles by a line of connection between the two pollar ends. The three-dimensional graphic reconstructions of the distribution of muscle spindles and GTO's of one specimen (Z2) are represented in this publication (figure 6.3 to 6.9 in par. 6.2 .1 ). Three projection directions were used: latero-medial (i) and antero-posterior (ii) - perpendicular to each other and both at an angle of $90^{\circ}$ with the Zaxis - and lateromedial like (i) in proximodistal direction at an angle of about $30^{\circ}$ with the $\mathrm{Z}$-axis (iii). These directions were chosen to get maximal insight in the actual spatial distribution.

Of two specimens ( $\mathrm{Cl}$ and $\mathrm{Z} 2$ ) the zones of muscular tissue that contain muscle spindles and GTO's (muscle spindle/GTO zones) were circumscribed per section. Those zones were reconstructed three-dimensionally. The outlines of those zones were defined according to the following criteria:

- the zone should contain all muscle spindles and GTO's present.

- the concerned muscular tissue zone should be limited by muscle-connective tissue transitions particularly if GTO's are present. GTO's were assumed to be present in the muscle-connective tissue transitional areas with those extrafusal muscle fibers between which the muscle spindles are situated (Swett and Eldred, 1960a; Arendt and Asmussen, 1974; Barker, 1974; Richmond and Stuart, 1985).

- abrupt narrowing of the zone to nearly zero - if none or only one muscle spindle was present in a section - was avoided by smoothing of the outline between successive sections. It was taken into account that muscle spindles run in parallel to the extrafusal fibers (Barker, 
1974). Their direction therefore is an indication of extrafusal tiber architecture. The procedure could lead to the definition of two or more zones per muscle.

In figure 6.10 and $6.11(6.2 .2)$ the threedimensional graphic reconstruction of specimen $\mathrm{Cl}$ is represented.

Of five specimens (A2, B2, C1, C2 and Z2) so-called summative projections were constructed. This means that the complete foreleg was divided into six standardized portions. As proximal reference plane the transverse section through the middle of the supinator sesamoid bone was chosen (figure 3.16B in 3.6.). Distal reference plane was formed by the transwerse section corresponding to the most distal section through the supinator muscle (figure $3.16 \mathrm{G}$ in 3.6.). At equal distances four other reference planes were calculated between those two reference sections. Next the positions of (capsular poles and equators of the) muscle spindles, GTO's and Pacinian corpuscles, situated in the halves of the foreleg portion situated proximally and distally to a given reference plane, were projected onto the chosen six standardized sections. This means that on each of these summative projection sections more mechanoreceptors are represented than actually exist, because of possible double projection onto two successive standardized sections. The slight error caused by the possibly oblique course of the structures with respect to the transversal plane of the sections was disregarded. Since the summative projections of $Z 2$ and C1 could be compared with and interpreted from the corresponding graphic 3D-representations, this procedure enabled reproduction of the spatial organization of the substrate of mechanoreception in more than two specimens without the elaborate procedure of $3 \mathrm{D}$-reconstruction. Of three specimens ( $\mathrm{C} 1, \mathrm{~A} 2$ and $\mathrm{Z} 2$ ) the summative projections are represented (figure 6.1 and 6.2 in par. 6.2.1 and figure 7.1 in par. 7.3.2).

\subsubsection{Quantification of the substrate of proprioception}

The number of muscle spindles and Golgi tendon organs (GTO's) was counted in all eight specimens embedded in toto in polyester resin. The discrepancy in numbers of those receptors between left and right limb, which is a common finding (Barker and Chin, 1960; Hnik and Zelena, 1961; Arendt and Asmussen, 1974; Cennartson, 1980b) was met by the fact that four left and four right forelegs have been studied. In this study muscle spindles capsules were counted, not the number of muscle spindles. In this way tandem spindles - i.e. more than one encapsulated sensory region occurring along the length of the intrafusal bundle are counted as two (or more) spindles (Barker, 1962; Barker, 1974; Bakker and Richmond 1981, 1982; Scott and Young, 1987). First each selected tenth section (vide supra) was screened on the presence of a muscle spindle capsulle cross-sectioned at (iuxta-)equatorial level. A camera lucida drawing of this section with the position of the spindle indicated, allowed us to determine the same spindle capsule in sections situated proximally and distally of this particular section. The spindles of a given extensor muscle were numbered sequentially, with the most proximally situated spindle numbered as muscle spindle 1 (Arendt and Asmussen, 1974; Lennartson, 1980a)

A similar procedure was applied for counting the GTO's. They were counted per muscle as well as per connective structure that they are related to $(n=8)$. The GTO's present at the transition of the muscular tissue of the triceps muscle and the muscle compartment walls of the lateral and medial head of this muscle, were counted in the two series of silver stained (Spaethe) specimens of those muscle entities $(n=2)$. In some of the latter specimens diameter and length of the GTO's were measured in those sections where the receptors were cut along their longitudinal axis.

The Pacinian corpuscles were counted in 
the eight plastic embedded specimens of the foreleg by the same method as applied to GTO's. Their dimensions were measured in six of those specimens. Only those corpuscles were measured - with a micrometer at a magnification of $250 \mathrm{x}$ - of which the crosssection was perpendicular to the long axis of the receptor. This could be deduced from the concentrical orientation of the lamellae and the position of the lamellae related to the central axis cylinder. The section with its maximal diameter was selected and the diameter was measured in two directions (maximal and minimal dimension). Length was calculated by counting the number of sections between the most proximal and the most distal section. The possible error - because of the intersectional distance of 150 $\mu \mathrm{m}$ - was disregarded.

Data about the number of the lamellated (or Pacini) corpuscles were derived from observations of silver stained (Spaethe) serial sections of selected areas of the region. Their diameters were measured occasionally in some sections, their length calculated by counting the number of successive sections in which they were present. Dimen- sions were also measured in some semi-thin sections.

'To calculate the density of muscle spindles and GTO's per muscle it was necessary to measure the wet weight of the individual muscle. This was carried out in three rats. Immediately after sacrificing the animal under aether anaesthesia, the muscles were taken out separately and weighed $(n=6)$.

In two specimens ( $\mathrm{C} 1$ and $\mathrm{Z} 2)$ the volume of the muscle spindle/GTO zones was measured. After defining the outlines of those zones in camera lucida drawings of the cross-sections (vide supra), the surface of the zone was calculated with an XY-tablet (Summagraphics) as well as the surface of the cross-section of the corresponding muscle. Taking into account the intersectional distance and the magnification factor of the drawings, the volume of the zones and muscles was calculated. Each surface was considered the equatorial plane of a cylinder with the intersectional distance as height. The volume of possible intramuscular collagenous connective tissue (i.e. mainly distal tendons) was disregarded. 



\section{ARCHITECTURE OF MUSCULAR AND CONNECTIVE TISSUE IN THE LATERAL CUBITAL REGION}

\section{Contents}

3.1 Muscular and skeletal tissue structures in the lateral cubital and antebrachial region (definitions and nomenclature)

3.2 Architecture of regular dense collagenous connective tissue (in relation to the architecture of muscular tissue)

3.2.1 Superficial muscle compartments and connective tissue layers

3.2.2 Deep muscle compartments and connective tissue layers

3.3 Architecture of muscular and connective tissue in the lateral cubital region (integral description)

3.4 Discussion

3.5 Conclusions

3.6 Some characteristic transverse sections of the cubital and antebrachial region (Appendix)

\section{Summary}

To define the applied descriptive terms, the topography of the locomotor apparatus in the region under consideration is presented first (par. 3.1). Then the architecture of the regular dense collagenous connective tissue is described in relation to the architecture of the muscular tissue (par. 3.2). A complex apparatus of regular dense collagenous connective tissue layers exists in the proximal part of the region, mainly consisting of the collagenous connective tissue walls of muscle compartments. Those layers converge towards the lateral humeral epicondyle and the olecranon. The majority of the collagenous fibers is interposed between skeletal tissue and muscle fascicles; ligaments as separate entities consisting of collagenous connective tissue running from bone to bone, cannot be discriminated. Muscle/connective tissue units are identified in the proximal lateral cubital region. Muscular and collagenous connective tissue are organized in series and do not coincide with the usual anatomical classification into muscles and ligaments (par. 3.3). The possible role of the found architecture in the maintenance of stability and integrity in the elbow joint is discussed (par. 3.4). It is concluded that the region may serve as a model to study the relation between the (spatial) organization of the morphologica! substrate of proprioception and the in-series architecture of muscular and regular dense collagenous connective tissue (par. 3.5). Finally the architecture of the muscular and connective tissue is illustrated by means of some characteristic transverse sections of the cubital and antebrachial region (par. 3.6). 


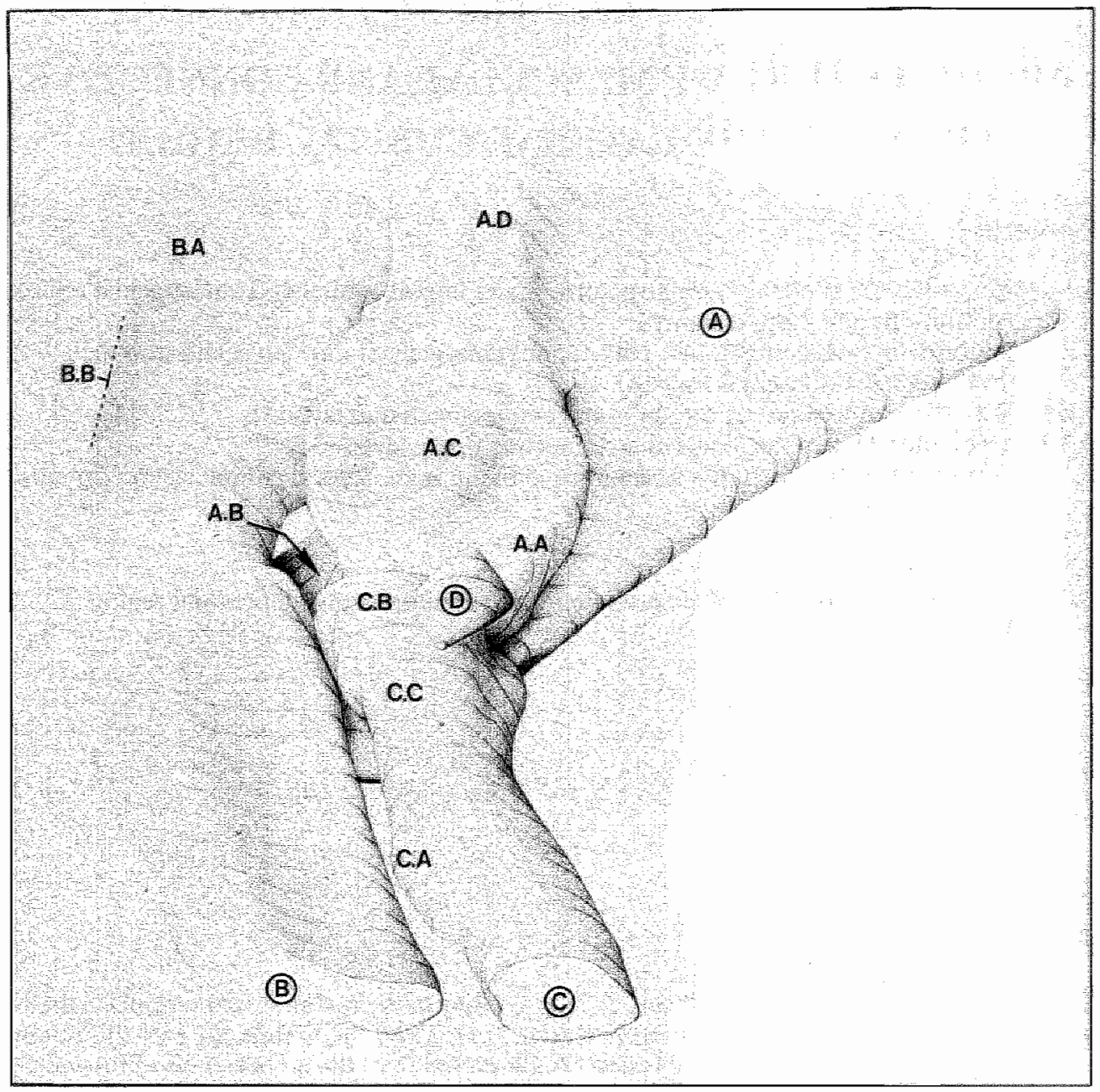

Figure 3.1

Lateral aspect of the articulating bones of the elbow joint viewed in proximal direction. Three-dimensional graphic reconstruction based on specimen $\mathrm{C} 1$ (right foreleg).

Humerus (A) with capitulum (A.A), trochlea (A.B), lateral epicondyle (A.C) and supracondylar crest (A.D). Ulna (B) with olecranon (B.A) and ulnar crest (B.B). Radius (C) with radial tuberosity (C.A), caput (C.B) and collum (C.C). Os supinatoris (D) 


\subsection{Muscular and skeletal tissue structures in the lateral cubital and antebrachial region (definitions and nomenclature)}

In this paragraph the topography of the constituents of the locomotor apparatus in the studied area will be presented. This is done in order to introduce and define the relevant nomenclature. The presented topography is compared with textbooks and atlasses on the anatomy of the locomotor system of the rat which are available up to now (Greene, 1959; Chiasson, 1980; Hebel and Stromberg, 1986). The controversial nomenclature and classifications in those textbooks sometimes need correction. Therefore it is required to clarify and define our terms before the description of the architecture of muscular and connective tissue can be given.

The main relevant skeletal structures in the region are represented in figure 3.1.

The following muscles in the region are of interest:

- Extensor carpi ulnaris muscle (ECU)

- Extensor digitorum lateralis muscle (EDL)

- Extensor digitorum communis muscle (EDC)
- Extensor carpi radialis muscle (ECR)

- Extensor digiti primi muscle (EDP)

- Extensor indicis muscle (EI)

- Supinator muscle (SUP)

- Lateral head of the triceps muscle (TR.lat.)

- Medial head of the triceps muscle (TR.med.)

- Anconeus muscle (ANC)

The first seven muscles mentioned are considered antebrachial extensor muscles. They are topographically organized into two layers: four muscles constitute a superficial layer (ECU, EDL, EDC and ECR) and three muscles a deep layer (EDP, EI and SUP). Topographically the lateral and medial head of the triceps muscle as well as the anconeus muscle are part of the lateral cubital region.

The topography of the muscles in the region will be described based on 3D-reconstruction drawings of the region (figure 3.2 to 3.6 ). 

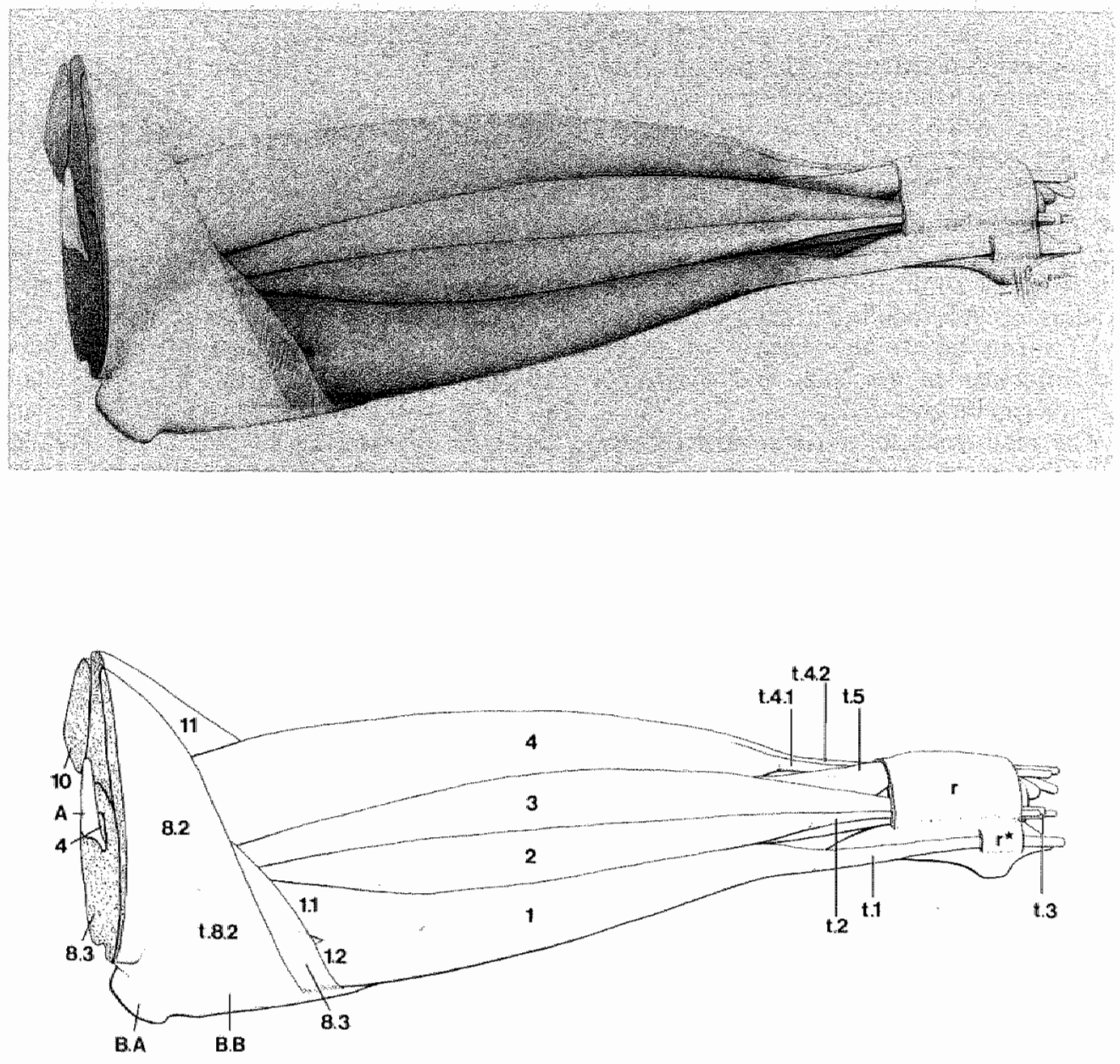

\section{Figure 3.2}

Lateral aspect of the cubital and antebrachial region. Three-dimensional graphic reconstruction based on specimen $Z_{2}$ (represented as right foreleg).

Superficial antebrachial extensor muscles with distal tendons are represented after removal of the antebrachial superficial fascial connective tissue.

r: retinaculum extensorum. I*: separate tendon sheath for t.ECU (t.1). 
The extensor carpi ulnaris muscle (1) is divided proximally into a humeral head (1.1) and an ulnar head (1.2). The topographical relation with the overlaying triceps muscle and the underlying anconeus muscle is further elucidated in figure 3.6. Distally the muscle is attached by a relatively strong tendon (t.1) to the fifth metacarpal bone.

The distal tendon of the adjacent extensor digitorum lateralis muscle (t.2) splits into two slender tendons attached to the distal phalanx of the fourth and fifth digit. Contrary to Greene (1959) and Chiasson (1980), we prefer (like Hebell and Stromberg, 1986) the term "extensor digitorum lateralis muscle" to the term "extensor digiti quarti and extensor digiti quinti muscle". Our finding that in the rat no separate muscle bellies can be distinguished in this muscle, is confirmed by the results of a comparative anatomical study by Kaneff (1959).

The extensor digitorum communis muscle (3) shows four small tendons (t.3) that insert to the distal phalanx of digit II to $\mathrm{V}$.

The extensor carpi radialis muscle (4) splits distally into two different muscular entities with separate tendons. The situation described and drawn in the avallable atlasses as two muscle bellies originating from the humeral supracondylar crest - can not be confirmed. The extensor carpi radialis brevis muscle $(4.1)$ is situated at the ulnar side, thus adjoining the EDC muscle. Its tendon (t.4.1) inserts to the distal end of the third metacarpal bone. The extensor carpi radialis longus muscle (4.2) is situated at the outer radial side of the region. Its tendon (t.4.2) inserts to the second metacarpal bone. In comparison to the situation in man, the proximal insertion of this muscle to the supracondylar crest of the humeral bone reaches far more proximally.

At the level of the wrist the tendons of the three radially situated muscles pass underneath a retinaculum extensorum (r), while the tendon of the extensor carpi ulnaris muscle follows a separate osteofibrous tunnel $\left(r^{*}\right)$.

The proximal insertions of the four superficial antebrachial extensor muscles are covered by the triceps muscle (see also figure 3.3 ). The lateral head $(8.2)$ of this muscle inserts to the ulnar crest (B.B.) via a broad aponeurotic layer of regular dense collagenous connective tissue indicated as lateral olecranal retinaculum $(t, 8,2)$. Beneath the lateral head of the triceps muscle the medial head of the same muscle $(8.3)$ is situated. Muscle fascicles of this head insert to the distal part of the lateral olecranal retinaculum. The topographical relation between those two muscle entities is also explained in figure 3.5 and 3.6 .

The anconeus muscle (9) is situated directly underneath the medial head of the triceps muscle as a triangular muscular structure between lateral humeral epicondyle (tip) and the ulnar crest (base) (figure 3.4). At its proximal edge it is continuous with the muscular mass of this medial head. It is situated directly beside the joint capsule of the humero-ulnar joint. The epimysial layer actually constitutes the capsular demarcation of the joint cavity. Its position between the ulnar head of the ECU muscle (1.2) and the ulnar head of the EDP muscle (5.1) is demonstrated in figure 3.5 and 3.6 . Though the demarcation from the mediall head of the triceps muscle is difficult to define, we have not found any indication of an anconeus muscle arising from both humeral epicondyles as stated by others (Greene, 1959; Hömig, 1970). 

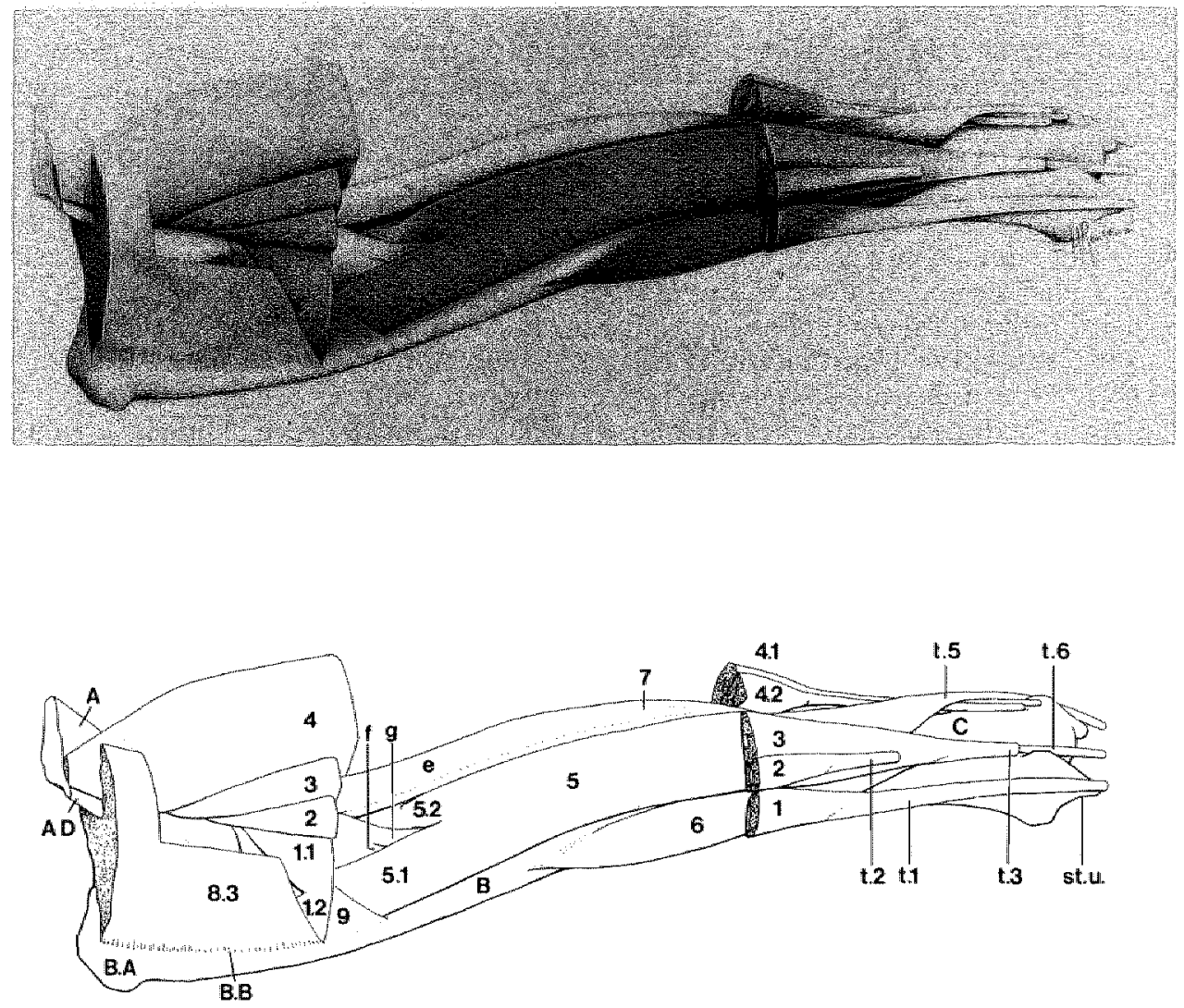

\section{Figure 3.3}

Lateral aspect of the cubital and antebrachial region. Three-dimensional graphic reconstruction based on specimen Z2 (represented as right foreleg).

Part of the superficial antebrachial extensor muscles has been removed in order to present the deep extensor muscles $(5,6$ and 7$)$. The lateral head of the triceps muscle has also been removed, thus presenting the medial head (8.3). The latter has been partly "excised" to show the proximal extensions of the superficial antebrachial extensor muscles.

st.u.: styloid process of the ulnar bone. 
In the deep layer of the antebrachial region the extensor digiti primi muscle (5) is dominating. Proximally this muscle has two parts: an ulnar head (5.1) reaching up to the olecranal process of the ulna and a radial head (5.2) reaching up to the radial tuberosity. The muscle inserts with a relatively strong and broad tendon (t.s) to the proximal phalanx of the first digit (pollux), sometimes (with a bifurcated tendon) also to the first metacarpal bone. The tendon crosses the two tendons of the extensor carpi radialis muscle. Contrary to the descriptions by Greene (1959), Chiasson (1980) and Hebel and Stromberg (1986) we do not find any indication of the existence of more than one distal tendon of this muscle or of a distinction between abductor digiti primi, extensor digiti primi brevis and extensor digiti primi longus muscles. A comparative anatomical study by Kaneff (1960) supports our findings. He concluded that there is no extensor pollicis longus muscle in the rat and that the muscle with its distal tendon attached to the first proximal phalanx - indicated by us as extensor digiti primi muscle - can be con- sidered as the homologon of the abductor pollicis longus muscle.

In the distal part of the antebrachial region the extensor indicis muscle (6) is situated at the ulnar side of the extensor digiti primi muscle. Its distal tendon ( $t .6$ ) crosses underneath the tendons of the EDC muscle, reaching the distal phalanx of the second and third digit as distal attachment. In about $60 \%$ of the cases at the proximal end of the muscle a small aponeurotic insertion to the ulnar shaft is present $(\mathrm{m})$.

The radial part of the deep layer is occupied by the supinator muscle (7). This muscle originates as a broad aponeurotic tendon (s.s.) from the lateral humeral epicondyle. A small sesamoid bone (D) is incorporated in this proximal tendon (figure $3.1)$. The exact configuration of the proximal insertion of this muscle will be elucidated in par. 3.2.2. Distally the supinator muscle fascicles are either directly attached to the radial periosteum or insert via an aponeurotic tendon (t.7) to the anterior (or flexor) side of the distal third of the radial shaft (figure 3.4). 

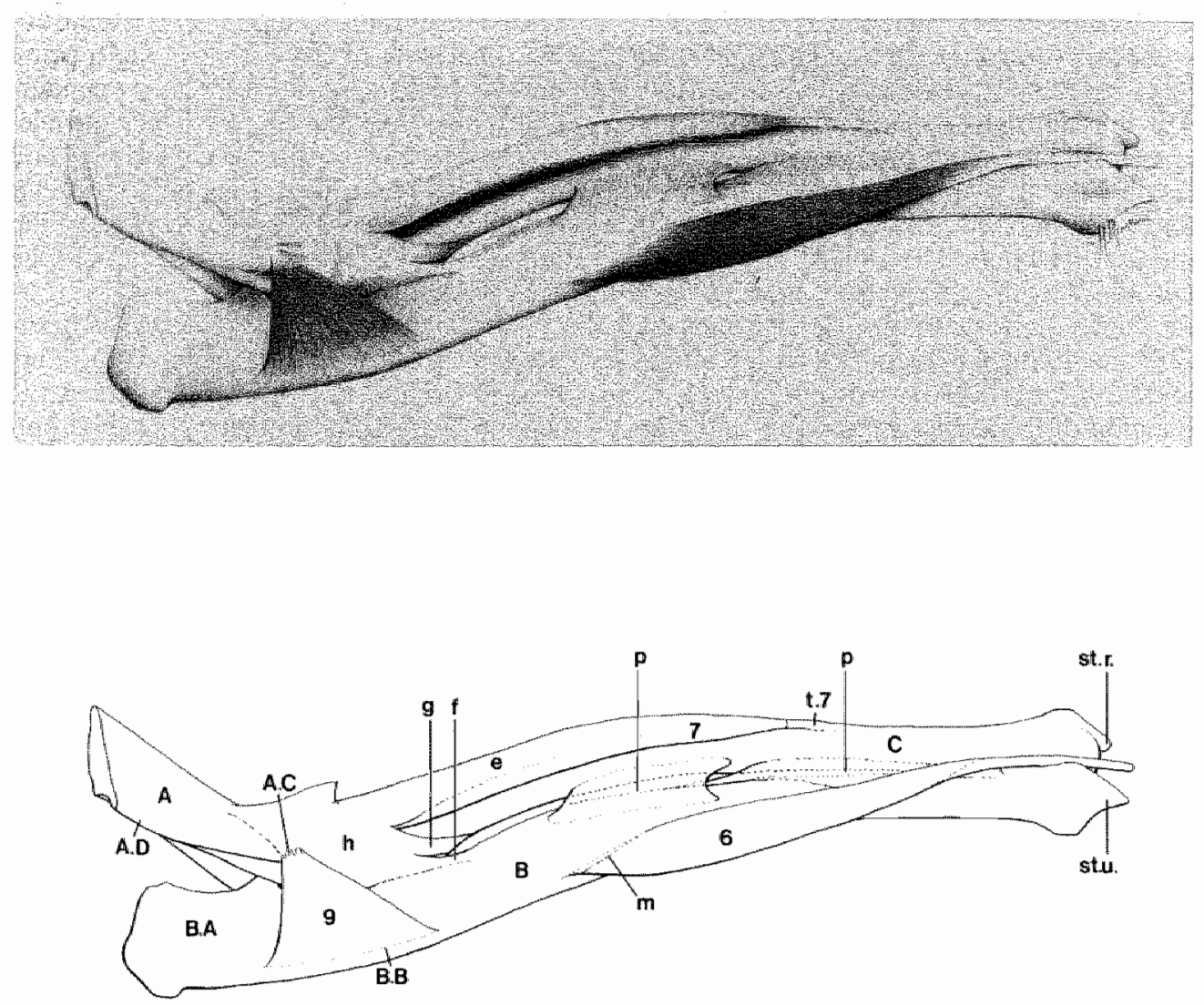

\section{Figure 3.4}

Luteral aspect of the cubital and antebrachial region. Three-dimensional graphic reconstruction based on specimen $\mathrm{Z} 2$ (represented as right foreleg).

All muscles have been removed except ANC, SUP and EI muscles. The interosseal membrane (p) is also present as well as the two divisions of the lateral collateral connective tissue layer ( $f$ and $g$ ).

si.u.: styloid process of the ulnar bone. st.r.: styloid process of the radial bone. 


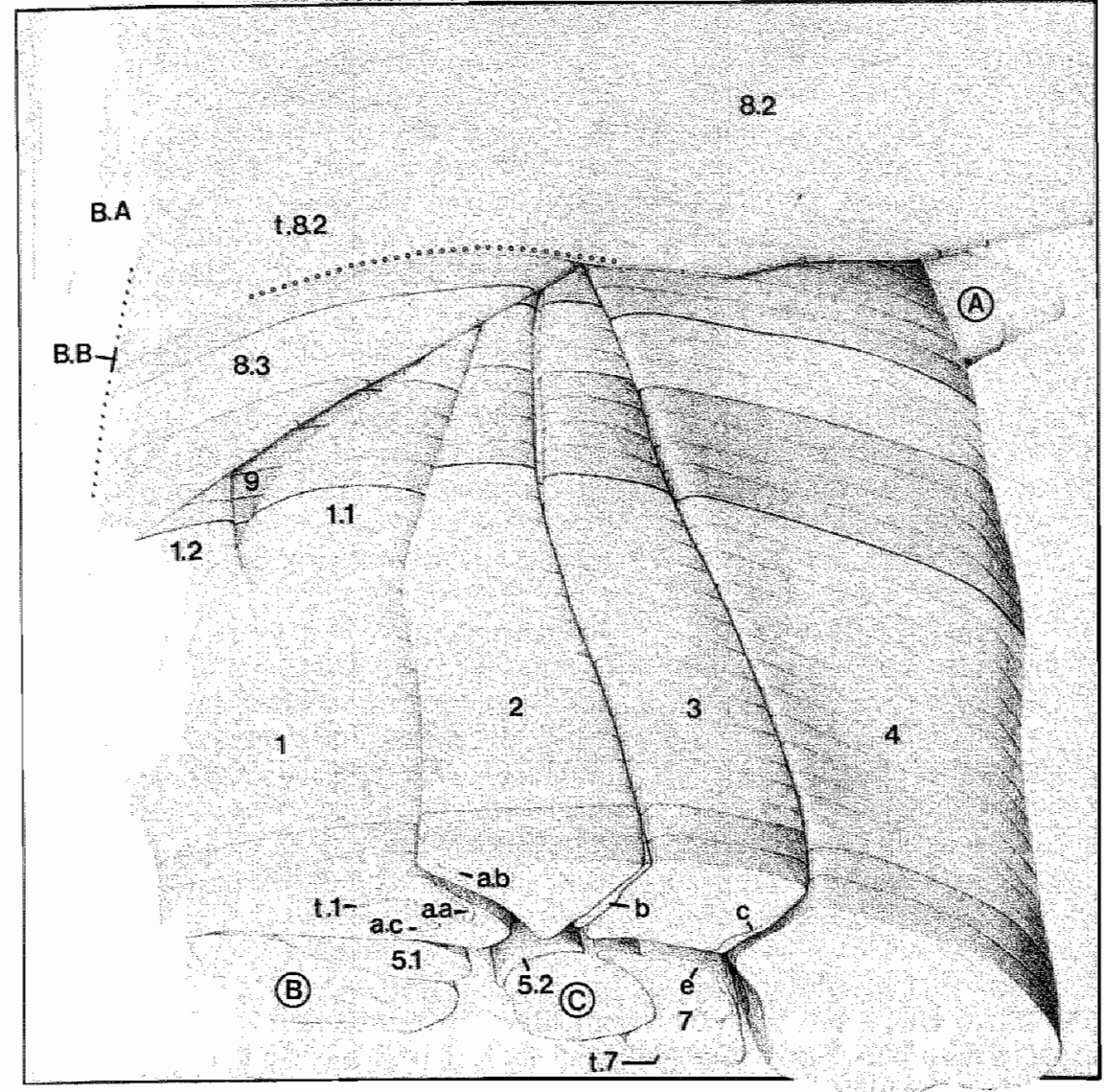

Figure 3.5

Lateral aspect of muscular and regular dense collagenous connective tissue structures in the proximal part of the lateral cubital region viewed in proximal direction. Three-dimensional graphic reconstruction based on specimen C1 (right foreleg).

Superficial (fascial) connective tissue is not present distally from the level indicated with ..... where the olecranal retinaculum (t.8.2) is cut in order to demonstrate the distal prolongation of the TR.med, muscle (8.3). The level of the distal transwerse section of the foreleg corresponds with the level of section drawing 3.16D. The dark. zones correspond with the zones of figure 3.6 where the muscular tissue has been left in sitw. 


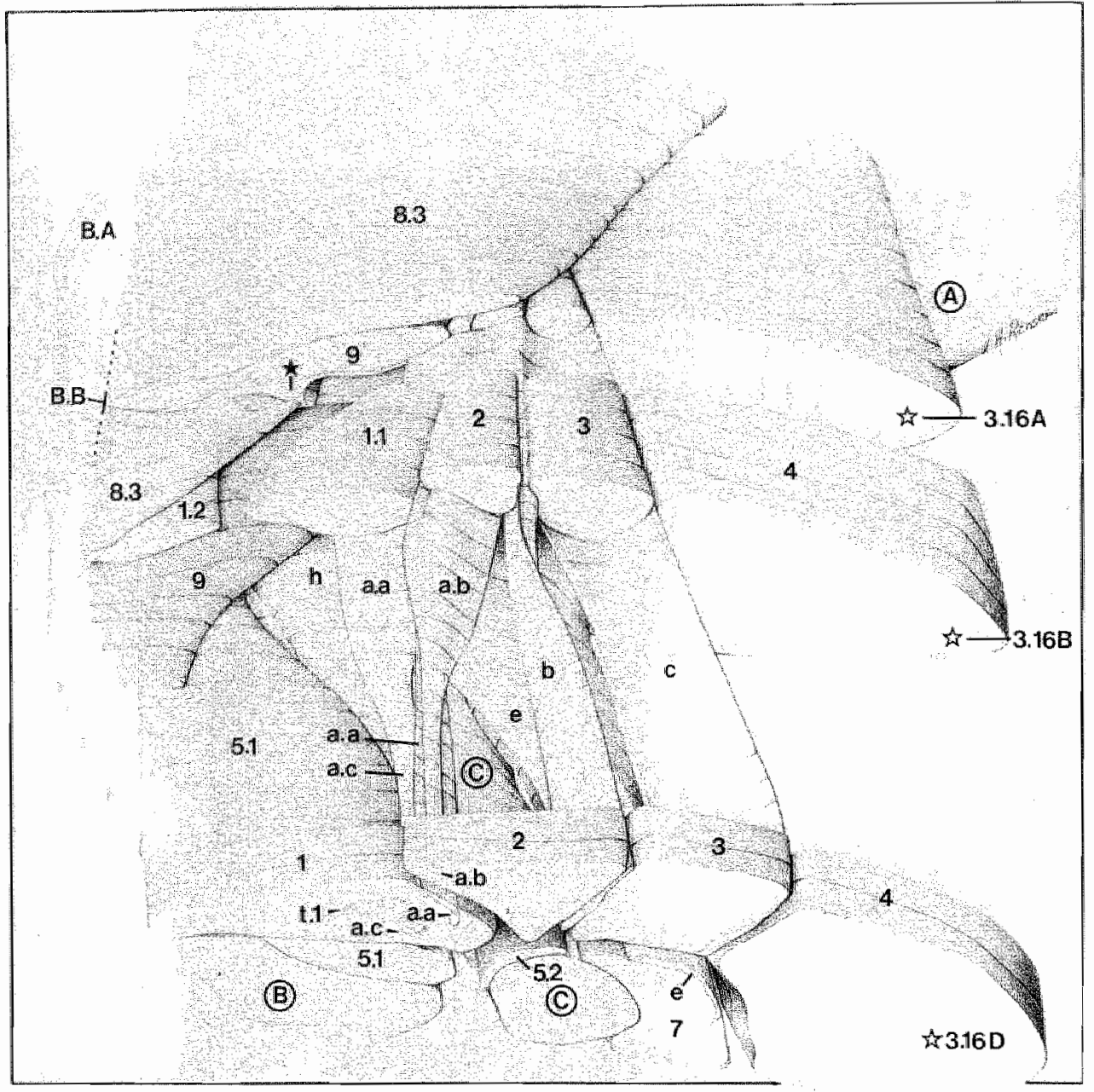

\section{Figure 3.6}

Same three-dimensional graphic reconstruction as figure 3.5 with muscular tissue omitled between the dark zones of figure 3.5. The TR.lat. muscle has also been removed demonstrating the TR med. muscle (8.3). The connectiwe tissue of the humero-ulnar joint capsule $(\star)$ which is continuous with the epimysial connective tissue of the ANC muscle (9). The position of the unar portion of the ECU muscle (1.2) between the TR.med. muscle (8.3) and the ANC muscle (9) and the position of ANC muscle between the ulnar portion of the EDP (5.1) and the ulnar portion of the ECU muscle (1.2) is demonstratted.

The transwerse section lewels corresponding with section drawings $3.16 \mathrm{~A}, 3.16 \mathrm{~B}$ and $3.16 \mathrm{D}$ are indicated ( t) ). 


\subsection{Architecture of regular dense collagenous connective tissue (in relation to the architecture of muscular tissue)}

In general there exists a complex apparatus of regular dense collagenous connective tissule layers converging towards the lateral humeral epicondyle and to the ulnar crest of the ulnar bone. These layers form the walls of muscle compartments occupied by the muscles present in the area. The majority of the muscle fascicles of the muscles concerned insert to these connective tissue layers and in this way are attached indirectly to the mentioned osseous structures.
If not indicated otherwise, the terms "connective tissue layer", "connective tissue structure", "connective tissue apparatus" or similar indications in the following descriptions are defined macroscopically as a layer that consists of regular dense collagenous connective tissue (to which muscle fascicles are attached). Details about architecture of the layers at microscopical level are given in the paragraphs concerned.

\subsubsection{Superficial muscle compartments and connective tissue layers}

The superficial antebrachial fascia (or common epimysial layer) in the lateral cubital and antebrachial region actually is constituted by the outer muscle compartment walls of the underlying superficial extensor muscles.

The proximal part of this connective tissue layer - continuous with the periosteum of the olecranal process and synonymous with the lateral olecranal retinaculum - is formed by the superficial muscle compartment wall of the lateral and medial head of the triceps muscle (figure 3.2). It serves as insertion area for fascicles of these underlying muscles. These muscle fascicles indirectly insert to the ulnar crest of the olecranon via this layer (figure 3.8). At the proximal edge of the lateral head it is continuous with the outer muscle compartment of the long head of the triceps muscle and with the posterior (or proximal) compartment wall of the lateral head. The latter may be considered as a tendon situated deeply between the medial and long head of the triceps muscle (figure 3.7).

Also proximal muscle fascicles of some superficial antebrachial extensor muscles (i.e. ECU, EDL and EDC muscle) insert to the superficial fascial connective tissue. Here the relatively thick collagenous connective tissue can only be separated from underlying muscular tissue by sharp dissection. Over the extent of the ECR muscie the relatively thin outer compartment wall can be easily stripped off. At about one third of the distance elbow-wrist the connective tissue of the outer compartment walls of all superficial muscles also can easily be stripped from the underlying muscular tissue: no muscle fascicles insert to it. Here the connective tissue layer is organized as the outer wall of a "sliding" sheath continuous with the sheath of the distal tendons of the muscles. So there exists an ulno-radial and proximo-distal gradient in the number of fascicles of the superficial muscles that insert to their outer compartment walls.

In cross-sections of the foreleg, microscopically two zones of connective tissue can be seen in the fascial layer constituted by the outer superficial muscle compartment walls. At the deep level a layer of regular dense collagenous connective tissue is present to which muscle fascicles may be attached (stratum musculare), superficially a layer consisting of reticular collagenous connective tissue with fatty tissue, vessels and nervous tissue elements (stratum reticulare). Distally to the anterior (or distal) edge of the triceps muscle the deep regular dense collagenous layer situated over the antebrachial extensor muscles, gradually splits into two layers with a layer of reticular connective tissue in between. The superficial one is - in proximal direction - contimuous with the outer muscle compartment wall 
of the triceps muscle (lateral olecranal retinaculum) and (indirectly) with the olecranal periosteum. The deep collagenous layer is in proximal direction - continuous with the periosteum of the lateral humeral epicondyle and part of the humeral supracondylar crest and - in ulnar direction - with the periosteum of the ulnar shaft (cf. figure 3.7). In summary, the following conclusions are drawn about the outer compartment walls of the superficial muscles. Part of the muscle fascicles of the ulnar head of the ECU muscle inserts indirectly to the ulnar periosteum via their outer muscle compartment wall (with the remaining part directly attached to the periosteum of the ulnar shaft). Muscle fascicles of the (humeral head of the) ECU, EDL and EDC muscles

\section{Figure 3.7}

Lateral aspect of the right foreleg (fwed specimen) after removal of the skin. Strands of regular dense collagenous connective tissue converge to the olecranon (B.A) and to the bumeral epicondyle, which is covered by the TR.lat. muscle (8.2). Position of the epicondyle is indicated with $\star$. Broken line indicates the position of intermuscular connective tissue layer between TR.lat. (8.2) and TR.lo. (8.1). FCU: flexor carpi ulnaris muscle.

\section{ligure 3.8}

Same specimen as in figure 3.7 after nearly complete removal of the superficial antebrachial fascial connectiwe tissue. The proximal part of the EDL muscle has been dissected out of its compartment. The TR.lat. muscle has been dissected free from adjoining TR. $10 .(8.1)$ and TR.med. (8.3) and taken out. The distal part of the olecranal retinaculum (d.a) is left in situ with the TR.med. muscle fascicles still attached to it.

\section{Figure 3.9}

Lateral aspect of muscular and regular dense collagenous connective tissue structures in the lateral cubital region viewed in proximal direction. Three-dimensional graphic reconstruction based on specimen C1 (represented as left foreleg).

The EDP, EI, ANC and TR muscles are not present. The inter- and intra-muscular layers of regular dense collagenous connective tissue are present. Outer muscle compartment walls and distal extensions of the floor layers as well as distal tendons are not reconstructed. The muscular and connective tissue is represented in their spatial relation (attachments of muscle fascicles to the connective tissue layers are not indicated). With $x \times x$ the insertion area of ANC muscle fascicles to ecu/edl,u-layer (a.a) is indicated.

The level indicated with $\rightarrow$ corresponds with the lewel indicated in figure 3.11.
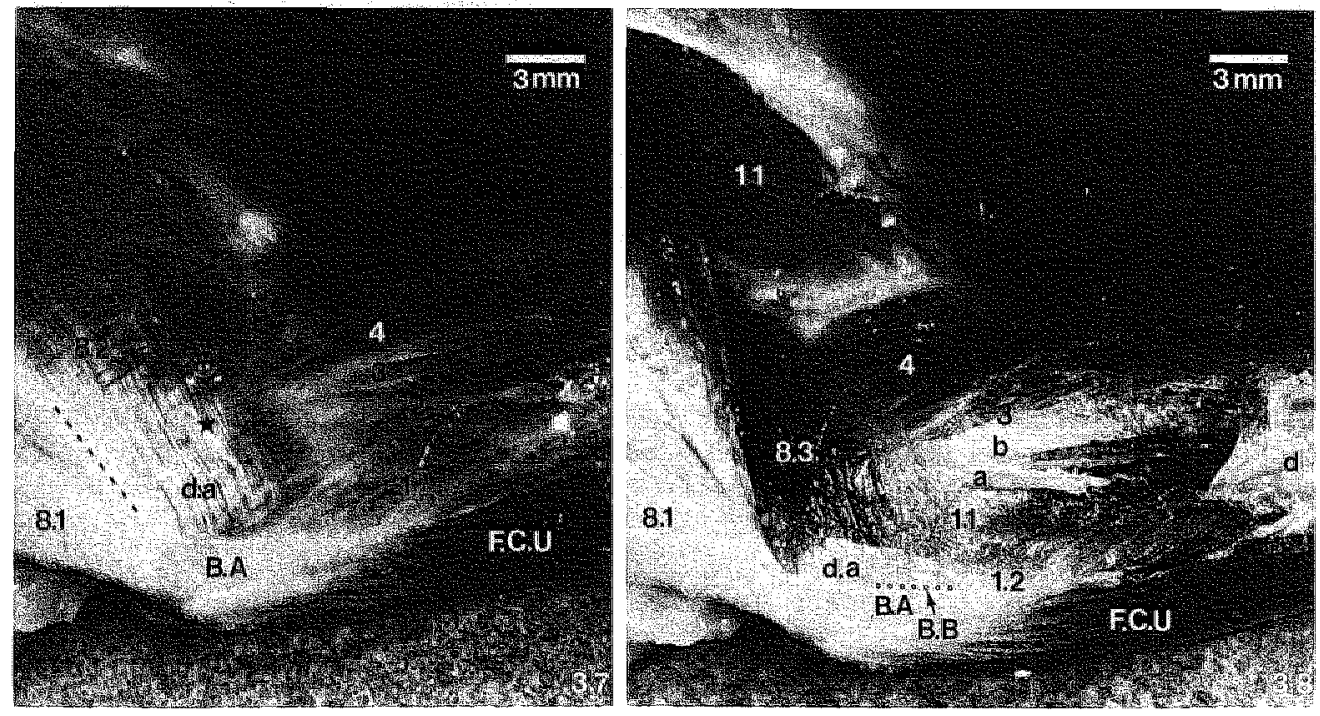


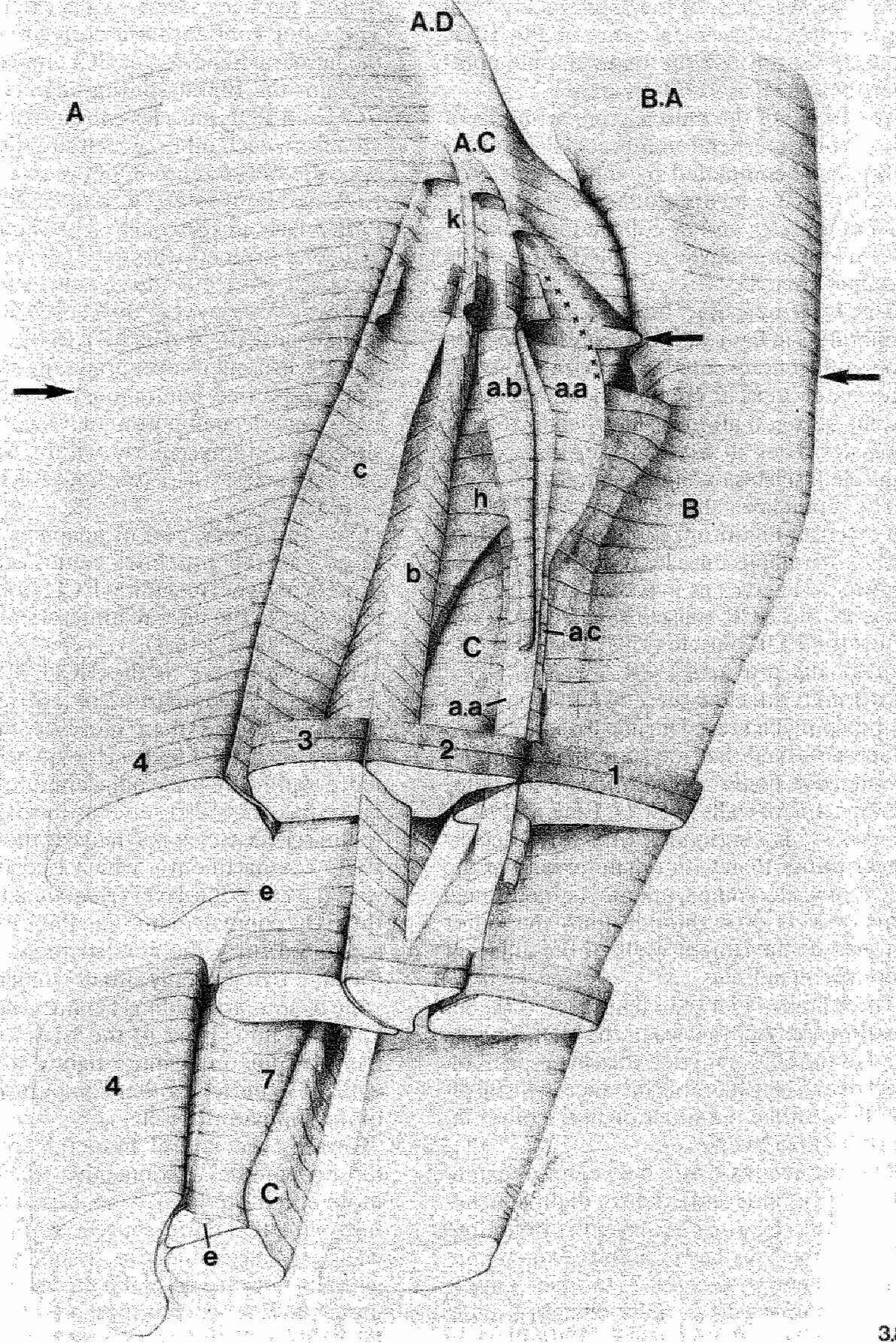


insert via the superficial fascial connective tissue layer indirectly to the lateral humeral epicondyle. Muscle fascicles of the ECR muscle do not use the outer muscle compartment wall as insertion area.

The lining of the muscle compartments of the four superficial antebrachial extensor muscles is completed by collagenous connective tissue layers situated between adjacent muscles and by collagenous connective tissue forming the so-called floors of the compartments.

The intermuscular layers - represented separately in figure 3.9 - are continuous with the collagenous connective tissue forming the outer muscle compartment walls and occur between all four superficial extensor muscles. They all serve as insertion area for muscle fascicles of adjoining muscles.

The septal layer shared by muscle fascicles of extensor digitorum communis and extensor carpi radialis muscles (edc/ecr-layer, c in figure 3.9) serves as insertion area for that part of the ECR muscle fascicles that adjoins the EDL muscle (ulnar portion). The rest of the proximal ECR fascicles (radial portion) is attached directly to the humeral supracondylar crest. During dissection it has been observed that the superficial (fascial) connective tissue - constituted by the outer compartment walls of ECU, EDL and EDC muscles - is continuous with this edc/ecrlayer rather than with the outer wall of the ECR muscle compartment. As mentioned this wall is also thinner than the outer muscle compartment walls of the adjacent superficial muscles.

The edl/edc-layer ( $b$ in figure 3.9 ) is the insertion area of fascicles of the EDL muscle and of the EDC muscle. Muscle fascicles insert over a considerable distance in distal direction, unlike the situation in the other intermuscular layers.

The connective tissue between the extensor carpi ulnaris and extensor digitorum lateralis muscles (ecu/edl-layer) is organized differently. This layer exhibits two components: one layer (ecu/ed..I) to which muscle fascicles of the EDL. muscle insert (a.b. in figure 3.9) and one layer (ecu/edl.u) to which approximately half of the ECU muscle fascicles insert (a.a. in figure 3.9). The latter configuration corresponds with the humeral head of the ECU muscle. This explains the finding during dissection that ECU and EDL muscles can easily be separated from each other, which situation is the opposite of the relation between EDL and EDC and between EDC and ECR muscle. Particularly in proximal cross-sections the ecu/edl.u-layer appears to be curved around the ECU muscular mass and in fact continues as floor layer of this muscle compartment (figure 3.9 and 3.16B). In distal direction the ecu/edl.u-layer gradually splits into two layers: one continuous as wall of the ECU muscle compartment (a.a) and one situated intramuscularly within the ECU muscular mass (a.c) (cf. figure $3.16 \mathrm{C}$ and 3.16D).

The muscle fascicles of anconeus muscle insert via the proximal extension of the ecu/edl.u-layer (including ECU floor layer) indirectly to the lateral humeral epicondyle (figure 3.9 and $3.16 \mathrm{~A}$ ).

The floor layers of the ECU, EDL and EDC muscle compartments are relatively more developed than those of the ECR muscle. In distal direction they grow thinner more rapidly than the adjacent intermuscular septa. They also serve as insertion area for muscle fascicles, particularly those of the ECU compartment - which is continuous with the ecu/edl.u-layer (vide supra) - and of the EDC compartment. The floor layers are separated from the compartment walls of the underlying deeply situated muscles by a zone of areolar ("sliding") connective tissue. Only the floor layer of the EDC compartment is sometimes more tightly connected with the underlying outer compartment wall of the supinator muscle.

Towards the Lateral humeral epicondyle the intermuscular connective tissue layers more and more intertwine. Gradually they fuse with the outer muscle compartment walls (fascial connective tissue layer) and with the floor layers of the muscle compartments. In this way a common layer of regular dense collagenous connective tissue ( $k$ 


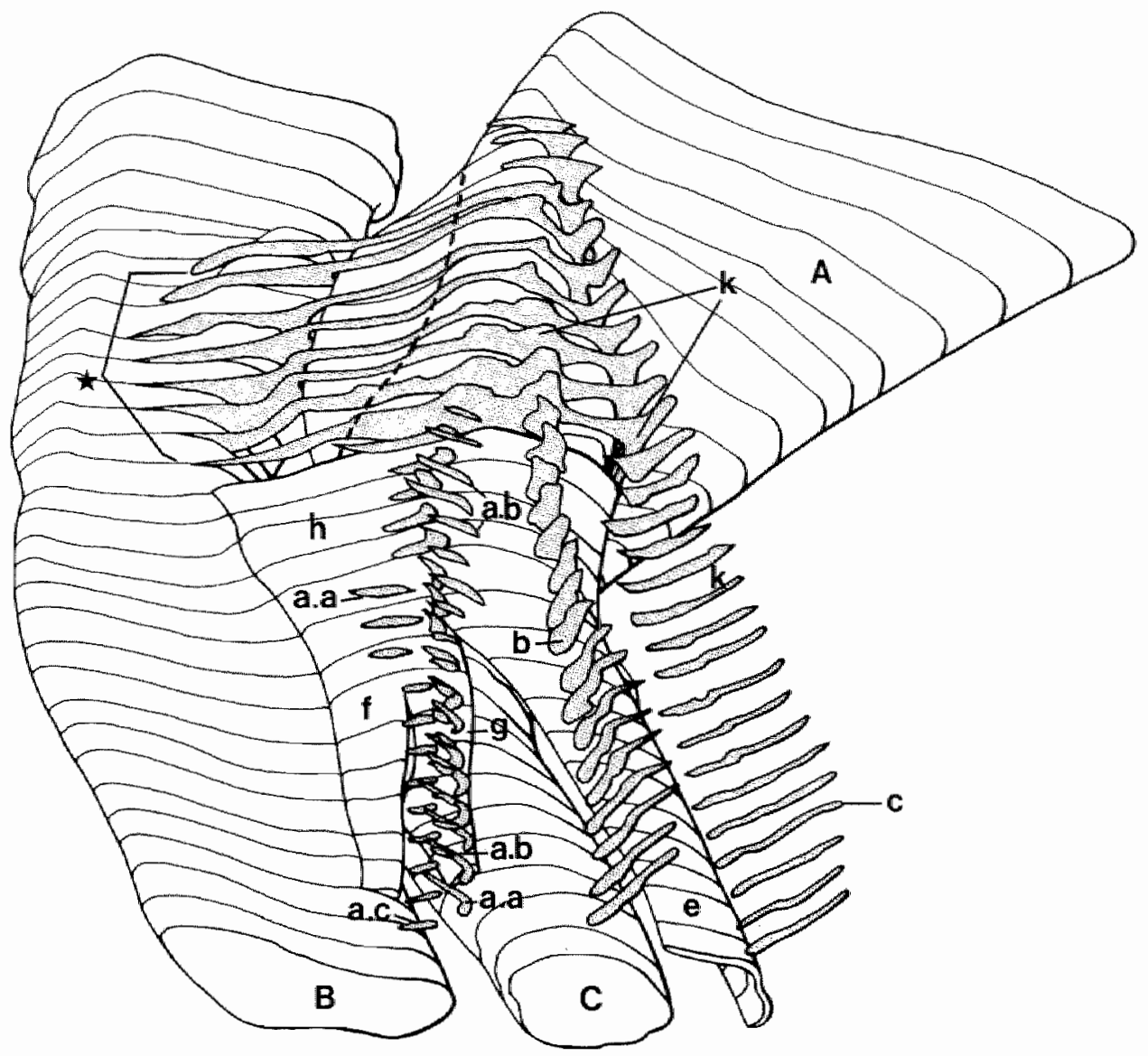

Fingure $3.10 \mathrm{~A}$

The articulating bones of the elbow joint and the epicondylar connective tissue apparatus. Right lateral aspect viewed in proximal direction. Three-dimensional graphic reconstruction based on specimen $\mathrm{Cl}$. Deep division of the apparatus $(f, g$ and $h)$ indicated in white. The superficial division (a to c) including joint capsular connective thissue is represented by serial cross-sections (grey). Along the broken line the ct.com. ( $\mathrm{k}$ ) is continuous with joint capsular connective tissue $(\star)$ ). 


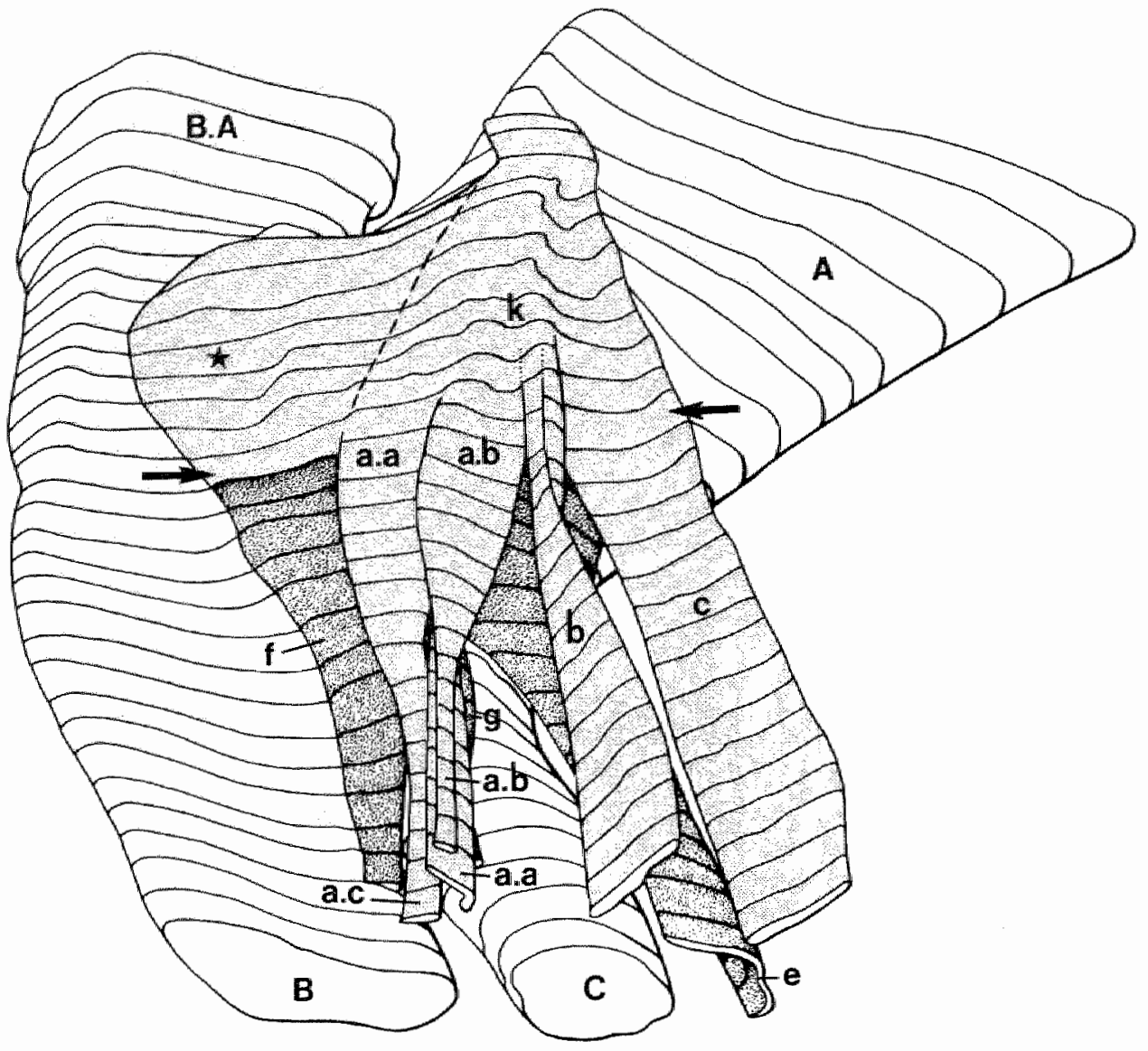

Figure 3.10B

Epicondylar connectiwe tissue apparatus. Right lateral aspect viewed in proximal direction. Three-dimensionall graphic reconstruction based on specimen $\mathrm{Cl}$. Articulating bones of the elbow joint are indicated in white, the deep division of the epicondylar connective tissue apparatus in dotted black and the superficial part of this apparatus in grey Outer walls of superficial muscle compartments are not present. Only the proximal extemsions of the floor layers are represented. Along the broken line the ct.com. (k) is continuous with joint capsular connective tissue ( $\star$ ).

The level where deep regular dense collagenous connective tissue structures fuse with floor layers of the superficial muscle compartments is indicated $(\rightarrow)$. 
in figure 3.10 ) is formed which is continuous with the periosteum of the lateral humeral epicondyle and supracondylar crest. At its ulnar side this common layer is continuous with the capsular connective tissue of the humero-ulnar joint (figure 3.10).

\section{Summary of 3.2.1.}

The superficiall antebrachial fascia actually is constituted by the outer compartment walls of the underlying superficial extensor muscles. Particularly the ulnoproximal area of the fascial layer serves as insertion area for muscle fascicles of the superficial antebrachial extensor muscles and of the lateral and medial head of the triceps muscle. Muscle fascicles of the latter two muscles insert in this way indirectly to the ulnar crest of the olecranon via the proximal extension of this regular dense collagenous connective tissue layer - synonymous with the lateral olecranall retinaculum -. Part of the muscle fascicles of the ulnar head of the ECU muscle also insert via their outer compartment wall to the ulnar bone. Muscle fascicles of the (humeral head of the) ECU, EDL and EDC muscle insert in this way indirectly to the humeral bone. In distal and radial direction the fascial connective tissue is organized as the outer wall of a sheath of "sliding" connective tissue.

The muscle compartments of the superficial extensor muscles are completed by collagenous connective tissue layers situated between the muscular masses and converging towards the lateral humeral epicondyle (figure 3.9). Muscle fascicles of adjacent muscles insert to these layers and in this way are attached indirectly to the humeral bone. The layer between EDC and EDL muscle has muscle fascicle insertions over a longer distance than the other layers. The layer between the ECU and EDL muscle splits into two components. The floor layers of the muscle compartments are well-developed, only up to a relatively short distance from the lateral epicondyle and are particularly distinguishable in ECU, EDL and EDC muscle. They also serve as insertion area for muscle fascicles. The floor layer of the ECU muscle is particularly strong and also serves as insertion area for fascicles of the anconeus muscle (figure 3.9). Near the lateral humeral epicondyle intermuscular and floor layers of the muscle compartment more and more intertwine with each other and with the outer compartment walls to form a common layer of regular dense collagenous connective tissue. This structure is continuous with the humeral periosteum and - at its ulnar side - with the joint capsular connective tissue (figure 3.10 ). 


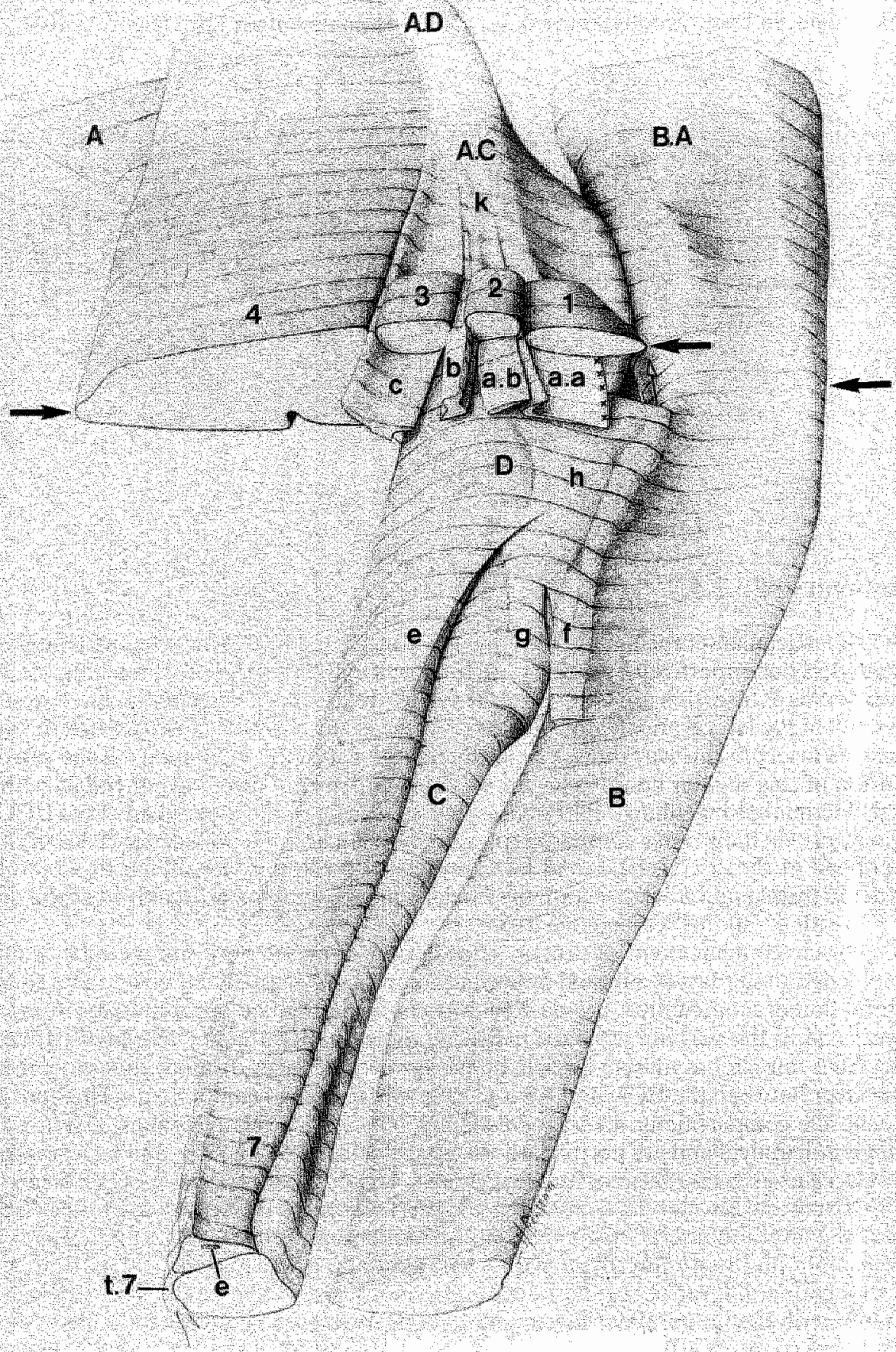




\subsubsection{Deep muscle compartments and connective tissue layers}

Under the floor layers of the superficial muscle compartments a relatively thick aponeurotic layer of regular dense collagenous connective tissue extends from the lateral humeral epicondyle in distal direction. This layer mainly coincides with the outer wail of the SUP muscle compartment.

At the radial (i.e anterior or flexor) side muscle fascicles of the SUP muscle reach more proximally than at the ulnar (i.e posterior or extensor-) side (figure 3.12). An extension of the outer muscle compartment wall is interposed between those two muscle portions giving the proximal part of the supinator muscle a partly bicipital appearance (figure $3.16 \mathrm{C}$ and $3.16 \mathrm{D}$ ). The muscle fascicles of the radial muscle portion insert to this intramuscular extension rather than to the outer muscle compartment wall which also is thinner than the compartment wall of the ulnar muscle portion. At about one-fourth of the total length of the supinator muscle this intramuscular connective tissue layer gradually disappears and the supinator muscle fascicles all insert to the inner side of the outer muscle compartment wall (figure 3.12).

The relatively thick part of the outer supinator compartment wall together with the intramuscular layer is indicated as supinator septum (e in figure 3.11). In distal direction it gradually decreases in thickness and finally it is continuous with the periosteum of the radial bone, to which the SUP muscle has its main distal insertion (figure 3.4). All muscle fascicles of the underlying supinator muscle insert indirectly to the humeral epicondyle via this layer.
The proximal continuation of the supinator septum is free from inserting muscle fascicles as it extends towards the lateral humeral epicondyle. Near the humeromradial joint it gradually joins a strong (lateral collateral.) collagenous connective tissue strand that originates with two divisions (crura) from the neck of the ulnar and the radial bone ( $f$ an $g$ in figure 3.11). A strong iuxta-articular plate of regular dense colllagenous connective tissue (deep common connective tissue layer, $h$ in figure 3.11), that extends towards the lateral humeral epicondyle, is formed by fusion of these three layers.

In this layer a small sesamoid bone (os supinatoris or supinator bone, $D$ in figure 3.11 ) is incorporated, right at the site where the septum fuses with the collateral collagenous connective tissue strands. It protrudes into the joint cavity and is covered at its articular side with a cartilaginous layer. The collagenous fibers of the proximal continuation of the supinator septum mainly run over the outer side of this supinator bone (figure 3.12). Reticular collagenous connective tissue covers the inner (iuxta-articular) side of the deep common connective tissue layer around the supinator bone (figure 3.12 and 3.16.B). At the radial (anterior) and ulnar (posterior) side the deep common connective tissue layer is continuous with the capsular connective tissue (figure 3.11). During dissection a kind of "cross" configuration can be noted. Traction on the supinator septum reveals displacement of the supinator bone in radial direction and tension of the capsular connective tissue fibers from the

\section{Figure 3.11}

Lateral aspect of muscular and regular dense collagenous connective tissue structures in the deep part of the lateral cubital region viewed in proximal direction. Three-dimensional graphic reconstruction based on specimen C1. (represented as left foreleg).

The EDP, EI, ANC and TR muscles mot present. Only the intermuscular layers and the proximal extension of the floor layers of the superficial muscle compartments are reconstructed. The muscular and connective tissue is represented in their spatial relation (attachments of muscle fascicles to the connective tissue layers are not indicated). With $(x \times \times)$ the insertion area of ANC muscle fascicles to ecu/edla-layer (a.a) is indicated (cf. figure 3.9). The arrow indicates where the deep common connective tissue layer is continuous with the connective tissue of the humero-radial joint $(\longrightarrow)$.

The level indicated with $\rightarrow$ corresponds with the level indicated in figure 3.9 . 


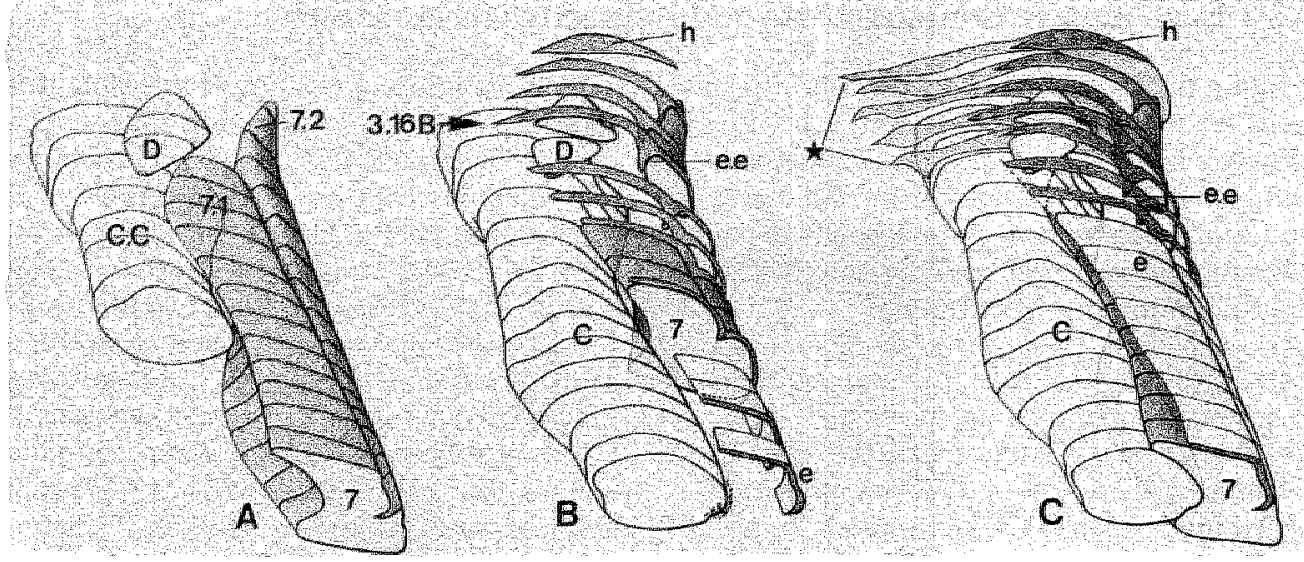

Figure 3.112

The supinator muscle, the supinator seplum and their relation to the supinator bone. Lateral aspect of right foreleg viewed in proximall direction. Three-dimensional graphic reconstruction based on specimen $\mathrm{Cl}$.

A. Muscular lissue of the SUP muscle (7), the supinator bone (D) and the proximal part of the radial bone (C) represented without adjoining regular dense collagenous connective tissue. The bicipital appearance of the proximal part of the SUP muscle is demonstrated.

B. Parts of the muscular tissue of the SUP muscle (7) and several cross sections of the regular dense collagenous connective tissue of the supinator septum (grey). The septal layer is running over the outer side of the supinator bone (D). The level indicated with $\rightarrow$ corresponds to the level of transwerse section drawing $3.16 \mathrm{~B}$.

C. As figure B with joint capsular connective tissue ( $\star$ ) also present.

7.1 ulnar part of the SUP muscle (extensor side)

7.2 radial part of the SUP muscle (flexor side)

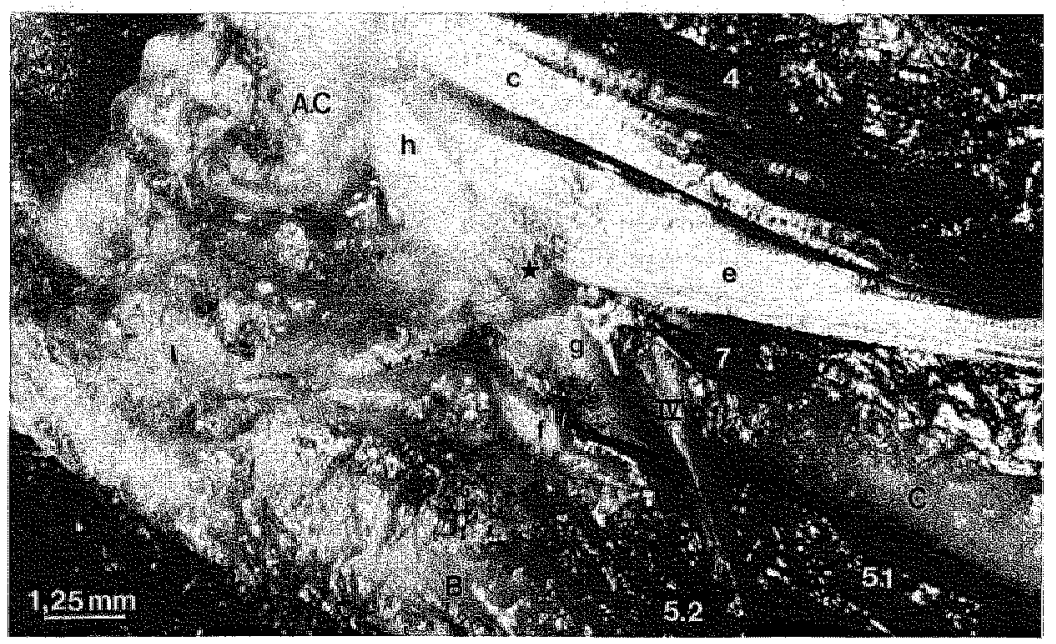

Figure 3.13

Dissection of the deep part of the epicondylar connective tissue apparatus. Lateral aspect of the cubital region of same specimen as in figure 2.2. The ECU, EDL and EDC muscles with adjoining comnective tissue layers have been removed. The ede/ecr-layer (c) has been left in situ with the ECR muscle fascicles (4) attached to it. The position of the supinator bone (D) is indicated with ( $)$

Traction at the supinator septum (e) evokes tension of the capsular connective tissue of the humero-ulnar joint $(x x)$ 
supinator bone to the olecranal attachment of the capsule (figure 3.13 ).

At some distance from the lateral epicondyle the deep common connective tissue layer fuses with the proximal continuations of the compartment walls of the superficial extensor muscles, first with the floor layers. In this way the aforementioned common connective tissue layer ( $\mathrm{k}$ in figure 3.11 ) is formed.

\section{Summary of 3.2.2.}

The outer wall of the muscle compartment of the supinator muscle is continuous with a strong and broad layer of regular dense collagenous connective tissue that extends towards the lateral humeral epicondyle. All supinator muscle fascicles insert via this layer - and its distal intramuscular extension - indirectly to the epicondyle. This layer is indicated as the supinator septum (e in figure 3.11 and 3.12). At some distance from the epicondyle the septal connective tissue layer fuses with a (lateral collateral) collagenous connective tissue strand that originates in the form of two crura from the neck of the uinar and the radial bone ( $f$ and $g$ in figure $3.11)$. In this way a strong iuxta-articular common layer of regular dense collagenous connective tissue (h in figure 3.11) is formed that extends in proximal direction towards the lateral humeral epicondyle. At this site a small sesamoid bone (supinator bone, $D$ ) is incorporated within the connective tissue. The deep common connective tissue layer is continuous with the joint capsular connective tissue. Near the lateral epicondyle it gradually intertwines with the muscle compartment walls of the superficial extensor muscles to form the common proximal regular dense collagenous connective tissue layer (ct. com., $k$ in fig. 3.11 ) which is continuous with the humeral periosteum (figure 3.10). 


\subsection{Architecture of muscular and connective tissue in the lateral cubital region (integral description)}

Most components of the proximal colllagenous connective tissue apparatus described in par. 3.2 serve as insertion area for muscle fascicles of ECU, EDL, EDC, ECR, SUP, TR med, TR.lat and ANC muscle. Those muscle fascicles are organized in series with regular dense connective tissue layers via which they are connected indirectly to the humeral (epicondyllar) or ulnar (olecranal) periosteum. Therefore at least two muscle/connective tissue units can be distinguished consisting of muscle fascicles of various muscles organized in series with the two divisions of the proximal connective tissue apparatus that converge towards the lateral humeral epicondyle and the ulnar olecranon.

A. The epicondylar muscle/connective tissue unit (figure 3.14).

It converges towards the lateral humeral epicondyle (and partly the supracondylar crest) and is constituted by the muscle fascicles of:

- anconeus muscle

- that part of the extensor carpi ulnaris muscle that is attached to the ecu/edllayer (ECU.hum.)

- extensor digitorum lateralis muscle

- extensor digitorum communis muscle

- that part of the extensor carpi radialis muscle that is attached to the edc/ecrlayer

- supinator muscle

that are organized in series with components of the epicondylar connective tissue apparatus (figure $3.10 \mathrm{~B}$ ) that consists of:

- the walls of the compartments of the superficial extensor and anconeus muscles - including a.o. intermuscular layers (ecu/edl, edl/edc and edc/ecr) and superficial fascial connective tissue -

- supinator septum

- lateral collateral connective tissue layer

- common deep connective tissue layer (d.c.com.)

- common connective tissue layer (ct.com.)
B. The olecranal muscle/connective tissue unit (figure 3.14).

It converges towards the ulnar crest (and olecranon) and is constituted by the muscle fascicles of:

- lateral head of the triceps muscle

- medial head of the triceps muscle

- that part of the extensor carpi ulnaris muscle fascicles that is attached to fascial connective tissue continuous with the lateral olecranal retinaculum (ECU.uln.)

that are organized in series with components of the olecranal connective tissue apparatus that consists of:

- that part of the outer compartment wall of the extensor carpi ulnaris muscle that is situated over the ulnar head of this muscle

- the outer compartment wall of the lateral and medial head of the triceps muscle (lateral olecranal retinaculum)

Actually also the compartment wall of the long head of the triceps muscle and the deep triceps tendon between lateral and long triceps head - with inserting muscle fascicles (par. 3.2.1) should be included in this unit. However we limit ourselves to the lateral cubital region.

The main part of the muscular tissue of the epicondylar muscle/connective tissue unit extends between components of the proximal (epicondylar) connective tissue apparatus and distal collagenous connective tissue structures (tendons). The supinator muscle fascicles are organized differently: they extend between the supinator septum (as a well-developed deep division of the epicondylar connective tissue apparatus) at the proximal side and, mainly, the radial periosteum at the distal side. Muscle fascicles of the medial head of the triceps muscle show a similar configuration - short muscle fascicles organized between a relatively strong aponeurotic connective tissue layer and a skeletal element - though in a reverse way. Here muscle fascicles extend between hum- 
eral periosteum (proximally) and lateral olecranal retinaculum (distally). In both situations the regular dense collagenous connective tissue layer concerned is continuous with the periosteum of the skeletal element opposite to the one to which the considered muscle fascicles insert.

The muscie fascicles of the radial portion of the ECR muscle are to be excluded from the epicondylar unit as defined above. Proximally those muscle fascicles are directly at tached to the periosteum of the humeral bone at the supracondylar crest. In-series configuration with a component of the proximal collagenous connective tissue apparatus does not occur here. Roughly this portion of muscular tissue coincides with that part of ECR muscle that in distal direc- tion is connected mainly with the ECR.lo. tendon. In the proximal lateral cubital region it can be distinguished as a humeral (muscular) unit.

A (small) part of the muscle fascicles of the ulnar head of the $\mathbb{E C U}$ muscle inserts directly to the periosteum of the ulnar shaft and do not strictly belong to the olecranal unit as defined above. Those muscle fascicles are found between ulnar periosteum (proximally) and the ECU tendon (distally). Of the deep antebrachial extensor muscles, the muscle fascicles of the SUP muscle are an integral part of the epicondylar muscle/connective tissue unit. Muscle fascicles of the two heads of EDP muscle and of El muscles extend between distal tendons of the same name and the periosteum

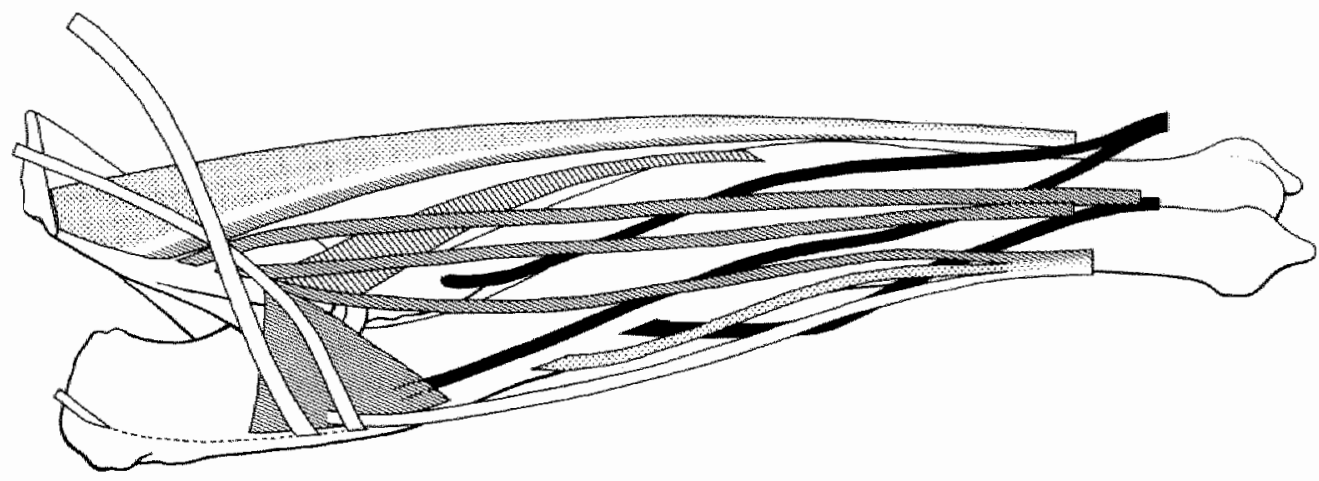

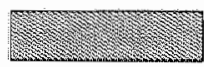

1

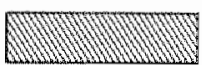

2

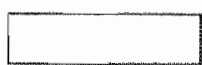

3

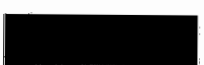

4

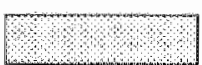

5

Figure 3.14

Schematic representation of the muscle/connective tissue units in the foreleg.

1 superficial diwision of the epicondylar unit

2 deep division of the epicondylar unit

3 olecranal unit

4 EDP and EI muscles

5 radial portion of ECR muscle and distal ulnar portion of ECU muscle 
of the radial and the ulnar bone (to which they insert directly). An in-series situation with a component of the proximal connective tissue apparatus does not occur. In 60 of of the specimens studied, EI muscle fascicles insert proximally via a small layer of connective tissue which is continuous with the ulnar periosteum - the so-called edp/eilayer ( $m$ in figure 3.4) -. In that case part of the ulnar EDP muscle fascicles also inserts via this small connective tissue layer to the ulnar periosteum.

\section{Summary of 3.3.}

The main portion of the muscular and connective tissue in the proximal lateral cubital region is part of two muscle/connective tissue units. In the so-called epicondylar and olecranal unit, muscular tissue is organized in series with components of the epicondylar and the ulnar connective tissue apparatus. The radial portion of the ECR muscle and the distal ulnar portion of the ECU muscle do not belong to those proximal units. Of the deep extensor muscles, the complete SUP muscle is part of the epicondylar unit, the EDP and EI muscles do not belong to one of the units under consideration.

\subsection{Discussion}

Like in man (v.Mameren, 1981; Drukker et al., 1983a-c; v.Mameren and Drukker, 1984), the majority of regular dense collagenous connective tissue structures in the proximal lateral cubital region is interposed between skeletall periosteum and muscular tissue. Most deep as well as superficial regular dense collagenous connective tissue structures are organized in series with muscle fascicles. Collagenous fibers running from bone to bone - to be stressed passively by displacement of the articulating bones - hardly occur (only a few in the lateral collateral connective tissue layer).

In an in-series configuration, as in nearly all the proximal collagenous connective tissue structures in the region, the role of the collagenous fibers in the conveying of tensile stresses also depends on what muscle fascicles are active. In vivo not only displacement of bones influences the state of stress and strain of connective tissue structures (passively), also muscular action may do so. In an architecture as described here no adequate basis exists for the distinction between passively and actively joint-stabilizing structures - organized in parallel to each other - i.e. muscles and ligaments. The exclusive role of the joint capsule and its reinforcements in the passive conveying of tensile stresses - already questioned by Van
Mameren (1983) and Drukker et al. (1983a) on the basis of experiments - can no longer be accepted. The functional units involved in the transmission of forces do not consist of topographically defined and separate entities of muscular ór collagenous connective tissue. Collagenous connective tissue structures are not either ligamentous structures or auxilliary muscle structures. For instance, astructure like the supinator septum may be classified as epimysial fascia but also as aponeurose or tendon and even as a ligament (with adjustable length and tension).

The usually implicitly assumed topographical orientation of constituents of the locomotor apparatus, passively or actively involved in the maintenance of joint stability and integrity - i.e. deep (ligaments) respectively superficial superficial (muscles) - is also challenged by the in-series architecture described here.

We do not distinguish ligaments as deep iuxta-articular structures from muscles, i.e. more superficial structures, because units that function in maintaining joint stability (in which regular dense collagenous connective tissue is organized in series with muscular tissue) are present in the deep as well as superficial part of the region. For instance, the epicondylar muscle/connective tissue unit may be divided into a deep divi- 
sion and a superficial division. Also noteworthy in this respect is the similarity between the (in-series) organization of the olecranal retinaculum and that of the supinator septum. In both situations there occur broad aponeurotic layers of regular dense collagenous connective tissue to which relatively short muscle fascicles insert that - on the opposite side - are directly attached to skeletal elements. Such configurations of muscle fascicles attached to the periosteum of one articulating bone and via a layer of regular dense collagenous connective tissue indirectly attached to another articulating bone, could be considered to be "dynamic ligaments". Such "dynamic ligaments" apparently are not necessarily situated directly beside the joint cavity or in the deep part of the joint region.

Thus, like in man, ligaments can not be distinguished as separate entities in the lateral cubital region of the rat (v.Mameren, 1981; Drukker et al., 1983b, 1983c; v.Mameren et al., 1983; w.Mameren and Drukker, 1984). For instance, an anular ligament cannot be discerned. The proximal extension of the compartment wall of the supinator muscle i.e the supinator septum could be mistaken for it. If the supinator muscle would be dissected as an entity by sharp cutting, a structure like the anular ligament would remain. The functional continuity of the supinator muscle and the regular dense collagenous connective tissue lining with its proximal continuation (supinator septum) would be artificially interrupted by this procedure. Contrary to the situation in man, a lateral collateral ligament seems to be present in the rat in the form of the (two divisions of the) collateral connective tissue layer of the epicondylar connective tissue apparatus. Those collagenous connective tissue strands, however, are in fact longitudinally continuous with the supinator septum. Their mechanical behaviour may be thought to be influenced by the activity contraction state - of the muscle fascicles of the supinator muscle (figure 3.13).

Differences with the situation in the human lateral elbow region of course exist. For instance, the ulno-radial gradient in proportions of muscular and connective tissue differ. In the rat, the intermuscular layers between the superficial extensor muscles decrease in thickness from the ulnar to the radial side. In the same direction the extent to which the muscle fascicles insert to outer muscle compartments walls diminishes. In man, particularly the connective tissue layers around the extensor carpi radialis brevis muscle are relatively strong. The more ulnar orientation of the connective tissue apparatus in the rat is also expressed by the fact that the outer compartment walls of the ECR muscle as well as of the proximal radial portion of the supinator muscle do not serve as insertion area for muscle fascicles. An analogous configuration seems to exist in this respect between the edc/ecrlayer and the intramuscular extension of the supinator septum. Differences with the human situation like those mentioned here might be connected with the quadriped be haviour of the animal, more precisely with the inhibition of flexion of the elbow joint during locomotion. Another difference with the situation in man concerns the relation between the deep and superficial part of the epicondylar connective tissue apparatus. In man, the connective tissue layer between the extensor carpi radialis brevis muscle and the adjacent extensor digitorum muscle is continuous with the supinator muscle compartment wall (v.Mameren and Drukker, 1984; Peters, 1988). Such a well-developed connection does not occur in the rat. Here the compartments walls of all superficial extensor muscles are separated from the supinator septum by a zone of areolar "sliding" connective tissue.

Though there exist differences with the situation in man, in the rat the main principles regarding the existence in the proximal lateral cubital region of one joint stability system - in which muscular tissue and regular dense collagenous connective tissue mainly function in an in-series situation - are similar. Therefore the homologous region in the rat may serve as a model to study the 
relation between the (spatial) organization of the morphological substrate of proprioception and the type of architecture of muscular and connective tissue that occurs in the lateral cubital region.

In relation to the defined epicondylar muscle/connective tissue unit, another architectural feature that occurs in the lateral cubital region needs to be emphasized. In the proximal part of the region the functional units that convey tensile stress do not coincide with muscles as morphological entities. For instance, part of the ECR and of the ECU muscles have to be excluded from the epicondylar unit as not being organized in series with the epicondylar connective tissue apparatus. In the distal extent of the cubital and antebrachial region, however, forces are transmitted via distal tendons organized in series with muscular tissue units that indeed are identical with muscles as functional and topographical entities. Force transmission therefore occurs from one distal collagenous connective tissue structure to two proximal structures (and vice versa) and implies transitional zones or (sub)units of muscular tissue that mostly are organized like unipennate muscles between (one side of) a proximal and (the facing side of) a distal collagenous connective tissue structure. Therefore muscle entities are not the functional units in the conveying of stresses in the region.

Gans (1982) stated that the common view of a "muscle" as contracting entity is usually oversimplified. Each muscle actually is a collection of motor units with different properties. Its separate units (located in different parts of the single muscle) are also subject to different mechanical constraints (Gans and Bock, 1965; Gans, 1982; Woittiez et al., 1983). Muscles may be divided into different components - based on muscle architecture - and these divisions also have functional significance (Bout, 1987; Weijs, 1973; Zweers, 1974), also regarding the conveying of stresses. Most bundles of muscles are joined by connective tissue along their sides and often muscles share their perimy- sia, in this way providing an opportunity for a substantial fraction of forces to be transmitted to adjacent bundles (Landsmeer, 1955 ; 1976" Gans, 1982).

The conclusion that the majority of proximal regular dense collagenous connective tissue layers is organized in series with muscular tissue and that ligamentous structures in the usual definition hardly exist, challenges the usual division of the morphological substrate of proprioception into joint receptors and muscle receptors. The distinction between joint and muscle receptors is principally based on the concept of the existence of two kinds of joint stability structures organized more or less in parallel. In the architectural relations described here, the state of stress and strain (e.g. tension) of connective tissue structures is influenced by displacement of the osseous structure they are connected with, but also by the activity of attached muscular tissue (be it concentric, static or eccentric). This also holds for the substrate of mechanoreception that is possibly connected with the collagenous connective tissue ("joint receptors"). The tension of periarticular connective tissue structures can be modulated in various positions and does not only depend on passively imposed stress or strain. So-called agonist muscles not only induce passive stretching of connective tissue structures at the antagonist side, but also influence the tension of connective tissue structures at the agonist side. In the concept of the "dynamic ligaments" as stated abowe this also implies that "joint receptors" do not necessarily have to be situated in connective structures directly beside the joint capsular tissue, but for instance in the olecranal retinaculum. Several authors mention that low threshold mechanoreceptors in a joint can be influenced by contraction of muscles acting at that joint in the absence of joint movement (Skoglund, 1956; Millar, 1973, 1975; Clark, 1975; Grigg, 1975; Baxendale and Ferrell, 1983; Rossi and Rossi, 1985). Still the main hypothesis to explain findings in physiological experiments about joint position signalling, is the as- 
sumption that changes in activity of articular nerves reflect passively induced changes in tension of capsular and extra-capsular tissue (Grigg, 1975; Rossi and Grigg, 1982). Not only the in-series organization might be an important feature of the spatial organization of a substrate for perception of tensile stresses and of joint position and movement. Mechanoreceptors in the muscular tissue zones between distal and proximal connective tissue structures or between periosteum and a connective tissue layer, is also influenced by the state of stress and strain or by relative displacement of the connective tissue (including periosteum) to which this muscular tissue is attached. The muscular zones connecting proximal and distal collagenous connective tissue (mostly in an unipennate configuration) may be taken as crucial areas for the conveying of tensile stresses, but also as strategic for the perception of force transmission and of movement of the skeletal structures that they are indirectly connected with. The muscle fiber architecture of such areas may also influence those functions. In many mechanical models of limbs and jaws muscles are considered as force factors, but the implications of muscle architecture are not fully appreciated. Gans and Bock (1965), Gans (1982), Woittiez et al. (1983) suggested to change this view by pointing out the advantages and limitations of pennation for a given muscle. Muscle pennation allows more and shorter fibers to be packed into the available space. Since such pennate muscles possess a relatively larger number of fibers than parallel-fibered muscles do, there may be more flexibility and variation in the recruitment of different motor units. In a relatively broad area available between two adjacent connective tissue layers, regionalized subunits of muscle fascicles are able to react directly and more differentially to the behaviour of those structures. Therefore such muscular zones may have the potential for increased control (including perception) of the applied force (Gans and Bock, 1965; Gans, 1982). Richmond and Stuart (1985) point out the effect of muscle pennation on muscle spindle activity and suggest that the spindles in the "short line of pull" are in the most sensitive position to monitor length changes. Bout (1987) concludes that muscle spindles in the jaw muscles of the mallard are concentrated in those muscle fiber groups that are continuously stretched during the complete range of beak opening and absent in those fiber groups that (can) only monitor certain phases of gape. Dividing muscles into different components (or functional units) - which in this region closely depends on the architecture of regular dense collagenous connective tissue - may elucidate the variation in proportion of mechanoreceptors in muscles as described by many authors (reviewed a.o. Voss, 1971; Barker, 1974; Peck et al., 1984, 1988).

English (1985) notes in a review about the possible comparability of jaws and limbs as mechanical systems, that "the topographic organization of the fibers in the muscle or its architecture is an area of general importance". But in principle most models of muscles and muscle functioning in a joint area remain based on the idea that limbs (and jaws) "essentially are mechanical systems in which the bony elements are moved by the attached muscles about moveable joints" (English, 1985). We like to add the following issues to those statements as essential for the rest of this study. Firstly that the topographical organization of the fibers in a muscular area may be interpreted in terms of arrangement in relation to the architecture of regular dense collagenous connective tissue. Secondly that the architecture of the muscular and connective tissue rather (or also) has to be interpreted in terms of one type of joint stability units - consisting of muscular and collagenous connective tissue in series - reacting to movements of bones. Both issues particularly refer to those areas of muscular and connective tissue that are involved in the monitoring of stresses or of displacement of structures. So we strongly support the suggestion of English and Letbetter (1982a) that architectural study must always precede other studies 
about the substrate of proprioception in the locomotor system. Such a study however should not primarily be based on the concept of muscles as the functional entity of a presumed active joint stability system. The latter statement also applies to ligaments as thé functional units of a presumed passive joint stability system.

\subsection{Conclusions}

1. The majority of the collagenous fibers in the proximal lateral cubital region is interposed between skeletal tissue and muscle fascicles. Only a small portion of them runs from bone to bone and in this respect may be classified as ligamentous fibers i.e. collagenous fibers in the (ulnar and radial division of the) collateral connective tissue layer. No separate entities like collateral and/or anular ligaments can be described.

2 The usual classification of regular dense collagenous connective tissue structures based on their topographical relation to muscles, fails to express their functional role in the guiding of forces over the elbow joint.

3 In the proximal lateral cubital region there exists a complex apparatus of collagenous connective tissue layers which mainly consist of muscle compartments walls. These converge towards the lateral humeral epicondyle and the ulnar olecranon. Most muscle fascicles in the proximal joint region are organized in series with the connective tissue of this apparatus.

4 Muscle/connective tissue units are to be distinguished which in the proximal lateral cubital region form the functional units that transmit tensile stresses over the elbow joint. In these units muscular and collagenous connective tissue are organized in series. They do not coincide with the usual anatomical classification into muscles and ligaments. In the distal extent of the foreleg, such functional units indeed coincide with muscles and their distal tendons (as functional and morphological entities).

5 Units of short muscle fascicles attached on one side to the periosteum of a skeletal element and inserting at the opposite side via a broad layer of regular dense collagenous connective tissue indirectly to the periosteum of the other articulating skeletal element, are considered to be dynamic ligaments.

6 The architecture of the muscular and connective tissue in the lateral cubital region of the rat is analogous to that in man. The region may serve as a model to study the relation between the (spatial) organization of the morphological substrate of proprioception and the type of architecture of muscular and connective tissue that exists in the lateral cubital region. 


\subsection{Some characteristic transverse sections of the cubital and antebrachial region (Appendix)}

Figures $3.16 \mathrm{~A}$ to $3.16 \mathrm{H}$ are graphically refined drawings of actual sections of foreleg specimen C1. The estimated levels of the sections are indicated by lines in schematic diagram of four 3D-reconstruction drawings based on specimen $\mathbb{Z} 2$ (figure 3.15 ).

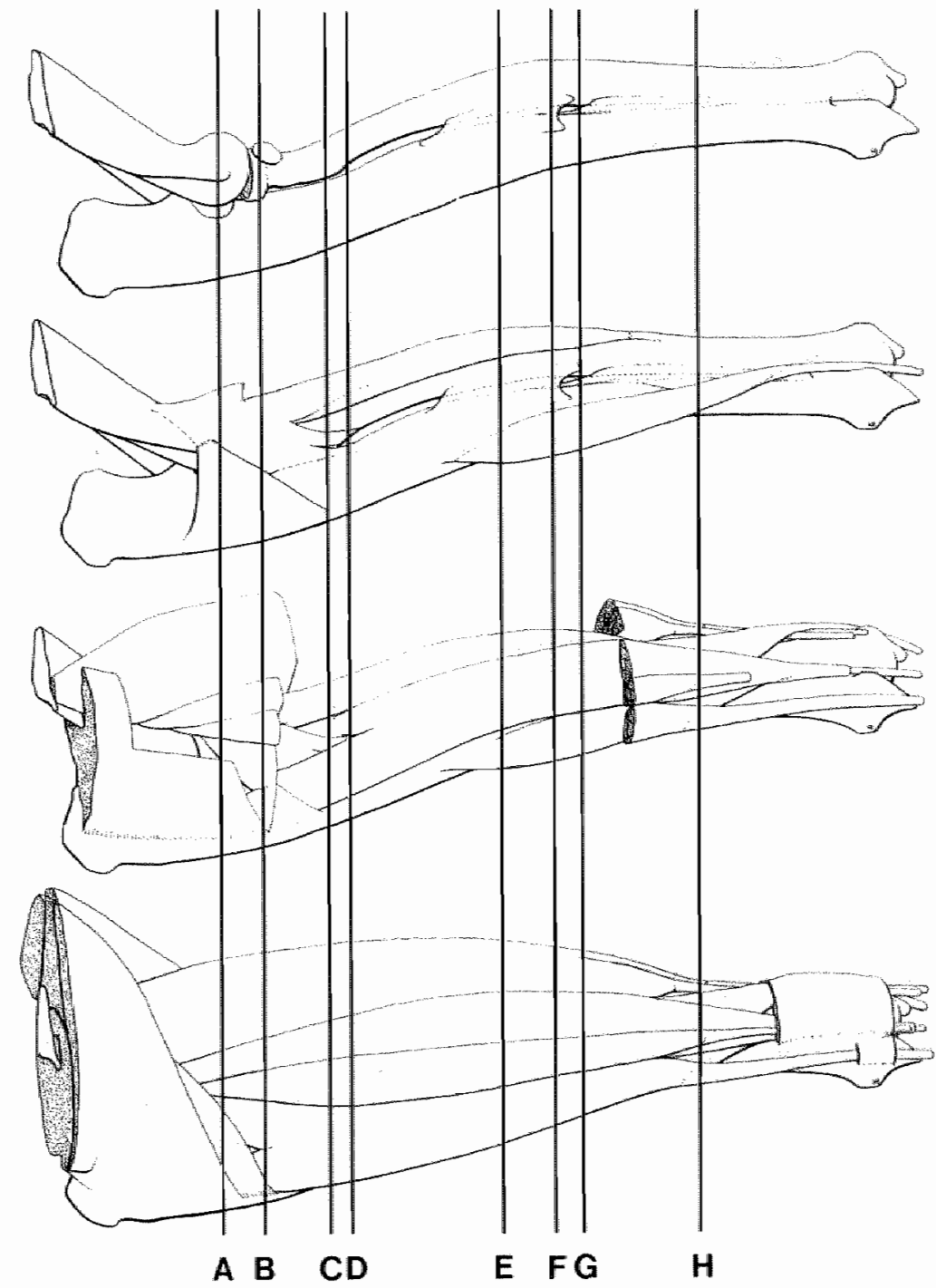

Figure 3.15

Schematic drawings of three-dimensional graphic reconstructions based on specimen Z2 (represented as right foreleg). The lower three drawings correspond with figures 3.2,3.3 and 3.4.

The estimated levels of the transwerse section drawings $3.16 \mathrm{~A}$ to $3.16 \mathrm{H}$ are indicated. 

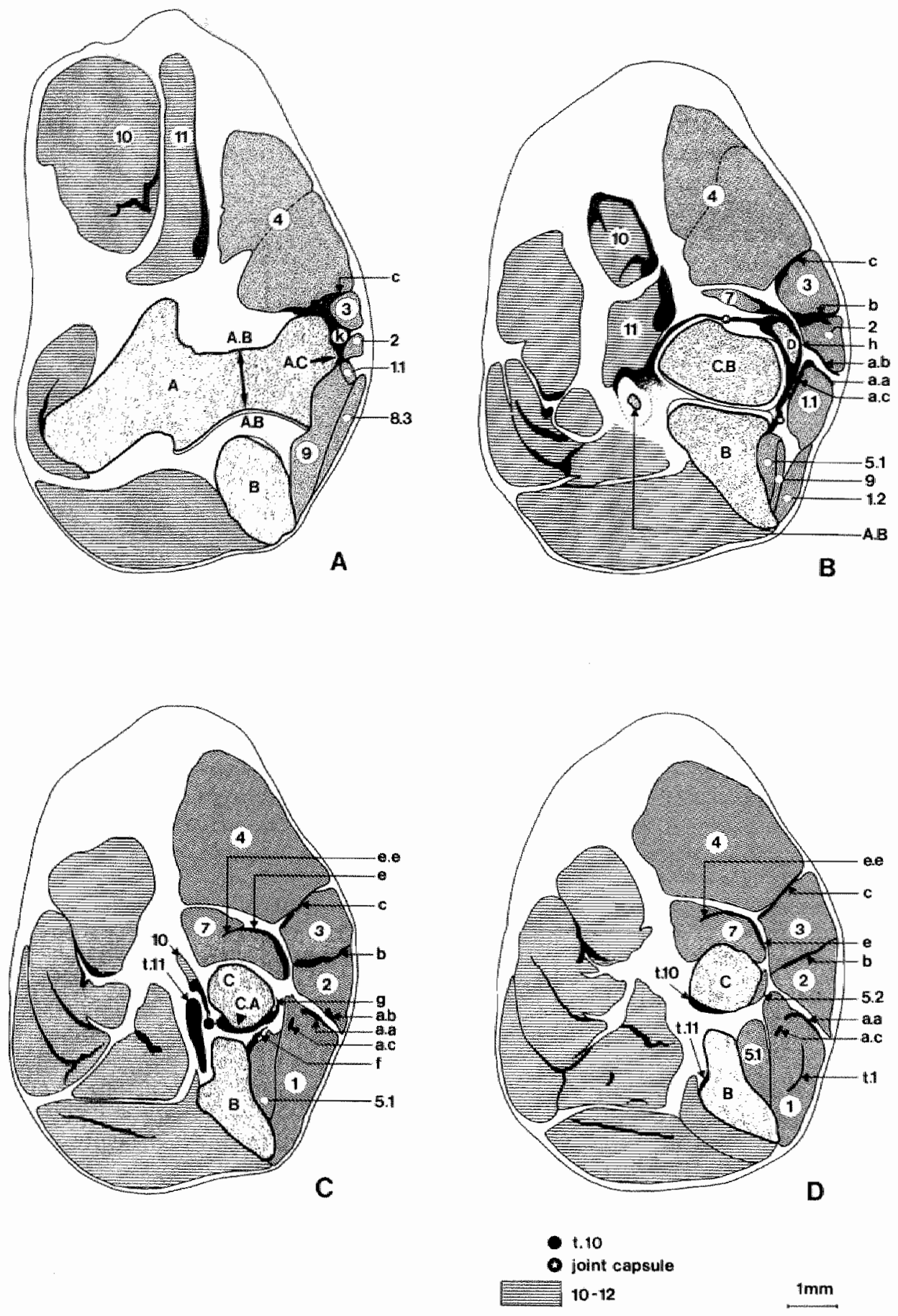
First section at the proximal side in which all four superficial antebrachial extensor nuscles are sectioned. Of the ECU muscle only the humeral head (1.1) is present. The epicondylar connective tissue apparatus is sectioned at the level where the intermuscular and floor layers are fused and intertwined to form the common epicondylar connectiwe tissue layer ( $\mathrm{k}$ ). The ANC muscle (9) is situated directly next to the jount cavity: its epimysial lining is con. timuous with the joint capsular connective tissue. The insertion of the ANC muscle to the proximal extension of the epicondylar connective tissue apparatus $(k)$ - in particular the floor layer of the ECU muscle compartment is also visible.

The level of this transverse section has also been indicated in figure 3.6 .

\section{Figure 3.16B}

Actual section number: 481

The supinator bone (D) has been sectioned at about its equator. The epicondylar connective tissue apparatus has been split into its major components: the intermuscular layers ( $a . a ., a . b ., b$ and $c$ ) and the common layer of regular dense collagenous connective tissue of the deep part of the apparatus ( $(b)$ in which the supinator bone is incorporated. a.c represents the well developed floor layer of the ECU muscle compartment (in distal direction ex. tending intramuscularly). The SUP muscle is sectioned at the level, where only the proximal radial portion of the muscle can be sectioned (cf. figure 3.12A, structure 7.2).

The position of the anconeus muscle (9) between the ulnar portion of the ECU muscle (1.2) and the ulnar portion of the EDP muscle (5.1) is demonstrated (cf. figure 3.6).

The level of this transverse section has also been indicated in figure 3.6.

Figure 3.16C

Actual section number: 591

Unlike the situation in section 3.16B the deep division of the epicondylar connective tissue apparatus has been split into its warious components i.e. the supinator septum (e) and the ulnar (f) and radial (g) division of the lateral collateral connective tissue layer. Also the regular dense collagenous connectiwe tissue layer bet ween the ECU and EDL muscle has split up into three components indicated with $a . a, a, b$ and a.c. The section is situated directly proximally to the level where the biceps tendon (t.10) reaches the radial tuberosity (C.A) and is continuous with the radial division of the collateral connective tissue layer $(\mathrm{g})$ via a periosteal thickening. The ulnar portion of the EDP muscle (5.1) is situated between the ulnar bone (B) and ulnar division of the lateral collateral connective tissue layer on the one hand ( $)$ and the ECU muscle on the other hand (1).

The bicipital appearance of the supinator muscle and the intramuscular extension of the supinator septum (e.e) is also demonstrated. The outer wall of its muscular compartment is thinner over the radiall (or flexor) portion than over the ulnar (or extensor) portion of the muscle (cf. figure 3.12B).

\section{Figure 3.16D}

Actual section number: 701

This is the most distal section where the insertion of the biceps tendon to the neck of the radial bone is present (t.10). The two portions of the EDP muscle (5.1 and 5.2) are discernible. The ECU muscle is the first muscle with a distal tendon to appear (t.1).

The appearance of the SUP muscle with related regular dense collagenous connective tissue (e and e.e) resembles the situation in cross section drawing 3.16C. At this llevel muscle fascicles of this muscle insert to the radial periosteum.

The level of this transverse section thas also been indicated in figure 3.6. 

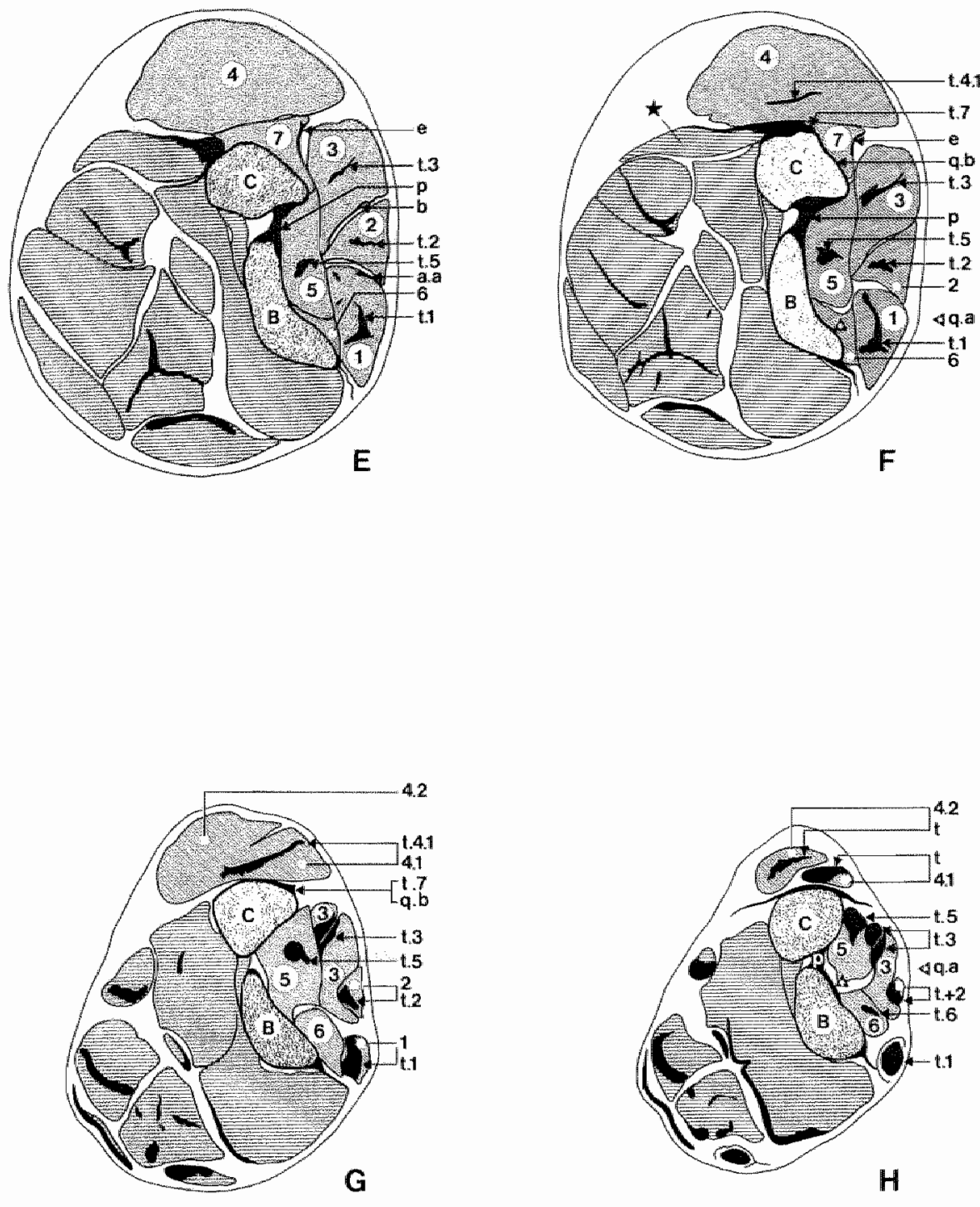
This is the first section at the proximal side where the interosseous membrane ( $p$ ) is present. The supinator septum (e) is still present at this lewel. In all the superficial extensor muscles (except ECR) as well as in the EDP muscle the distal tendon is sectioned $(t .1, t .2, t .3$ and $t .5)$.

The El muscle also is present in this section. A well-developed edp/ei-layer carnot be distinguished in this specimen.

Figure $3.16 \mathrm{~F}$

Actual section number: 1100

In this section also the distal tendon of the ECR brevis muscle is sectioned (t.4.1). In their proximal extension the distal tendons of the superficial extensor muscles exhibit a different orientation. In ECU and ECR muscle they are oriented more or lless in parallel to the surfaces of the ulnar and the radial bone. The distal tendons of the EDL and EDC muscles exhibit an orientation more or less perpendicular to the surlaces of the foreleg bones.

The distal tendon of the SUP muscle (t.7) is continuous with the radial periostenm (q.b) and with the distal tendon of the pronator teres muscle $(\star)$ at the flexor side.

This is the most distal section in which the tendon of the SUP muscle is present (t.7).

Only a small portion of the ECU and EDL muscular tissue is left at this level. The characteristic position of the EDL muscle in the distal foreleg region - i.e. superficially to the EDC muscular mass - is demonstrated (cf. figure 3.3). The separation of the ECR muscle into two distal muscle portions is slightly indicated at this level.

\section{Figure $3.16 \mathrm{H}$}

Actual section number: 1500

Here the ECR muscle can be divided into the ECR brevis muscle (4.1) and the ECR longus muscle (4.2) with related distal tendons ( $t$ ). The ECU muscle is sectioned just at the level where its distal tendon runs through a separate osseo-fibrous canal (cf. figure 3.2). The second (distal) fraction of the interosseous membrane ( $\mathrm{p}$ ) is sectioned (cf. figure 3.4). This collagenous connective tissue layer is continuous in particular with the ulnar periosteum (q.a). 


\section{CHAPTER 4}

\section{QUANTITATIVE PARAMETERS OF THE \\ MORPHOLOGICAL SUBSTRATE OF \\ PROPRIOCEPTION}

\section{Contents}
4.1 Introduction
4.2 Results
4.3 Discussion
4.4. Conclusions

\section{Summary}

Quantitative data about the occurrence of muscle spindles and Golgi tendon organs (GTO's) in the lateral cubital and antebrachial region are presented (par. 4.2). Absolute numbers as well as relative numbers per muscle or per regular dense collagenous connective tissue structure are provided. The relative number of muscle spindles per muscle is expressed per gram of muscle (spindle density), per gram of muscle related to muscle size (spindle abundance) and per muscle zone (spindle volume). The data are compared with data available in literature on receptor content of muscles. The use of such data for the evaluation of the spatial distribution of mechanoreceptors in a given joint region is discussed (par. 4.3). It is preliminarily concluded that the applied quantitative parameters per muscle fail to express the functional characteristics of the muscle because the spatial distribution of the muscle receptors as substrate for the perception of stresses and joint movements in the region is not taken into consideration (par. 4.4). 


\subsection{Introduction}

The occurrence of mechanoreceptors is often expressed by means of quantitative data related to the usually distinguished morphological entities of the locomotor apparatus. Absolute and relative numbers of mechanoreceptors in those entities form a prevalent basis of considerations about the possible functional significance of those structures in the process of proprioception. In comparisons between different muscles for instance with the parameter of spindle density (muscle spindlles per gram of adult muscle) - it is often concluded that high densities characterize muscles initiating fine movements or maintaining posture, low densities those initiating gross movements (Barker, 1974).

In this study spatial distribution of the morphological substrate of proprioception is the central issue. It is questionable whether quantitative parameters - including those usually applied in literature, like receptor density - are suitable to express spatial distribution of mechanoreceptors and how those parameters relate to the actual spatial distribution. This is of particular interest. since muscles form the morphological entities to which most often the value of such parameters is related (for review: Voss, 1971; Barker, 1974; Williams and Warwick, 1980; Brodal, 1981). Since we have introduced the concept of functional morphology of muscle/connective tissue units, it seemed worthwile to reestimate some quantitative parameters in relation to this alternative view on the architecture and classification of the constituents of the locomotor apparatus.

In this chapter quantitative data on the occurrence of muscle spindles and Golgi tendon organs (GTO's) will be presented. In literature considered to be the main muscle receptors, their occurrence is often quantified (a.o. Wohlfart and Henriksson, 1960; Bridgman et al., 1962; Barker, 1962; Eldred et al., 1962; Voss, 1971; Richmond and Abrahams, 1975; Botterman et al., 1978; Lund et al., 1978; Lennartson, 1980a, 1980b; Goldfinger and Fukami, 1982; Peck et al., 1984; Scott and Young, 1987; Banks and Stacey, 1988). The data provided here relate the occurrence of those receptors to muscles and to proximal and distal collagenous connective tissue structures in the foreleg of the rat. 


\subsection{Results}

The absolute number of muscle spindles per muscle is given in column B of table 4.1. The relative number per muscle - calculated as number of muscle spindles per gram of muscle (density) - is listed in column $\mathrm{E}$ of table 4.1. The ranking of the muscles according to those parameters is represented in figure 4.2 .

The ECR muscle exhibits the highest absolute number, but the lowest relative number. The opposite holds for the EI muscle of which the density is nearly equal to that of the SUP muscle.

Table 4.1

\begin{tabular}{|c|c|c|c|c|c|c|c|}
\hline \multicolumn{8}{|c|}{ NUMBER OF MUSCIE SPINDLES per muscle } \\
\hline $\begin{array}{c}\text { Muscle } \\
\text { A }\end{array}$ & $\begin{array}{c}\text { Number } \\
\mathbb{B}\end{array}$ & $\begin{array}{c}\text { SD abs. } \\
\mathrm{Cl}\end{array}$ & $\begin{array}{c}\mathrm{SD} 8 \\
\mathrm{C} 2\end{array}$ & $\begin{array}{c}\text { Range } \\
\text { C3 }\end{array}$ & Muscle w & ght (SD) & $\underset{E}{M S / g r a m}$ \\
\hline EOU & 14.13 & 2.03 & 14.4 & $11-17$ & 54.33 & $(8.06)$ & 261.6 \\
\hline EDL & 9.00 & 1.31 & 14.6 & $7-10$ & 31.83 & $(5.00)$ & 281.3 \\
\hline EDC & 21.63 & 2.88 & 13.3 & $16-25$ & 63.17 & $(7.73)$ & 343.3 \\
\hline ECR & 22.38 & 3.46 & 15.5 & $18-29$ & 218.66 & $(17.0)$ & 102.2 \\
\hline EDP & 12.38 & 1.69 & 13.6 & $10-15$ & 36.50 & $(4.32)$ & 339.0 \\
\hline $\mathbb{E I}$ & 5.00 & 0.93 & 18.5 & $4-6$ & 9.83 & $(1.94)$ & 510.2 \\
\hline SUP & 13.38 & 1.77 & 13.2 & $12-17$ & 26.17 & $(4.79)$ & 510.7 \\
\hline
\end{tabular}

B Absolute number of muscle spindles per muscle (mean value, $n=B$ )

C Standard deviation, absolute (C1) and sage (C2) with range (C3)

D Mean wet muscle weight (in $\mathrm{mg}$ ) $(\mathrm{n}=6)$

E Number of muscle spindles (B) per gram of muscle (mean value, $\mathrm{n}=8$ )

(A) NUMBER OF MUSCLE SPINDLES $\square \mathrm{SID}$

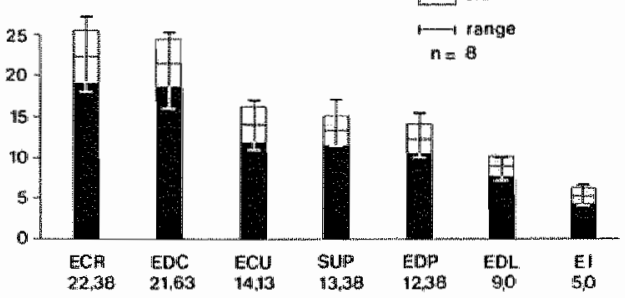

(B) MUSCLE SPHHDLES PEER GFAM MUSCEE

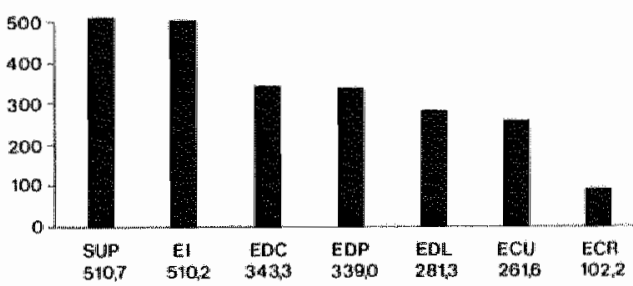

Tigure 4.2

Absolute number of muscle spindles per muscle (A) and number of nuscle spindles per gram of muscle (B) sequemtially ordered. 
With a formula provided by Banks and Stacey (1988) it is possible to measure relative spindle abundance in terms of the deviation of the spindle content from the value expected for muscles of the same size. For the muscles under study those deviations are given in column $F$ of table 4.3. In table 4.4 the ranking of the muscles according to muscle spindle densities is compared with the ranking according to muscle spindle abundances.

In the EDC muscle many more muscle spindles are present than expected for its size. The relatively high density in the $\mathrm{EI}$ muscle appears to be much more related to its small size than in the case of the SUP muscle; the actual spindle density of the latter muscle is high in relation to its size.

The spindle density of ECU and ECR muscles only slightly deviates from the expected value (in negative direction). The number of muscle spindles in the EDL muscle is much lower than expected for a muscle of that size, in contrast to the situation in the EDC muscle (vide supra).

Table 4.3

\begin{tabular}{|c|c|c|c|c|c|c|c|}
\hline \multicolumn{8}{|c|}{ MUSCLE SPINDLE DENSITY and ABUNDANCE per muscle } \\
\hline $\begin{array}{c}\text { Muscile } \\
\text { A }\end{array}$ & $\begin{array}{c}\text { Actual } \\
\text { number } \\
\text { B }\end{array}$ & $\begin{array}{c}\text { Actual } \\
\text { density } \\
\text { c }\end{array}$ & $\begin{array}{c}\text { Muscle } \\
\text { weight } \\
\text { D }\end{array}$ & $\begin{array}{c}\text { Expected } \\
\text { number } \\
E\end{array}$ & $\begin{array}{l}\text { Dev } \\
\text { Linear } \\
\text { F1. }\end{array}$ & $\begin{array}{l}\text { Eion } \\
\text { Log } \\
\text { F2 }\end{array}$ & $\begin{array}{c}\text { Expected } \\
\text { density } \\
G\end{array}$ \\
\hline $\mathrm{ECO}$ & 14.13 & 261.6 & 54.33 & 14.9 & 0.96 & -0.02 & 275.9 \\
\hline $\mathrm{EDL}$ & 9.00 & 281.3 & 31.83 & 12.6 & 0.71 & -0.15 & 393.8 \\
\hline EDC & 21.63 & 343.3 & 63.17 & 15.7 & 1.40 & +0.15 & 249.2 \\
\hline $\mathrm{ECR}$ & 22.38 & 102.2 & 218.66 & 23.4 & 0.96 & -0.02 & 106.8 \\
\hline EDP & 12.38 & 339.0 & 36.50 & 13.2 & 0.94 & -0.03 & 356.8 \\
\hline EI & 5.00 & 510.2 & 9.83 & 8.6 & 0.58 & -0.24 & 877.6 \\
\hline SUP & 13.38 & 510.7 & 26.17 & 12.0 & 1.10 & +0.04 & 461.5 \\
\hline
\end{tabular}

B Absolute number of muscle spindles per muscle (mean value, $n=8$ )

C Number of muscle spindles per gram of muscle (mean value, $n=8$ )

D Mean wet muscle weight (in $\mathrm{mg}$ ) ( $\mathrm{n}=6$ )

E Expected nuscle spindle number for a muscle of the same weight (*)

F Abundance of muscle spindles as deviation of E from B (*)

G Expected muscle spindle density for a muscle of the same weight (*) * Courtesy of R. Banks, Durham, UK.

Table 4.4

\begin{tabular}{|c|c|c|c|c|c|c|c|c|c|c|c|c|}
\hline $\begin{array}{l}\text { Ranking acoonding } \\
\text { to spindle densities }\end{array}$ & $\frac{102.2}{\mathrm{ECR}}$ & $\alpha$ & $\begin{array}{l}261.6 \\
\text { ECU }\end{array}$ & $\leq$ & $\begin{array}{c}281.3 \\
\text { EDL }\end{array}$ & $\ll$ & $\begin{array}{l}339.0 \\
\text { EDP }\end{array}$ & $\leq$ & $\begin{array}{c}343.3 \\
\mathrm{EDC}\end{array}$ & $\alpha$ & $\begin{array}{l}510.2 \\
\mathrm{EI}\end{array}$ & $=\begin{array}{l}510.7 \\
\text { SUPP }\end{array}$ \\
\hline $\begin{array}{l}\text { Ranking acoonding to } \\
\text { spindle abundances }\end{array}$ & $\begin{array}{l}\text { EI } \\
-0.24\end{array}$ & $*$ & $\begin{array}{c}\text { FDL } \\
-0.15\end{array}$ & « & $\begin{array}{l}\text { EDP } \\
-0.03\end{array}$ & & $\begin{array}{l}\text { ECR } \\
-0.02\end{array}$ & $=$ & $\begin{array}{c}\text { ECU } \\
-0.02\end{array}$ & 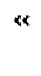 & $\begin{array}{l}\text { SUP } \\
+0.04\end{array}$ & $\begin{array}{c}\text { EDC } \\
+0.15\end{array}$ \\
\hline
\end{tabular}


We suppose that the extent to which muscle spindles are concentrated in a given zone, is a quantitative indication for (uneven) spindle distribution. Therefore in two specimens $(\mathrm{Cl}$ and $\mathrm{Z} 2)$ the relative muscle spindle volume -i.e. the relative volume of that part of the muscle that contains all muscle spindles - was calculated. Those volumes were defined according to the criteria mentioned in par. 2.2.2.3.

Muscles may greatly differ in the concentration of their muscle spindles in a certain limited volume (column D). For instance they are least concentrated in the SUP muscle. Muscles with equal numbers of spindles (e.g. EDC and ECR muscles repectively ECU and EDP muscles) may have similar or different relative spindle volumes. Muscles with similar spindle densities (cf. table 4.1, column E) may differ in relative spindle volume (e.g. EI and SUP muscles or EDC and EDP muscles).

The number of muscle spindles per muscle spindle volume (density, table 4.5 , column F) is an indication of the extent to which the spindles are packed into the available space of the zone. The lowest rate exists in the SUP muscle. The two zones in the ECR muscle differ in number of muscle spindles per volume, whereas the two zones in the EDP muscle do not. The density rates per spindle volume in the EI and ECR.lo. muscles are relatively high and similar.

Table 4.5

\begin{tabular}{|c|c|c|c|c|c|}
\hline \multicolumn{6}{|c|}{ VOLUMES and DENSITIES of MUSCIE SPTNDLE (MS-) ZONES } \\
\hline $\begin{array}{c}\text { Muscle } \\
\text { A }\end{array}$ & $\begin{array}{c}\text { Volume of } \\
\text { muscle } \\
\text { B }\end{array}$ & $\begin{array}{l}\text { Valume of } \\
\text { MS-zone } \\
\text { C }\end{array}$ & $\begin{array}{c}\text { Relative vol. } \\
\text { MS-zone } \\
\text { D }\end{array}$ & $\begin{array}{l}\text { Number } \\
\text {-spindles } \\
\mathrm{E}\end{array}$ & $\begin{array}{c}\text { Density } \\
\text { MS-zone } \\
F\end{array}$ \\
\hline $\mathrm{ECU}$ & 30.69 & 3.29 & 10.7 & 12.0 & 2.0 \\
\hline EDL & 17.49 & 1.03 & 5.9 & 8.5 & 4.7 \\
\hline $\mathbb{E D C}$ & 38.21 & 3.71 & 9.7 & 21.5 & 3.6 \\
\hline ECR & 144.53 & 4.77 & 3.3 & 21.5 & 3.0 \\
\hline ECR.br. & - & 4.29 & 3.0 & 17.5 & 2.7 \\
\hline ECR. 10. & - & 0.48 & 0.3 & 4.0 & 6.2 \\
\hline EDP & 26.52 & 3.46 & 13.1 & 12.5 & 2.6 \\
\hline EDP.uin. & - & 2.68 & 9.1 & 9.0 & 2.7 \\
\hline EDP.rad. & - & 1.03 & 4.0 & 3.5 & 2.5 \\
\hline EI & 6.33 & 0.46 & 7.6 & 5.0 & 8.0 \\
\hline SUP & 14.87 & 5.98 & 40.2 & 13.0 & 1.3 \\
\hline
\end{tabular}

B Volume of the total muscle in $\mathrm{mm}^{3}$ (mean value, $\mathrm{n}=2$ )

C Volume of the muscle spinale zone in $\mathrm{mm}^{3}$ (mean value, $\mathrm{n}=2$ )

D Relative volume of the muscle spindle zone (C:B) in

E Absolute number of muscle spindles per muscle (mean value, $n=2$ )

F Number of muscle spindles per gram of muscle spindle volume expressed in (MS $\left./ \mathrm{g}^{-1}\right) \times 10^{3}(\mathrm{n}=2)$ 
The absolute number of Golgi tendon organs per muscle is given in column $\mathbb{B}$ of table 4.6. The relative number of Golgi tendon organs per gram of muscle (density) is listed per muscle in column $E$ of table 4.6. The ranking of the muscles based on those par- ameters is represented in figure 4.7 .

The ECR muscle possesses the highest absolute number, but the lowest relative number. The highest density of GTO's per muscle is exhibited by the EDP muscle.

Table 4.6

\begin{tabular}{|c|c|rcc|rc|r|}
\hline \multicolumn{7}{|c|}{ NUMBER OF GOLGI TENDON ORGANS per muscle } \\
\hline $\begin{array}{c}\text { Muscle } \\
\text { A }\end{array}$ & $\begin{array}{c}\text { Number } \\
\text { B }\end{array}$ & $\begin{array}{c}\text { SD abs. } \\
\text { C1 }\end{array}$ & $\begin{array}{c}\text { SD } \\
\text { C2 }\end{array}$ & $\begin{array}{c}\text { Range } \\
\text { C3 }\end{array}$ & $\begin{array}{r}\text { Muscle wght (SD) } \\
\text { D }\end{array}$ & $\begin{array}{c}\text { GTo/gram } \\
\text { E }\end{array}$ \\
\hline EOU & 12.13 & 1.55 & 12.8 & $10-15$ & 54.33 & $(8.06)$ & 224.6 \\
EDL & 4.13 & 0.64 & 15.5 & $3-5$ & 31.83 & $(5.00)$ & 129.1 \\
EDC & 10.13 & 1.89 & 18.6 & $8-14$ & 63.17 & $(7.73)$ & 160.8 \\
ECR & 19.63 & 2.83 & 14.4 & $17-25$ & 213.66 & $(17.0)$ & 89.6 \\
EDP & 14.88 & 1.46 & 9.8 & $13-17$ & 36.50 & $(4.32)$ & 407.7 \\
EI & 1.00 & 0.76 & 75.6 & $0-2$ & 9.83 & $(1.94)$ & 102.0 \\
SUP & 9.00 & 2.62 & 29.1 & $6-13$ & 26.17 & $(4.79)$ & 346.2 \\
\hline
\end{tabular}

B Absolute number of GTO's per muscle (mean value, $\mathrm{n}=8$ )

C Standard deviation, absolute (C1) and sage (C2) with range (C3)

D Mean wet muscle weight (in $\mathrm{mg})(\mathrm{n}=6$ )

E Number of GTO's per gram of muscle (mean value, $n=8$ )

(A) NUMHER: OF GOLGI TENDON OHRANS:

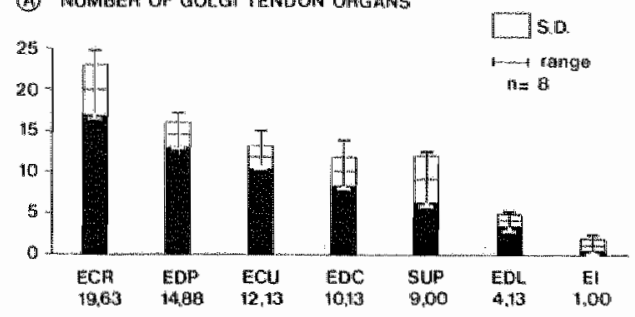

(B) GOLGI TENDON ORGANS PER GRAM MUSCLE

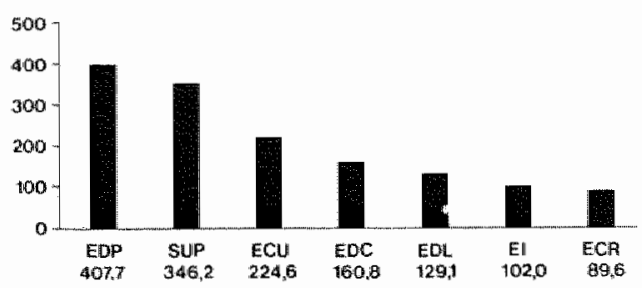

Figure 4.7

Absolute number ol Golgi tendon organs per muscle (A) and number of Golgi tendon organs per gram of muscle (B) sequentially ordered. 
In table 4.8 the relative numbers of GTO's inserted to the proximal (septali), respectively the distal (tendinous) collagenous connective tissue attachments of the antebrachial muscles are given per muscle (column C). In column $D$ the ratio muscle spindles/Golgi tendon organs ( $M / G$ index) per muscle is represented.

The SUP muscle possesses the largest per- centages of proximally inserting GTO's. The ECU and SUP muscles far outstand the other extensor muscles in this respect.

The EDP muscle is the only antebrachial extensor muscle in which the GTO's outnumber the muscle spindles. Taking into account the parameters for the EI muscle in table 4.6 and table 4.1 this muscle in some cases purely contains muscle spindles being devoid of GTO's.

Table 4.8

\begin{tabular}{|c|c|c|c|c|c|}
\hline \multicolumn{6}{|c|}{ NUMBER OF GOLGI TENDON ORGAN per muscle } \\
\hline $\begin{array}{c}\text { Muscle } \\
\text { A }\end{array}$ & Number & $(\mathrm{SD})$ & $\begin{array}{l}\text { (proximal GTO's) } \\
\text { Ratio }\end{array}$ & $\begin{array}{l}\text { : (distal GTO's) } \\
\text { C } \quad \text { tage }\end{array}$ & $M / G-\frac{\text { index }}{D}$ \\
\hline ECU & 12.13 & $(1.55)$ & 0.80 & 44.3 & 1.165 \\
\hline EDL & 4.13 & $(0.64)$ & 0.10 & 9. 1 & 2.179 \\
\hline EDC & 10.13 & $(1.89)$ & 0.08 & 7.4 & 2.135 \\
\hline ECR & 19.63 & $(2.83)$ & 0.09 & 8.3 & 1.140 \\
\hline $\mathrm{EDF}$ & 14.88 & $(1.46)$ & 0.04 & 3.4 & 0.832 \\
\hline EI & 1.00 & 10.76 & 0.00 & 0.0 & 5.000 \\
\hline SUP & 9.00 & $(2.62)$ & 4.54 & 81.9 & 1.486 \\
\hline
\end{tabular}

B Absolute number of GTO's per muscle (mean value, $n=8$ )

C (Number of proximal GIO's) : (Number of distal GTO's), expressed as ratio and as percentage proximal GTO's of whole population of GTO's $(n=B)$

D (Number of muscle spindles) : (Number of GTO's), expressed as ratio per muscle $(n=8)$

WAGE OF PFOXIMAL G.TO

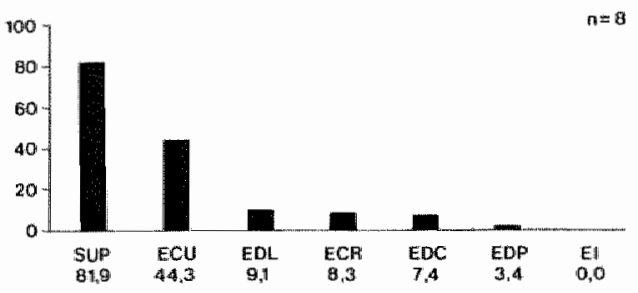

Figure 4.9

Percentage of proximal Golgi tendon organs per muscle sequentially ordered. 
In table 4.10 the numbers of GTO"s per (regular dense) collagenous connective tissue structure are presented. These numbers are based on the 8 specimens embedded in toto in polyester resin. The numbers of GTO's attached to the triceps tendon are based on countings in two serially cut silver stained (Spaethe) specimens.

Of the regullar dense collagenous connective tissue layers that are part of the epicondylar connective tissue apparatus the ecu/edlu-layer and the supinator septum are quantitatively best equipped with GTO's.

The part of the antebrachial collagenous connective tissue belonging to the olecranal connective tissue apparatus (olecranal retinaculum) possesses rellatively many GTO's (12.00), about $80 \%$ of the number of GTO's relat ted to the epicondylar connective tissue apparatus (15.50). If the complete compart- ment wall of the lateral head of the triceps muscle (deep triceps tendon) is also taken into account, this olecranal connective tissue apparatus is equipped with 51.50 GTO's. This is about three times more than the epicondylar connective tissue apparatus (15.50 GTO's).

Of the distal tendons those of the ECR.br muscle and of EDP muscle are nearly equally well-equipped. The distal tendons of SUP and EI muscle are poor in GTO's. The distal tendons connected via muscular tissue zones with the epicondylar muscle/connective tissue unit (indicated with $\div$ ) posses 34.38 GTO's. The GTO's connected with the distal ECU tendon are all included in this number, those connected with the ECR.lo. tendon are excluded. The ratio (proximal GTO's) : (distal GTO's) in the epicondylar unit therefore is about $1: 2$ $(15.50: 34.51)$.

Table 4.10

\begin{tabular}{|c|c|c|c|c|c|c|c|}
\hline \multicolumn{8}{|c|}{ NUMBER OF GOLGI TIENDON ORGANS per CONMECTTVE TISSUE STRUCTURE } \\
\hline \multirow[t]{2}{*}{ Structure (*) } & \multicolumn{3}{|c|}{ Number GTO's } & \multirow[t]{2}{*}{ Structure (*) } & \multicolumn{3}{|c|}{ Number GTO's } \\
\hline & Mean & SD & Rng. & & Mean & $\mathrm{SD}$ & Rangle \\
\hline ecu/edl.u layer & 5.38 & 1.06 & $4-7$ & $\div$ t.EOU & 6.75 & 1.04 & $5-8$ \\
\hline ecu/edl.1 layer & 0.38 & 0.51 & $0-1$ & $\div$ t.EDL & 3.75 & 0.70 & $3-5$ \\
\hline edl/edc EDL silde & 0.00 & - & - & $\div$ t.EDC & 9.38 & 1.77 & $8-12$ \\
\hline EDC side & 0.50 & 0.54 & $0-1$ & $\div$ t.ECR.br. & 13.00 & 1.41 & $10-14$ \\
\hline EDC side & 0.25 & 0.46 & $0-1$ & t. ECR. 10 & 5.00 & 1.69 & $3-8$ \\
\hline ECR side & 1.63 & 1.06 & $0-3$ & t. EDP & 14.38 & 1.06 & $13-16$ \\
\hline EDP side & 0.50 & 0.53 & $0-1$ & t. EI & 1.0 & 0.76 & $0-2$ \\
\hline S.S SUP side & 7.3 .8 & 1.92 & $5-11$ & $\div$ t.SUP $(\#)$ & 1.63 & 1.30 & $0-3$ \\
\hline ret. ol. TR.med side & 12.00 & 1.451 & -13 & TR deep tend. & 39.50 & 4.95 & $43-36$ \\
\hline \multirow{4}{*}{\multicolumn{5}{|c|}{$\begin{array}{l}\text { "TOTAL GTO's epicondylar connective tissue apparatus } \\
\text { "TOIAL GTO's olecranal connective tissue apparatus } \\
\text { "TOTAL GIO's distal connective tissue structures } \\
\text { "TOTAL distal GIO's connected with epicondylar unit }(\div)\end{array}$}} & 15.50 & 2.40 & $11-19$ \\
\hline & & & & & 51.50 & 3.50 & $54-49$ \\
\hline & & & & & 54.89 & 5.20 & $50-64$ \\
\hline & & & & & 34.51 & 4.21 & $29-40$ \\
\hline
\end{tabular}

* For abbreviation see general legend.

- Distal tendon connected via muscular tissue zone with the epicondylar unit

\# Including GTO's attached to the radial periosteum 


\subsection{Discussion}

The relatively large range in the figures regarding the occurrence of muscle spindles and GTO's is in line with data avallable in literature. It is known that differences exist between left and right limbs in the same animal (Hnik and Zelena, 1961; Chin et al., 1962; Arendt and Asmussen, 1974; Lennartson, 1980b)) and that interindividual variation often is large (for review, Barker, 1974). Moreover, the sample of animals from which the data on receptor content of muscles are derived, is seldom larger than 4 animals (a.o. Wohlfart and Henriksson, 1960; Swett and Eldred, 1960a; Eldred et al., 1962; Lennartson, 1980a, 1980b; Goldfinger and Fukami, 1982; Peck et al., 1984; Richmond and Stuart, 1985; ) with an exception for Richmond and Bakker (1982) with a population of 8 cats. The formulas of Bout (1987) and Banks and Stacey (1988) that relate spindle number to muscle weight, are based on data of 50 respectively 75 (mainly human and cat) muscles collected from various sources in literature. The forms vary from $(y=1.491+0.442 x)$ to $(y=1.58+$ $0.32 x$ ) - in which $y$ is $\log 10$ spindle number and $x$ is $\log 10$ muscle weight in grams -.

Taking into account the magnitude of the studied population $(n=8)$, the deviations of the mean numbers of spindles and GTO's are assumed to originate mainly from interindividual variation. In table 4.1 (muscle spindles) and table 4.6 (GTO's) the percentual standard deviation varies between 9.8 and $18.6 \%$ with EI and SUP muscles as exception. The relatively large range in the number of GTO's in the SUP muscle may be due to the difficulty we had in discriminating distal GTO's attached to the periosteum from the periosteal connective tissue (see also the variance for t.SUP in table 4.10). The relatively large standard deviation in the EI muscle relates to the range in number of GTO's ( 0 to 2 , see table 4.6 and 4.10).

Since Sherrington noted that muscles differ in their muscle spindle endowment, the receptor "wealth" has commonly been assessed by measures of spindle density (spindles per gram of adult muscle) per muscle. Tables of values have been developed which classify muscles by their spindle densities (a.o. Chin et al., 1962; Voss, 1971; Barker, 1974; Botterman et al., 1978; Peck et al., 1984, 1988). Interspecial comparison of those data is impeded by the fact that spindle density is also related to muscle size and indirectly to the size of the organism (Matthews, 1972; Bout, 1987; Banks and Stacey, 1988). In man the highest densities are found in the $\mathrm{m}$. longissimus capitis i.e. 63 spindles/g (Voss, 1958, 1971). In cat the values for limb muscles seldom exceed 40 - 50 spindles/g (Swett and Eldred, 1960a; Bridgman et al., 1962; Chin et al., 1962; Botterman et al., 1978; Richmond and Stuart, 1985; Scott and Young, 1987) with higher values in forelimb muscles than in hindlimb muscles. Higher densities (50 150 spindles/g) hold for small paw muscles (Goldfinger and Fukami, 1982), interosseal and tenuissimus muscles (Barker, 1974; Devanandan et al., 1983) and large neck muscles (Richmond and Abrahams, 1975, 1979; Bakker and Richmond, 1981.). The highest values (247 - 460 spindles/g) are given for small muscles of the vertebral column (Abrahams, 1982; Bakker and Richmond, 1982). Densities of several hundreds of spindles/g are noted for avian jaw and tongue muscles (Bout, 1987). Rosser and George (1985) mentions a spindle density in coracotriceps muscle in the pigeon of 14582 (SD 2302) spindles/g.

Data on the rat limb muscles are derived from values for soleus muscle i.e. 146 (Hnik and Zelena, 1961) and 310.5 (Arendt and Asmussen, 1974). In cat and man analogous data are 23.0 respectively 0.94 spindles/g (Banks and Stacey, 1988). Values for rat plantaris muscle and gastrocnemius muscle are 142.6 respectively 40.0 (Arendt and Asmussen, 1974). Analogous data for the latter muscle in cat and man are 6.5 respectively 0.4 (Arendt and Asmussen, 1974). Sum- 
marizing, it can be stated that the antebrachial muscles in the rat probably do not contain an extraordinary number of spindles if measured in spindles per gram of muscle, if animal and muscle size are taken into account.

The usual parameter of muscle spindle density however is based on the consideration of the muscle as morphological and functional entity and implicitly upon the assumption that the spindles are evenly distributed throughout the muscle. Though it is a common finding that muscle spindles are not evenly distributed in a muscle, only a few authors calculate spindle densities differentially per muscle spindle area (Bakker and Richmond, 1982; Richmond and Stuart, 1985), but do not mention how they define the outlines of the volumes. In table 4.5 we tried to quantify the distribution of spindles per muscle by measuring the spindle-rich volume and the number of spindles per such volume or zone. Two muscles with relativeIy high spindle densities (EI and SUP, table 4.1) differ completely in the concentration of the spindles within a given muscle area i.e in their relative muscle spindle volume (table 4.5). Similar considerations (similar density - different relative volume) are to be applied to e.g. ECU and EDL muscles. In EDP and EDC muscles - with comparable density per muscle - the relative volume rate differs less strikingly. In a muscle with a relatively low density rate (ECR) the muscle spindles are concentrated in a very restricted area $(3.0 \%)$. From these data it is concluded that the muscle spindle density can not fully reflect the extent to which the spindles are possibly concentrated within a given muscle area (zone). At least both mentioned parameters should be available if one is interested in the functioning of the different components of a muscle.

These considerations also hold, if muscle spindle abundances are related to muscle size (Bout, 1987; Banks and Stacey, 1988). As shown in table 4.3 and 4.4 the so-called muscle spindle abundance formula of Banks and Stacey (1988) influences the ranking of the antebrachial extensor muscles as to their densities. But also this ranking does not imply a possible concentration of the spindles and has also to be annotated by the volumetric data. For instance, Banks' formula seems to "correct" the similar spindle densities in EI and SUP muscle for muscle size. But still muscles with similar spindle abundances may differ greatly in relative muscle spindle volume e.g. the EDP and SUP muscles. The same holds for the ECU and ECR muscles. Therefore the conclusion that intermuscular comparison of spindle densities per gram muscle is at least overshadowed by intermuscular comparison of relative muscle spindle volumes, still holds for spindle abundances correlated to muscle size.

Intermuscular comparison of relative muscle spindle volumes as possible parameter for spindle distribution or concentration is challenged by the fact that - according to our criteria in defining the outlines of a muscle spindle volume (par. 2.2.2.3) - sometimes more than one concentration zone of spindles have to be defined. This does not permit to draw conclusions about spatial spindle distribution or spindle concentration in a given muscle by comparing muscles with a similar relative spindle volume rate (e.g. ECU and EDP).

Muscle spindle volumes or zones may exhibit different densities (or concentration rates) expressed by the number of spindles per gram of muscle spindle volume (table 4.5 , column F). The value of this parameter is influenced of course by the absolute number of muscle spindles and the absolute measures of the volume. We hypothesize that comparing spundle densities in those volumes with each other is more valuable, since not topographical outlines define the considered volume (as is the case in calculating densities per muscle), but the outlines of the zones defined in relation to the actual spatial occurrence of muscle spindles in a given muscular tissue area. The difference between ECU and SUP muscle - with nearly the same number of spindles, but different relative spindle volume and density of 
spindles within the volume - draws attention to a possible factor related to the spatial distribution of the receptors within the spindle zone. We hypothesize that the direction of the long axis of the muscle spindles - and implicitly extrafusal muscle fiber architecture - within a given muscle spindle volume or zone influences the size of the relative muscle spindle volume and therefore the density of spindles within such a volume. If muscle spindles are situated in line (or in series) with each other - for instance in a parallel-fibered muscle area - a larger number of spindles can be concentrated within a given volume than in the situation where spindles run mainly obliquely in parallel with each other - for instance in a pennate muscle portion -. Thus, relative muscle spindle volume (and number of spindles per volume) is an expression of muscle fiber architecture with related spatial configuration of the spindles.

Remarks about the quantitative parameters per muscle as stated above, question the relation of spindle distribution to muscle morphology and emphasize that threedimensional parameters are needed to interprete the functional significance of muscle spindle distribution. Moreover, it is indicated by the calculated data that the parameters of muscle spindle density are greatly influenced by the way the functional units of muscular tissue are defined. Spindle densities may vary greatly per muscle (vide supra) and per muscle area. For instance, the overall spindle density in the flexor carpi radialis muscle of the cat (50 spindles/g) varies from 300 for the spindle-rich region ( $20 \%$ of total muscle volume) to 2 for the "obvious spindle-poor region" ( $55 \%$ of total muscle volume) (Richmond and Stuart, 1985). If the density of the spindle volumes as we have defined them is reproduced in spindles per gram muscular tissue, densities as large as 3000 to 4000 spindles per muscle area are not exceptional (table 4.5, column F).

Peck et al. (1984) calculated that small muscles running in parallel with larger mus- cles exhibit a comparably high muscle spindle clensity and propose the concept that these small muscles serve as "kinesiological monitor muscles" as to the joint movement in which such a Parallel Muscle Combination (PMC) is involved. Their density values are based on random volumetric measurements of muscle spindle numbers in the midbelly region (Peck et al, 1984, 1988). Thus in principle they consider the spindles as evenly distributed over the muscle and take muscles as the functional entities to which muscle spindle concentration should be related. It is questionable whether this concept is correct or that it should be extended by considering spindlerich "kinesiological monitor zones" within muscles, in parallel with spindle-poor zones. Again the necessity for three-dimensional parameters for muscle spindle distribution is put forward.

Our results indicate that, if conclusions are drawn about sensory equipment of muscles from intermuscular comparison of densities of muscle spindles per gram muscle weight, this parameter at least should be related to the concentration rate of the spindles in those muscles (relative muscle spindle volume) and to the concentration rate of spindles within the spindle-rich zone (absolute muscle spindle volume and number of spindles per spindle volume). Eventually an analysis of the distribution of spindles in zones - in relation to muscular (and connective) tissue architecture - seems to be the most appropriate way to evaluate the possible functional significance of spindle distribution. In our opinion quantitative parameters can only be fully appreciated, if three-dimensional arrangement of muscle spindles is known. It might be expected that no longer muscles but muscle zones will prove to be the appropriate entities for functional considerations.

Comparing the number of GTO's found in the considered muscle with data from literature is only possible per muscle, since this is the way the number of GTO's is usually expressed in literature (a.o. Swett 
and Eldred, 1960a; Barker, 1974; Scott and Young, 1987). From the sparse data on the absolute and relative number of GTO's per muscle available in literature, a similar conclusion may be drawn as about the number of muscle spindles in the considered muscles (vide supra): taking into account the size of the muscles under consideration, the measured values are not extraordinary. An exception however exists in the ratio of (muscle spindles) : (GTO's). In general, in limb and tail muscles the spindles outnumber GTO's by a relatively modest ratio of 1.2 : 1 to $3: 1$ (Barker, 1974; Botterman et al., 1978; Goldfinger and Fukami, 1982; Devam nandan et al.., 1983; Richmond and Stuart, 1985). In jaw muscles (Lund et al., 1978; Lennartson, 1980b) and neck muscles (Richmond and Abrahams, 1979; Abrahams, 1982) the muscle spindles even outnumber the GTO's with a factor up to 20 . In this respect the considered EDP muscle exhibits the remarkable feature that in all cases more GTO's are present than muscle spindles, if considered per muscle (table 4.8). In the EI muscle the spindles outnumber GTO's about 5 times, which is relatively high for a limb muscle.

Measuring the number of GTO's per muscle however is considered by us as inappropriate for the evaluation of the functional significance of their occurrence in a region. Their function as strain receptors at muscle-connective tissue transitions at least poses the question to which (regular dense) collagenous connective tissue layer they are related. The extent to which GTO's are attached to a regular dense collagenous connective tissue structure forms an indication for the extent to which such a structure is equipped for perception of stresses induced to it. Quantitative parameters of their occurrence related to muscle morphology seems to have no sense since their functioning is rellated to muscle-connective tissue transition zones and not to muscular masses alone. For instance the parameter of number of GTO's per muscle fails to express the variable extent to which a given proportion of GTO's is related to the proximal respec- tively the distal connective tissue insertion (apparatus) of the considered muscle. The ECU and EDP muscle (with a comparable number of GTO's) differ greatly in this respect (table 4.8); the same conclusion tholds for EDC and SUP muscles.

Therefore relating numbers of GTO's to regular dense collagenous connective tissue structures provides a more direct indication of their spatial distribution (table 4.10). The restriction of the data in table 4.10 is, that actual spatial distribution over the total area of a given connective tissue structure cannot be concluded from those quantitative data. Even if a number per area of the connective tissue structure would be available, still three-dimensional parameters are needed for a full appreciation of their distribution. Nevertheless the occurrence of GTO's per connective tissue structure allows functional interpretation if related to the architecture of muscular and regular dense collagenous connective tissue as described in chapter 3 . The ecu/edl.u-layer, the supinator septum and the olecranal retinaculum as relatively well-developed structures of the proximal collagenous connective tissue apparatus, are relatively richly equipped with GTO's. The edc/ecr-layer seems the next best-equipped layer, while it is not as long and well-developed as the edl/edc-llayer. So, the absolute number of GTO's at the superficial intermuscular muscle compartment walls do not fully reflect the ulnoradial gradient that exists.

Similar considerations might be applied to the distal tendons of which the ECR and EDP (as strongly developed tendons) exhibit a rellatively large population of GTO's. However a strong and broad tendon like the distal ECU tendon is relatively poor in GTO's. This might coincide with the relatively large number of GTO's attached to the ecu/edl.u-layer. Also the finding that in the epicondylar muscle/connective tissue unit the ratio (proximal GTO's) : (distal GTO's) per subunit differs from the overall $1: 2$ ratio for the epicondylar unit (cf. table 4.8 and 4.10 ), emphasizes the importance of insight into the architectural features of the 
region as a whole.

It is concluded for GTO's as well as for muscle spindles, that three-dimensional study might fully elucidate and appreciate the occurrence and distribution of receptors as a substrate for the perception of stresses and movements in the region under consideration.

\subsection{Conclusions}

1. The EDC muscle has the greatest abundance of muscle spindles per muscle and EDL and EI muscles the smallest abundances.

2 The antebrachial extensor muscles differ greatly in the extent to which muscle spindles are concentrated in a given (spindle-rich) volume or zone. The ECR muscle exhibits the highest, the SUP muscle the lowest concentration rate.

3 The spindle density per spindle(-rich) volume (zone) varies, with the lowest value for the SUP muscle and highest values for EI and ECR.lo. muscle.

4 The chosen quantitative parameters do not provide optimal insight in the spatial distribution and orientation of the muscle spindles in relation to the architecture of muscular and regular dense collagenous connective tissue.

5 Of the regular dense collagenous connective tissue structures under consideration the olecranal retinaculum and the distal tendons of the ECR.br. and EDP muscles are relatively best equipped with GTO's. Of the epicondylar connective tissue apparatus the ecu/edl.ulayer and the supinator septum are best equipped with GTO's.

6 Quantification of GTO's per connective tissue structure is a more appropriate parameter than the number of GTO's per muscle, if receptor content is considered as a measure for the monitor function of GTO-containing muscle/connective tissue transitions. 


\section{CHAPTER 5}

\section{PROPRIOCEPTIVE SUBSTRATE RELATED TO THE PROXIMAL CONNECTIVE TISSUE APPARATUS}

\section{Contents}

5.1 Introduction

5.2 Materials

5.3 Results

5.3.1 Nervous tissue elements related to the superficial muscle compartment walls

5.3.2 Nervous tissue elements related to the supinator muscle compartment walls

5.4 Discussion

5.5 Conclusions

\section{Summary}

Specimens of the components of the proximal regular dense collagenous connective tissue apparatus - in situ as well as taken out - are studied for the presence of nerve elements (par. 5.2). Particularly in the outer and some intermuscular components of the apparatus, plexiformly arranged nerve fascicles are demonstrated (par. 5.3). The nerve fascicles terminate in lamellated corpuscles, Golgi tendon organs, free nerve endings and (sometimes) muscle spindles. Those structures are situated at the transition of the regular dense collagenous connective tissue structures with adjacent areolarly organized capsular connective tissue or with muscle fascicles organized in series with the concerned collagenous layers. The demonstrated free nerve endings show ultra-microscopical features characteristic for mechanosensitive nerve terminals. Similar nerve endings are present within the collagenous connective tissue apparatus at the transitional area with the periosteal connective tissue. The possible functional significance of the demonstrated nerve plexuses and substrate of proprioception is discussed in relation to the architecture of the muscular and conmective tissue and the occurrence of stress and strain in the region (par. 5.4). It is concluded that the proximal extensions of the muscle compartment walls are well-equipped with mechanosensitive substrate in relation to the assumed extent to which stresses are conveyed via those collagenous layers. There exists no morphological basis for the description of so-called joint receptors being deformed exclusively by strain that is induced passively in collagenous connective tissue structures e.g. by displacement of the articulating bones. (par. 5.5). 


\subsection{Introduction}

In his classical studies on the innervation of tendons and aponeuroses Stilwell (1957a-c) mentions nerve plexus formation in fascial sheaths as at regular finding. In several tendons and aponeuroses of various species he demonstrated plexiform and paratendinous fascicles, apparently connected with intramuscular and cutaneous nerves. These networks terminate in small "paciniform corpuscles" and in "freely ending axons" on the surface connective tissue of tendons, aponeuroses and muscles and in periosteal connective tissue, nearly always in the wicinity of other mechanoreceptors. Wilson and Lee (1983, 1986) and Lee and Wilson (1985a) show plexiformly arranged nervous tissue elements in peripatellar connective tissue in mice, rats, kittens and man. In line with several studies (Andres and v.Düring, 1972; v.Düring et al,, 1984; Andres et al., 1985), Andres states, that the configuration of a "Terminalretinaculum" - a network of tubes formed by perineural tissue enclosing nerve fascicles on the route to their areas of innervation - is a common feature in tendons and aponeuroses (Andres et al., 1985). Plexiform innervation of the anterior and posterior longitudinal ligament of the vertebral column is described in human fetuses (Baljet and Groen, 1986; Groen, 1986; Groen et al., 1988). Freeman and Wyke (1967a, $1967 \mathrm{~b})$ complete their classification of "cap-

\subsection{Materials}

The proximal connective tissue apparatus left in situ was investigated with the acetylcholinesterase in toto staining method (par 2.1.1). The same method was applied to components of the apparatus taken out separately, after detachment of the adjoining muscular tissue. Separate specimens were particularly made of the superficial (fascial) connective tissue layer and of the deep division of the epicondylar connective tissue apparatus. The following dissection procedure was carried out to gain specimens of the superficial (fascial) connective sule receptors" with so-called type IV-endings: fine peri-articular plexuses with free nerve endings (FNE's) as high threshold, non-adapting receptors involved in nocicepsis. They are either derived from poorly myelinated type III (A delta) nerve fibers or from unmyelinated type IV (C-) fibers. Nowadays the exclusively nociceptive function of such plexuses with free nerve endings is challenged by physiological findings (Kruger et al., 1981; Mense and Meyer, 1981, 1985; Mense et al., 1985; Spray, 1986). Morphological criteria for ultramicroscopical recognition of putative nociceptive and/or mechanosensitive free nerve endings have been postulated (Halata and Munger, 1983; Munger and Halata, 1983; v.Düring et al., 1984; Andres et al., 1985; Strasmann et al., 1987).

Based on the literature cited it is hypothesized that within the collagenous connective tissue layers constituted by the muscle compartment walls of the antebrachial extensor muscles, nervous tissue elements are also present serving either as putative substrate of mechanoreception or as pathway for such substrate. Therefore the components of the collagenous connective tissue apparatus in the rat foreleg were investigated for nervous tissue elements in situ, taken out separately and in tissue blocks with adjoining muscular tissue.

tissue layer. The subcutanous areolar tissue was dissected away as much as possible. Then the fascial layer was dissected from inserting muscle fascicles. An incision, starting at the tip of the olecranon, was made along the dorsolateral edge of the ulnar shaft up to the wrist region. The incision was continued transversely to the radial side of the wrist and from there the boundary of the extensor carpi radialis muscle was followed up to the anterior (or distal) edge of the lateral head of the triceps muscle. From that point the incision was completed by cross- 
ing transversely over the lateral head of the triceps muscle as far as the tip of the olecranon.

To prepare specimens of the deep division of the epicondylar connective tissue apparatus, the outer compartment wall of the supinator muscle (including the supinator septum) was freed from inserting muscle fascicles. After cutting the distal attachments of the two divisions of the lateral collateral connective tissue layer, the complete deep portion of the epicondylar connective tissue apparatus was taken out, together with the lateral humeral epicondyle cut from the humeral bone.

Separate components of the proximal connective tissue apparatus (e.g. intermuscular layers) were also dissected, serially sectioned at $15 \mu \mathrm{m}$ and impregnated with silver according to Holmes (par. 2.1.3). In four rats the superficial (fascial) connective tissue layer and supinator septum were also processed for Formaldehyde Induced Fluorescence technique (par. 2.1.2).

The investigation of the regular dense collagenous connective tissue layers in their relation with adjoining muscular tissue was carried out in three separate tissue blocks per region, taken from the two animals that were processed for silver staining according to Spaethe (par. 2.1.4). The triceps muscle was dissected from its olecranal insertion, separated from adjacent antebrachial muscles and taken out together with the overlaying lateral olecranal retinaculum. The four superficial antebrachial extensor muscles were also taken out en bloc by separa-

\subsection{Results}

With the acetylcholinesterase in toto staining the intermuscular and floor layers of the various muscle compartments appeared to be relatively "empty" of nervous tissue elements. An exception is formed by the $\mathrm{ecu} / \mathrm{edl} . \mathrm{u}-\mathrm{layer}$ and the floor layer of the ECU muscle, within or upon wich sometimes positive elements are present, running in longitudinal direction. The same holds for the outer supinator muscle com- ting them from their humeral and uhar attachments. Finally the supinator muscle was dissected from its radial insertion and taken out by sharply cutting the proximal continuation of the supinator septum from the humeral epicondyle and after detachment of the lateral collateral connective tissue layer from the necks of the ulnar and radial bone. Of each set of four specimens, the sectioning direction in two specimens was chosen parallel to the outer or superficial surface of the block, in the other two specimens perpendicular to this surface, once in the transverse plane, once in a sagittal plane of the foreleg.

Parts of the connective tissue apparatus were also processed for ultramicroscopical study, as separate specimens as well as with adjoining muscular tissue present. In four animals the complete superficial fascial connective tissue layer was dissected and cut in at least three parts. The supinator muscle with its septum and the lateral collateral connective tissue layer were dissected as one tissue block from their skeletal attachments. In two other animals the proximal extension of the superficial fascial connective tissue layer (olecranal retinaculum) was taken together with a small strip of underlying muscular tissue and divided in at least six rectangular portions. Semi-thin sections were cut parallel to the outer (or superficial) surface of the embedded structures or perpendicular to this, half of them in the transverse plane, half of them in a sagittal plane of the foreleg.

partment wall, though rarely demonstrated with this method. In silver impregnated (Holmes) specimens of the outer muscle compartment walls, the floor layers and the intermuscular layers, nerve fascicles sometimes appeared running between the collagenous connective tissue layer and muscle fascicles that were not completely removed from them (figure 5.1).

In the superficial (fascial) connective tissue 
layer - or outer wall of the superficial muscle compartments - plexiformly arranged nerve fascicles have been demonstrated with the acetylcholinesterase in toto staining (superficial plexus, figure 5.5). Plexiformly arranged nervous tissue elements are also present in the deep common layer of regular dense collagenous connective tissue (d.c.com.) and its proximal continuation towards the epicondyle (deep plexus, figure 5.18).
In the next two paragraphs these plexuses will be described extensiwely. This is combined with a description of the occurrence of nervous tissue elements in and related to the compartment walls of the superficial extensor muscles including triceps muscle (par. 5.3.1), respectively of nervous tissue elements in and related to the muscle compartment walls of the supinator muscle particularly the supinator septum - (par. 5.3.2).

\subsubsection{Nervous tissue elements related to the superficial muscle compartment walls.}

In general the nerve fasciclles of the superficial plexus are mainly situated within the stratum reticulare of the fascial layer (figure 5.1 and 5.3) i.e superficially to the collagenous stratum musculare. In the proximal extension of the superficial extensor muscles where also a superficial collagenous layer exists - they run in the reticular layer between the latter collagenous layer and the deep collagenous stratum musculare (figure 5.1). In silver stained and semi-thin sections, smaller nerve fascicles appear to pass through the stratum musculare (figure 5.4) and nerve fascicles are also observed between the latter layer and underlying muscular tissue (figure 5.1, 5.2 and 5.4). These fascicles appear to be branches either of larger bundles situated intramuscularly (particularly in the area of the triceps muscle) or of bundles of the superficial nerve plexus. In specimens stained in situ for acetylcholinesterase, nerve fascicles in the distal and radial extension of the antebrachial area turn out to be continuous with positive elements in the subcutaneous connective tissue. In silver stained (Spaethe) transverse sections of the tissue blocks containing the superficial antebrachial extensor muscles, nerve fascicles appear to be situated in the stratum reticulare at the "T-junctions" of the intermuscular layers with superficial (fascial) connective tissue layer. Nerve fibers are found that run longitudinally along the intermuscular collagenous

\section{Figure 5.1}

Nerve fascicle (m) containing several axons running between the stratum musculare ( $\mathrm{s}$ ) of the superficial antebrachial fascia and the muscle fascicles of the ECU muscle (1). Another nerve fascicle situated in the reticular connective tissue layer ( $\mathrm{s} . \mathrm{r}$ ) is cut transversely (arrow). Silver staining according to Holmes.

\section{Pigure 5.2}

Nerve fascicle containing several axons (n) situated between the regular dense collagenous connective tissue of the ollecranal retinaculum ( $\mathrm{d} . \mathrm{a})$ and the muscle fascicles of medial head of triceps muscle (8.3). A GTO is also present in the transition between muscle and retinaculum (arrow). Silwer staining according to Spaethe.

\section{Figure 5.3}

Nerve fascicle $(\mathrm{n})$ in the reticular connective vissue layer of the superficial antebrachial fascia. Some fat cells (arrows) and blood wessels ( $\star$ ) are also present. Staining according to Laczko and Levai.

\section{Figure 5.4}

Nerve fascicle (n) piercing through the regular dense collagenous connective tissue of the olecranal retinaculum (d.a) and a nerve fascicle (nm) situated between the retinaculum and muscular tissue of TR.med. muscle (8.3). Staining according to Laczko and Levai. 

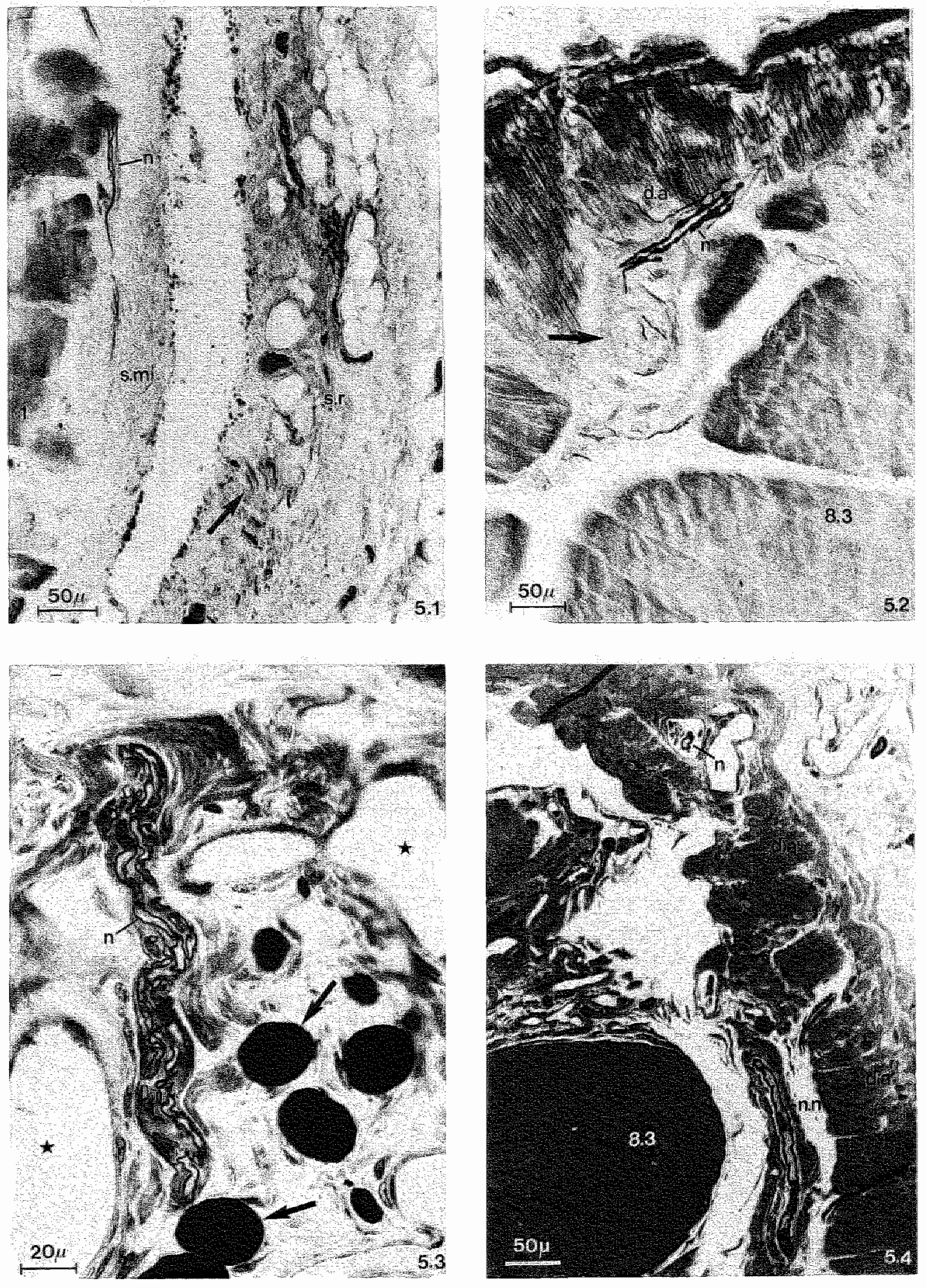

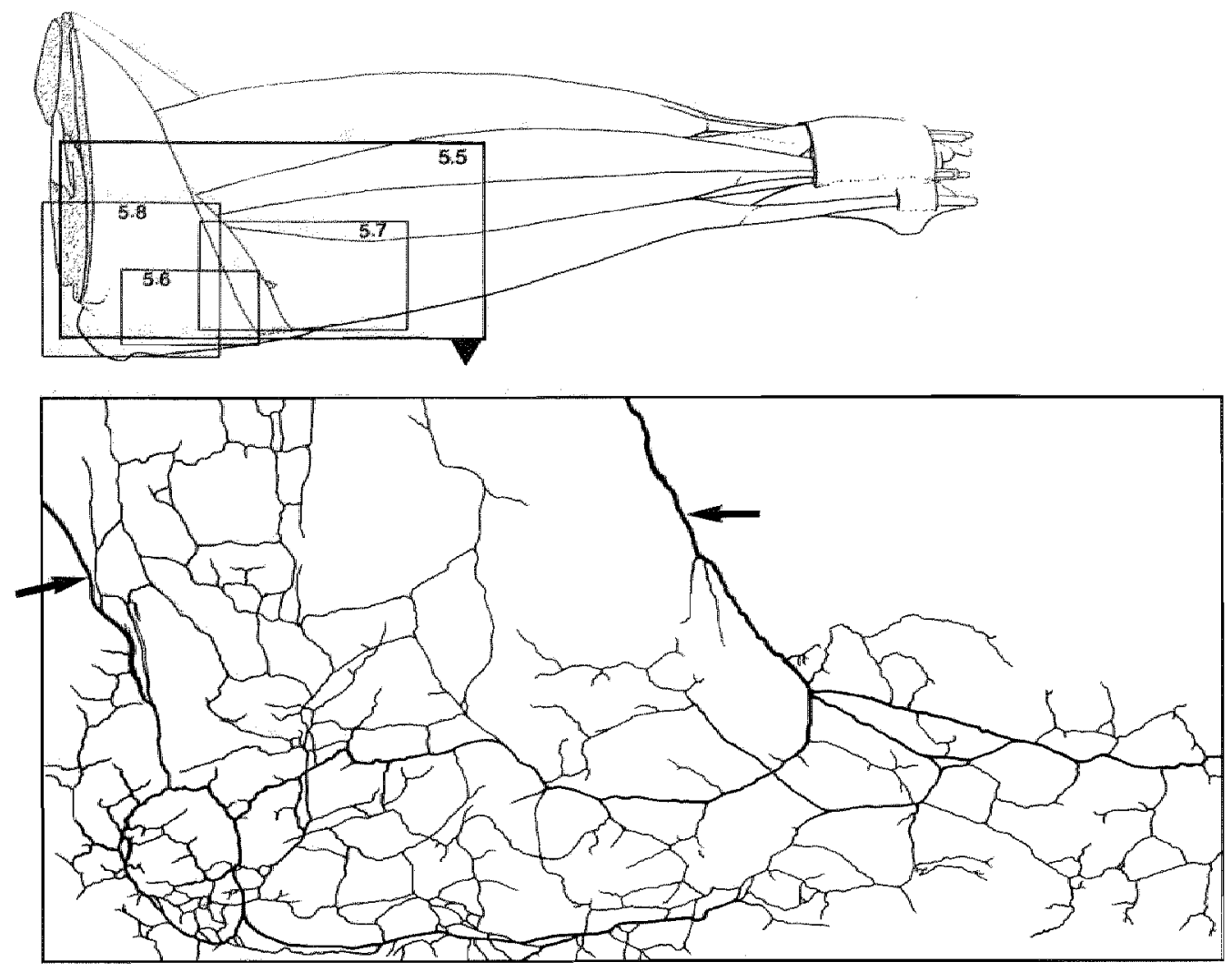

Figure 5.5

Schematic drawing of the superficial nerve plexus. Line drawing of three-dimensional graphic reconstruction based on specimen Z2. Nerve plexuses of two specimens of the superficial fascia stained for AChEase in toto have been projected on this drawing by means of camera lucida technique. The rectangles correspond to the outlines of figure 5.5 to 5.8. The branches of the radial nerve that supply the superficial plexus are indicated with arrows.

\section{Figure 5.6}

Superficial nerve plexus in a specimen of the olecranal retinaculum taken out separately. Right foreleg. P* proximall dircction. U: ulnar side.

Part of the fascicles of TR.ned. muscle (8.3) are left in situ attached to the retinaculum. Bonndary between retiinaculum and ulnar periosteum is indicated with arrows. Acetylcholinesterase in tolo staining.

Figure 5.7

Detail of superficial nerve plexus at the outer ECU muscle compartment wall in a specinen of the antebrachial superficial fascia taken out separately. Right foreleg. P: proximal direction. U: ulnar side.

Muscle fascicles that are left in situ still attached to the specimen belong to the ECU (1), EDL (2), TR.med. (8.3) and flexor carpi ulnaris muscle $(++)$. Boundary between ulnar periosteum and antebrachial fascial connective tissue is indicated with arrows. Acetylcholinesterase in toto staining.

Figure 5.8

Superficial nerve plexus in a specimen of the olecranal retinaculum taken out separately. $\mathbb{R}$ ight foreleg. P: proximal direction, U: ulnar side.

Some muscle fascicles of TR. lo. (8.1), TR.lat. (8.2) and TR.med. (8.3) are left in situ still attached to the retinacular connective tissue. Branches of radial nerve supplying the superficial plexus are indicated with arrows. Acetylcholinester ase in toto staining.

Figure 5.9

Detail of superficial nerve plexus. Several bifurcations are indicated with arrows.

Acetylcholinesterase ist toto staining. 

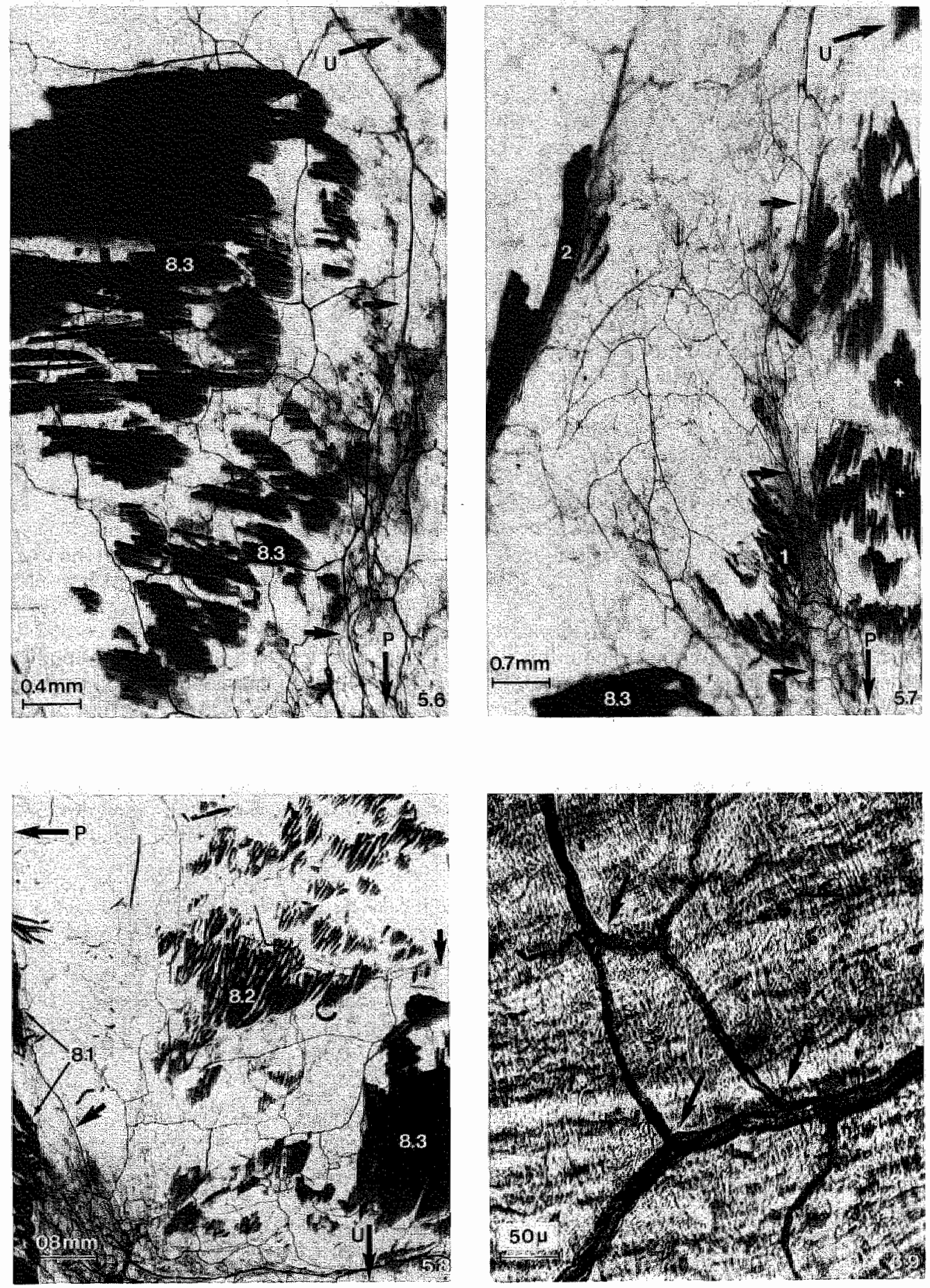
connective tissue layers in the muscle-connective tissue transitional area. At the ecu/edl.u-layer also nerve fascicles are present on the outer surface of the layer (directed towards the EDL muscle). Such nerve fibers apparently are continuous with nerve fascicles in the outer muscle compartment walls or with nerve fascicles near the site where the superficial muscle compartments proximally are continuous with the humeral periosteum.

The polygonal pattern of the plexus (figure 5.5 ) is formed by crossing of nerve fascicles but also by splitting and fusing of the bundles. Axons can be followed over a relatively long distance in some fascicles, leaving them and fusing with another bundle (figure 5.9). In bifurcations that have been studied in serial semi-thin $(1 \mu \mathrm{m})$ sections, no branching of the axons themselves has been observed.

Towards the ulna the plexus pattern exhibits more and smaller polygons than at the radial side. The transition to the ulnar periosteal comnective tissue is often demarcated by nerve fascicles running longitudinally along the ulna (figure 5.7). The number of polygons is larger in the proximal than in the distal region, while their dimensions decrease in the proximal region (figure 5.7). In and near the periosteal layer of the dorsolateral aspect of the olecranon, this culminates in a dense, fine and irregular network of nerve fascicles (figure 5.6. and 5.8). In the lateral olecranal retinaculum the polygonal pattern appears nearly as rectangles with nerve fascicles parallel and perpendicular to the main direction of the collagenous fibers in this area i.e. parallel to the main direction of the muscle fascicles of the lateral head of the triceps muscle (figure 5.6).

Large nerve fascicles run mainly parallel to the vessels. Characteristically they often cross the vessels several times in their course. At two sites larger nerve bundles connecting the plexus with branches of peripheral nerves can be observed. One to three of such bundles are twigs of the subcutaneous superficial branch of the radial nerve as it pierces between the anterior (or distal) border of the triceps muscle and the adjacent biceps muscle and runs along the extensor carpi radialis muscle (figure 5.5 and 5.8). Two or three other bundles "supplying" the plexus appear between the long and lateral head of the triceps muscle. Camera lucida drawings of serial silver stained (Spaethe) sections of the complete triceps muscle reveal that the latter bundles are twigs of the ("muscular") deep branches of the radial nerve as they run from proximo-medial to disto-lateral between the long and medial head of the triceps muscle (figure 5.8). The relatively dense plexus in the (periosteal) area of the olecranon and the dorsolateral aspect of the ulnar shaft is

\section{Figure 5.10}

Detail of superficial nerve plexus treated with FIF technique. A blood vessel (v) with perivascular network of noradrenergic nerve fibers is present. A non-fluorescent merve fascicle-bellonging to the AChEase positive plexus . (n) runs parallel to the blood vessel. Fluorescencent nerve fibers towards the perivascular plexus are indicated with arrows.

\section{Figure 5.11}

Same specimen as in figure 5.10, Bifurcation of a non-fluorescent nerve fascicle (n) containing F.I.F.-positive elements (arrow). Fluorescent mast cells ( $\mathrm{m}$ ) are present as well as a venous blood vessel ( $\mathrm{v}$ ).

\section{Figure 5.12}

Large nerve fascicle (n) with several myelinated axons and one Remak bundle in the reticular connective tissue layer (s.r) of the superficial antebrachial fascia. At the deep side the regular diense collagenous connective tissue of the stratum musculare of the fascia $(s, m)$ is present. Staining according to Laczko and Lewai.

\section{Figure 5:13}

Characteristic nerve fascicle of the superficial nerve plexus. A delta-axons with myelin sheaths of various thickness $(\star)$ are present as well as several unmyelinated axons enveloped by a single Schwann cell $(-)$.

Electron micrograph. In collaboration with Z. Halata and Th. Strasmann, University of Hamburg, F.R.G. 

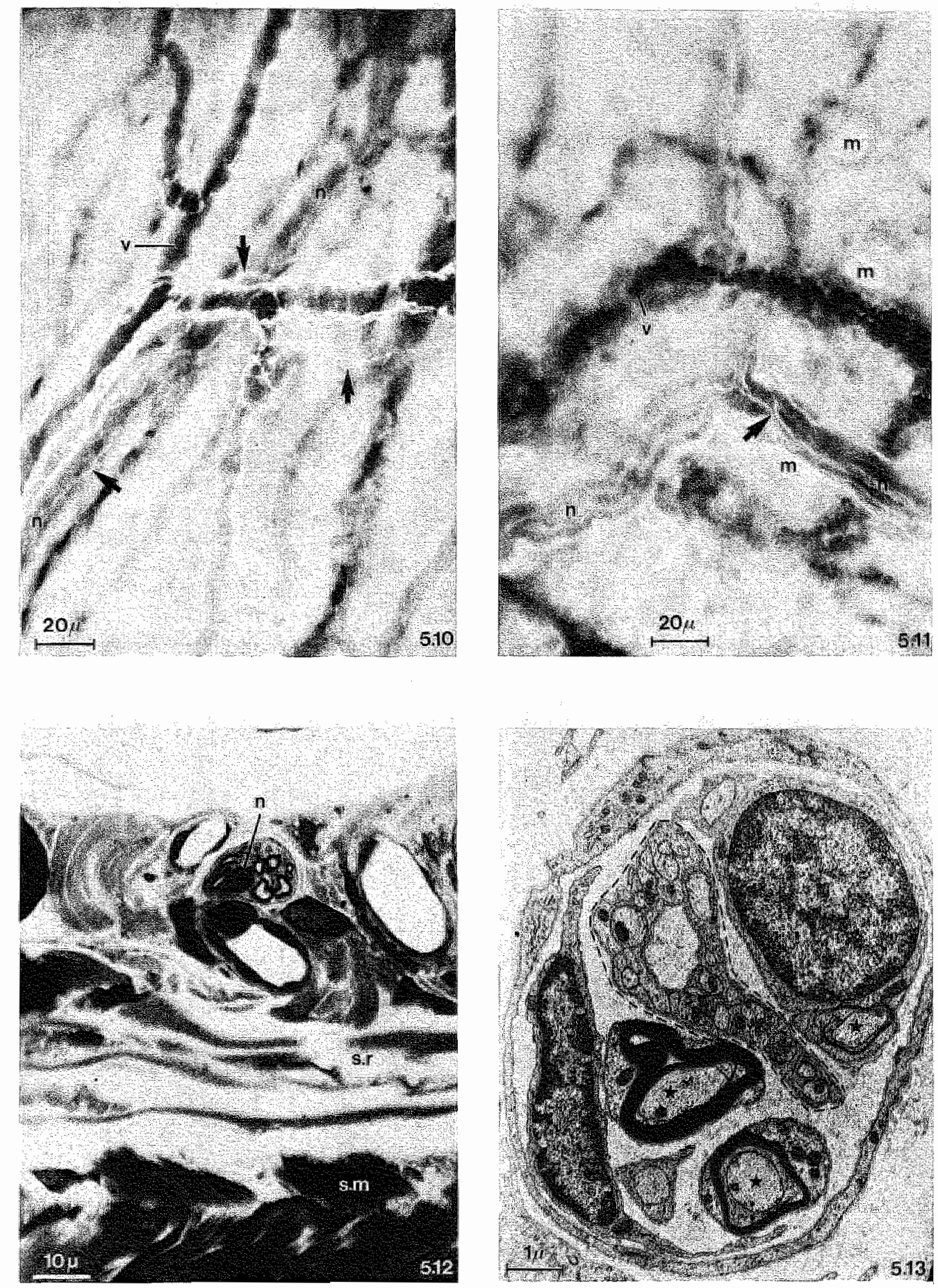

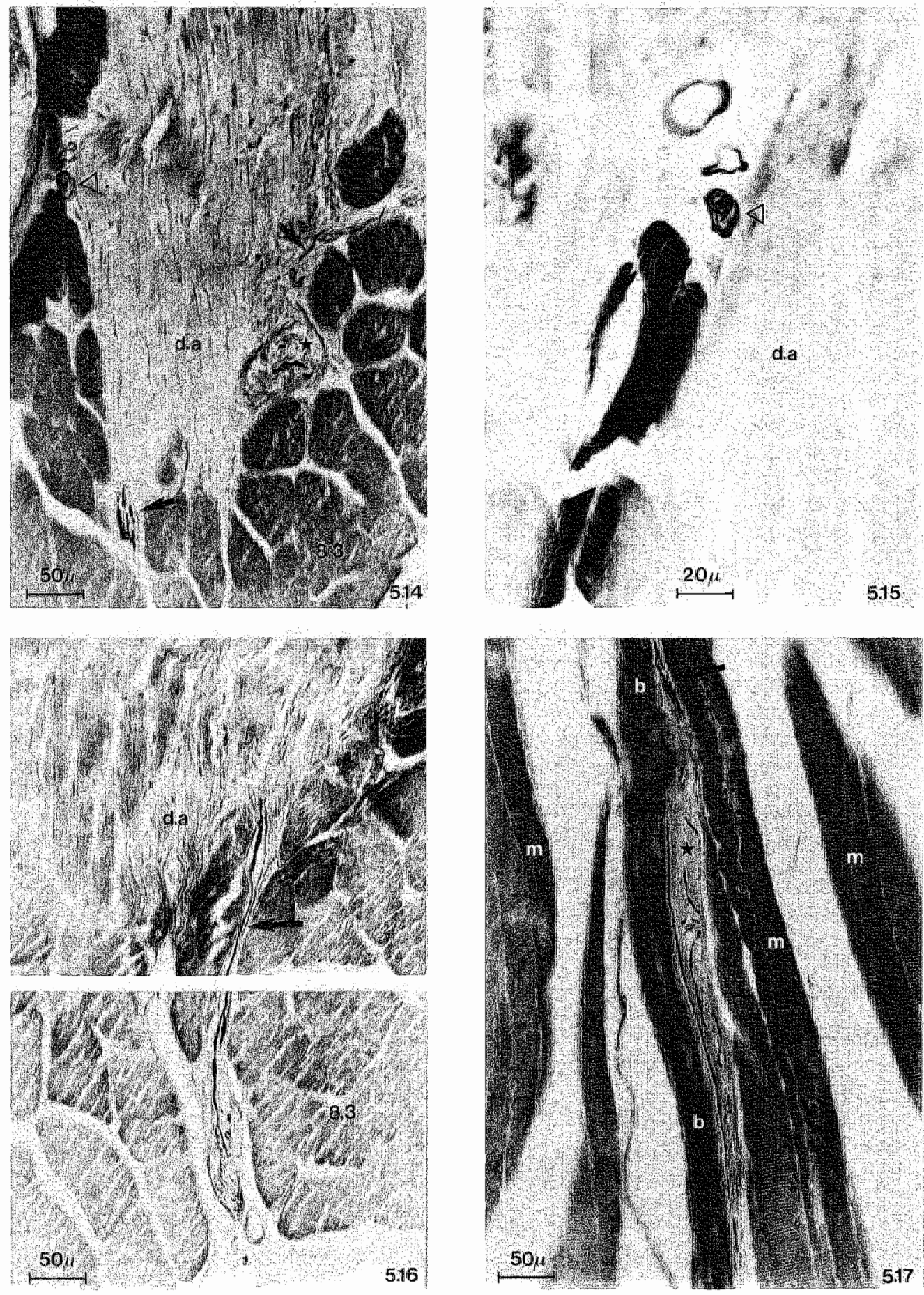
continuous with a similar plexus of nerve fascicles in the fascial connective tissue layer constituted by the outer muscle compartments walls of the superficial flexor muscles (figure 5.7).

In figure 5.10 and 5.11 some characteristic results of the F.I.F. procedure applied to separate specimens of the fascial layer are shown. Allong the arterial vessels a fine perivascular network of fluorescent noradrenergic elements is present. The acetylcholinesterase positive fascicles (double staining) are present as dark non-fluorescent bundles of twisted elements running in parallel with those wessels, crossing them many times. Sometimes a fine F.I.F. positive element can be observed between the large non-adremergic elements of those bundles or running from those main nerve fascicles to the fine perivascular plexus of noradrenergic elements (figure 5.11).

In electron microscopical observation the plexus consists of larger nerve fascicles with perine $\quad$ (diameter up to $20 \mu \mathrm{m}$ ) and smaller bu adles without perineural sheath (diameter up to $4 \mu \mathrm{m}$ ). Three types of axons are demonstrable in the larger fascicles (figure 5.12 and 5.13):

- one to four isolated myelinated axons up to 4-5 $\mu \mathrm{m}$ in diameter, apparently group III (A delta) nerve fibers.

- bundles of up to 20 small. unmyelinated axons with a diameter of less than $0.8 \mu \mathrm{m}$ enveloped by one single Schwann cell (so-called Remak bundles)

- one or two isolated unmyelinated axons with a diameter up to 0.8 to $1 \mu \mathrm{m}$, presumably group IV (or C-)fibers.

With the methods applied neither encapsulated nor non-encapsulated nerve endings are detectable in specimens of the compartment walls of the superficial muscles, taken out and studied separately. In such specimens, when processed for electron microscopy, no free nerve endings can be described that meet the criteria for such endings as postulated by Halata and Munger (1983) and Von Düring et al. (1984) and Andres et al. (1985).

In material in which the muscular tissue inseries with the regular dense collagenous connective tissue layers still is present, various kinds of morphological substrate of proprioception have been identified.

In the silver stained (Spaethe) sections of connective tissue with adjoining muscle fascicles, many free (unencapsulated) nerve endings (FNE's) are present. They particularly occur between muscle fascicles and "ridges" of dense collagenous fibers protruding into the muscular mass with several muscular fibers converging to them. They are numerous in the transitional zone between the medial head of the triceps muscle and the in-series olecranal retinaculum. In the outer compartment walls of the superficial antebrachial extensor muscles, such configurations are mainly observable in the

\section{Figure 5.14}

Transition between the muscular tissue of TR.med. muscle (8.3) and the regulat dense collagenous connective tissue of the olecranal retinaculum (d.a). A GTO ( $\star$ ), a nerve fascicle (arrow) and a lamellated corpuscle $(\Delta)$ are present. Silwer staining according to Spacthe.

\section{Figure 5.15}

Detail of the same lamellated corpuscle $(\triangle)$ as of figure 5.14 in another section.

Silver staining according to Spaethe.

\section{Figure 5.16}

GTO sitwated between the muscular tissue of TR.med. muscle (8.3) and the regular dense collagenous connective tissue of the olecranal retinaculum (d.a) with afferent nerwe (arrow). Photomontage based on two successive sections combined. Silwer staining according to Spaethe.

\section{Figure 5.17}

GTO ( $\star$ ) attached to the collagenous connective tissue of the edl/edc-layer (b). The afferent nerwe fiber (arrow) enters the receptor at its proximal pole. m: muscie fascicles. Silwer stain according to Spaethe. 
area where those walls converge to the common iuxta-epicondylar layer of regular dense collagenous connective tissue. This parallels observations in acetylcholinesterase incubated specimens - with the connective tissue left in situ - where positive elements are present in the transitional area near the epicondylar periosteum. The ultramicroscopical nature of such endings however has not been studied.

In the transition between triceps muscle fascicles and olecranal retinaculum Golgi tendon organs (GTO's) and sometimes small lamellated (or Pacini) corpuscles occur particularly near the above mentioned ridges of collagenous tissue (figure 5.2, 5.14 to 5.16). Those encapsulated mechanoreceptors are concentrated in the area of the olecranal retinaculum where the muscle fascicles of the medial triceps head insert. In total about twelve GTO's (cf. chapter 4) and about six lamellated corpuscles have been identified $(n=2)$. The average diameter of the GTO's measures 50 to $80 \mu \mathrm{m}$. The lamellated corpuscles are about 10 to $20 \mu \mathrm{m}$ in diameter and have a 2 to 4 layered capsule (figure 5.15).

It has been observed in silver stained (Spaethe) serial sections that the afferent nerve fiber of an encapsulated or non-encapsulated nerve ending runs to the superficial connective tissue layer and there joins a larger nerve fascicle (figure 5.2 and 5.16). Camera lucida drawings of those serial sections reveal that the majority of those fas- cicles unite with nerve bundles that run more deeply along the tendon between the medial and long triceps head and originate from deep intramuscular branches of the radial nerve. Afferent nerve fibers from GTO's attached to this deep intramuscular triceps tendon also join those nerve branches. A minority of afferent nerve fibers can be traced up to the plane where the tissue block was cut from the olecranon and the adjacent antebrachial muscles including their fascial compartment wall. These features parallel the pattern of nerve fascicles as revealed by the acetylcholinesterase in toto staining.

No encapsulated nerve endings can be demonstrated related to the outer wall of the compartments occupied by the superficial antebrachial extensor muscles. In longitudinal, silver stained (Spaethe) sections of antebrachial tissue blocks sometimes a GTO is present attached to an intermuscular muscle compartment wall (figure 5.17). The afferent nerve fiber of such a GTO reaches the receptor from the septal side and can sometimes be observed to run along the intermuscular connective tissue layer in proximal direction. The presence of GTO's at the intermuscular septa of regular dense collagenous connective tissue and the absence of such substrate at the antebrachial part of the superficial fascia has also been obserwed in serial sections of complete forelegs embedded in toto in polyester resin. 


\subsubsection{Nervous tissue elements related to the supinator muscle compartment walls}

Contrary to the superficial plexus, the deep nerve plexus is situated in a layer of areolar "sliding" connective tissue upon the deep common layer of regullar dense collagenous connective tissue (d.c.com.). The plexus is located at the site where the supinator bone is incorporated in this layer (figure 5.18). It is constituted by a narrow zone of plexiformly arranged nervous tissue elements extending from the ulnar edge of the septum in radial direction up to the lateral humeral epicondyle (figure 5.18). At the ulnar edge of the septum some fascicles appear to be connected with twigs from the deep branch of the radial nerve as it pierces through the triangular opening between the septal collagenous connective tissue and the lateral collateral connective tissue layer (cf. figure 3.13). Fine twigs from the same nerve form a dendritic pattern on the outer side of the latter structure, reaching up to the capsular connective tissue of the humero-ulnar joint. Nerve fascicles extend from the plexus in all directions: up to the humeral periosteal connective tissue and in distal direction to the supinator septum, particularly its intramuscular extension. The nerve fascicles running in distal direction are situated upon or under the collagenous layer of the septum, up to halfway the extension of the supinator muscle. This is confirmed by silver stained (Spaethe) sections (figure 5.28) and semi-thin sections where such fascicles appear piercing through the collagenous layer (figure 5.19). Sometimes a nerve fascicle running between the septal collagenous connective tissue and underlying muscular tissue appears to be connected with intramuscular nerve fascicles originating from branches of the deep radial nerve. These features resemble the topographical relation of the nerve fascicles of the superficial plexus with the antebrachial fascial connective tissue (including olecranal retinaculum). Specimens of the network processed for F.I.F. showed similar characteristic features as the superficial plexus (vide supra).
In electron-microscopical observation, the types of axons present within the fascicles resemble those of the smaller nerve fascicles of the superficial plexus. There are Remak bundles with up to 20 unmyelinated axons $(0.8 \mathrm{\mu m}$ in diameter) enveloped by one single Schwann cell, small single unmyelinated axons with a diameter of 0.5 to $1 \mu \mathrm{m}$ (presumably group IV or C-type) and myelinated axons from 2 to $4 \mu \mathrm{m}$ in diameter (group III or A delta-type).

In specimens of the deep division of the epicondylar connective tissue apparatus taken out separately, free unencapsulated nerve endings (FNE's) are present. They exist at the level of the continuation of the deep common connective tissue layer towards the epicondylar periosteum as well as in the intermediate zone of areolar collagenous connective tissue between the distal edge of the supinator bone and the proximal boundary of the supinator muscle mass. Some of such endings can also be observed in the pericapsular connective tissue continuous with this intermediate zone. The nature of several FNE's has been established by means of the criteria of Halata and Munger (1983) and of Von Düring et al. (1984) and Andres et al. (1985).

Some nerve endings lack a perineural sheath and are only partly enveloped by a Schwann cell of which sometimes 2 to 3 lamellar processes are visible (figure 5.20 and 5.21). They are mostly found in dense collagenous connective tissue, arranged into groups of several endings (figure 5.21). Sometimes they are topographically closely related to blood vessels, small lymphatic vessels or to a mast cell. The neurilemma is only separated from the collagen fibrils in the direct vicinity by a basal lamina. In those endings electron-clear vesicles (about 60 $\mathrm{nm}$ ), more mitochondria than characteristic for non-terminal axons, only a few (or none) microtubules and dense core vesicles are present. Other nerve endings exhibit a peri- 

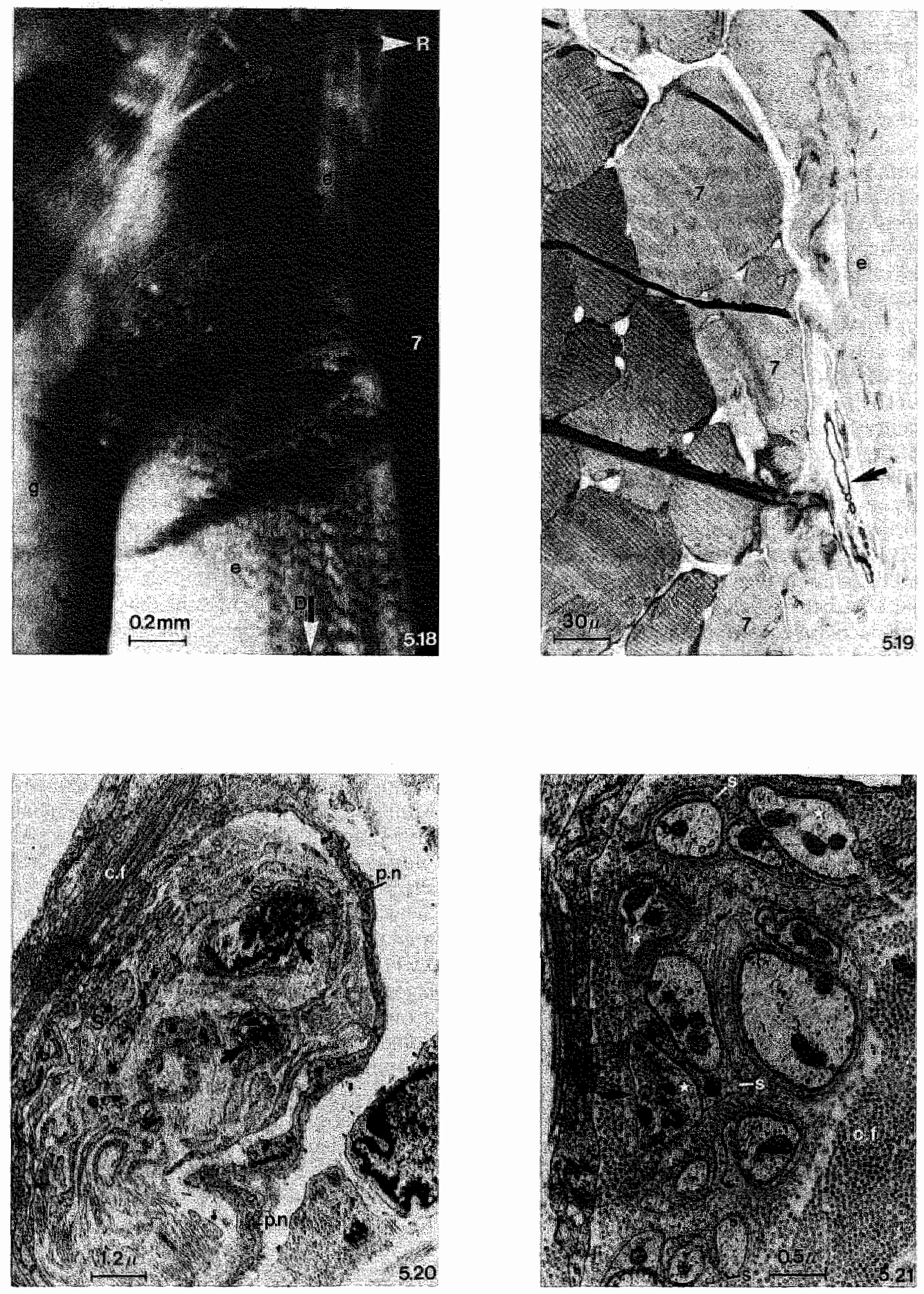
neural sheath and a simple Schwann cell lamination and resemble primitive lame]lated corpuscles (figure 5.19). This type is rare. They display several central axons covered by 1 to 3 lamellar processes of terminal Schwann cells and are enveloped by a two-layered perineural capsule. Here also the axon membrane is only separated from the collagen fibrils by a basal lamina (figure 5.20 ).

About 15 small lamellated corpuscles (counted in two serially sectioned specimens) are present between the plexiformly arranged collagenous fibers of the intermediate connective tissue zone between the supinator bone and the proximal boundary of the supinator muscular mass (figure 5.22 and 5.24). They are mainly situated between the supinator bone and the ulnar (or flexor) portion of the supinator muscle (figure 5.25). Only a few of them (2 to 4) are located within the areolar (reticular) connective tissue on the inner side of the lateral collateral connective tissue layer (figure 5.23).

The corpuscles measure about $10-20 \mu \mathrm{m}$ in diameter and rarely exceed a lenght of 60 $\mu \mathrm{m}$. They are composed of an inner core with a 1 to 4 layered perineural capsule. The afferent myelinated axon of 3 to $4 \mu \mathrm{m}$ in diameter enters the corpuscle on one pole of the ovoid organ.
A few lamellated corpuscles are interposed between the collagenous fibers of the supinator septum and muscle fibers in-series with the septum (figure 5.26). This type is located somewhat more distally in the supinator muscle in the angle between the inserting muscle fibers and the collagenous bundles of the septal connective tissue. In semi-thin sections a putatively afferent myelinated axon of 3 to $4 \mu \mathrm{m}$ in diameter is sometimes present just beneath the septal collagenous tissue or piercing through the septal connective tissue layer (figure 5.19). A smaller population of lamellated corpuscles ( 3 to 7 per area) is situated in the more loosely organized connective tissue at the ulnar edge of the septum i.e. near the triangular opening between the septum and the collateral ligaments. They are also situated in loose areolar connective tissue between the neck of the radial bone and adjacent supinator muscular tissue (figure 5.27). These corpuscles are somewhat larger than those of the former cluster and measure about $100 \mu \mathrm{m}$ in length and up to $40 \mu \mathrm{m}$ in diameter.

In all specimens evaluated, three small lamellated corpuscles were found situated on the outer surface of the collateral lateral connective tissue layer, directly connected with the collagenous fibers of this structure.

\section{Figure 5.18}

Lateral aspect of the supinator septum (e) with the deep nerve plexus in situ. The outline of the supinator bone is indicated with a broken line. Right foreleg. D: distal direction. R: radial side. Acetylcholinesterase in toto st ain ing.

\section{Figure 5.19}

Supinator muscle (7) with adjoining supinator septum (c). A nerve fascicle (arrow) with two myelinated axons (cut tangentially) runs obliquely through the regular dense collagenous connective tissue. Staining according to Laczko and Levai.

\section{Figure 5.20}

Several axons (arrows) enveloped by one to three lamellar processes of a (erminal Schwann cell (s) and with at two-layered perineural sheath ( $\mathrm{pn}$ ) in the direct vicinity of collagen fibrills.

Electron micrograph. In collaboration with Z. Halata and "Th. Strasmann, Uniwersity of Hamburg, F, R, G.

\section{Figure 5.21}

Cluster of about 15 nerve endings incompletely enveloped by a Schwann cell (s) in dense collagenous connective tissue. Arrows indicate some areas where only basal lamina separates the axolemma ( $)$ from adjoining bundles of collagen fibrils (cf)

Electron micrograph. In collaboration with Z. Halata and Th. Strasmann, University of Hamburg, F.R.G. 


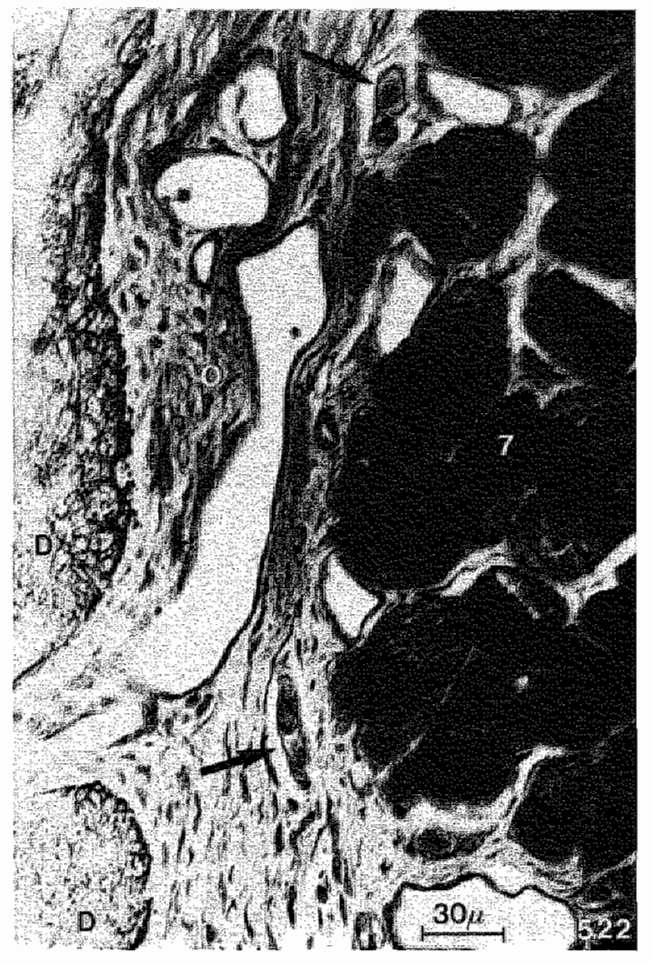

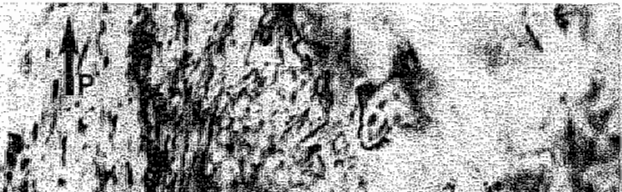

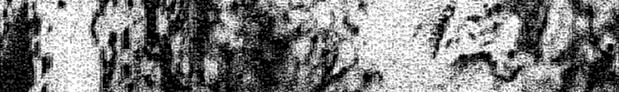

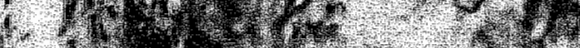

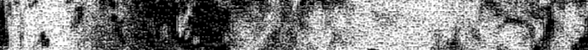

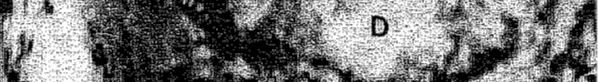
p y

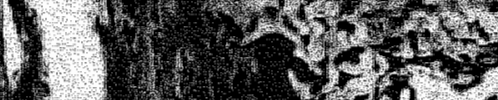
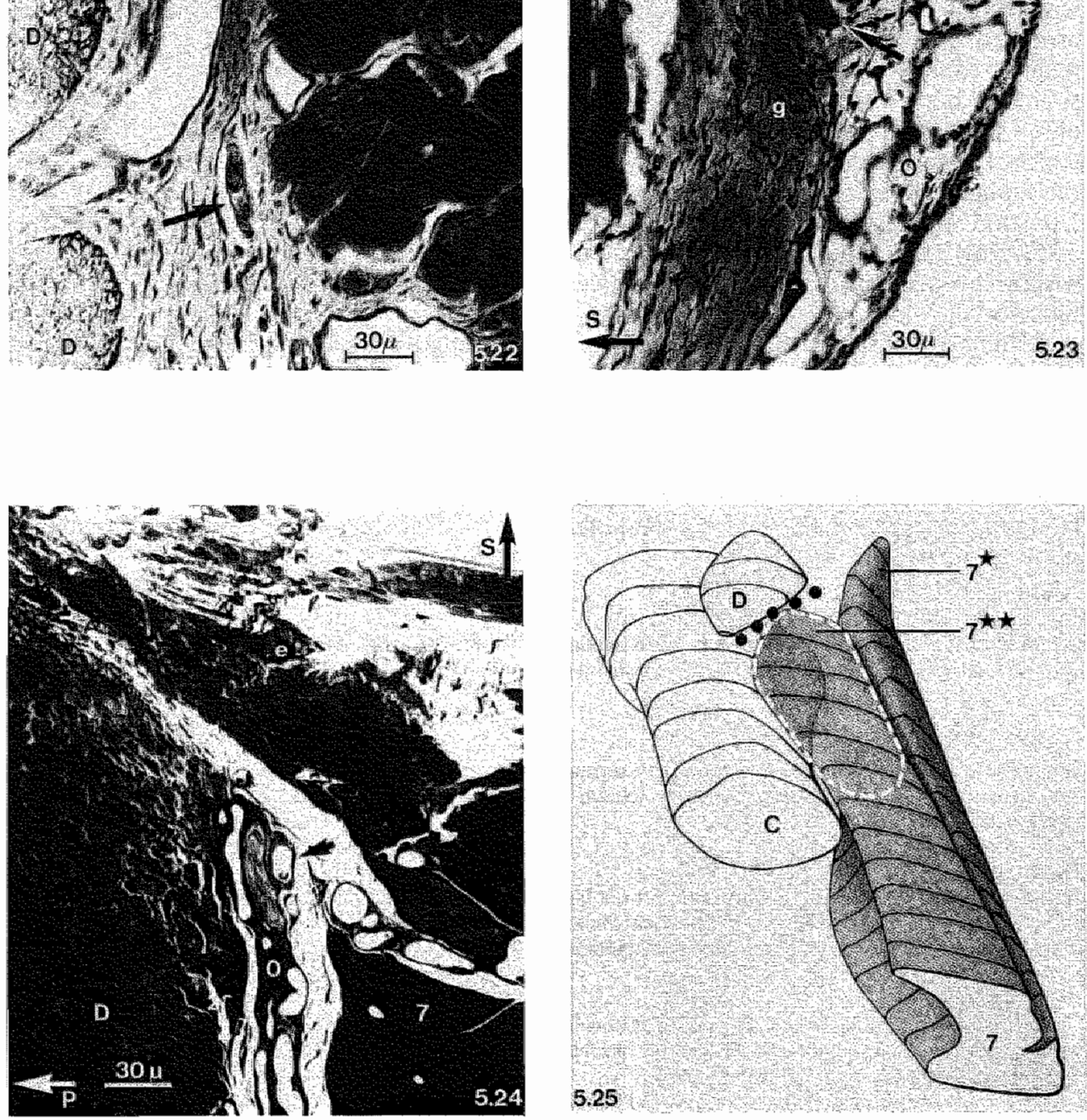
In serially sectioned silver stained (Spaethe) specimens of the supinator muscle it has been observed that nerwe fibers situated upon or underneath the distal extension of the supinator septum where muscle fascicles insert to it, originate from encapsulated nerve endings (figure 5.28). The afferent nerve fiber ( 4 to $6 \mu \mathrm{m}$ in diameter) enters the receptor at the pole that is attached to the septum and displays a spray-like pattern (4 to 5 twigs) between the collagenous fibers of the inner core of the receptor (figure 5.28 and 5.29). The endings are spindle-shaped and run obliquely to the plane of the septum parallelly to adjacent muscle fascicles (figure 5.29). They are mainly attached to the regular dense colllagenous connective tissue of the ulnar side of the supinator septum and measure not more than $450 \mu \mathrm{m}$ in length and $50-60 \mu \mathrm{m}$ in diameter. According to the criteria mentioned in chapter 1 we describe those receptors as Golgi tendon organs (see discussion).

\section{Figure 5.22}

Lamellated corpuscles (arrow) between muscle fibers of the supinator muscle (7) and the distal edge of the supi* nator bone (D) situated in the reticular collagenous connective tissue of the intermediate zone (o).

Silver staining accordling to Spacthe.

\section{Figure 5.23}

Lamellated corpuscle (arrow) in the the angle between the radial division of the lateral collateral connective tissuc layer (g), the supinator bone (D) and the reticular colllagenous connective tissue of the joint capsule and intermediate zome (o). P* proximal direction. S: superficial side. Silver staining according to Spaethe.

\section{Figure 5.24}

Lamellated corpuscle in the intermediate zone (o) between SUP muscle (7), the supinator bone (D) and supinator septum (e), Longitudinal section. P: proximal direction. S: superficial side.

Staining according to Lacrko and Levai.

\section{Figure 5.25}

Three-dimensional graphic reconstruction of the muscular tissue of the SUP' muscle (7).

$7^{*} \quad$ ulnar muscle portion.

7** radial muscle portion.

- : lamellated corpuscles in zo. int.

- : arca where lamellated corpuscles occur that are interposed between muscular tissue and the regular dense collagenous connective tissue of the supinator septum. 

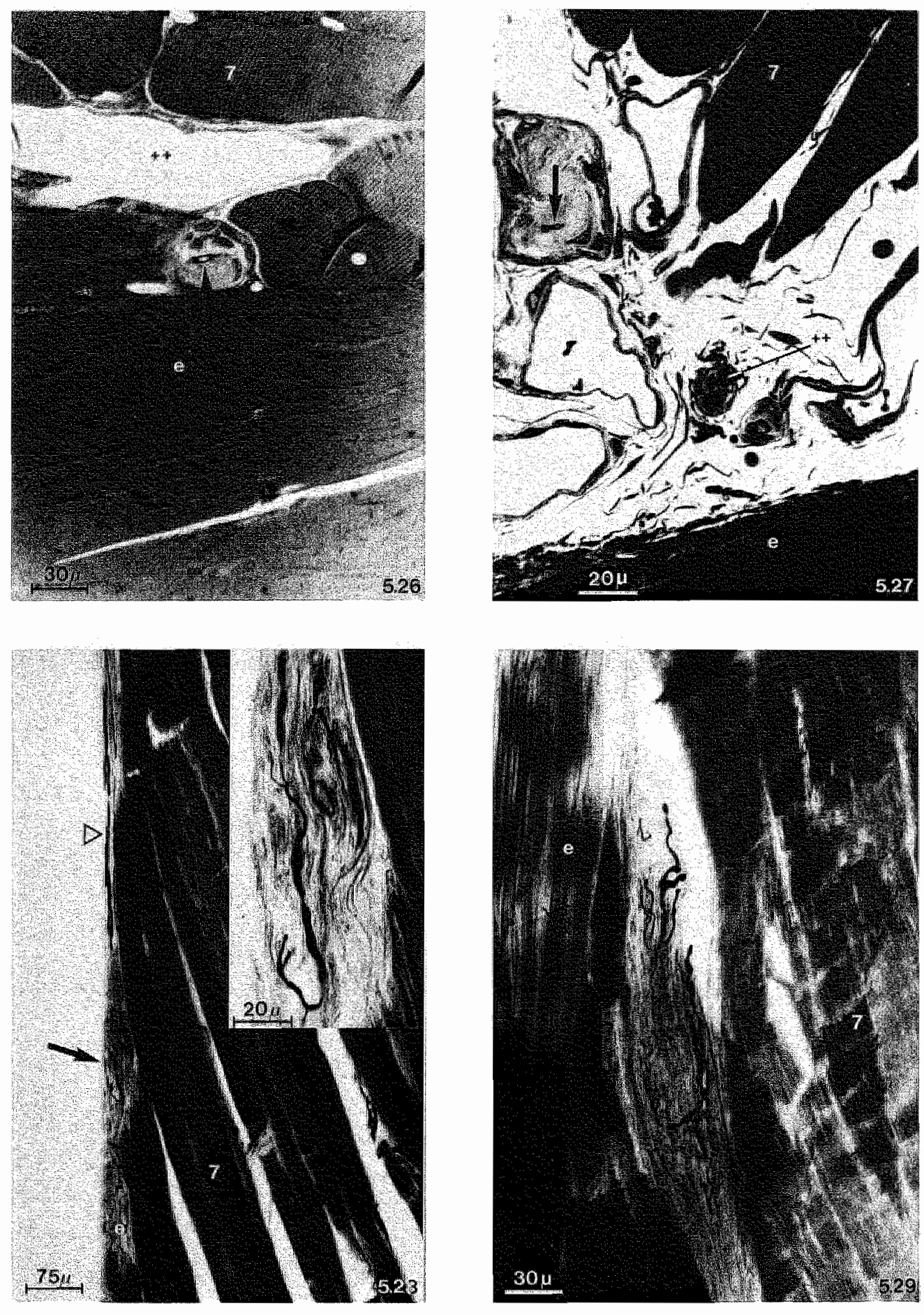


\subsection{Discussion}

Nerve plexuses in connective tissue structures

Results of qualitative interspecies and interarticular comparisons about plexiform arrangements of peripheral nerves sprouting over tendons and ligaments indicate, that the polygonal network is a consistent feature in the innervation pattern in the periarticular aponeuroses of the knee and elbow joint (Wilson and Lee, 1986). Stilwell (1957a-c) states that such networks terminate in small "paciniform corpuscles" and in "freely ending axons" on the surface connective tissue of tendons, aponeuroses and muscles and in periosteal connective tissue, nearly always in the vicinity of other mechanoreceptors. The type of axons present in the nerve fascicles of both plexuses as well as the demonstrated (or putative) origin of those axons from substrate of mechanoreception in our material, confirm the concept that such peri- or iuxta-articular nerve plexuses are not exclusively involved in nociceptive processes as stated by Wyke (1967) and Freeman and Wyke (1967a, 1967b).

The putatively mechanosensitive properties of iuxta-articular plexuses has been demonstrated on physiological grounds by Schaible and Schmidt (1983a, 1983b) for peripatellar plexuses in the rat (Wilson and
Lee 1983, 1986; Lee and Wilson, 1985a). Neuronal activity was present throughout the whole range of joint movements rather than only at the extremes. This is not consistent with the discharge characteristics of so-called joint receptors which tend to fire maximally towards the exiremes of joint position (Burgess and Clark, 1969; Grigg, 1976; Grigg and Greenspan, 1977; Ferrell, 1980; Ferrell et al. 1986). Based on our findings it is hypothesized that the neuronal activity of the peripatellar plexus as reported by Wilson and Lee $(1983,1986)$ originates from a similarly organized substrate of mechanoreception as has been demonstrated in our material. The substrate is not situated exclusively within the collagenous connective tissue layers themselves but at the transition to adjacent (and inserting) muscular tissue. Such periarticular plexuses may be considered as extensions of a muscular rather than a purely articular mechanism to provide position sense. This is consistent with the finding that the units identified in the peripatellar plexus showed to be active throughout the entire range of joint movement (Schaible and Schmidt, 1983a, 1983b). It may be concluded that plexus configuration in or near aponeurotic structures itself has no mechanosensitive function. Number and density of the polygons in-

\section{Figure 5.26}

Lamellated corpuscle interposed between muscle fibers of the SUP musele (7) and the regular dense collagenous connective tissue of the proximal extension of the supinator septum (e). The arrow indicates the centrall axon. ++: blood vessel. Staining according to Laczko and Levai.

\section{Figure 5.27}

Lamellated corpuscle situated in loose connective tissue between the ulnar edge of the supinator septum (e) and muscle fibers of the SUP muscle (7) with a nerve fascicle containing the afferent axon $(++)$. The arrow indicates the central axon. Staining according to Laczko and Levai.

\section{Figure 5.28}

Longitudinal section the SUP muscle ( 7 ) and distal end of the supinator septum (e). A GTO is present (arrow) attached to the septal collagenous connective tissue. The afferent axon $(\Delta)$ runs on the outer side of the septum and ramifies within the receptor capsule in a spray-like manner. Detail in insert. Silver staining according to Spaethe.

\section{Figure 5.29}

Longitudinal section of a GTO attached to the supinator septum (e).

Silver staining according to Spaethe. 
dicate at the most the amount (or spatial concentration) of nerve fibers and (indirectly) of sensory endings present at the transition to the adjacent muscular tissue.

Denervation experiments revealed that the vast majority of receptor fields in the anteriorly located peripatellar plexus unexpectedly projected along the posteriorly located tibial nerve (Lee and Wilson, 1985a, 1985b). In our material there are no indications of such a "reciprocal" innervation. The projection pattern of the superficial plexus was investigated by denervation experiments (Burg, 1988) The superficial plexus exhibits Wallerian degeneration after neurotomy of the radial nerve. Contribution from the ulnar and the antebrachial medial cutaneous nerve was demonstrated for the olecranal and ulnar periosteal part of the plexus. The musculocutaneus nerve and the median nerves were excluded by these experiments as afferent nerves for the superficial plexus in the lateral antebrachial region. Gardner (1948) mentions a nerve plexus around the anular ligament in man, supplied by branches of the radial and musculocutaneous nerves (dissection study). In the denervation experiments of Burg (1988) the deep branch of the radial nerve appeared to contain exclusively the projecting nerve fibers from the deep plexus in the considered region.

Innervation of substrate of mechanoreception at muscle-connective tissue transitions is of clinical importance. Wilson and Lee (1986) mention that the nerve fibers which provide connections for afferents from the peripatellar plexus, are likely to be interrupted when surgical incisions are applied in the area. Clinical defects following knee surgery might have their anatomical substrate in lesions of the peripatellar plexus. The significant reduction of complications of this kind coincident with the advent of modern arthroscopic techniques (O'Connor and McConnaughey, 1978), could also be explained on these grounds. Functional instability after ankle trauma or surgery is thought to be caused by interruption of proprioceptive afferents (Freeman et al., 1965;
Freeman and Wyke, 1967c). Similar considerations may particularly regard the superficial plexus as present in the proximal antebrachial extensor region. Dealing with the therapy of the "tennis elbow" a lot of surgical procedures are avallable. They range from a simple extensor fasciotomy (Post e.a., 1978) to a transverse division of the deep fascial covering of the common extensor muscles together with the intermuscular septa, one centimeter distally to the lateral humeral epicondyle. In all types of operations however, the "common attachments of extensors" are severed (Campbell, 1971; Nirschl and Pettrone, 1979). In their studies on the architecture of the muscular and connective tissue in the human elbow region, Van Mameren and Drukker (1984) already question the consequences of such damage to joint stability. The current study moreover supplies evidence that also substrate of mechanoreception might be damaged or interrupted by such procedures.

\section{The putatively mechanosensitive free nerve endings (FNE's).}

It is generally accepted that myelinated group III (A delta) nerve fibers are involved in so-called deep propriocepsis from muscles and tendons (Boyd and Davey, 1968; Voorhoeve, 1978; Brodal, 1981). Nowadays a lot of evidence exists that the majority of type IV (C-) fibers in peripheral muscular nerves is not autonomic, but also sensory, originating from intramuscular connective tissue (v.Düring et al. 1984; Andres et al., 1985, 1987; Zenker, 1988; v.Düring, 1988). Such fibers are thought to originate from nerve endings with nociceptive and/or mechanosensitive quality (v.Düring et al. 1984; Andres et al., 1985; Mense and Meyer, 1981; Mense et al., 1985; Heppelman et al., 1988; Zenker, 1988). The presence of nerve terminals of group III and IV nerve fibers is a regular finding in the joint capsule and epimysial connective tissue in many species (Halata et al., 1984, 1985; Halata and Strasmann, 1988; Strasmann and Halata, 1988). Heppelman et al. (1988) found that axons of 
group III and IV may run through collagenous tissue up to a distance of 60 to $200 \mu \mathrm{m}$, exhibiting about 6 to 10 swellings where (intra-) neurilemmal and periaxonal morphology very much resembles the characteristic sensory terminal axon morphology. Since serial ultramicroscopical sections over a long distance have not been performed in this study, it cannot be excluded that some small unmyelinated axons ( 0.5 to $1 \mu \mathrm{m})$ enveloped by one Schwann cell as demonstrated in our material, are not $\mathrm{C}$ axons but prolongations of group III preterminal axons that have lost their myelin sheath during their course (cf. figure 5.13). Since sympathectomy has not been carried out in the studied material, $\mathrm{C}$-axons cannot be discriminated definitively from autonomic efferent axons in the nerve fascicles of both plexuses. The results from the F.I.F. experiments give evidence that also noradrenergic axons in the plexus fascicles occur.

Recently more information has become available about the ultrastructural features of putatively mechano(noci)ceptive nerve endings (Andres and v.Düring, 1972; Halata and Munger, 1983; v.Düring et al., 1984; Halata et al., 1984, 1985; Andres et al., 1985; Strasmann et al., 1987). Halata and Munger (1983) developed criteria to differentiate FNE's in ultramicroscopical sections from passing non-myelinated axons and from efferent terminals. Von Düring et al. (1984) and Andres et al. (1985) inferred a new morphological classification of free or unencapsulated nerve endings. The lack of Schwann cell covering and the occurrence of a receptor matrix in the neurilemma are proposed as main morphological criteria for distinguishing receptive (or transductive) areas of afferent nerve terminals from conductive areas. At least two types of unencapsulated FNE's demonstrated in the components of the deep portion of the epicondylar connective tissue apparatus meet their classification. The first type of FNE's described (figure 5.21) is classified as similar to the group-III/type-2 (PTgc) endings, the second type (figure 5.20) as group-III/type-5 (PTic) endings in the proposed nomenclature of Von Düring and Andres.

On physiological grounds, various types of so- called III an IV receptors: nociceptors, pressure-sensitive receptors, contractionsensitive receptors and thermo-sensitive receptors are differentiated by Mense and Meyer (1985) and Mense (1988). They conclude that there exist different types of receptors rather than a single population of polymodal receptors. This conclusion might fit with the ultrastructural morphology of periterminal structures that are supposed to be able to transmit the mechanical forces to the transducer areas of such nerve terminals (Andres and v.Düring, 1972; v. Düringet al., 1984). Further evidence of the existence of group III mechanosensitive free nerve endings in muscular and connective tissues is given by the finding that their spinal projections differ in course and area of termination from that of nociceptive group III afferent units (Mense et al., 1985; Mense, 1988). Also other investigators (Kruger et al., 1981; Abrahams, 1982; Schaible and Schmidt, 1983a, 1983b; Spray, 1986) provided evidence that free nerve endings are not a purely nociceptive substrate but are also involved in mechanoreception. This has already been postulated in principle by Stilwell $(1957 \mathrm{a}-\mathrm{c})$. Also the studies of Richmond and Abrahams (1975, 1979) and Richmond et al. (1976) strongly support the idea of mechanosensitive function of group IIIfibers from dorsal neck muscles. The mechanosensitive properties of endings of group IV nerve fibers has been confirmed for cutaneous nerves by Iggo (1985).

In the deep division of the epicondylar connective tissue apparatus (deep plexus) at least two types of group III nerve endings are identified that meet the aforementioned criteria for mechano(noci)ceptive FNE's. Based on the analogous typology of the axons in the nerve fascicles of the superficial fascial plexus it is assumed that the lightmicroscopically demonstrated FNE's in and near layers of the superficial division of the epicondylar connective tissue apparatus, also include such mechanosensitive sub- 
strate. No absolute evidence can be prowided that sensory endings of type IV nerve axons are present in the studied material. The results from the applied F.I.F. technique suggest that some group IV axons in the nerve fascicles of both plexuses are efferent axons involved in nor-adrenergic pathways.

It is concluded that the FNE's as demonstrated in the studied region are involved in mechanosensitive processes as well as in the process of pain perception.

\section{Classification of the (encapsulated) sen- sory nerve endings}

The pathway and spectrum of afferent nerve fibers in both plexuses exhibit analogies to the innervation pattern usually described for joint capsular reinforcing collagenous connective tissue structures. Sensory innervation of the knee joint capsule for instance mainly occurs via fine afferent axons partly originating from FNE's and partly from encapsulated mechanoreceptors (Halata, 1977; Langford and Schmidt, 1983; Halata et al., 1984, 1985; Strasmann et al., 1987). In the region under consideration there exists sufficient evidence for linkage of FNE's, GTO's and lamellated corpuscles attached to the olecranal retinaculum with the nerve fascicles of the superficial plexus. The linkage of the GTO's related to the intermuscular muscle compartment walls of the superficial extensor muscles and of the FNE's present in the proximal extension of the same muscle compartment walls with the superficial plexus, is tentative. For the lamellated corpuscles and FNE's in and near the deep division of the epicondylar connective tissue apparatus, connections with the deep plexus are demonstrated in our material. Linkage of the encapsulated ("spray-like") nerve endings attached to the distal part of the supinator septum with the deep nerve plexus, might occur via nerve fibers from these receptors running in longitudinal direction upon or underneath the supinator septum. Observations of serial silver stained (Spaethe) sections however show that a few of the latter mechanoreceptors are axons branching from intramuscular nerve fascicles derived from the deep branch of the radial nerve. In the case of the olecranal retinaculum such connections between nerve fascicles in the superficial plexus and deeply situated branches of the radial nerve, are evident.

Already Stilwell (1957a-d) notes the nearly constant association of "Ruffini endings" with "small encapsulated corpuscles and free terminations" in the innervation of aponeuroses and tendons. He adds that "Golgi tendon spindles" are hardly morphologically distinguishable from the "Ruffini type ending". In a light-microscopical study in joint capsules of various birds and mammals, Polacek (1966) states the trias free nerve endings, Pacini or Paciniform corpuscles and "spray-like nerve endings" (Ruffini corpuscles) as characteristic for joint capsule innervation. Ruffini corpuscles are slowly adapting mechanoreceptors involved in recording strain of the collagenous matrix in which they are embedded (Eklund and Skoglund, 1960; Grigg et al.,1982; Grigg and Hoffman, 1982, 1984). They are characterized by sensory cores with fine arborizing filaments (Polacek, 1966; Halata, 1977; Halata et al., 1984, 1985; Sathian and Devanandan, 1983). Freeman and Wyke (1967a, 1967b) and O'Connor and Gonzales (1979) classify them as type I mechanoreceptor measuring $100 \times 40 \mu \mathrm{m}$ with a myelinated parent nerve of 4 to $9 \mu \mathrm{m}$ in diameter (cat). The corpuscles however exhibit a great variability in both size and structure, apparently depending on the texture of the surrounding connective tissue (Andrew, 1954; Halata et al., 1985; Strasmann et al., 1987). The more dense and regularly organized the surrounding connective tissue is, the greater the resemblance of Ruffini corpuscles to GTO's (Schoultz and Swett, 1972, 1974).

The typical GTO is a (very) slowly adapting mechanoreceptor (Schoultz and Swett, 1972,1974 ; Burgess and Perl, 1973), is situated in ligaments and in muscle-tendon transitional zones, measures about $600 \times 100$ $\mu \mathrm{m}$ and is usually innervated by a myeli- 
nated type Ib nerve fiber with a diameter of 13 to $17 \mathrm{\mu m}$ in the cat (Bridgman, 1968, 1970; Freeman and Wyke, 1967a, 1967b; Schoultz and Swett, 1974; O'Connor and Gonzales, 1979). Other authors (Merrilees, 1962; Soukup, 1983; Zelena and Soukup, 1983; Sathian and Devanandan, 1983) mention a diameter of 8 to $12 \mu \mathrm{m}$ of the afferent nerve fiber in the rat.

With respect to the well-developed capsule, the spindle-shaped form and the parallel organization of the collagenous fibers within the inner core, we tend to classify the encapsulated ("spray-like") nerve endings at the distal extension of the supinator septum and at the olecranal retinaculum as Golgi tendon organs. GTO's are said to receive afferents only from intramuscular nerve fascicles (Boyd, 1954; Stilwell, 1957b; Merrilees, 1962; Schoultz and Swett, 1972, 1974; Sathian and Devanandan, 1983). The entrance of the nerve into the GTO usually is stated to occur in the middle third of the receptor (Zelena and Soukup, 1983), while in most receptors under consideration the afferent nerve fibers enter the receptor at the polar side. This pattern rather resembles the situation in Ruffini endings (Boyd, 1954; Polacek, 1966; Sathian and Devanandan, 1983). In our material there is evidence that myelinated group III nerve fibers in both nerve plexuses also include afferents from these GTO's. This has been demonstrated for the olecranal GTO's; for GTO's related to the supinator septum it has been made plausible. The fact that the diameter of the afferent nerve fibers seldom exceeds $8 \mu \mathrm{m}$, is mentioned as typical for Ruffini endings (a.o. Boyd, 1954; Sathian and Devanandan, 1983) though there is some overlap with the diameter of the GTO afferent nerve (a.o. Merrilees, 1962; Zelena and Soukup, 1983). The dimensions $(450 \times 50 \mu \mathrm{m})$ and the location between a collagenous connective tissue layer and inserting muscle fascicles again are characteristic for Golgi tendon organs. The difficulty to discriminate unambiguously between GTO's and Ruffini corpuscles has also been noted by Richmond and Bakker (1982) and Sathian and Deva- nandan (1983).

For this study it is important that - with respect to the typology of the associated mechanoreceptors - the muscle compartment walls under study are equipped with encapsulated receptors that may be considered as a transitional type of receptors between those usually attributed to capsuLar reinforcements and those usually attributed to aponeuroses or tendons of muscles. This view implies that the regular dense collagenous connective tissue layers in this region should not be subdivided into joint-related and muscle-related structures, but that the considered collagenous connective tissue is in fact a continum between skeletal and muscular tissue with characteristics usually attributed to joint capsular reinforcements or to muscle auxilliary connective tissue structures. Physiologically the Ruffini corpuscles and GTO's - both slowly adapting receptors - are sometimes distinguished from each other because the Ruffini endings show a dynamic response that the GTO lacks (Skoglund, 1956, 1973; Freeman and Wyke, 1967a, 1967b). How this functional classification relates to morphological features is still a matter of discussion (O'Connor and Gonzales, 1979; Sathian and Devanandan, 1983; Zelena and Soukup, 1983) and would require further study in the considered region. It is hypothesized that the intrinsic structural differences between the two types of receptors are not the only explanation for this distinctive behaviour but that also the tissue texture of the receptors influences their physiological behaviour (Grigg and Hoffman, 1982, 1984).

Small lamellated (or Pacini) corpuscles usually are located in capsular insertions at the periosteum and in ligaments (Halata et al., 1984, 1985; Strasmann et al., 1987; Strasmann and Halata, 1988). They are rapidly adapting mechanoreceptors (Burgess and Clark, 1969; Clark, 1975; McCloskey, 1978; Tracey, 1979, 1980), supplied by myelinated axons with a diameter of $3 \mu \mathrm{m}$ in man (Halata et $\left.\mathrm{al}_{.}, 1985\right)$ and up to $4-5 \mu \mathrm{m}$ in the cat (Freeman and Wyke, 1967a, 1967b; Wyke, 1967; Novotny, 1973). They are considered 
as the variant of the classical Vater-Pacini or Pacinian corpuscles, that occurs in mechanically strained areas, characteristically in dense but non-linearly organized connective tissue (Halata et al., 1984, 1985; Strasmann et al, 1987). The lamellated corpuscles demonstrated in the intermediate zone near the deep common layer of regular dense collagenous connective tissue (d.c.com.) exhibit the characteristic features of this type of "joint receptors". The occurrence (though infrequent) of such receptors in the transitional zone between muscular tissue and aponeurotic regular dense collagenous connective tissue - as found in areas of the medial head of the triceps muscle and the proximal extension of the supinator muscle - seems to be rather unexpected for "joint receptors". Similar configurations are described by Richmond and Bakker (1982) at musculo-tendinous interfaces in the deep intervertebral muscles of the cat, "wedged between highly organized bands of collagen, and frequently alongside GTO's". In our opinion this finding is again consistent with the concept of one joint stability system in which collagenous connective tissue structures are not to be classified exclusively as "capsular" or "muscular". Barker (1974) mentions that the "Paciniform corpuscle" exceptionally occurs as muscle receptor, and if present, is situated at the muscle-tendinous transitions. Swett and Eldred (1960a), Richmond and Bakker (1982) and Richmond and Stuart (1985) describe the occurrence of corpuscles of similar type and size as the lamellated corpuscles under consideration at muscle-tendon transition areas. The latter authors note that such receptors are easily overlooked (or removed during dissection) and that there probably exist more such receptors than previously thought, presumably in close association with muscle spindles and GTO's.

Nearly all the periarticular substrate of mechanoreception in the region studied here, is situated in or near the transitional zones between muscle compartment walls and adjacent muscular tissue. Its behaviour therefore is influenced by the state of stress and strain of the connective lissue (connected with skeletal tissue) and of the inserting muscle fascicles. It is concluded that classifying so-called joint receptors by their occurrence in or near topographically defined entities - e.g. ligaments, tendons, fasciae - (a.o. Freeman and Wyke, 1967a, 1967b; Malinovsky and Pac, 1982; Malinovsky, 1986) cannot be used for the description of substrate of mechanoreception in the lateral cubital region of the rat.

\section{Relation to occurrence of stress and strain.}

Both areas where an apparently mainly mechanosensitive plexus exists, are - in architectural respect - strategic areas for the perception of movements and stresses. Relatively broad layers of regular dense collagenous connective tissue are present, attached to and in-series with a skeletal element (olecranon/epicondyle), organized in series with short muscle fascicles in a pennate configuration (triceps /supinator) that directly originate from the periosteum of the opposite skeletal elements (humerus (radius). In chapter 3 we have hypothesized that those centrally oriented subunits of the epicondylar and olecranal muscle/connective tissue units may be considered as the "dynamic ligaments" (with adjustable tension) of those units. It is assumed that in their environment, stresses conveyed over the elbow joint and induced by displacement of skeletal elements or by (tr)action of in-series muscle fascicles, are concentrated. The substrate of proprioception at the transition of the regular dense collagenous connective tissue layers and inserting muscle fascicles as demonstrated here, supplies a good equipment for the perception of stresses transmitted via the elbow joint and of joint position or movement. Various features of the proprioceptive substrate hypothetically fit with the definition of those areas as "dynamic ligaments" on grounds of the architecture of muscular and connective tissue (chapter 3). In particular if compared with the usual classification into joint and muscle receptors, the typology and spec- 
trum of nerve fascicles and nerve terminals present in those areas exhibit features usually associated with tendons as well as with joint capsules and ligaments. Summarizing we mention here:

- an external pathway for the afferent nerve fibers.

- the presence of group III and group IV nerve fibers.

- the presence of putatively mechano(noci)ceptive FNE's.

- the occurrence of "Ruffini-like" Golgi tendon organs at the transitional zone between collagenous connective tissue layers and muscle fascicles.

- the occurrence of lamellated corpuscles in transitions between regular dense collagenous connective tissue and adjoint reticular collagenous connectivei tissue as well as inserting muscle fascicles.

A difference between the olecranal and epicondylar muscle/connective tissue unit as to the organization of the morphological substrate, is formed by the proportion of lamellated corpuscles and Golgi tendon organs. In the direct vicinity of the supinator septum a relative large amount of lamellated corpuscles is present. The intermediate zone in which they occur may be thought to be compressed c.q. deformed due to displacement of the adjoining structures. 'This might relate to the "collateral" situation of this connective tissue complex in relation to the adjacent joint(s). The preferential localization of those receptors at the ulnar extension of the septum (near the supinator bone) - and near the lateral collateral connective tissue layer - is in line with the ulnoradial gradient that exists in the deep epicondylar connective tissue apparatus. Apparently a different situation exists in the region of the olecranal retinaculum. Though in principle a similar spectrum of mechanosensitive substrate exists, an intermediate connective tissue zone with lamellated corpuscles is lacking here. This coincides with the prevalence here of GTO's as strain-perceiving substrate probably consistent with a more stress-conveying and strain-resisting function of this muscle/connective tissue unit during locomotion. Near the transition of the collagenous connective tissue structures to the periosteal connective tissue structures, both areas exhibit the "endotenonial spectrum" of proprioceptive substrate (Andres et al. 1985) with mainly (mechanosensitive) FNE's from group III and IV fibers. Such substrate may be consistent with the occurrence of strain. 


\subsection{Conclusions}

"With exception of FNE's in the transitional areas of the connective tissue apparatus towards the periosteum, no mechanosensitive nerve terminals are present within the stressconveying components of the proximal connective tissue apparatus, but at the transition of regular dense collagenous connective tissue with muscular tissue or reticular collagenous connective tissue.

2 Nervous tissue ellements present within the components of the proximal collagenous connective tissue apparatus, are (preterminal conductive) nerve fascicles which contain besidle autonomic nerve fibers - group III (A delta) and group IV (C-) nerve fibers. Those nerve fibers are involved in the afferent pathway of proprioceptive information from the transitional areas between the connective tissue layers and the muscle fascicles organized in series with them. The fascicles are mainly organized as nerve plexus.

3 A spectrum of mechanosensitive substrate occurs at the transitional areas between the regular dense collagenous connective tissue layers and the muscle fascicles organized in series with them. This substrate exhibits features of type and location of the mechanosensitive nerve terminals that usually are considered to be characteristic for "joint receptors" as well as for "muscle receptors".

4 Particularly the olecranal retinaculum and the supinator septum (and its proximal continuation) with the muscle fascicles in series to those layers, are well-equipped with morphological substrate as characterized in preceding conclusions. This supports the definition of those subunits of the epicondylar and olecranal muscle/connective tissue units as "dynamic ligaments".

5 Based on architecture and spatial distribution of the substrate of mechanoreception, it may be assumed that the "joint receptors" in the studied region are also influenced by the state of activity of the muscle organized in series with the collagenous connective tissue in or near which those receptors occur. Therefore they may function as "muscle receptors". 


\section{MUSCLE SPINDLES AND GOLGI TENDON ORGANS IN RELATION TO THE ARCHITECTURE OF MUSCULAR AND CONNECTIVE TISSUE}

\section{Contents}

6.1 Introduction

6.2 Results

6.2.1 Occurrence of muscle spindles and GTO's per muscle area

6.2.2 Occurrence of muscle spindle/GTO zones considered regionally

6.3 Discuission

6.4 Conclusions

\section{Summary}

The occurrence of mechanosensitive nerve terminals in that part of the locomotor apparatus that is complementary to the proximal collagenous connective tissue apparatus i.e. muscular tissue, is represented by three-dimensional reconstructions of the spatial distribution of muscle spindles and Golgi tendon organs (GTO's) in the region (par. 6.2). Those receptors are concentrated in areas of muscular tissue situated in series with and between distal regular dense collagenous connective tissue structures (tendons) on the one hand and proximal regular dense collagenous connective tissue structures (muscle compartment walls) on the other hand. This leads to the clefinition of "monitor muscle/connective tissue units", the topography of which parallels the architecture of the in-series muscle/connective tissue units described in chapter 3 . The patterns of distribution of muscle spindles and GTO's are discussed in relation to current concepts regarding receptor distribution (par. 6.3). It is concluded that the receptors concerned are concentrated in those areas where the conveying of tensile stresses over the elbow joint is expected to take place (par. 6.4). 


\subsection{Introduction}

Searching for putative proprioceptive substrate within the components of the proximal collagenous connective tissue apparatus, we paid attention to mechanoreceptors present in the transitional area between muscle compartment walls and adjoining (in-series) muscular tissue. The following part of this study deals with the occurrence and distribution of morphological substrate of proprioception in the complementary constituent of the locomotor apparatus i.e. the muscular tissue in the cubital region. The main type of receptors in the muscular tissue and the muscle-connective tissue transitional areas are considered to be muscle spindles and Golgi tendon organs (GTO's) (for review: Barker, 1974). Rarely Pacinian or Paciniform corpuscles are described as muscle receptors (Stilwell, 1957a-c; Swett and Eldred, 1960a, 1960b; Barker, 1974; Richmond and Bakker, 1982; Richmond and Stuart, 1985; Strasmann, 1988).

Muscle spindles (for review a.o. Barker, 1974; Hunt, 1974; Williams and Warwick, 1980) are involved in monitoring the (changes in) length of adjoining muscle fibers, the length of the whole muscle in which they are embedded and indirectly the movements and position of skeletal elements the muscles are connected with (Goodwin et al, 1972; Grigg et al.,1973; McCloskey, 1978; Matthews, 1981; Abrahams, 1982; Gandevia, 1983; Wei et al., 1986; Bout, 1987; Ferrell and Smith, 1987). Muscle spindles may occur in various configurations like tandems (two or more spindles linked with each others poles), paired linkages (spindles with adjoining or fused capsules) or dyads (linkages of spindles with GTO's) and "unipolar" spindles (with one pole directly attached to (intra)muscular tendons). Such configurations are considered to be related to (extrafusal) muscle fiber architecture (Barker and Ip, 1961; Thompson, 1970; Marchand et al., 1971; Bakker and Richmond, 1982; Richmond and Bakker, 1982; Richmond et al.
1986).

The occurrence and distribution of muscle spindles in literature are considered nearly exclusively per muscle, for instance the number of muscle spindles per gram of adult muscle. Comparisons between different muscles are usually based on such muscular parameters (reviewed a.o. by Voss, 1971; Barker, 1974 and Peck et al., 1984, 1988). Implicitly starting from the concept that muscles are the functional units in an assumed dynamic stability system regarding joint integrity, many authors handle such parameters to express the degree of "kinesiological monitor function" of muscles (a.o. Peck et al., 1984, 1988).

Uneven distribution of muscle spindles in a muscle area however is a common rather than an exceptional feature. Different explanations are given for such a zonation or regionalization of spindles in a muscle. Some authors mention the branching pattern of the intramuscular nerve as organizing principle (Barker and Chin, 1960; Chin et all., 1962; Arendt and Asmussen, 1974; Letbetter, 1974; Scott and Young, 1987). Others note the phenomenon of "sensory specialization" of the (relatively) spindlerich muscle zones as related to the occurrence of slow-oxydative extrafusal fibers (Yellin, 1969; Grim, 1972; Botterman et al., 1978; Richmond and Abrahams, 1975, 1979; Maier 1979; Binder and Stuart, 1980) or related to motor unit compartmentalization (Binder et al. 1976; Cameron et al., 1981; English and Letbetter, 1982b; English and Weeks, 1984; Richmond and Stuart, 1985). Data on regional occurrence of muscle spindles are supplied by Peck (1988) who states that the more kinematically complex a joint is, the more spindles are associated with it, and that the higher the absolute spindle number associated with a joint, the lower the spindle densities in the muscles controlling it.

In all theories however the muscle as morphological and functional unit is the predominant concept. The architecture of the

\section{6}


collagenous connective tissue only plays a secondary instrumental role (a.o. Swett and Eldred, 1962a, 1962b; Richmond and Abrahams, 1979; Richmond and Stuart, 1985).

Generally speaking a muscle that is provided with muscle spindles possesses GTO's, though they may be absent in small muscles like cat tenuissimus muscle (Barker, 1974) and in e.g. avian jaw and tongue muscles (Bout, 1987). The occurrence of GTO's is often also expressed by the number of GTO's per muscle (Wohlfart and Henriksson, 1960; Eldred et al., 1962; Soukup and Zelena, 1977a; Botterman et al., 1978; Lund et al., 1978; Lennartson, 1980b; Goldfinger and Fukami, 1982; Devanandan et al., 1983; Scott and Young, 1987).

This receptor was first described by Golgi (1878) who called it a "musculo-tendinous end-organ". The current terminology "Golgi tendon organ" indicates the most common and wellknown situation of the receptor i.e. at all kinds of musculo-tendinous transitions (Stilwell, 1957a). This includes association with intramuscular tendons of pennate muscles (Eldred et al., 1962; Arendt and Asmussen, 1974; Richmond and Stuart, 1985) and with aponeuroses of origin as well as of insertion (Swett and Eldred, 1960a; Soukup, 1983; Kanatani et al., 1986; Scott and Young, 1987). Freeman and Wyke (1967a, 1967b) and O'Connor and Gonzales (1979) classify the GTO as type III mechanoreceptor (Skoglund, 1956; Schoultz and Swett, 1972) also related to ligaments (Wyke, 1967; Kanatani et al., 1986). Some authors supplied evidence that Ruffini endings and GTO's in fact are one and the same receptor type presenting gradual differences (Andrew, 1954; Halata et al., 1984, 1985; Strasmann, 1987). Each GTO is a thinly encapsulated bundle of small tendon fascicles generally fusiform in shape consisting of a neurotendinous core with a Ib sensory nerve ramifying and terminating between the loose fibers of the core (Bridgman, 1968, 1970; Soukup and Zelena, 1977a, 1977b; Soukup, 1983; Zelena and
Soukup, 1983; Soukup and Zelena, 1985). GTO's are (very) slowly adlapting mechanoreceptors, monitoring (muscle) tension and thus participating together with muscle spindles in reflex regulation of motor activity (Freeman and Wyke, 1967c; Matthews, 1972; Barker, 1974; Hunt, 1974; Stuart et al., 1972; Proske, 1979; Proske and Gregory, 1980; Fukami, 1981). The characteristic position of a Golgi tendon organ ensures that the receptor is stretched and activated by muscle contraction or elongation (Alnaes, 1967; Houk and Henneman, 1967; Stephens et al., 1975; Crago et al., 1982) apparently with a higher threshold for passive muscular strain (Matthews, 1972; Proske, 1979; Stuart et al., 1972). Recent studies emphasize the direct relation of GTO activity with adjacent motor unit activity (Gregory and Proske, 1979; Binder and Osborn, 1985; Gregory et al., 1986; Spielman and Stauffer, 1986). Zelena and Soukup (1983) emphasize the functional meaning of the in-parallel relation between the purely neurotendinous compartment in the GTO lumen and its capsular wall formed by one or more muscle fibers. Also adjacent extrafusal muscle fibers may run and insert in parallel to the GTO. Such in-parallel configurations can protect the GTO from elongation, for instance during muscle stretching. A similar mechanism could "silence" the GTO during (dynamic or static) muscle contraction. This extends the GTO from a purely passive stretch receptor to a receptor with a more dynamic mechanosensitive pattern in which adjacent muscle fascicles - and therefore muscle architecture - also play a role (Hnik et al., 1963; Alnaes, 1967; Houk and Henneman, 1967; Stuart et al., 1972; Stephens et al., 1975).

GTO's occur in relation to the regular dense collagenous components of the connective tissue apparatus in the studied region (chapter 4). It is questioned if and how their distribution at those components is related to the architecture of this apparatus and the muscular tissue in-series with it. 


\subsection{Results}

In this paragraph the spatial distribution of spindles and GTO's will first be described per muscle compartment (par. 6.2.1) based on seven projection drawings of threedimensional graphic reconstructions of the receptors in the antebrachial extensor muscles (figure 6.3 to 6.9 ). Then an integral description of their occurrence in the lateral cubital region is given (par. 6.2.2) related to two 3D-reconstruction drawings of muscle spindle/GTO zones (figure 6.10 to 6.11 ). These descriptions include (non-quantified) observations about receptor configurations (e.g. tandems and dyads) in the three-dimensionally reconstructed specimens or in the specimens processed for silver staining (Spaethe).

The topographical relation of spindles and GTO's with regular dense collagenous connective tissue structures is also elucidated by two summative projections of the receptors in the complete region (figure 6.1 and $6.2)$.

Figure 6.1 to 6.2 are summative projections (par. 2.2.2.3) of the distribution of muscle spindles, GTO's and Pacinian corpuscles in specimens $\mathrm{C} 1$ and $\mathrm{A} 2$. In each figure the actual serial section numbers of the reference transverse sections are given. Comparable transverse sections with legend for the structures are given as figure $3.16 \mathrm{~A}$ to $3.16 \mathrm{H}$ in par. 3.6.

Figure 6.3 to 6.9 are projections of 3D-reconstructions of the spatial distribution of muscle spindle capsules and GTO's per muscle area in specimen $\mathbf{Z} 2$. In each figure the following information is given:

A Projection with "eye direction" in distoproximal direction at an angle of about $30^{\circ}$ with the $Z$-axis and the sagittal plane and in antero-posterior direction at an angle of $45^{\circ}$ with the $\mathrm{Z}$-axis and the fron- tal plane. "Eye position" near the distal end of ulna and radius. "Eye opening" (optic angle) 17.00 degrees. (*)

B Lateromedial projection onto a sagittal (antero-posterior) plane. Proximo-distal "eye direction" with an angle of about $80^{\circ}$ with the longitudinal $Z$-axis and the sagittal plane. "Eye position" proximal from the olecranall tip. "Eye opening" (optic angle) 10.00 degrees. (*). . . . in $B$ represents the plane where figure $A$ is sectioned.

c Representation of three characteristic spindle capsules (-०) with their corresponding muscle cross-sections in the same projection direction as figure $B$. The sections indicated with $\Delta$ and $\triangle$ are also represented in figure $A$ and $B$.

A diagram of the foreleg in the same projection direction as in figure $B$ - with the muscle concerned indicated - is added.

- Muscle spindle capsules are represented by lines connecting the capsular poles. Golgi tendon organs are indicated with o for proximal GTO's and with for distal GTO's.

- In each figure the adjoining intermuscular compartment walls (for SUP muscle the supinator septum and lateral collateral connective tissue layer) as well as the distal tendons are represented in grey. Those regular dense collagenous connective tissue layers are represented up to a limited thickness. They actually extend more distally or proximally than indicated here and/or are continuous with a (not represented) floor or outer layer of the muscle compartments.

(*) For an indication of the projection directions, see the orientation of the proximal section in figure $6.6 \mathrm{~A}$ and $\mathrm{B}$. 
6.2.1 Occurrence of muscle spindles and GTO's per muscle area 

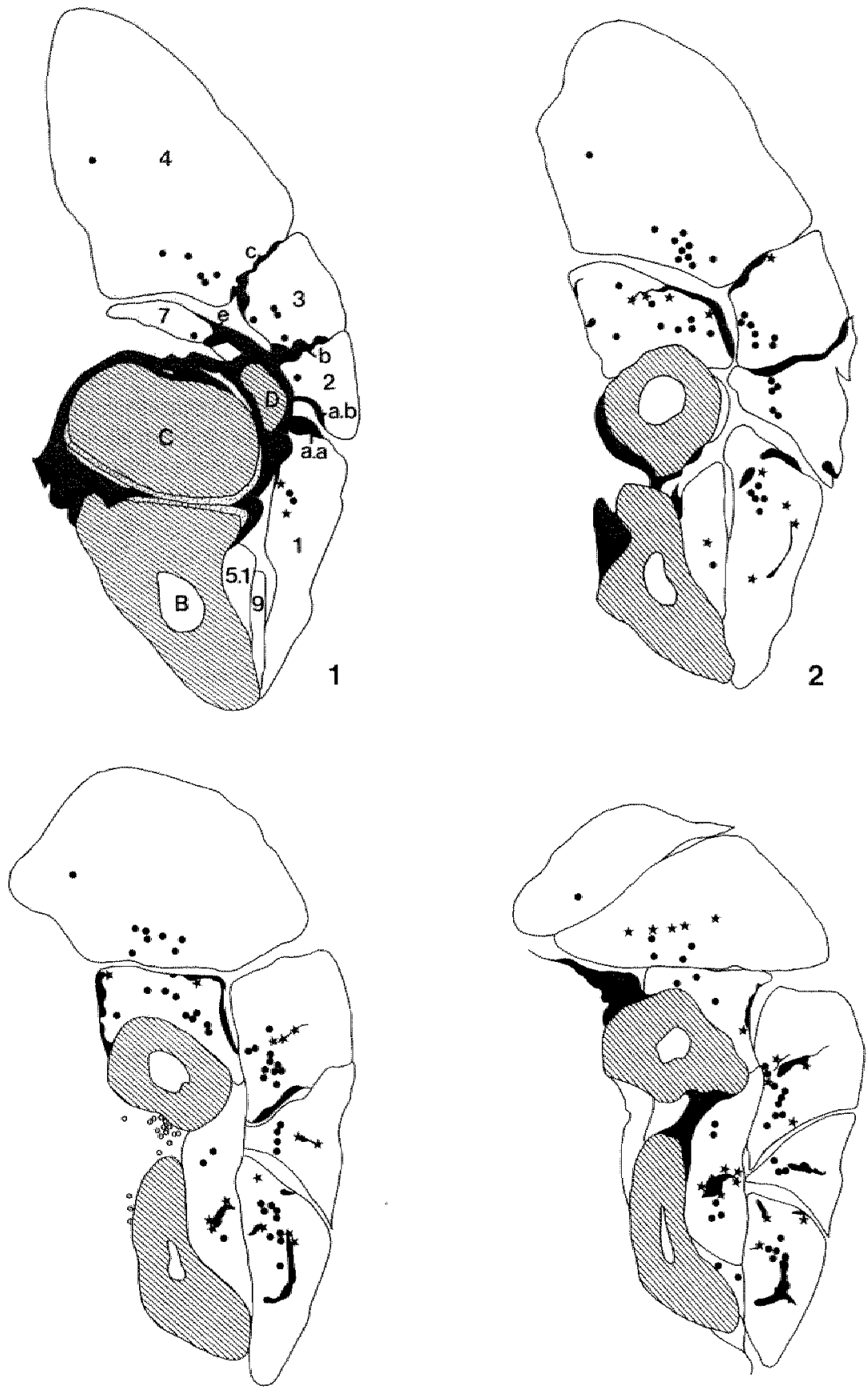

3

4 

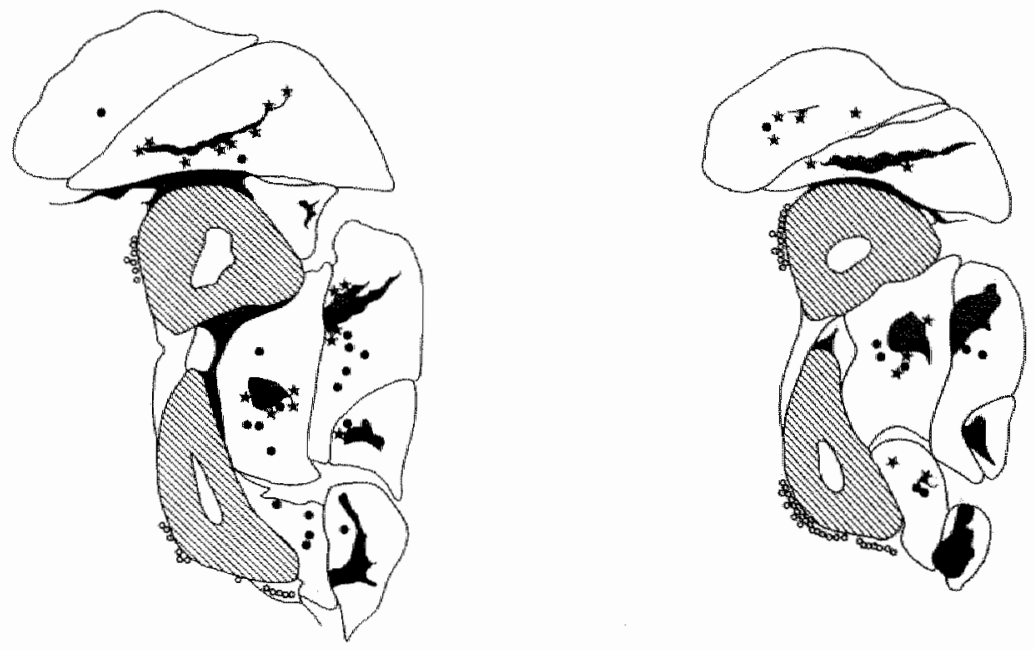

5

\section{Figure 6.1.}

Distribution of muscle spindles, GTO's and Pacinian corpuscles in 6 successive proximo-distal projections along the $Z$-axis of specimen $\mathrm{Cl}$ (summative projection).

Actual serial numbers of the $15 \mu \mathrm{m}$ sections that limit the foreleg portion that is projected onto the six reference sections (number indicated in bold):

$\begin{array}{llllllll}1 . & <360 & (491) & 570 & 2 . & 580 & (661) & 740 \\ 3 . & 750 & (840) & 910 & 4 . & 920 & (1000) & 1080 \\ 5 . & 1090 & (\mathbf{1 1 7 0 )} & 1250 & 6 . & 1260 & (\mathbf{1 3 4 0 )} & 1610>\end{array}$

The first reference section coincides with at transversal plane through the equator of the supinator bone, the last reference section with the most distal plane in which the supinator muscle is sectioned. Section 2 to 5 are equally distributed between section 1 and 6 .

Skeletal tissue shaded. Regular dense collagenous connective tissue black. Muscular tissue white.

-: muscle spindle

*: GTO

a: Pacinian corpuscle

See also general legend and figures $3.16 \mathrm{~A}$ to $3.16 \mathrm{H}$. 

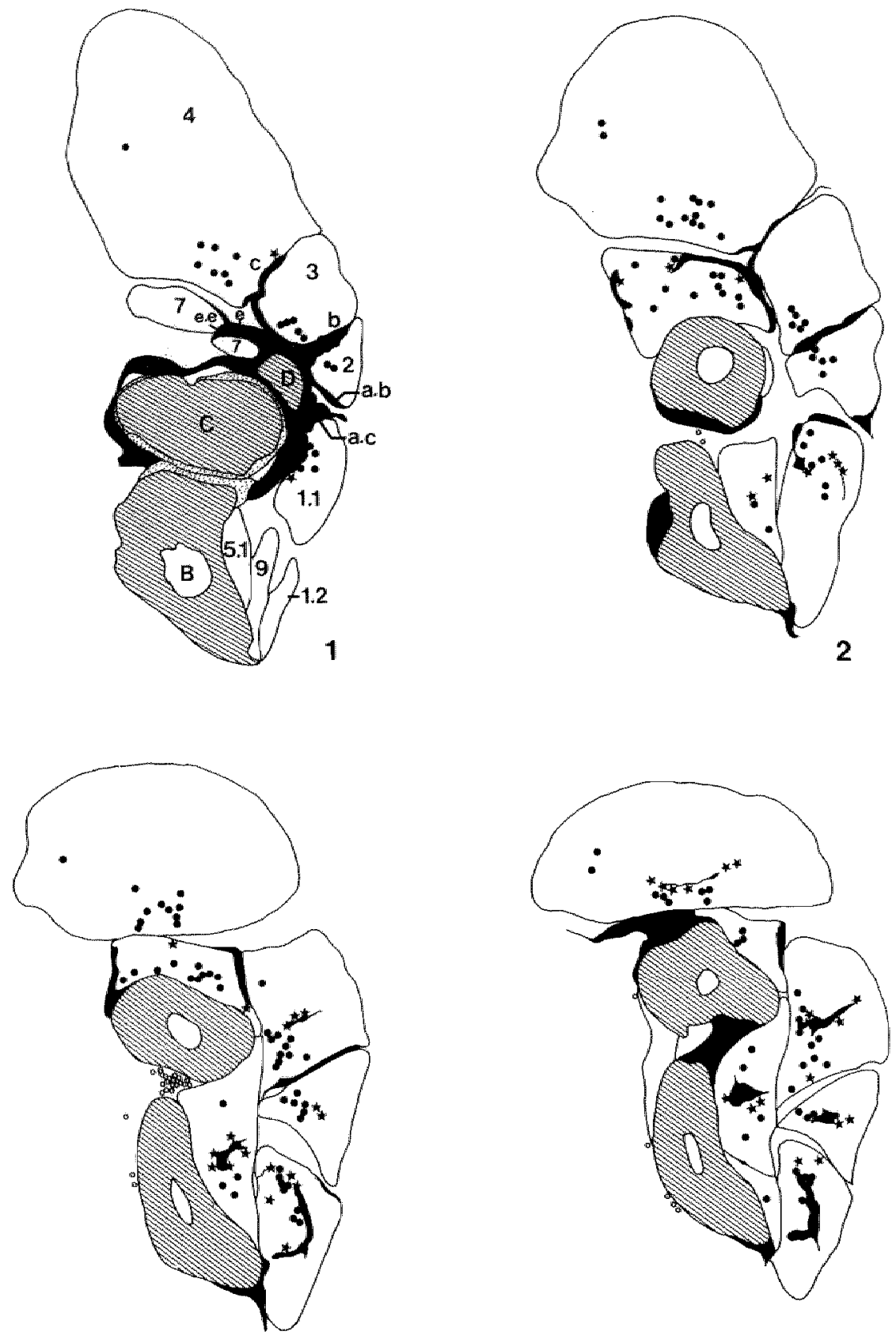

3 


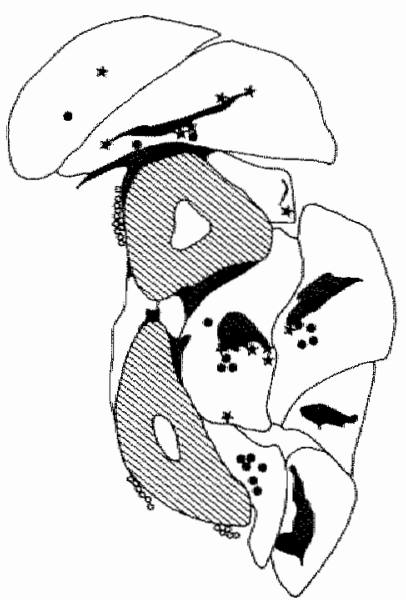

5

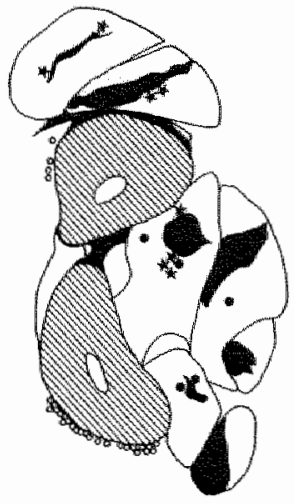

6

Figure 6.2

Distribution of muscle spindles, GTO's and Pacinian corpuscles in 6 successive proximomistal projections along the Z-axis of specimen A2 (summatiwe projection).

Actual serial numbers of the $15 \mu \mathrm{m}$ sections that limit the foreleg portion that is projected onto the six reference sections (number indicated in bold):

1. $<360 \quad(520)$

3. 780

(860)

600

2.

6110

(690)

770

5. 1120

(1200)

940

950

(1030)

1110

The first reference section coincides with a transwersal plane through the equator of supinator bone, the last reference section with the most distal plane in which the supinat or muscle is sectioned. Section 2 to 5 are equally distributed between section 1 and 6

Skeletal tissne shaded. Regular dense collagenous connective tissue black. Muscular tissue white.

- muscle spindle

*: GTO

See also general legend and figures 3.16 $\mathrm{A}$ to $3.16 \mathrm{H}$. 

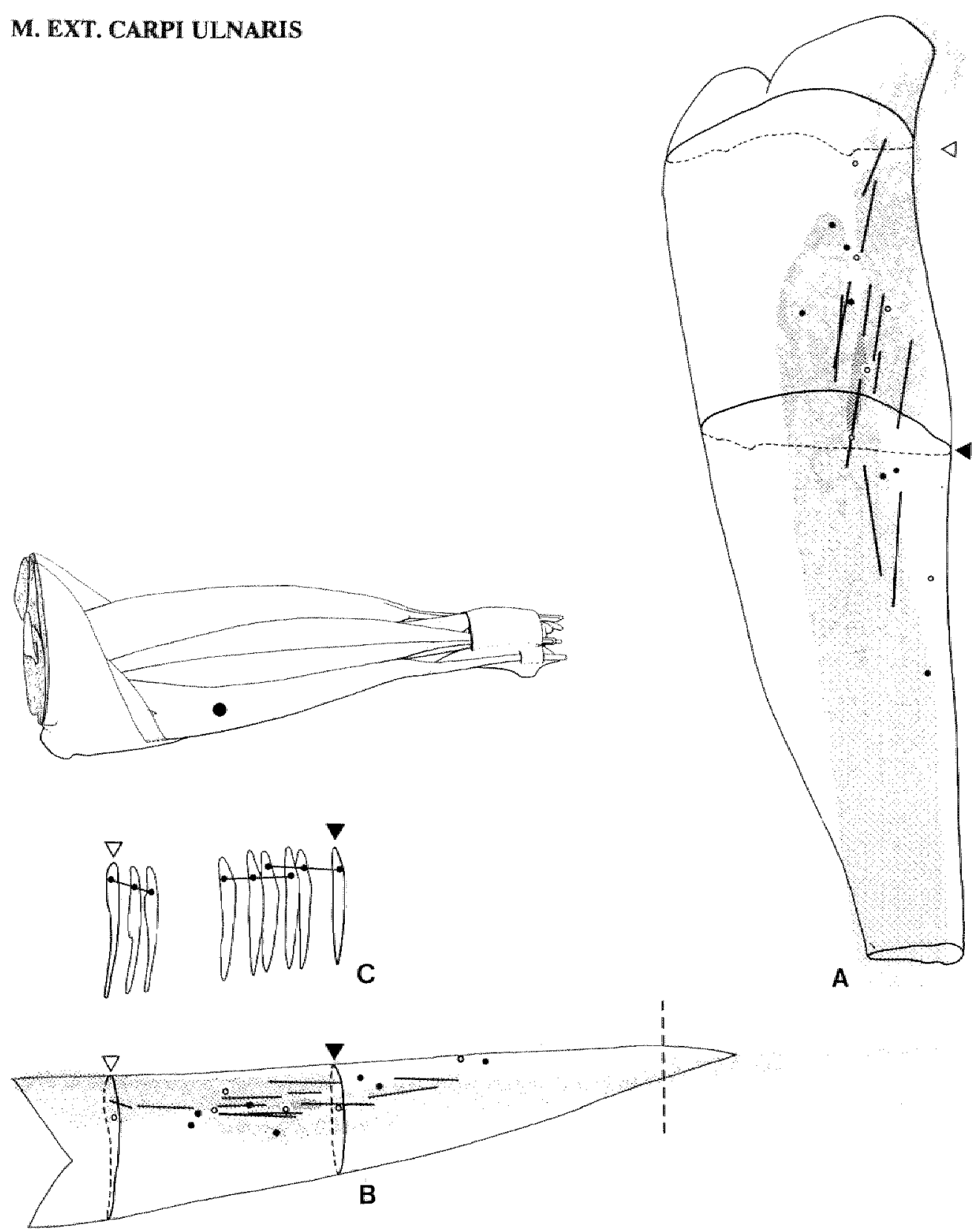

Figure $63 \mathrm{~A}$ to $\mathrm{C}$

Distribution of muscle spundle capsules and GTO's in relation to the proximal and distal regular dense collagenous connective tissue structures in the extensor carpi ulnaris muscle, based on graphic 3D-reconstruction of specimen Z2. For explanation see also par. 6.2 and general legend. 
In the extensor carpi uInaris muscle the eccentric distribution of the muscle spindles is obvious (figure $6.3 \mathrm{C}$ ). They are concentrated in that pennate muscular tissue zone that extends between the distal ECU tendon and the proximal ecu/edl.u-layer. The ulnar head of this muscle is completely devoid of muscle spindles and GTO's.

The majority of the spindles is attached with its proximal (extracapsular) pole to the proximal collagenous connective tissue layers, in particular the intramuscular extension of the ecu/edl.u-layer (non-quantified observations).

In particular in figure $6.3 \mathrm{~A}$ it is demonstrated that the spindles run obliquely in parallel to each other and that hardly any in line or in-series configuration exists between two successive or adjacent spindles. The GTO's in this muscle are attached in nearly equal numbers to the ecu/edlu-layer as well as to the distal tendon, mainly restricted to that area where the extrafusal muscle fibers of the spindle-rich zone also insert.

The distal GTO's are mainly situated at the inner side of the tendon i.e. that side that is directed towards the ullnar bone and the adjacent EDL muscle mass (figure 6.3 D).

Several dyad configurations between muscle spindles and GTO's may occur in the proximal as well as the distal muscle/connective tissue transitional area (cf. figure 6.3 D).
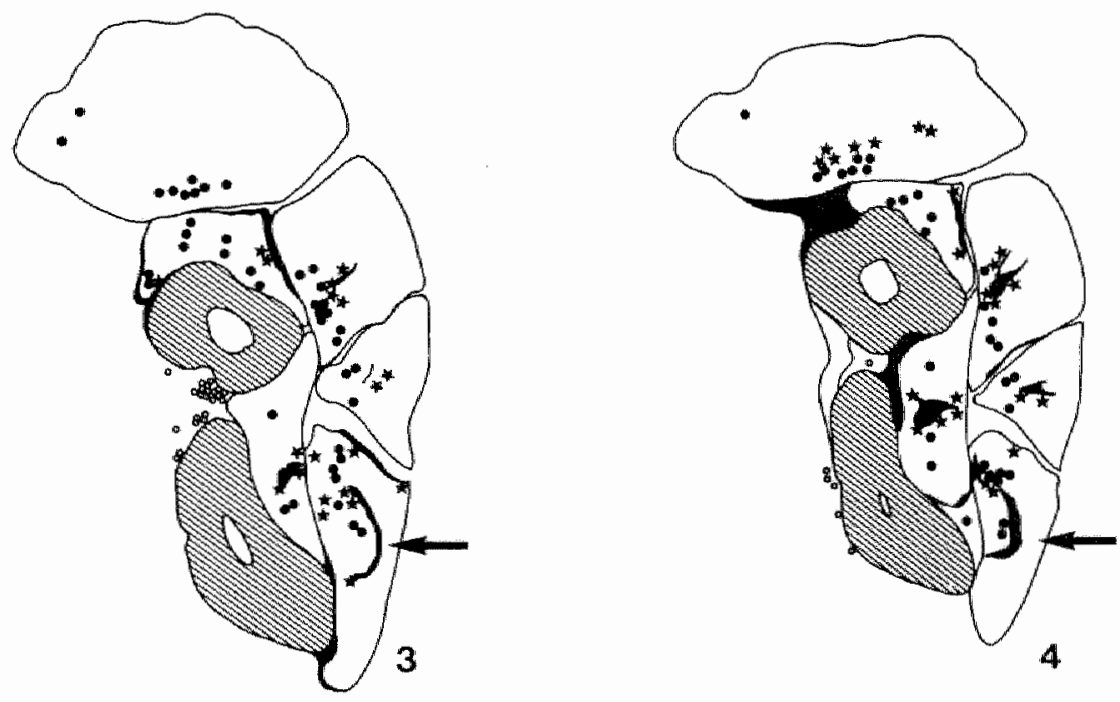

Figure 6.3 D

Section 3 and 4 of the summative projection of specimen B2. ECU muscle indicated. 

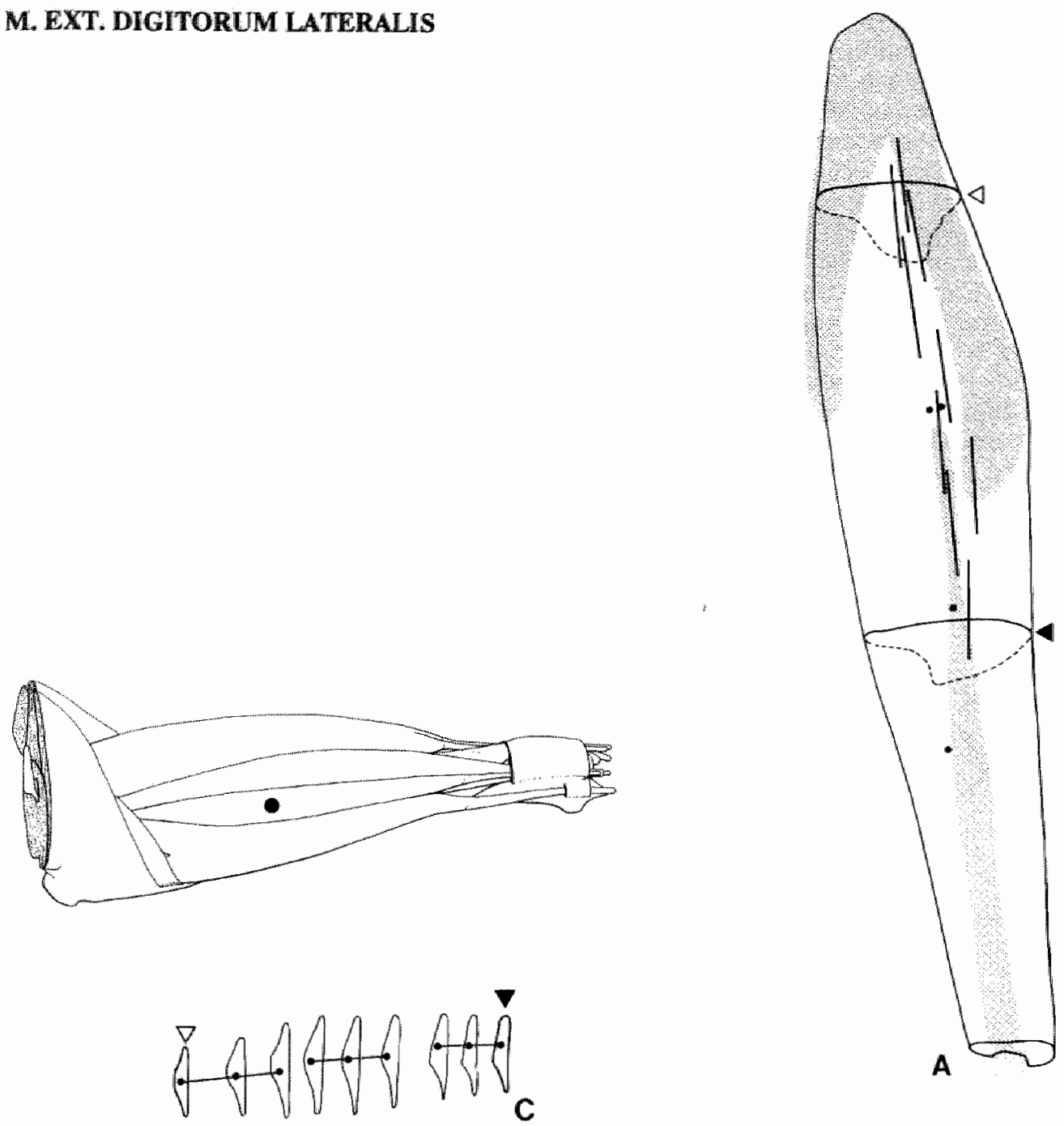

C

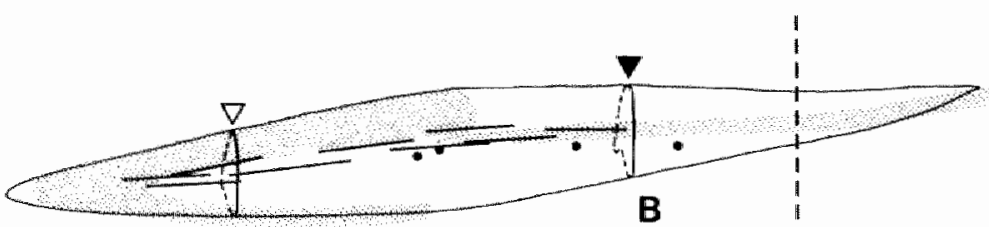

Figure $6.4 \mathrm{~A}$ to $\mathrm{C}$

Distribution of muscle spindle capsules and GTO's in relation to the proximal and distal regular dense collagenous connective tissue structures in the extensor digitorum lateralis muscle, based on graphic 3D-reconstruction of specimen $\mathrm{Z2}$. For explanation see also par. 6.2 and general legend. 
In the extensor digitorum lateralis muscle the distribution of muscle spindles is eccentrical, if related to the outlines of the EDL muscle mass (figure $6.4 \mathrm{C}$ ). In particular demonstrated in the summative projections, the muscle spindle zone is situated in the deep part of the muscle (figure 6.4 D). The spindles appear in a narrow elongated zone extended between the distal EDL tendon and the proximal edl/edc-layer (figure $6.4 \mathrm{~A}$ and $\mathrm{B}$ ) which proximally deviates towards the floor layer of the EDL muscle compartment (figure 6.4 D, section 3 ).

In this zone the spindles are mainly arranged longitudinally in line with each other. The elongated configuration of their spatial distribution is accentuated by the ex- istence of an in-series orientation between some spindles and by the (non-quantified) observation of spindle tandem configurations in some specimens.

The GTO's are all attached to the distal collagenous connective tissue layer. Very rarely a proximal GTO has been observed and if so, it was attached to the very proximal extension of the muscle compartment, where both adjacent intermuscular layers fuse. GTO's occur at both sides of the proximal extension of the tendon with preference for the deep side of it i.e. the part directed towards the ulnar bone (figure $6.4 \mathrm{D}$, section 4).
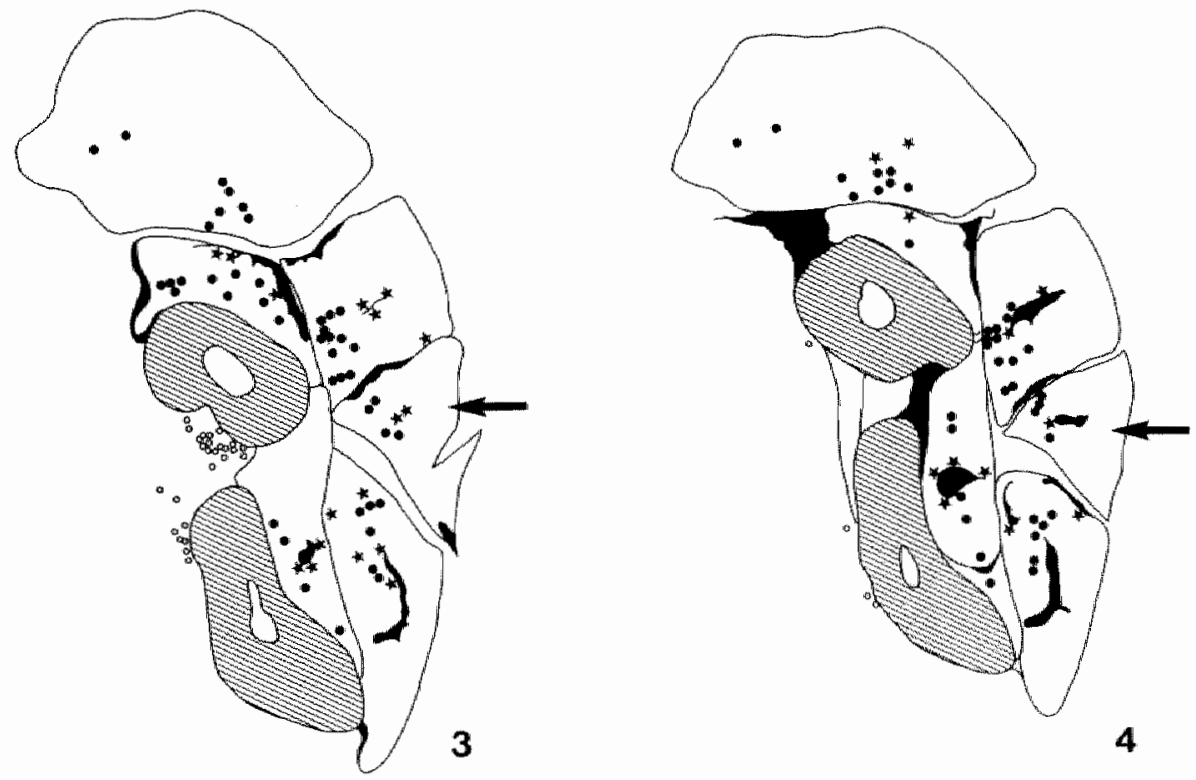

Figure 6.4 D

Section 3 and 4 of the summative projection of specimen C2. EDL muscle indicated.

- muscle spindle

$\star$ : GTO

$\circ$ : Pacinian corpuscle 
M. EXT. DIGITORUM COMMUNIS
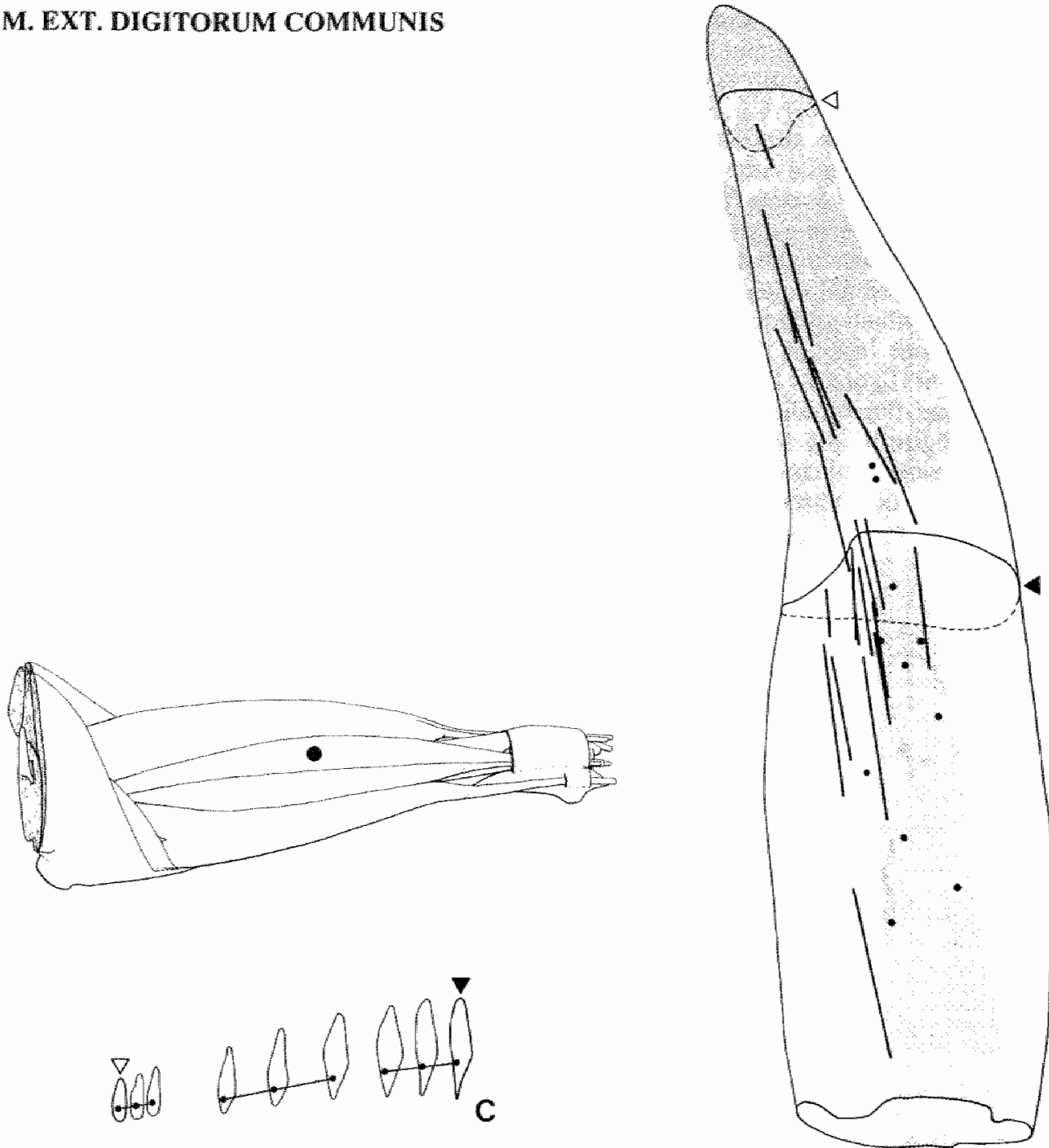

A

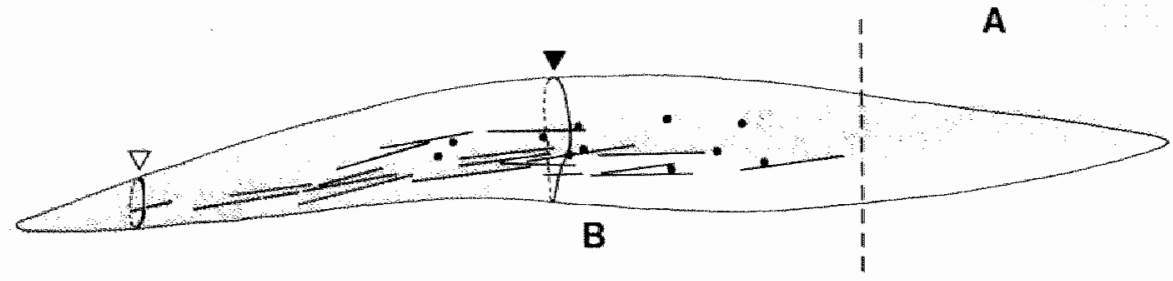

Figure 6.5 A to $\mathrm{C}$

Distribution of muscle spindle capsules and GTO's in relation to the proximal and distal regular dense collagenous connective tissue structures in the extensor digitorum communis muscle, based on graphic $3 \mathrm{D}$-reconstruction of specimen Z2. For explanation see also par. 6.2 and general legend. 
The distribution of muscle spindles in the extensor digitorum communis muscle is also uneven if related to muscle outlines (figure $6.5 \mathrm{C}$ ). The spindles are concentrated in the deep portion of the muscle with in particular proximally an orientation towards the edl//edc-layer (figure $6.5 \mathrm{D}$ ). The muscle spindles form an elongated zone - not as narrow as in EDL muscle -between the distal EDC tendon and the edl/edc-layer and directed towards the welldeveloped floor layer of the muscle compartment. In the relatively narrow proximal extent of the compartment sometimes a spindle might occur that is attached to the edc/ecr-layer. Distaily the spindle zone is oriented to both sides of the distal EDC tendon that (like the EDL tendon) is oriented in a plane longitudinally perpendicular to the long axis of the foreleg (cf. figure 3.16F). Within the zone the spindles are oriented mainly longitudinally in line (and in series) with each other.

The distal GTO's are attached to both sides of the flat proximal portion of the distal EDC tendon. Sometimes a proximal GTO is observed, mostly attached to the edl/edclayer (figure $6.5 \mathrm{D}$, section 4 ). Only in one case a GTO occurred at the proximal extension of the edc/ecr-layer just near its continuation with the floor layer of the EDC muscle compartment.
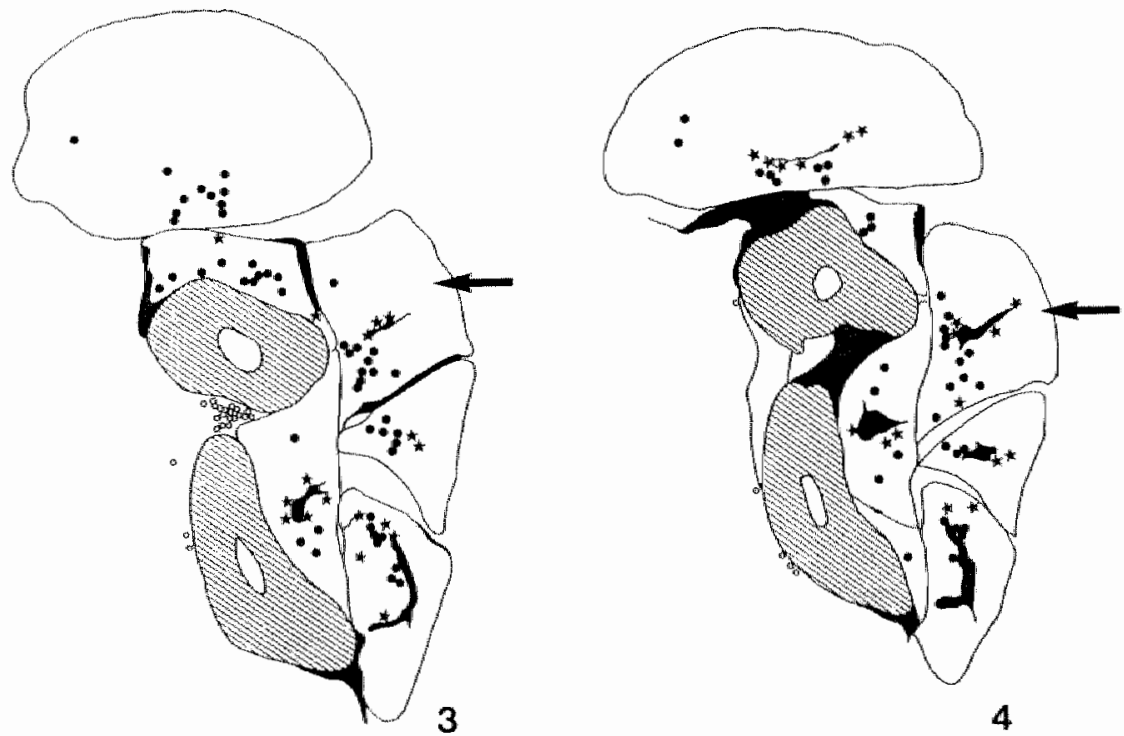

4

Figure $6.5 \mathrm{D}$

Section 3 and 4 of the summative projection of specimen A2. EDC muscle indicated.

- : muscle spindle

$\star$ : GTO

- : Pacinian corpuscle 

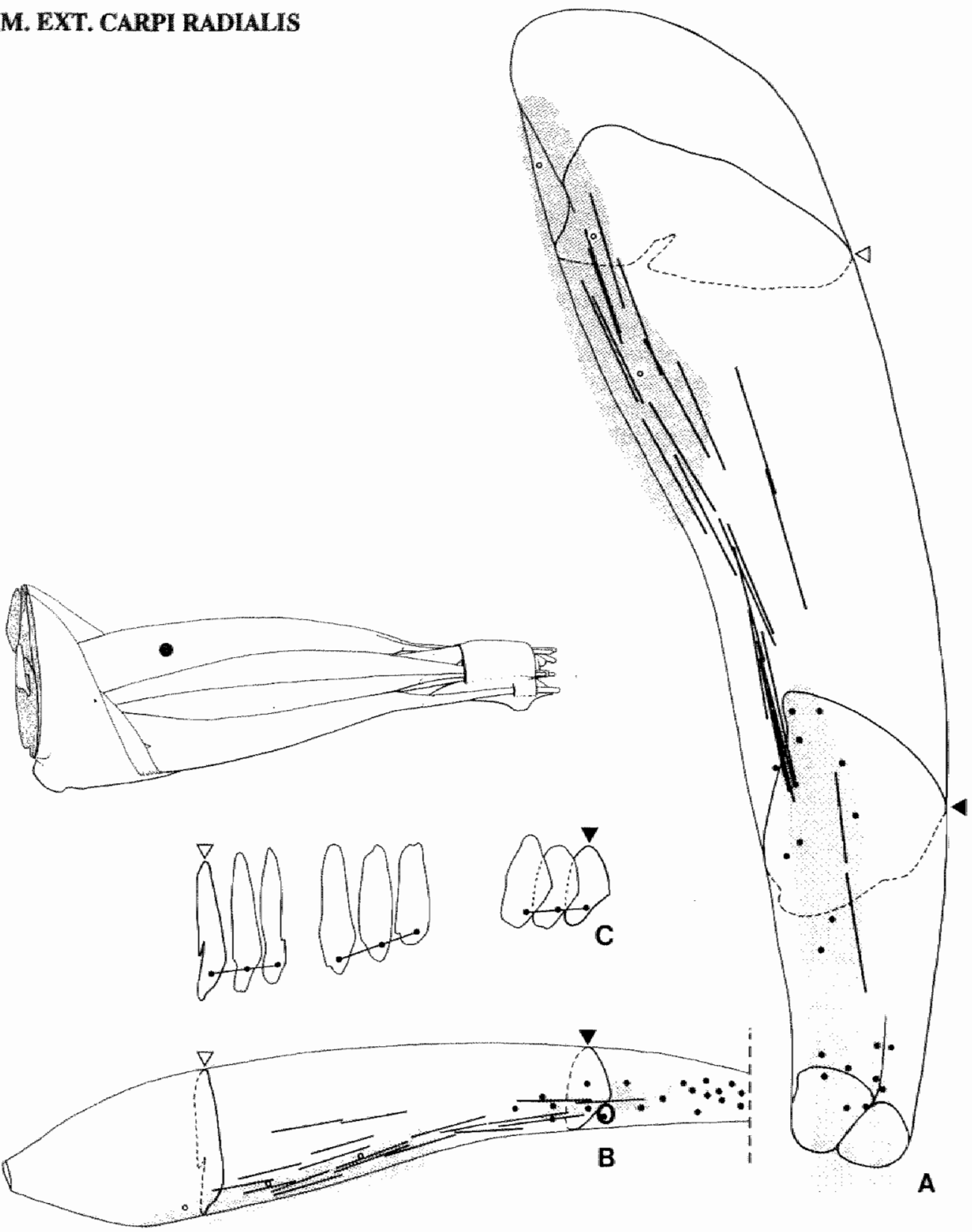

Fig. 6.6 A to C

Distribution of muscle spindle capsules and GTO"s in relation to the proximal and distal regular dense collagenous connective tissue structures in the extensor carpi radialis muscle, based on graphic $3 \mathrm{D}$-reconstruction of specimen Z2. For explanation see also par. 6.2 and general legend. 
The feature of uneven distribution of muscle spindles in a muscle in particular occurs in the extensor carpi radialis muscle (figure $6.6 \mathrm{C}$ ). In a relatively narrow elongated zone the spindles are concentrated at the side of the muscle that adjoins the EDC muscle. The great majority of them is situated in the muscular zone oriented between the distal ECR.br. tendon and the proximal edc/ecr-layer. In connection with the in-parallel rather than pennate orientation of the muscle fibers in this area, the spindles are mainly oriented in line and in-series with each other. Regularly a spindle tandem configuration has been observed (non-quantified observations). Only a few proximally situated spindles are attached to the muscle compartment wall (mainly edc/ecr-layer). The spindles in the midportion of the zone are not inserted to or directed towards the muscle compartment wall. The orientation of the spindle zone towards the adjacent EDC compartment is distinguishable in the proximal two sections of the summative projections (figure 6.1 and 6.2 and figure 6.6 D).

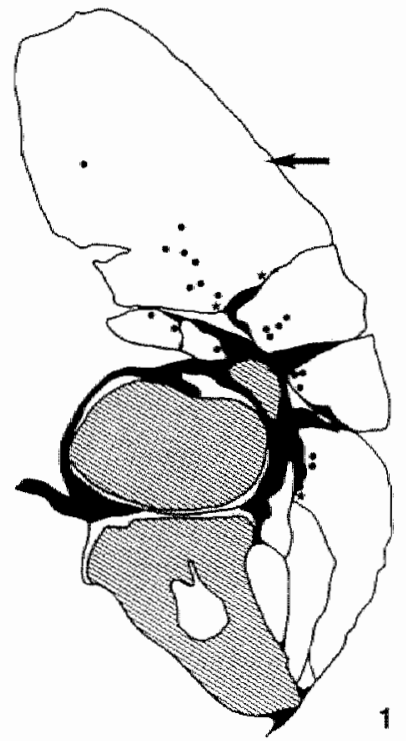

A remarkable feature is the occurrence of two muscle spindle zones (figure 6.6. A). A minority of the spindles is situated in a narrow elongated zone situated in the muscle portion that is organized in series with the ECR.lo. tendon. These muscle spindles are clearly distinguishable in the cross- sections of the summative projections (figure 6.1 and 6.2 and $6.6 \mathrm{D}$ ). Here spindle tandems are often observed. In all specimens the most proximal spindle of this cluster has never been observed in the proximal quarter of the muscle.

A small portion of the GTO's in this muscle area is attached to the edc/ecr-layer (e.g. figure $6.6 \mathrm{D}$ ). A relatively large part is attached to the distal tendons. The majority of those distal GTO's is attached to the ECR.br. tendon. In proximo-distal direction the muscular tissue zone rich in muscle spindles as a whole is situated in series with the muscle-tendon transitional area that is rich in GTO's (figure 6.6 A and B). Many GTO's are attached to the tendon distally beyond the level where the most distal muscle spindle capsule ends.

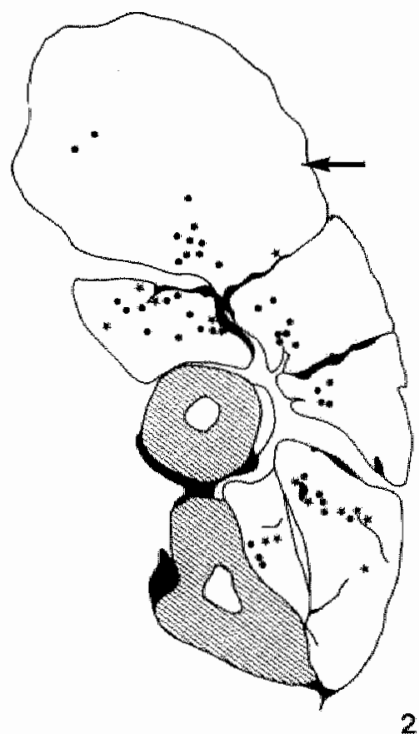

\section{Figure 6.6 D}

Section 1 and 2 of the summative projection of specimen Z2. ECR muscle indicated.

- muscle spindle $\quad$ : GTO $\quad$ :Pacinian corpuscle 

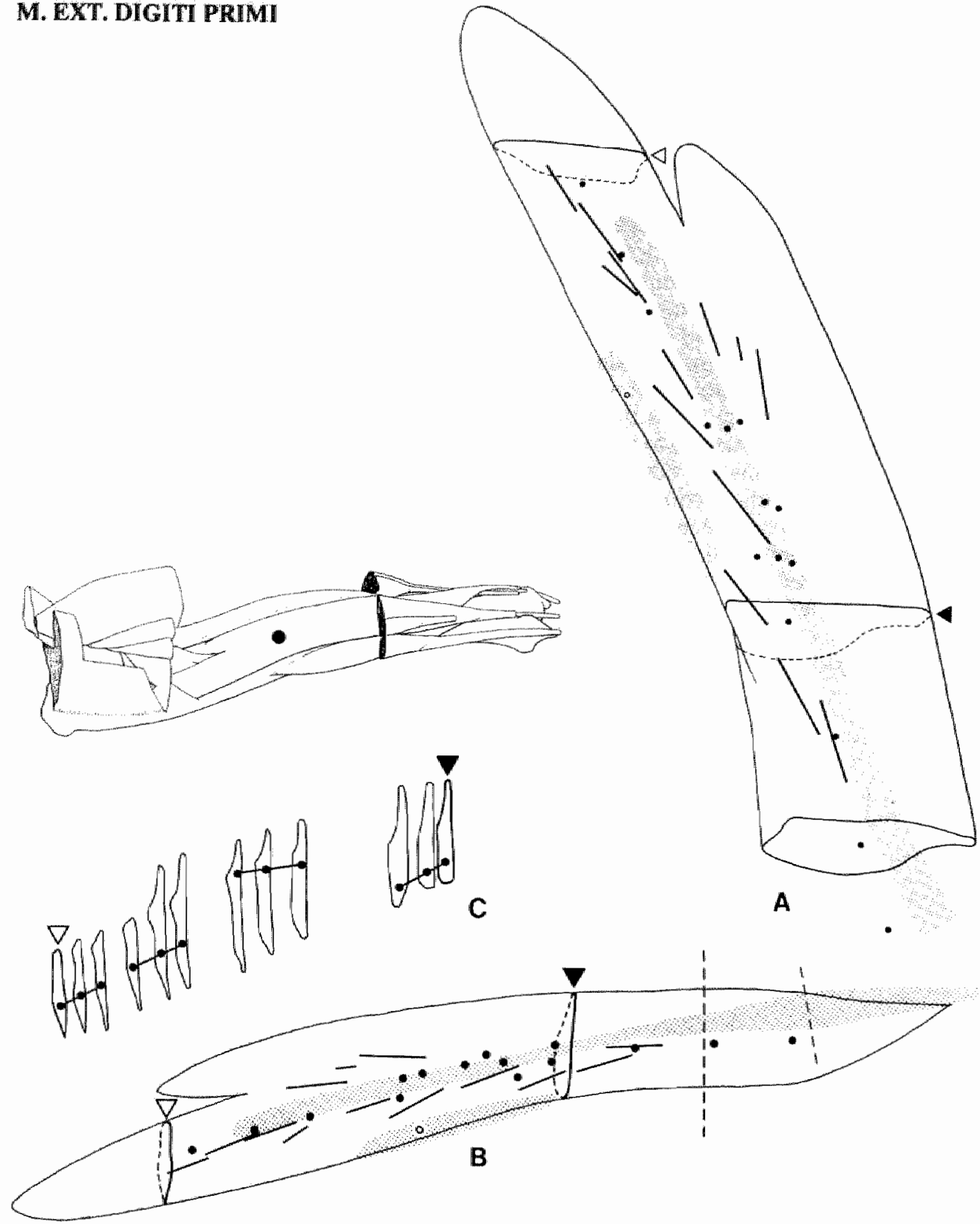

Fygure 6.7 to $\mathrm{C}$

Distribution of muscle spindle capsules and GTO"s in rellation to the proximal and distal regular dense collagenous connective tissue structures in the extensor digiti primi muscle, based on graphic 3D-reconstruction of specimen Z2. For explanation see also par. 6.2 and general legend. 
In the extensor digiti primi muscle the muscle spindles are not so obviously organized in eccentric zonation as may be described for the superficial extensor muscles. The spindles appear in a fan-shaped array (figure 6.5 A and B) with the distal pole of nearly all of them attached to the centrally situated distal EDP tendon (figure $6.7 \mathrm{D}$, section 3 ). Two rellatively short and flat muscle spindle zones can be distinguished coinciding with the ulnar and radial heads of the muscle (figure 6.7 $\mathrm{D}$, cf. figure 6.12). More spindles occur in the ulnar than in the radial zone. Both zones are proximally situated in the deep portion of the muscle i.e. oriented to the periosteal muscle compartment wall.

Nearly all GTO's occur at the distal tendon.
Here often dyads between a distal muscle spindle pole and a GTO are observed (figure $6.7 \mathrm{D}$, section 3 ). If a proximal GTO is present, it is attached to the small edp/eilayer to which sometimes muscle fascicles of the ulnar EDP head insert (e.g. figure 6.7 A, $B$ and D).

Though difficult to recognize in the sections of the summative projections - largely due to the irregular rounded shape of the central tendon - the GTO's can be described as situated on both the ulnar and radial side of the tendon (figure 6.7 D, section 4). Like in the distribution pattern in the ECR muscle, some GTO's are attached to the tendon distally beyond the level where the most distal muscle spindle capsule ends.
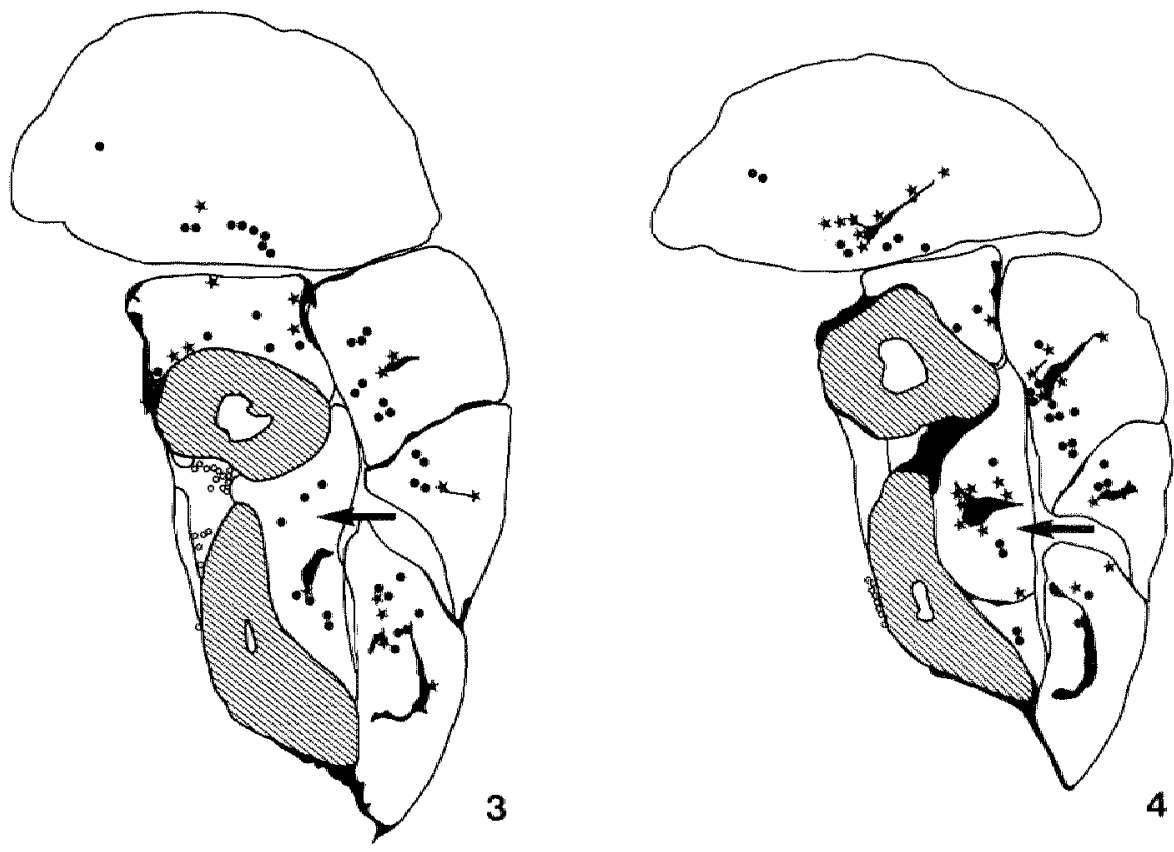

Figure $6.7 \mathrm{D}$

Section 3 and 4 of the summative projection of specimen Z2. EDP muscle indicated. 

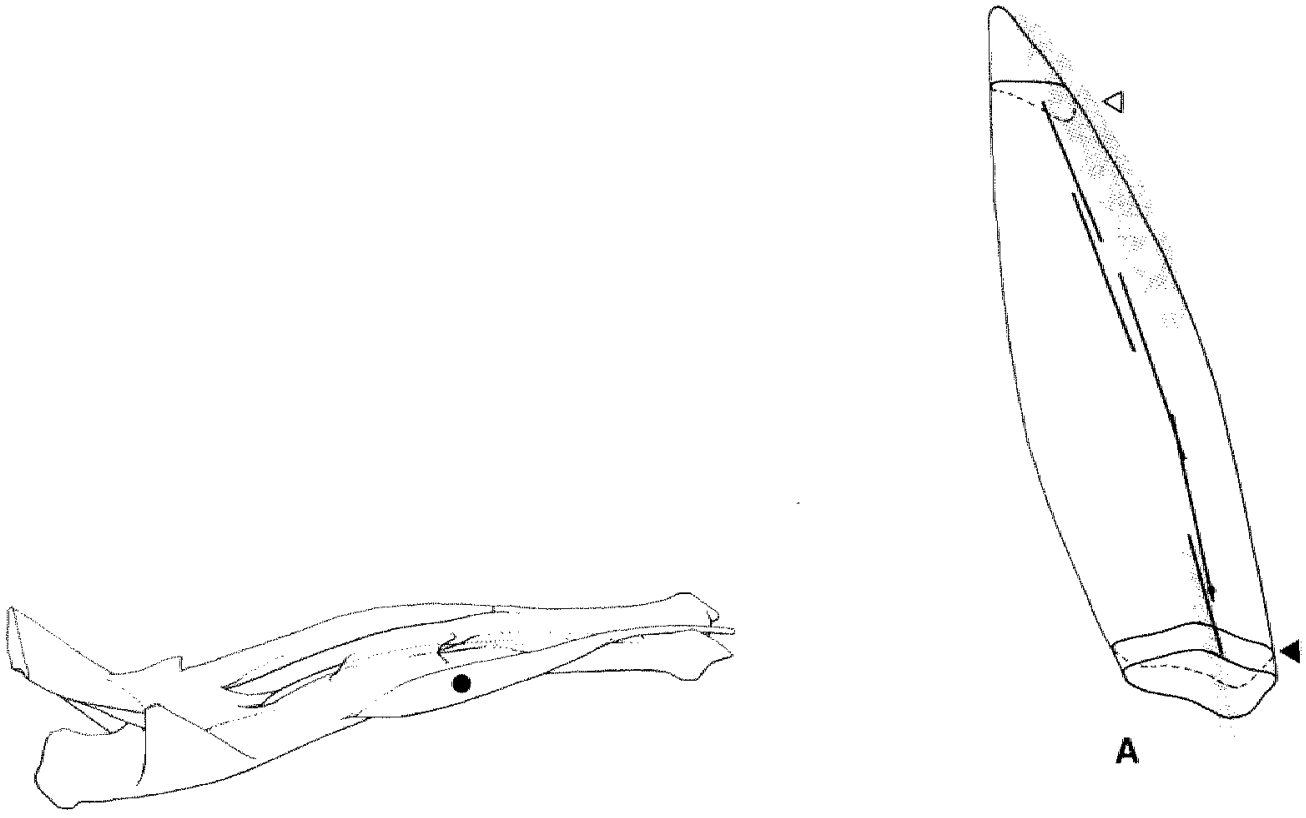

A
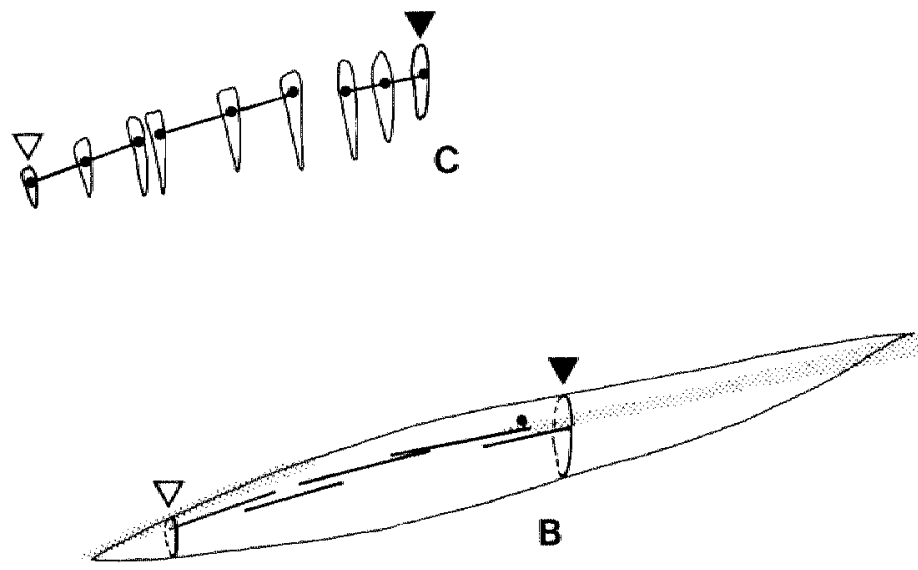

Flgure 6.8 A to C

Distribution of muscle spindle capsules and GTO's in relation to the proximal and distal regular dense collagen. ous connective tissue structures in the extensor indicis muscle, based on graphic 3D-reconstruction of specimen Z2. For explanation see also par. 6.2 and general legend. 
In the area of the extensor indicis muscle the muscle spindles occur in a narrow elongated zone of muscular tissue extended in the line of connection between its distal tendon and the proximal insertion of this muscle to the ulnar bone (figure 6.8 A and B). Proximally the zone is oriented to that side of the muscle insertion area where sometimes a collagenous connective tissue layer is present (edp/ei-layer) - as is the case in the specimen of figure 6.8 - i.e. in the deep muscle portion related with the (ulnar) periosteal compartment wall. This pairs with an eccentrical position of the zone with the outer or ulnar side of the muscle (away from the
EDP muscle) relatively devoid of spindles (figure $6.8 \mathrm{D}$ ). In two specimens (C1 and $\mathrm{C} 2$, cf. figure $6.8 \mathrm{D}$, section 4 ) a spindle is present that occurs in the ulnar portion of the muscle.

The spindles run mainly in line and inseries with each other like the spindles in the ECR.lo. zone (figure $6.6 \mathrm{~A}$ and B). Sometimes a tandem configuration between two spindles was observed (nonquantified observations). Hardly any GTO is present in this muscle area. If a GTO occurs, it is attached to the very proximal extension of the distal tendon (figure $6.8 \mathrm{~B}$ ).
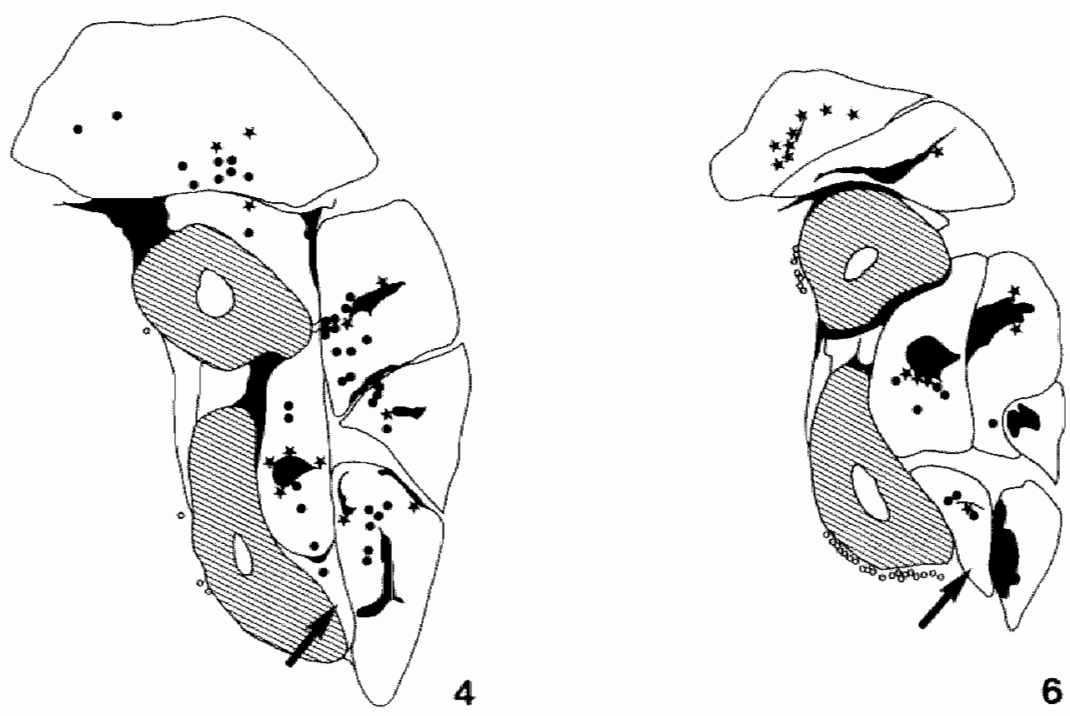

4

\section{Figure $6.8 \mathrm{D}$}

Section 4 and 6 of the summative projection of specimen $C 2$. EI muscle indicated. 

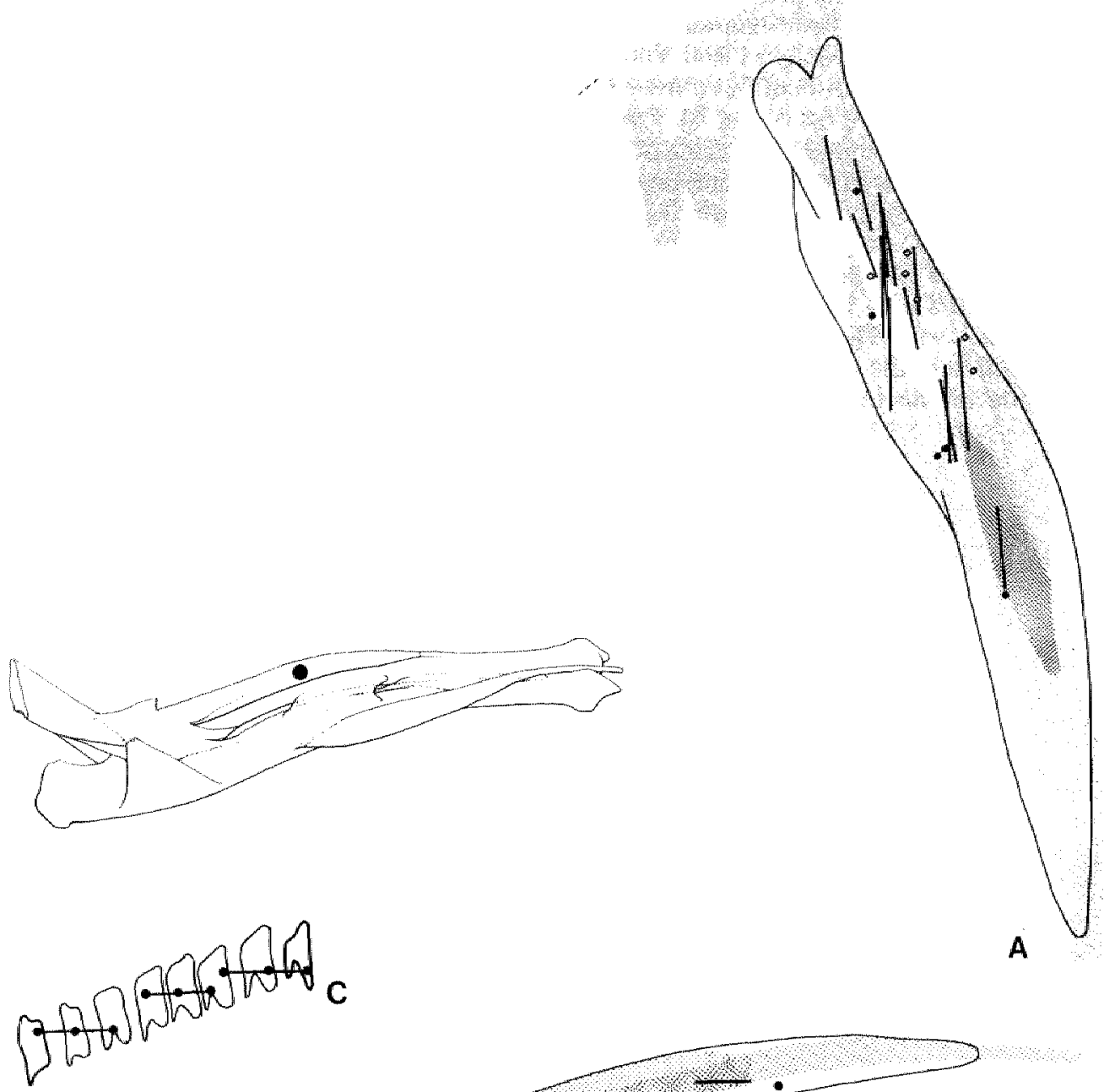

A

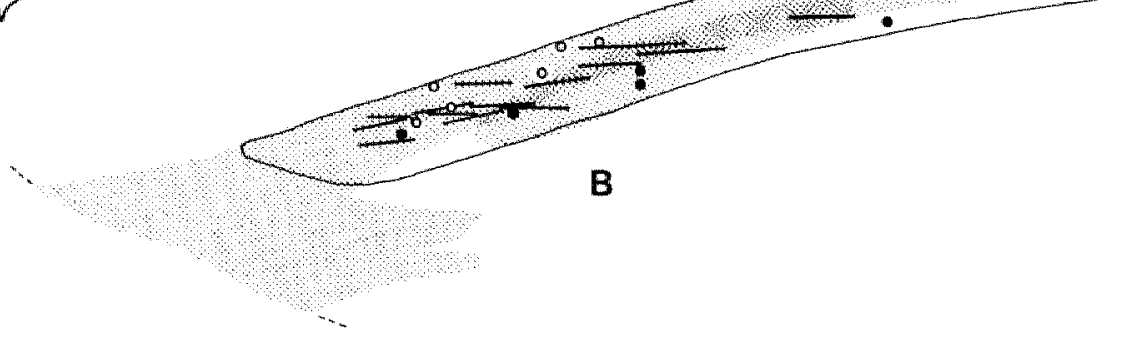

\section{Figure $6.9 \mathrm{~A}$ to $\mathrm{C}$}

Distribution of muscle spindle capsules and GTO's in relation to the proximal and distal regular dense collagenous connective tissue structures in the supinator muscle, based on graphic 3D-reconstruction of specimen $\mathbf{Z} 2$. For explanation see also par. 6.2 and general legend.

\section{6}


All muscle spindles in the supinator muscle area run obliquely in parallel to each other in a direction oriented obliquely to the transwerse plane of section (figure $6.9 \mathrm{C}$ ). Therefore a relatively large and broad area within the total muscular tissue mass should be regarded as muscle spindle zone. Most spindles occur in the proximal two third of the muscle. None of the spindles are situated in line or in series with an adjacent spindle.

The proximal poles of all spindles are attached to the supinator septum - i.e. to the muscle compartment wall of the ulnar muscle portion - including the intramuscular extension of this septum (figure $6.9 \mathrm{D}$, section 3). This is confirmed by the observations in serially cut silver stained (Spaethe) specimens of this muscle. Distally the muscle spindles are oriented towards and sometimes (non-quantified observations in in toto specimens of the foreleg) attached to the periosteum of the radial shaft or the distal aponeurotic tendon of the muscle (e.g. figure $6.9 \mathrm{D}$ ).

A large majority of the GTO's is directly attached to the supinator septum including its intramuscular extension (figure $6.9 \mathrm{D}$ ). All those proximal GTO's are concentrated in that part of septal regullar dense collagenous connective tissue to which muscle fascicles of the muscle spindle zone insert. Hardly any GTO is attached to the outer muscle compartment wall of the radial portion of the muscle. Dyad configurations between such a septal GTO and the proximal pole of a muscle spindle have been observed regularly (figure $6.9 \mathrm{D}$, section 2).

Distal GTO's are present at the periosteal layer of the raclial bone (figure $6.9 \mathrm{D}$, section 3) but are rarely observed to be attached to the distal SUP tendon (e.g. figure 7.1, section 4).
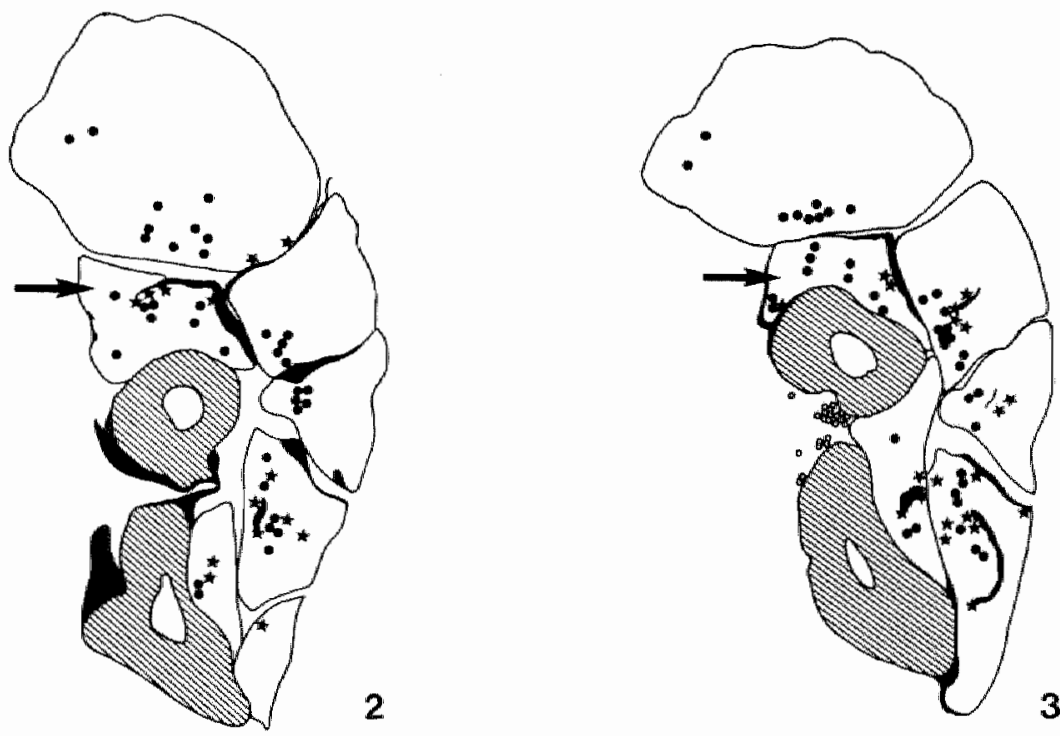

Figure $6.9 \mathrm{D}$

Section 2 and 3 of the summative projection of specimen B2. SUP muscle indicated.

- muscle spindle $\quad$ : GTO $\quad$ : Pacinian corpuscle 

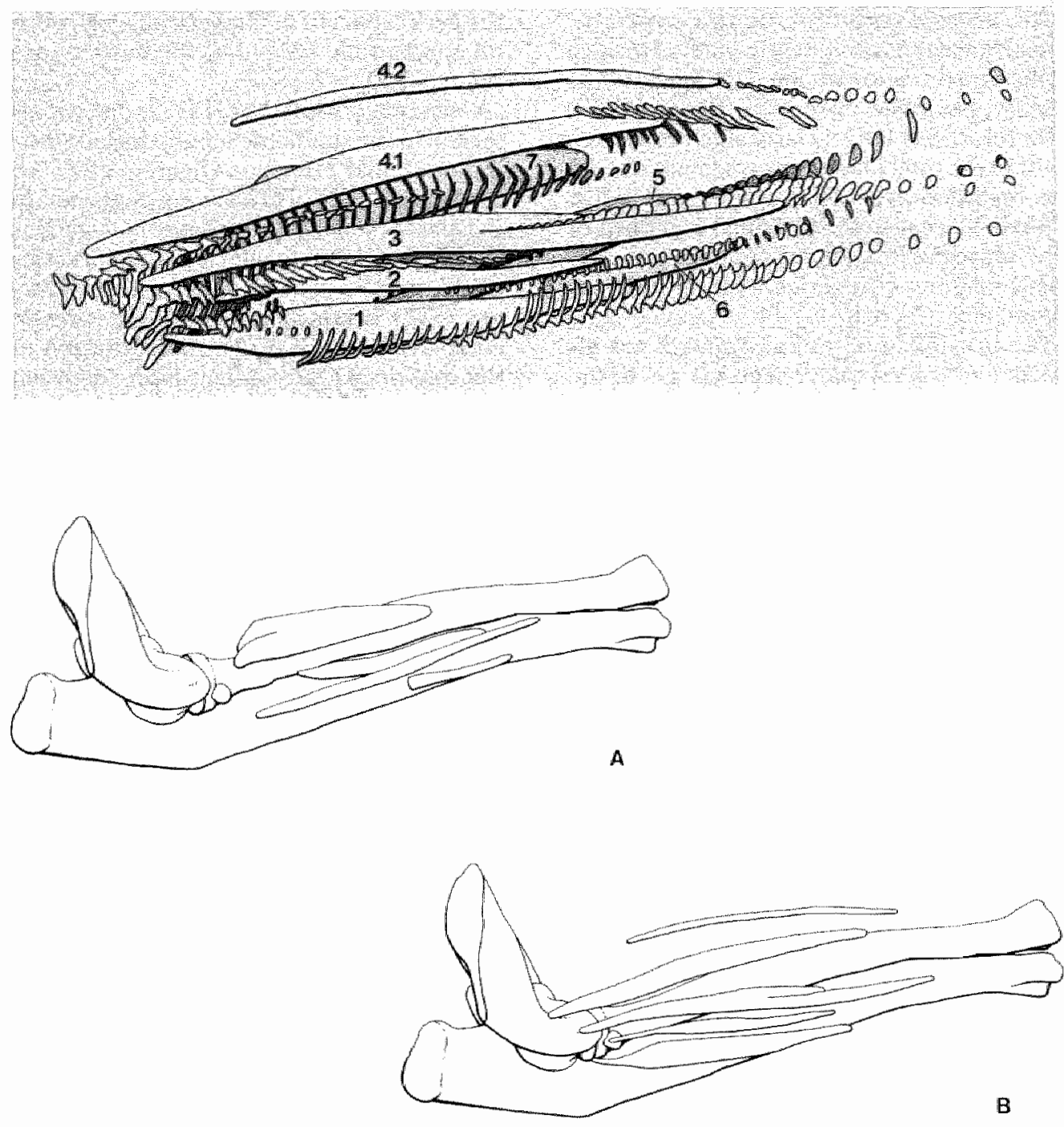

\section{Figure 6.10}

Muscle spindle/GTO zones in relation to the regular dense collagenous connective tissue structures. Lateral aspect of right foreleg. Three-dimensional graphic reconstruction based on specimen C1. Projection direction similar to that of figure $6.3 \mathrm{~B}$ to $6.9 \mathrm{~B}$.

Muscle spindle/GTO zones represented as separate structures with closed outlines (superfical zones white, deep zones grcyish). Regular dense collagenous conmective tissue structures are represented as series of sectioned outlines (superficial structures white, deep structures dark-grey). Numbers refer to related muscles.

$A$ and B: projections of muscle spindle/GTO zones in relation to the skeleton of the foreleg. Same aspect. 


\subsubsection{Occurrence of muscle spindle/GTO zones considered regionally}

Proximally the ECU, EDL, EDC and ECR.br. muscle spindle/GTO zones are oriented to the floor and intermuscular layers of the concerned muscle compartment walls (figure 6.10). The ecu/edl-layer and edc/ecr-layer serve as a unilateral proximal orientation point for adjacent spindle/GTO zones, the edl/edc layer as bilateral orientation point (cf. figures 6.4 and 6.5). Distally the ECU zone and the ECR.br. zone are related to the inner side of the distal tendons (directed towards the foreleg bones). The EDC zone distally has a bicipital appearance related to its orientation to both sides of the distal tendon (cf. figure 6.5) and the EDL zone takes an intermediate position in this respect with the muscle spindle/GTO zone distally mainly oriented to the EDC side of the distal EDL tendon.

The main proximal orientation center for the SUP muscle spindle/GTO zone is formed by that part of the outer SUP muscle compartment wall that is congruent with the supinator septum, including its intramuscular extension. This latter finding explains the bicipital appearance of the SUP muscle spindle/GTO zone in three-dimensional graphic reconstruction (figure 6.11). In the representation of the SUP muscle spindle/GTO zone in medial view (figure 6.11 ) - with the radial bone not represented - it is shown that distally the outline of this zone mainly adjoins the radial periosteal layer.

Of all four superficial antebrachial extensor muscles the outer areas of the muscular tissue are devoid of muscle spindles. This in particular regards the mid belly region of the muscles. In the very proximal extension where these muscle compartments narrow, this two-partioning in spindle-rich and spindle-poor zones is less prominent (cf. figure 6.1 and 6.2 , sections 1 to 4 ). The outer ulnar respectively radial portions of the ECU respectively ECR muscle, situated in the proximal cubital region, are devoid of muscle spindles (cf. figure 6.3 and 6.6). In the distal region there exists a small muscle spindle/GTO zone in the radial portion of the ECR muscle area that is not oriented towards the humeral epicondyle like the other four superficial nuscle spindle/GTO zones. The ulnar portion of the ECU muscle is devoid of muscle spindles and GTO's also in the distal region.

In the proximal region the muscle spindles and proximal GTO's in the ECU, EDL, EDC, ECR and SUP muscle masses, are oriented towards the main components of the epicondylar connective tissue apparatus. For the first four muscles this also means towards the floor layers of these muscle compartment walls, for the SUP muscle this also means towards the outer muscle compartment wall. In the four superficial muscles the zones converge to the edl/edc-layer. Summarizing, the muscle spindles in those muscles are mainly concentrated in the muscular tissue areas of the epicondylar muscle/connective tissue unit. Muscle portions in the proximal region that are related to skeletal elements (ulnar shaft and humeral epicondylar crest) are devoid of muscle spindles.

In the distal antebrachial region the superficial muscle spindle/GTO zones are situated in that part of the superficial muscles that connects the distal connective tilssue apparatus (tendons) with the epicondylar connective tissue apparatus.

The narrow muscle spindle/GTO zone in the ECR muscle organized in series with the ECR.lo. tendon, is mainly situated in the distall extension of that muscular tissue zone of the ECR that is not part of the epicondylar unit and is not converging to the epicondylar connective tissue apparatus. In the zone of the ECU muscle that does not belong to the epicondylar unit (ECU.uln.), muscle spindles and proximal as well as distal GTO's - the latter hypothetically to be attached to the outer side of the distal tendon - are absent. 

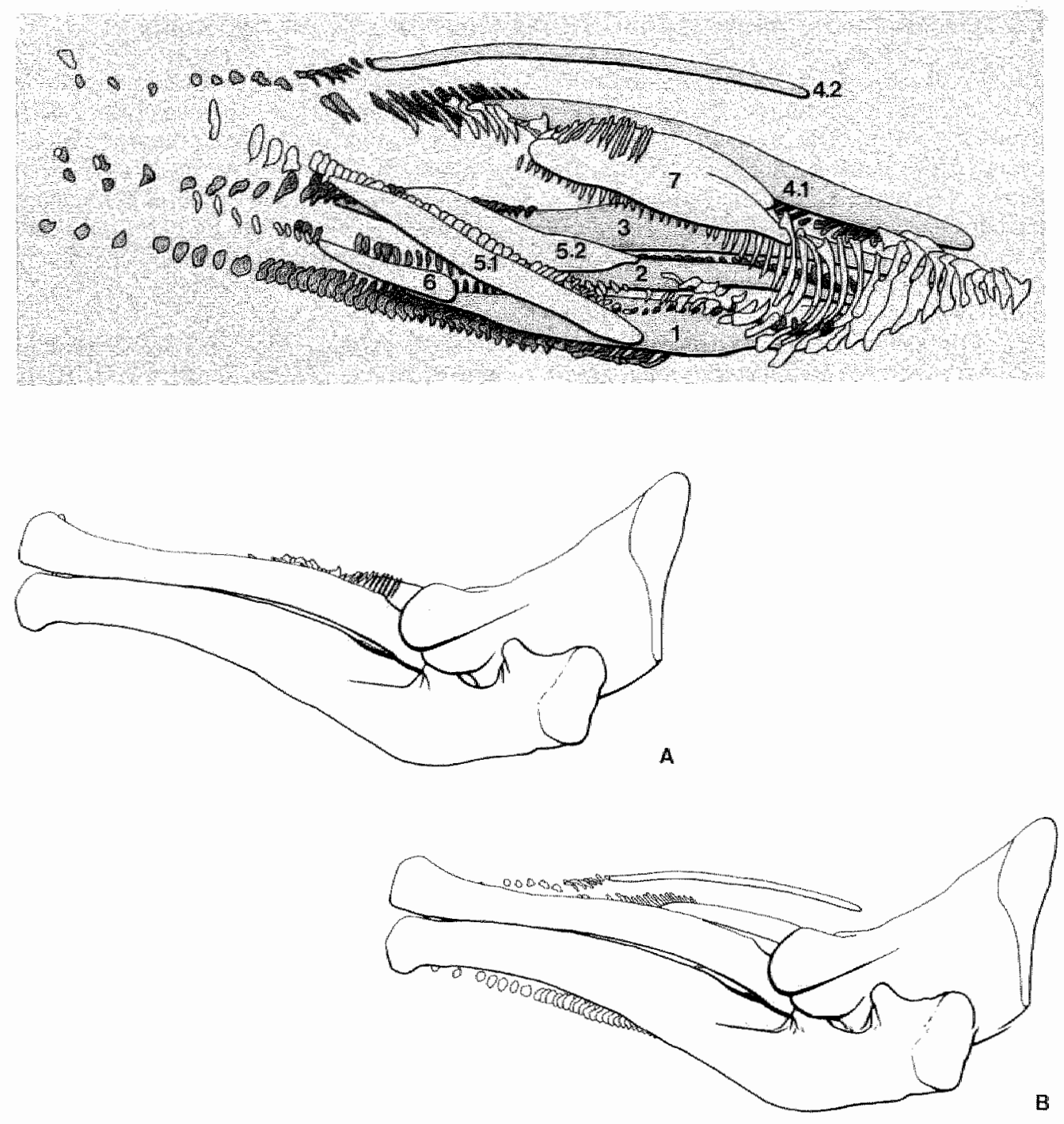

Figure 6.11

Muscle spindle/GTO zones in relation to the regular dense collagenous connective tissue structures. Medial aspect of right forcleg. Three-dimensional graphic reconstruction based on specimen C1. Projection direction 180 to that of figure 6.10 .

Muscle spindle/GTO zones represented as separate structures with closed outlines (deep zones white, superficial zones greyish). Regular dense collagenous connective tissue structures represented as series of sectioned outlines (deep structures white, superficial structures dark-grey). Numbers refier to related muscles.

$A$ and $B_{*}^{*}$ projections of muscle spindle/GTO zones in relation to the skeleton of the foreleg. Same aspect. 
In the EDP muscle the spindles are concentrated in two zones corresponding with the two muscular tissue portions (EDP.uln. and EDP.rad.) oriented to the periosteal muscle compartment wall i.e the deep portion of the muscle. The GTO's in this muscle are mainly distal and related to the centrally situated distal tendon (cf. figure 6.7). In the EI muscle a small elongated zone extends mainly between proximal (edp/ei-layer) and distal collagenous connective tissue (tendon) i.e. to the side of the muscle area related to the (ulnar) periosteal compartment wall. In specimen C1 (figure 6.11) the edp/ei-layer is absent and proximally a muscle spindle occurs in the outer muscle area (cf. figure 6.1 , section 5 ). Therefore the EI muscle spindle/GTO zone in figure 6.11 is not as elongated as in figure 6.8 . 


\subsection{Discussion}

\section{Zonation of receptors in muscles}

Regarded per muscle area, in all antebrachial extensor muscles an uneven distribution of muscle spindles exists. In the EDL, EDC, ECR and EI muscles the spindles are (more or less) concentrated in elongated zones. In ECU and EDP, and in particular in SUP muscles the spindle-rich zomes are relatively broader. In ECR and ECU.uln. muscles the proximal portion is devoid of muscle spindlles. In all superficial extensor muscles the spindle-rich zones are (at least proximally) situated in the deeper portion of the muscle area.

Since uneven distribution of muscle spindles over a muscle area is a regular finding rather than an exception, several hypotheses have been put forward to explain such zonation of muscle spindles.

According to some authors (Hagbarth and Wohlfart, 1952; Barker and Chin, 1960; Chin et al., 1962; Barker, 1974; Zelena and Soukup, 1979; Scott and Young, 1987) muscle spindles are present by preference in the immediate vicinity of the major intramuscular nerve branches. From developmental (Milburn, 1973, 1984) and experimental studies (Zelena, 1957, 1963; Soukup and Zelena, 1977b, 1985) it is known that the presence of an intramuscular sensory nerve ending during musculogenesis plays an important role in the "induction" of muscle spindles and GTO's. These findings suggest a causal relation between the intramuscular nerve branching pattern and the occurrence of muscle spindles, but still do not explain the apparently uneven distribution pattern of la nerve fibers connected with muscle spindles. Yellin (1969) states that the changes in relative proportions of the muscles related to outgrowth of the skeletal system during development, form the main factor for uneven distribution of Ia sensory endings.

The uneven spindle distribution in muscles has been suggested to result in a "weighed" signal which monitors movements in some muscle regions more sensitively than in others (Botterman et al., 1978; Binder and Stuart, 1980; Richmond and Stuart, 1985). Since spindles do not fire during fast contractions (Prochazka et al., 1979) this selective sensitivity may be considered as mainly involved in monitoring the stretching of the muscular tissue areas in which the spindles are concentrated. Voss $(1956,1958)$ relates the spindle content of muscles to the extent to which those muscles are subject to passive strain.

Careful histochemical analysis of limb muscles (Burke et al., 1973; Gonyea and Ericson, 1977; Galvas and Gonyea, 1980; English and Letbetter, 1982b; Erikson and Thornell, 1987) has revealed that the composition of muscles is not homogeneous. Different regions of muscles may have different histochemical composition associated with a differential distribution of muscle fibres into slow-twitch and fasttwitch regions. From these and other studies (Yellin, 1969; Botterman et al., 1978; Maier, 1979) it may be concluded that if a muscle shows segregation of slow-oxydative fibres, the present muscle spindles are associated with this SO fiber zone. Moreover, SO fiber zones are often found in close association with tendons of origin and insertion (Gonyea and Ericson, 1977; Galvas and Gonyea, 1980). Other authors state the existence of "sensory partitioning" of muscles based on the observation that proprioceptors are particularly sensitive to the activity of nearby motor units and may even react to the contraction of a single motor unit, unless this motor unit is in its direct surrounding (Meyer-Lohmann et al., 1974; Binder et al., 1976; Cameron et al., 1981; English and Weeks, 1984). It seems appropriate that the muscle spindles and tendon organs are optimally concentrated in that areas in which they may respond to small strains as well as to contractions of the whole muscle. It is postulated (a.o. Botterman et al. ,1978) that the regions with high oxydative index and 
spindle density are involved in contractions associated with fine movements and postural adjustment. Conversely, regions with a high percentage of $\mathrm{FG}$ fibres and a low spindle density would be restricted to relatively coarse and powerful movements. During grading development of muscle force first the type $\mathrm{S}$ motor units (composed of SO fibers) are recruted, while the motor units containing FG fibers (FF type) are only used for forceful contractions (for review: Burke, 1981). So the S type motor units being associated with the receptor rich core in the muscle as well as FF units being present in such an area, explains the aforementioned two-xway-sensitivity or responsiveness of the receptor-rich zone and results in a kind of weighed afferent signal which monitors movement in some muscle regions more sensitively than in others (Botterman et al., 1978; Binder and Stuart, 1980; Richmond and Stuart, 1985).

The close association of muscle spindles and SO fibres (i), the differential distribution of muscle fibres into slow-twitch and fast-twitch regions(ii), the architectural relation of the SO zone with connective tissue structures (iii) and "sensory partitioning" (iiii), allow muscle regions to function rather independently of one another when performing different tasks e.g in the conveying of tensile stresses.

English and Letbetter (1982b) and Weeks and English (1985) extended this concept of histochemical compartmentalization by revealing the existence of neuromuscular compartments that include the sensory compartments (English, 1985). Distinct muscular subvolumes were found to be innervated with a separate primary nerve branch, while the la fibres from the spindles in a given muscular subvolume course in the muscle nerve branch of that compartment. So, restricted areas of a muscle may be involved in small finely-controlled movements, while other parts of a muscle produce larger forces with less control by muscle spindles (English, 1985). This also regards excentric or static (force resisting) activity of muscles including the effect of "agonist" muscles on the "antagorist" region. The oxydative and/or spindle-rich region may be considered as the length-changemonitor zone, the glycolytic and/or spindlepoor region as the length-change-resisting zone.

A preliminary study was carried out on two series of the antebrachial extensor muscles under study, stained for ATP-ase (Lojda, 1976). Of the superficial extensor muscles, segregation of SO muscle fibers was clearly distinguishable in ECU and ECR muscles (figure 6.12A). They coincide with the muscle spindle/GTO zone in the considered muscle: the ECR muscle even exhibits a large and a small SO fiber area corresponding with the two spindle zones in this muscle. The SO fiber zone in the ECU muscle is situated in the muscle portion adjacent to the ecu/edl.u-layer (figure 6.12A). In EDL and EDC muscles zonation of SO fibers occurs (in the deeply situated muscle portion), but is obscured since the relative amount of those fibers is much smaller than in ECU and ECR muscles (figure 6.12A). In particular in the EDC muscle, SO fibers are hardly detectable.

In EDP muscle SO fibers are present, scattered throughout the muscle area. In the distal extension of the muscle they are confined to the ulnar portion of the muscle (figure 6.12B). The distribution of SO fibers in the SUP muscle displays a similar pattern as in EDP muscle with a preference for the ulnar portion of the muscle (figure 6.12C). This is interpreted as in accordance with the fact that in the latter two muscles the spindles (and GTO's) are distributed over a relatively large area. Only a few SO fibers are present in EI muscle - the relative amount is comparable to the situation in EDL and EDC muscle -. If they are present in sections, they appear in the radial part of the muscle i.e. in the area of the muscle spindles (figure 6.12B).

These preliminary results seem to fit with findings in literature, but would require more accurate histochemical analysis of fibers and motor units. 


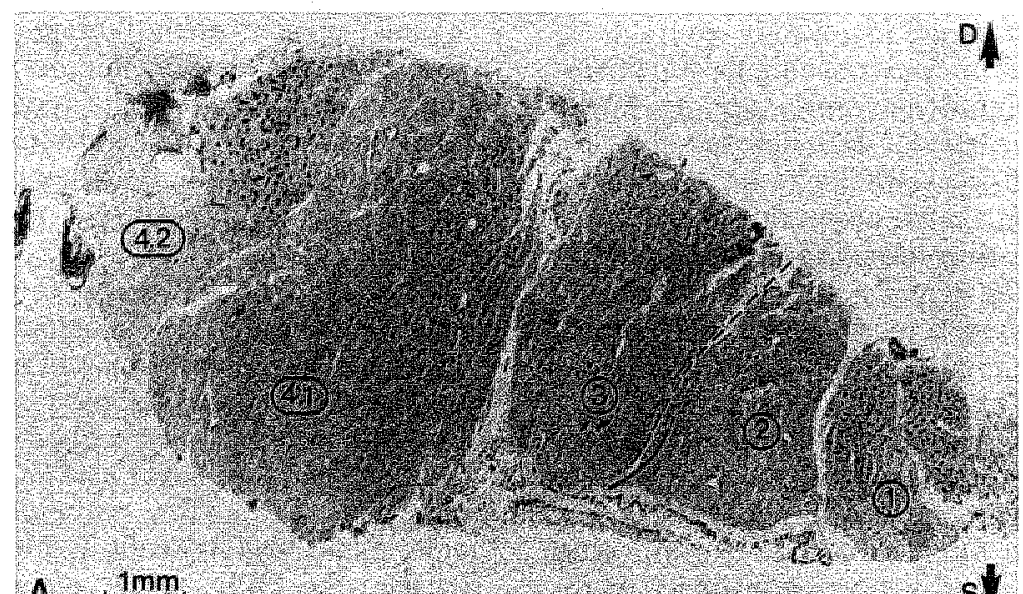

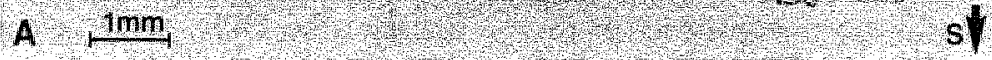

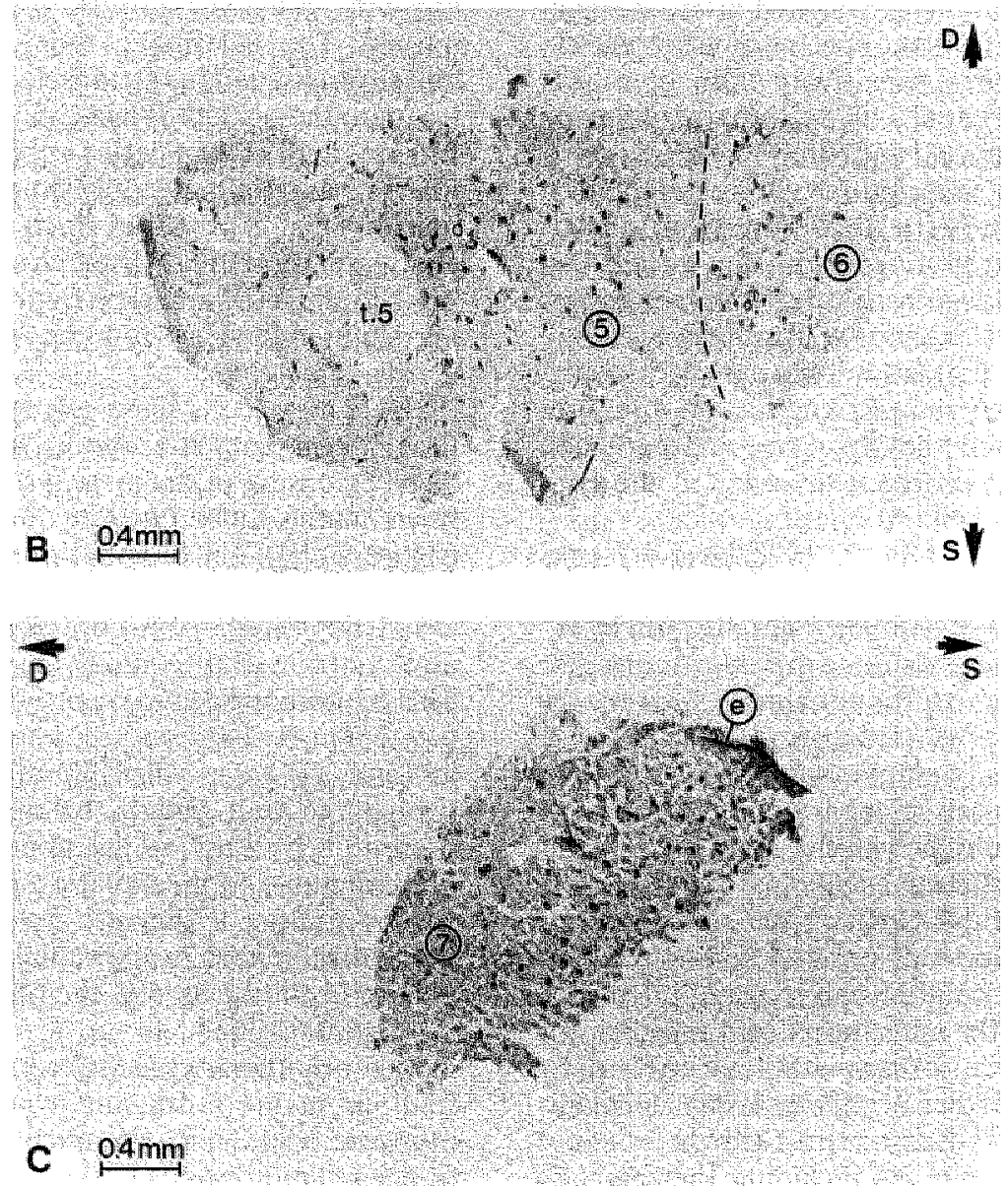


Distribution of receptors per muscle and considered regionally

The collagenous connective tissue apparatus may be considered as one of the major compartmentalization principles in the regional architecture studied here. In ECU, EDL, EDC and ECR.br. (and often EI) muscles the zone extends between a proximal and a distal regular dense collagenous connective tissue structure, in EDP and SUP (and sometimes EI) muscles between a distal or proximal collagenous connective tissue structure on the one hand and periosteal connective tissue on the other hand. In ECR.lo. muscle the zone is organized in series with only a distal collagenous connective tissue structure and is absent in the proximal muscle portion that is attached to the humeral periosteum. If the spatial distribution of muscle spindles in the region studied here is considered per muscle, it is difficult to detect a common factor that relates evidently to the distribution pattern in all muscles. It is hypothesized that relating the spatial distribution and orientation of the spindles - including the distribution of GTO's - to the regional architecture of the muscular tissue in-series with regular dense collagenous connective tissue structures, provides a common principle that may explain all kinds of distribution patterns present in the region.

Most studies on the distribution of muscle spindles and GTO's are based on muscles taken out separately. The relation that exists within a given muscle between distribution and organization of muscle spindles and auxilliary connective tissue structures of the muscle - including periosteal attachment - has been noted by many authors (Swett and Eldred, 1960a; Wohlfart and Henriksson, 1960; Eldred et al., 1962; Arendt and Asmussen, 1974; Lund et al., 1978; Lennartson, 1980b; Richmond and Bakker, 1982; Richmond and Stuart, 1985; Bout, 1987). Eldred et al. (1962), Bakker and Richmond (1982) and Richmond and Stuart (1985) for instance, describe the occurrence of series of tandem spindles bridging the complete distance between proximal and distal tendon of origin. But when, for instance, Richmond and Stuart (1985) mention the "notable" presence of GTO's at the tendons of origin in the cat flexor carpi ulnaris muscle and a "surprising absence of muscle spindles on the radial side of the tendon of origin", this finding would be more meaningful if the occurrence of similar receptors in the adjoining muscle area could have been taken into account. Similar considerations may be applied to the data of Swett and Eldred $(1960 \mathrm{a}, 1960 \mathrm{~b})$ on spindle and GTO distribution in gastrocnemius and soleus muscles; they describe differences in muscle spindle distribution between those muscles that are not fully deductable from (intra)muscular architecture.

In the studied joint region for instance the spindle-poor regions in the superficial extensor muscles all appear in the outer portion of the muscles. In the ECU and EDL muscle the spindle zone is oriented to the muscle compartment wall at the radial side, in EDC and ECR musclle the zones are oriented to the ulnar side. This configuration becomes understandable in view of the converging architecture of the epicondylar connective tissue apparatus - with edl/edclayer as a kind of "center layer" - and would have been obscured if the muscles would

\section{Figure 6.12}

Sections of antebrachial extensor muscles stained for ATP-ase (pre-incubation at pH 4.3). The type I fibers are stained black. D: deep side. S: superficial side. Muscle outlines partly indicated by a broken line.

$6.12 \mathrm{~A}$ Sections of the four superficial antebrachial muscles (1-4).

6.12B Section of EDP (5) and EI (6) muscles.

$6.12 \mathrm{C}$ Section of SUP muscle (7) and supinator septum (e). 
have been studied separately. Following similar considerations, the distribution pattern of spindles within the ECR muscle entity is more meaningful if it is taken into account that not only a distal morphologically distinguishable bicipital organization of the muscle (as entity) exists, but also that proximally the muscular tissue is incorporated into two different architectural units of muscular tissue.

Regarding muscle spindle and GTO distribution "trans-muscularly" reveals other functional aspects of the distribution pattern than purely intramuscular observation. This in particular holds for the relation of receptor distribution with architecture of muscular and regular dense collagenous connective tissue. Of course this does not exclude that sometimes architectural units coincide with topographical entities. For instance a "trans-muscular" organization of the muscle spindles seems to be absent in EDP muscle. The distribution of the spindles in EDP muscle is understandable in view of the architecture of the muscular tissue in relation to the periosteal and distal tendinous connective tissue within the muscle entity. The situation in the EI muscle also might be understood in terms of intramuscular organization. If however a proximal intermuscular layer is present (edp/eilayer), it represents an intermuscular organizing principle. For instance, if proximal GTO's exist in the EDP muscle, they are attached to this layer and if the layer is present, it forms a center point for the EI muscle spindle zone (cf. the situation in specimen C1 (figure 6.11) and Z2 (figure 6.8).

\section{Receptor distribution patterns}

It is concluded that muscle spindles and GTO's occur in muscular tissue areas in series with regular dense collagenous connective tissue structures. Such an area mainly does not coincide with a morphological muscle entity. The architectural relation between the regular dense collagenous connective tissue structures seems to define the spatial distribution of spindles and GTO's in the region as a whole. (Sub)units of muscular tissue in-series with regular dense collagenous connective tissue can be distinguished (muscle spindle/GTO zones) of which the spatial organization is defined by the architecture of the connective tissue. The pattern of distribution and orientation of the receptors within these zones is understandable in view of the architecture of the muscullar tissue related to the connective tissue architecture. Such zones may exhibit all the variants of organization usually attributed to muscles, like pennate or in-parallel configuration of the muscle fibers, like dominance of a given histochemical muscle fiber type and like distal or proximal orientation as to the conveying and monitoring of stresses.

The distribution pattern of muscle spindles within a muscle spindle zone shows two tendencies. Either they run mainly longitudinally in line with each other or they may run obliquely in parallel with each other. The former pattern is often paired with the occurrence of tandem configurations between two successive spindles and is most evidently present in the EDL, ECR.br., ECR.lo. and EI muscle areas. This situation occurs when the distal and proximal collagenous connective tissue structures (to which the zones are oriented) are situated in line with each other, with muscle fascicles tending to a parallel-fibered organization. The other pattern most evidently occurs in the EDP and SUP muscles: the related proximal and distal collagenous connective tissue structure are situated in parallel with each other - with muscle fascicles in a unipennate formation between them - and the spindles run in a relatively broad area more or less obliquely in parallel with each other. All distribution patterns in the region are variations and/or mixtures of these two patterns depending on the spatial relation between the proximal and distal connective tissue architecture (figure 6.13).

The spatial relation between muscle spindles and GTO's in the zones is connected with the aforementioned types of distribu- 

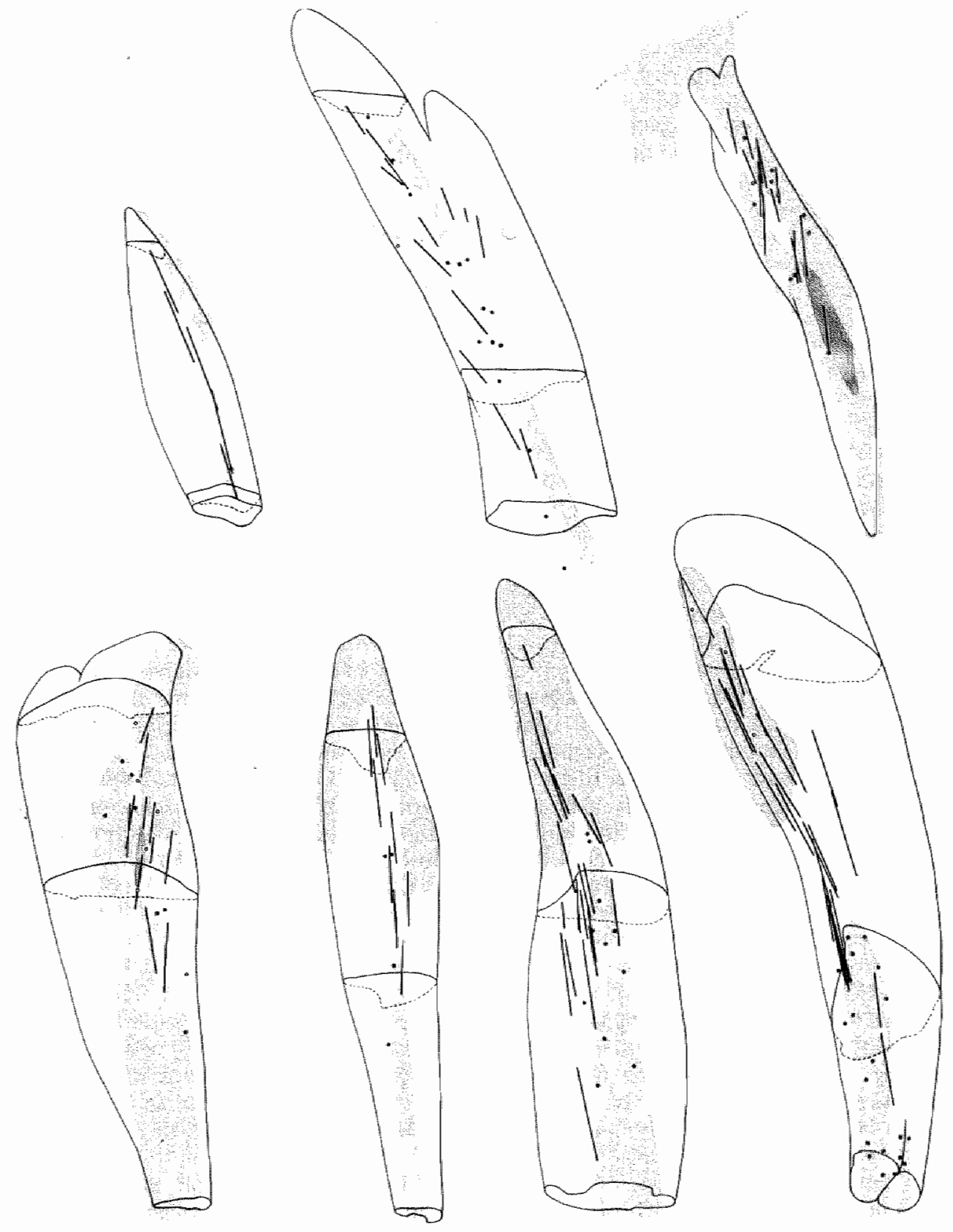

Figure 6.13

Compilation of the distribution patterns of muscle spindles and GTO's in the antebrachial extensor muscles based on figures $6.3 \mathrm{~A}$ to $6.9 \mathrm{~A}$. The proximal and distal regular dense collagenous connective tissue struetures are indicated as shaded areas. For explanation see also par. 6.2 . 
tion pattern of muscle spindles. An elongated muscular tissue zone (with spindles. longitudinally in line with each other) may as a wholle be organized in series with a GTO-rich muscle/connective tissue transitional area. Such a pattern most evidently occurs in the ECR.br, ECR.lo, and (if GTO's are present) EI muscle spindle/GTO zones. The GTO zone can even be "dissociated" from the muscle spindle zone as in the ECR.br. muscle. In the other pattern (where muscle spindles run obliquely in parallel with each other), the muscle-connective tissue transitional area where the GTO's are present is also in series with the muscle fibers between which muscle spindles are embedded, but over a relatively broad area. In this case smaller subunits may be distinguished in which individual spindles are in line or in series with individual GTO's. This latter pattern pairs with the observed occurrence of dyad configurations between a spindle and a GTO and most evidently exists in the SUP muscle. It also is present in the ECU and EDP muscles. It is known that GTO - like muscle spindles readily respond to contractions of near motor units and that this response is modulated by the activity of extrafusal fibers in parallel with those receptors (Binder and Stuart, 1980; Zelena and Soukup, 1983; Binder and Osborn, 1985; Gregory et al., 1986; Spielman and Stauffer, 1986). Differential loading and unloading of GTO's can more readily occur in the "pennate" pattern than in the "in-parallel" pattern where a more overall effect on the GTO's is generated. The dyad formation of a muscle spindle with a GTO - which is hypothesized to be linked with the "pennate" distribution pattern allows to sample different types of information from the same intramuscular site or muscle-connective tissue transition area (Marchand et al., 1971; Lund et al., 1978). It is concluded that the areas with a pennate muscle fiber organization are not per se better equipped with receptors than parallelfibered areas. The pennate fiber organization might have mechanical advantages (Gans and Bock, 1965; Gans, 1982; Rich- mond and Stuart, 1985) but this extrafusal fiber principle is not exclusively connected with "kinesiological monitoring". The pennate organization seems to be wellequipped to monitor mechanical events in a relatively large area and in various directions e.g. longitudinally, laterally as well as in a plane parallel to the connective tissue surfaces. The in-series (in line) organization pattern is hypothesized to be more involved in and equipped for such events in longitudinal direction, over a long distance.

As to the occurrence of GTO's, the muscle spindle/GTO zones may exhibit a preferential orientation in proximal or distal direction. Some zones have GTO-rich areas on both extensions, others only on one side, either proximally or distally. The zones in EDL, EDC, ECR and EDP muscles are mainly equipped with distal GTO's, the zone in the SUP muscle mainly with proximal GTO's. The zone in the ECU.hum. muscle displays an intermediate position. Integral description of the regional architecture of the regular dense collagenous connective tissue explains the proximal and/or distal preferential orientation of the GTO's in the various units. The finding of hardly any GTO's at the periosteal attachment of EDP and SUP muscle could be related with the relative non-deformability of those layers. It parallels our description of the architecture in the region: the supinator muscle and its septum as part of the epicondylar muscle/connective tissue entity is oriented proximally, in EDP muscle a reverse relation exists. The muscle spindle/GTO zones in the superficial extensor muscles architecturely are defined by the proximal connective tissue apparatus (epicondylar unit) as well as by the distal tendons. The occurrence of GTO's in the zone in the ECU.hum. muscle has a proximal and distal orientation; the other three superficial zones of the epicondylar unit are mainly oriented distally. This phenomenon relates to the ulno-radial gradient that exists in the superficial division of the epicondylar connective tissue apparatus as described in chapter 3 . The SUP muscle (supinator sep- 
tum) and ECU muscle (ecu/edl.u-llayer) have the majority of the GTO's related to the epicondylar connective tissue apparatus, reflecting their (assumed) predominant role in the conveying of stresses in the epicondylar region.

Absence of GTO's at the muscle compartment walls constituted by periosteal connective tissue, seems to be the rulle: no GTO's occur in the periosteal attachments of ECU, ECR, EDP and EI muscles. Only to the periosteal muscle compartment wall of SUP muscle a few GTO's are attached. Apparently some degree of deformability of the considered regular dense collagenous connective tissue layer is a prerequisite for the occurrence of GTO's. It is hypothesized that in the case of the radial periosteum, the fact that the distal insertion of the SUP muscle is subject to rotational movements of this bone, explains the presence of some GTO's in this muscle/periosteum transitional area.

As to receptor distribution in the "dynamic ligaments" as postulated in chapter 3 , the following conclusions can be drawn. They pair a unilateral concentration of regular dense collagenous connective tissue (with matching polarization of the GTO's) with the pennate receptor distribution pattern (and muscle fiber architecture). It is hypothesized that the ECU muscle spindle/GTO unit also exhibits features of the "dynamic ligament" configuration. "There is a pennate distribution pattern, a relatively proximal orientation of GTO's, uni-layered regular dense collagenous connective tissue configuration (ecu/edl.u-layer with only ECU fascicles inserting) and indications of an external pathway of the GTO afferents (chapter 5). These observations confirm our concept that a "dynamic ligament" is a particular type of muscle/connective tissue inseries unit (with adjustable tension and appropriate sensory equipment) and support the point of view that a distinction between a passive joint and an active joint stability system - organized in parallel and separately - is not possible in the region under consideration. This holds for the functional architecture in the region (chapter 3 ) as well as for the distribution of (so-called muscle) receptors.

\subsection{Conclusions}

1 In the lateral cubital region of the rat a topography exists of "monitor muscle/connective tissue units" - mainly organized between proximal and distal layers of regular dense collagenous tissue - that does not coincide with the topography of muscles as morphological entities and parallels the architecture of in- series muscle/connective tissue units as described in chapter 3.

2 These monitor units are represented by muscle spindle-/GTO zones. The patterns of distribution and orientation of receptors within such zones directly relate to the architecture of the muscle fibers which relates to the architecture of the regular dense collagenous connective tissue (including periosteal connective tissue).

3 The muscle spindles and Golgi tendon organs in the lateral cubital region of the rat are concentrated in those areas where - in view of the description of the architecture of the muscular and connective tissue - the conveying of tensile stresses over the elbow joint is expected to take place.

4 The spatial organization of muscle spindles and GTO's in the region is such as to enable the monitoring of stresses conveyed over the elbow joint as well as of movements of the articulating bones. This allows to classify those receptors also as "joint receptors". 


\section{CHAPTER 7}

\section{SUBSTRATE OF PROPRIOCEPTION RELATED TO THE PERISKELETAL CONNECTIVE TISSUE}

\section{Contents}

7.1 Introduction

7.2 Materials

7.3 Results

7.3.1 Nerve elements in the periosteal connective tissue

7.3.2 Pacinian corpuscles

7.4 Discussion

7.5 Conclusions

\section{Summary}

The muscle compartment walls coinciding with the periosteal lining of the antebrachial bones in combination with adjoining periskeletal collagenous connective tissue, have been studied for the occurrence of nerve elements (par. 7.3). A notable difference exists between the periosteum covering the superficial side of the ulnar bone and the rest of the periosteal tayers. In the former a rich nerve plexus exists. Encapsulated nerve endings could not be demonstrated within or near the periosteal collagenous connective tissue on the extensor side of the foreleg bones. Clusters of relatively large Pacinian corpuscles occur in the loose connective tissue between the necks of the two antebrachial bones and distally between the periosteal layers of the ulnar and radial bone and adjoining muscular tissue, mainly of the flexor muscles. It is discussed what role the latter receptors could play in the proprioceptive input from the region under consideration (par. 7.4). 


\subsection{Introduction}

The muscle compartment walls of some antebrachial extensor muscles are completed by periosteal collagenous connective tissue. The investigation of nervous tissue elements in the muscle compartment walls in chapter 5 has been concentrated on the non-periosteal regular dense collagenous connective tissue components and adjoining muscular tissue. In chapter 6 the occurrence of muscle spindles and GTO's related to periosteal muscle compartment walls has been described. In this chapter the results will be given of our search for possible substrate of proprioception in the peri-skeletal collagenous connective tissue, including the periosteum, not yet mentioned in former chapters. In search of putative substrate of mechanoreception in these connective tissue layers, Pacinian corpuscles have been found in connective tissue between and near the foreleg bones. Many of them are situated at the flexor side. Because of the typical and unexpected relationship of some corpuscles with the periosteal collagenous connective tissue, all the Pacinian corpuscles as found in the foreleg will be described in this chapter.

The innervation of periosteal connective tissue is mainly thought to be nociceptive and to be conveyed by free nerve endings (Barker, 1974). Others have proposed that the afferent information from long bone nerves incllude perception of strain, pressure and position as a contribution to the overall mechanism of coordinated movements of the limbs (Miller and Kasahara, 1963; Thurston, 1982). Recently the role of periosteal nerve endings in the neural control of bone metabolism has been put forward (Aro et al., 1985; Hohmann et al., 1986). Aro et al. (1985) state that the area of proprioceptive receptors in the distal tibiofibular bone of the rat (including Pacinian corpuscles) is essential for the healing of fractures.

Pacinian corpuscles in or near the perios- teum of long bones are a common finding. Clusters of those receptors are described near the interosseous membrane in the hindleg of the rat (Zelena, 1982, 1984) and of the cat (Barker, 1974) as well as around the distal end of the rat tibiofibular bone (Aro et al., 1985). The association of Pacinian corpuscles with collagenous connective tissue layers has also been mentioned by other authors. Stilwell (1957a-c) mentions their presence at the surfaces of fasciae, aponeuroses and tendons. They are rarely found within muscles but sometimes they are described in muscle-connective tissue transitional zones (Barker, 1962, 1974; Richmond and Bakker, 1982; Richmond and Stuart, 1985; Halata et al., 1985; Strasmann, 1988).

We define as "Pacinian corpuscles" those sensory nerve endings that consist of a single axis cylindre with a laminated capsule of 810 or more layers, that are conical or cylindrical in shape and that measure $100 \mu \mathrm{m}$ in diameter (chapter 1). Freeman and Wyke (1967a, 1967b), Wyke (1967) and O'Connor and Gonzales (1979) classify them as joint capsule receptors type II. Like Halata (1977), Halata et al. $(1984,1985)$ and Strasmann et al. (1987), we distinguish them from the much smaller lamellated (Pacini) corpuscles (2-4 layered and less than 100 $\mu \mathrm{m})$. Like all types of lamellated corpuscles they are rapidly adapting mechanoreceptors with low threshold (McCloskey, 1978; Tracey, 1978, 1979). Large Pacinian corpuscles are regularly observed in the tela subcutanea of the skin and in loose adipose periarticular connective tissue (Gardner, 1950; Polacek, 1966; Freeman and Wyke, 1967a, 1967b; Andres and v.Düring, 1972; O'Connor and Gonzales, 1979; Halata, 1977; Halata et al. 1985). The smaller (Pacini) type is mainly located in fibrous layers and ligaments of the joint capsule (Halata et al., 1984, 1985; Strasmann et al., 1987). 


\subsection{Materials}

The periosteal connective tissue was studied in foreleg specimens with the connective tissue left in situ and stained with the acetylcholinesterase in toto method. In some specimens the periosteum on the outer side of the ulnar shaft and the olecranon was taken out and stained together with the fascial connective tissue layer. Silver stained preparations were not made; neither has the tissue been processed for ultramicroscopical study. The Pacinian corpuscles were described and counted in the eight foreleg specimens embedded in toto in polyester resin, and measured in six of those specimens (par. 2.2.3).

\subsection{Results}

\subsubsection{Nerve elements in the periosteal connective tissue}

A dense and fine acetylcholinesterase positive plexus of nerve fascicles is present in the periosteum over the outer side of the ulnar shaft and the olecranon (figure 7.8). This plexus is continuous with the plexus in the superficial fascial connective tissue layer constituted by the outer compartment walls of the superficial extensor and superficial flexor muscles (cl. figure 5.6 to 5.8). In various specimens a longitudinal nerve fascicle demarcates the transition of the superficial (fascial) layer to the adjacent periosteum (figures 5.7, 5.8 and 7.8). During preparation it has been observed that the proximal extension of this ulnar periosteum is easily stripped from the skeletal element. This finding is opposite to the situation in the rest of the periosteal connective tissue, where the periosteal connective tissue presents only vaguely positive nervous tissue ele-

\subsubsection{Pacinian corpuscles}

The occurrence and distribution of Pacinian corpuscles are demonstrated in the ments when stained with the acetylcholinesterase in toto method. In only a few specimens a longitudinal nerve fascicle has been observed on the flexor side of the interosseal membrane. In the loose connective tissue between the necks of the foreleg bones, fine nerve fascicles are rarely demonstrable.

In spite of extensive study of the foreleg specimens embedded in polyester resin in toto no (encapsulated) nerve endings have been demonstrated within or near the periosteal collagenous connective tissue on the extensor side of the foreleg bones. An exception is formed by some GTO's attached to the periosteum of the radial bone in the area where muscle fascicles of the supinator muscle insert (chapter 6). Also the connective tissue of the interosseal membrane seems to be devoid of nerve endings.

summative projection of specimen $\mathrm{Z} 2$ (figure 7.1). For description see page 146. 

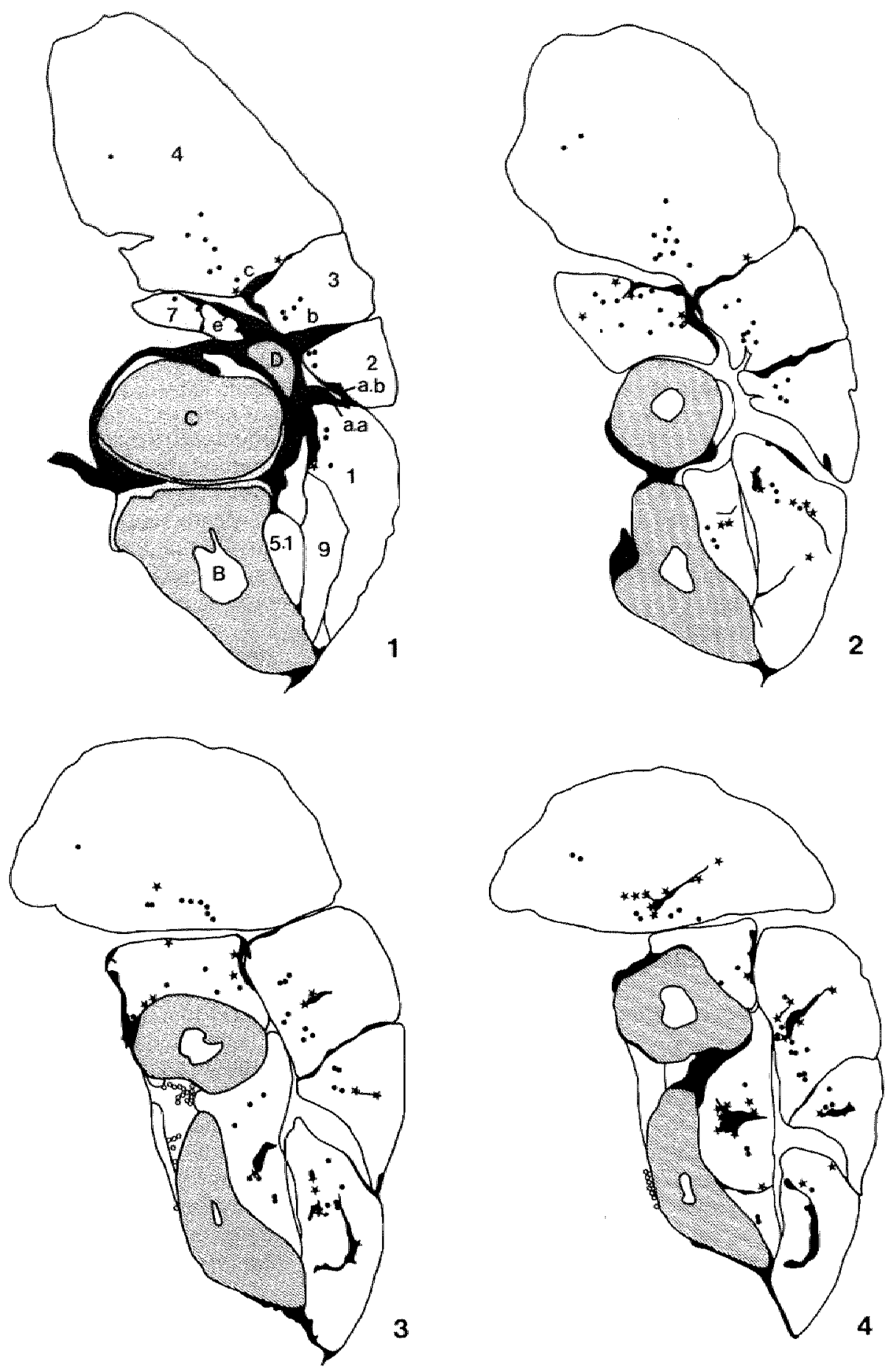


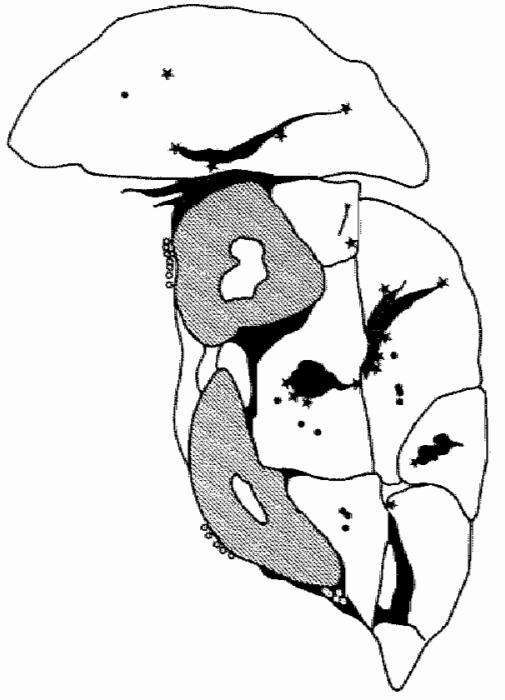

5

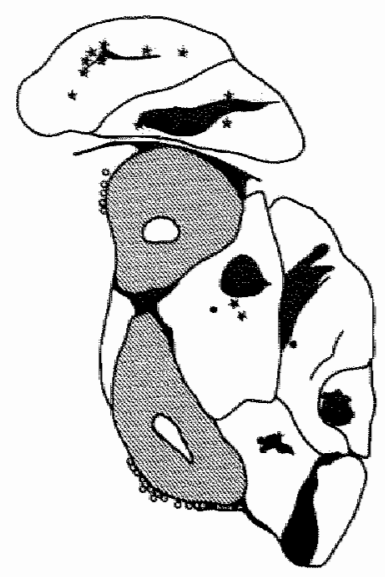

6

\section{Figure 7.1}

Distribution of muscle spindles, GTO's and Pacinian corpuscles in 6 successive proximo-distal projections along. the $\mathrm{Z}$-axis of specimen $\mathrm{Z} 2$ (summative projection).

Actual serial numbers of the $15 \mu \mathrm{m}$ sections that limit the foreleg portion that is projected onto the six reference sections (number indicalted in bold):

$\begin{array}{llllllll}1 . & <370 & (510) & 600 & 2 . & 610 & (690) & 780 \\ 3 . & 790 & (\mathbf{8 7 0}) & 960 & 4 . & 970 & (1050) & 1140 \\ 5 . & 1150 & (\mathbf{1 2 3 0 )} & 1320 & 6 . & 330 & (1410) & 1550>\end{array}$

The first reference section coincides with a transwersal plane through the equator of supinator bone, the last reference section with the most distal plane in which the supinator muscle is sectioned. Section 2 to 5 are equally distributed between section 1 and 6 .

Skeletal tissue shaded. Regular dense collagenous connective tissue black. Muscular tissue white.
- : muscle spindle
* : GTO

See also general legend and figures 3.16 A to 3.16H. 


\section{3 .2 (continued)}

Three main clusters of Pacinian corpuscles are present:

- An interosscal cluster (A)

- An ulnar periosteal cluster (B) and

- A radial periosteal cluster (C)

The number and size of the corpuscles are listed in table 7.3 .

The interosseal cluster is situated in loosely organized connective tissue with many blood vessels between the necks of the two antebrachial bones slightly distally from the insertions of the tendons of the brachialis and biceps muscle (figure 7.4). The corpuscles are spheric to ovoid (cf. table 7.3) and have up to twenty lamellae (figure 7.4). They are not found distally beyond the level where the interosseal membrane is present on the cross-sections (cf. figure 7.1, sections 2 to 4). The majority of them is situated near the neck of the radial bone in the loose interosseous connective tissue. A minority is situated at the flexor side of the ulnar bone just near the most proximal insertion area of the pronator quadratus muscle (figure 7.1, section 3 ). Those corpuscles form a transition to the corpuscles of the ulnar periosteal cluster (figure 7.2).

The ulnar cluster is the largest one (table 7.3) and is situated over a relatively long extent of the foreleg right near the shaft of the ulna (figure 7.2). These corpuscles are more cylindrical in shape (table 7.3 and figure 7.5) and somewhat larger than those of the interosseal cluster. They are often situated within the collagenous connective tissue layer that forms the transition of the epimysial fascia of flexor muscles to the ulnar periosteum (figure 7.5). Proximally a subcluster can be identified in somewhat looser connective tissue near the insertion of the pronator quadratus muscle onto the ulnar crest (figure 7.2 and figure 7.1 , section 4 ). The rest of the ulnar Pacinian corpuscles is arranged in a long oblique row along the flexor side of the ulna (figure 7.1, section 5 an 6). Distally they are found on the dorsal

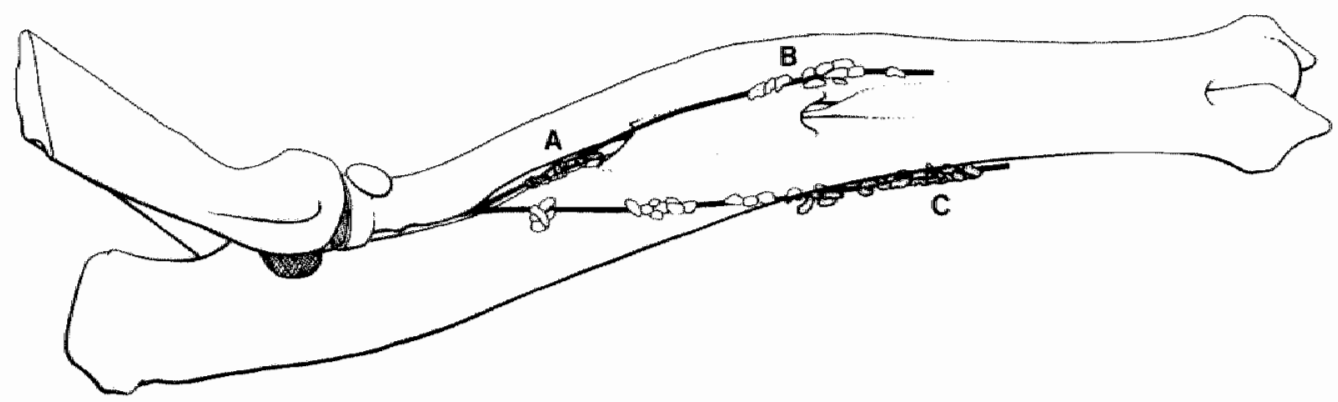

Figure 72

"Threc-dimensional graphic reconstruction of the right foreleg skeleton and the Pacinian corpsucles in the antebrachial region based on specimen $\mathrm{Z} 2$. Lateral aspect. If a corpuscle is obscured by the skeletal elements from this point of view, only the outlines are indicated.

$A, B$ and $C$ : interosseal, whar and radial clusters of Pacinian corpuscles. Hypothetical lines of connection are indicated. 
ridge of the bone and appear on the extensor side of the ulnar shaft (figure 7.2) at the level where the extensor indicis muscle is attached to the ulnar bone. Here they are situated within the collagenous tissue of an intermuscular septum between the extensor carpi ulnaris and adjacent antebrachial flexor muscles (figure 7.1, section 5).

The radial cluster resembles the previous cluster in its orientation i.e. an oblique row along the radial shaft (figure 7.2 and figure 7.1 , section 5 and 6 ). No transitional clusters

\subsection{Discussion}

The large number of nervous tissue elements within the periosteal collagenous connective tissue of the outer side of ulna and olecranon is in contrast with the relatively poor innervation pattern of the rest of the periosteum. The former periosteal layer is much more easily detachable from the underlying skeletal tissue than the rest of the periosteum and actually is continuous with the regular dense collagenous connective tissue of the olecranal retinaculum. The olecranal nerve plexus is continuous with the superficial plexus in the antebrachial (fascial) layer as described in chapter 5 . Burg (1988) described that the peripheral pathway for the plexus situated over the olecranon and outer ulnar shaft occurs via can be described between this cluster and the interosseal Pacinian corpuscles (figure 7.2). As to size and shape they resemble the corpuscles of the ulnar cluster (table 7.3). These receptors are situated within the well- developed collagenous layer of the radial periosteum (figure 7.6 and 7.7). They are concentrated at the flexor side of the radial shaft where the periosteal layer thickens strongly and is continuous with the distal aponeuroses of the pronator teres and the supinator muscles (figure 7.7 and figure 7.1 , section 5 and 6 ).

branches of the radial and ulnar nerve with a slight contribution from the medial antebrachial cutaneous nerve. Though not examined with additional techniques, it is assumed that in this outer ulnar part of the periosteum nerve fascicles are present similar to those found in the superfical antebrachial plexus (chapter 5). Those nerve fibers either may contain afferents from possibly free nerve endings in the periosteum or may serve as a pathway for nerve fibers from (at least the ulnar cluster of) Pacinian corpuscles. Recently sympathetic (vasoactive intestinal peptide-containing) nerves have been demonstrated in periosteal connective tissue, possibly involved in regulating bone mineralization (Hohmann et al., 1986).

Table 7.3

\begin{tabular}{|c|c|c|c|c|c|c|c|c|c|}
\hline \multicolumn{7}{|c|}{ NUMBER AND DIAMEIER OF THE PACINIAN OORPUSCIES } \\
\hline $\begin{array}{c}\text { Clus- } \\
\text { ter }\end{array}$ & $\begin{array}{l}\text { Mean } \\
\text { number }\end{array}$ & S.D. & Range & $\begin{array}{c}\text { Mean } \\
\text { length }\end{array}$ & S.D. & Range & $\begin{array}{l}\text { Mean } \\
\text { diam. }\end{array}$ & S.D. & kange \\
\hline A & 18.9 & 1.8 & $16-21$ & 185.4 & 40.1 & $161.5-205.8$ & 137.6 & 29.0 & $117.5-152.0$ \\
B & 34.9 & 4.1 & $30-40$ & 201.3 & 30.3 & $191.6-213.0$ & 97.7 & 24.1 & $82.8-106.4$ \\
C & 14.7 & 3.4 & $11-21$ & 216.9 & 30.3 & $189.0-233.1$ & 86.4 & 15.2 & $81.9-113.4$ \\
\hline
\end{tabular}

Number of corpuscles measured: 52 (A), 115 (B) and 45 (C). Based on specimens $\mathrm{A} 1, \mathrm{A2}, \mathrm{B1}, \mathrm{B} 2, \mathrm{C1}$ and $\mathrm{C} 2(\mathrm{n}=6)$ 


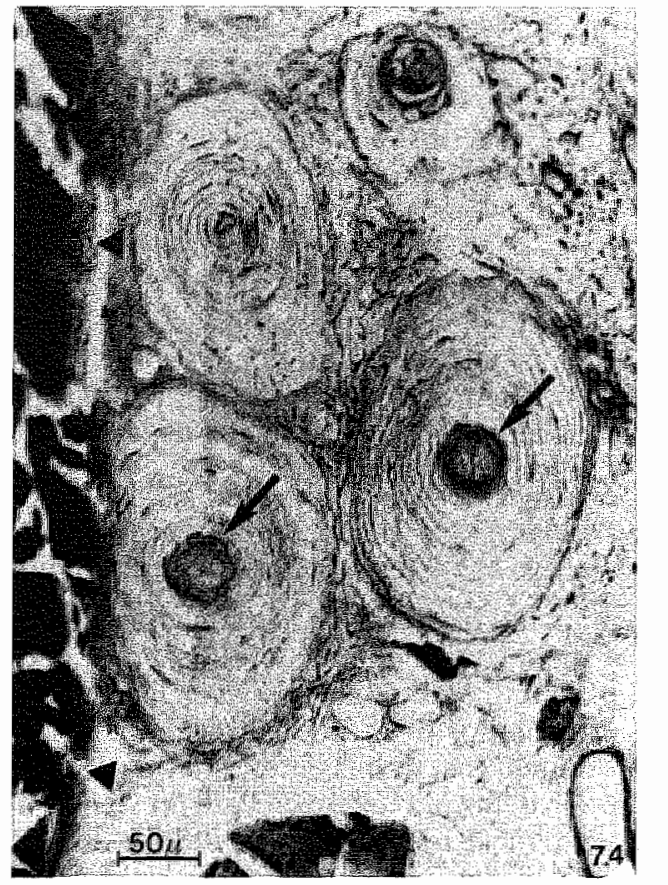

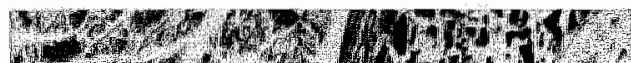
H. P.

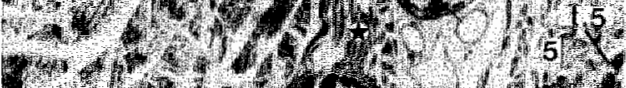

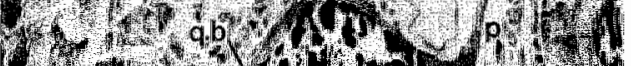

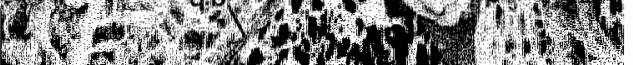

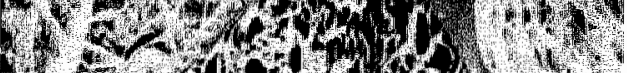

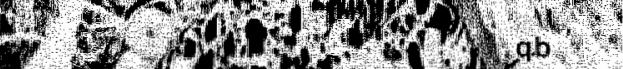

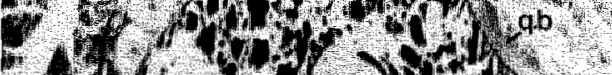

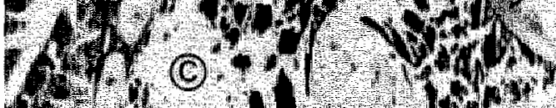

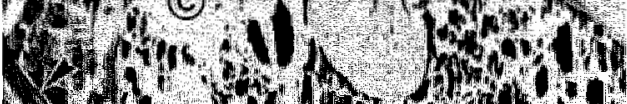

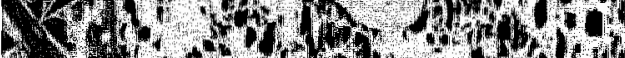
W. ${ }^{2}$ ', W

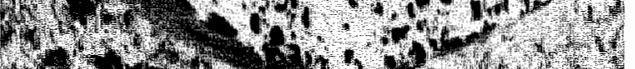
W

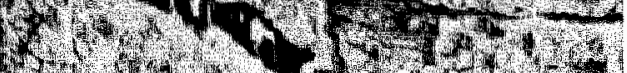

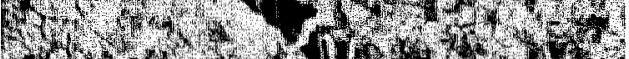

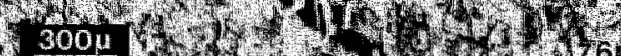
M.
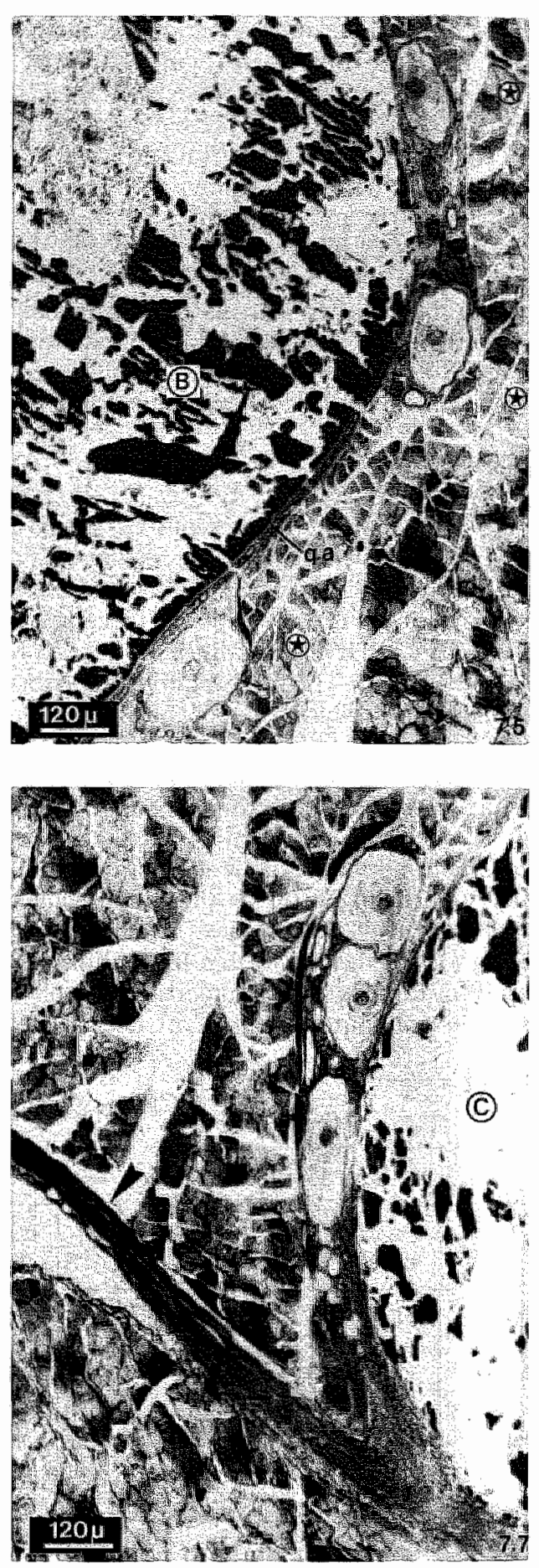


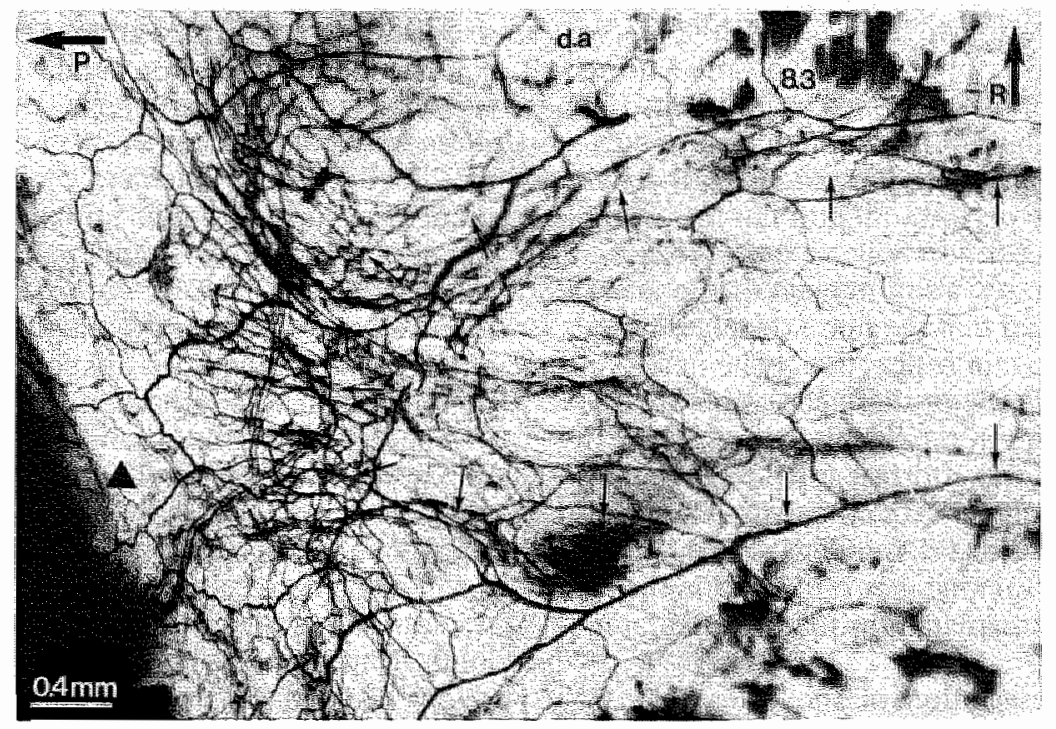

Figure 7.8

Nerve plexus in the collagenous connective tissue covering the dorsolateral aspect of the olecranon. Specimen taken out separately and stained for AChEase in toto. The arrows indlicate the outlines of the olecranal process where the olecranal periosteum is continuous with the adjoining superficial fascial connective tissue. Some muscle fascicles of medial head of the TR muscle (8.3) are left in situ attached to the olecranal retinaculum (d.a).

A: Anterior border of the long head of TR muscle.

$P$ : proximal direction. $R$ : radial side.

\section{Figure 7.4}

Four interosseal Pacinian corpuscles in loose connective tissue between the unar and radial bones. The atrows indicate the central axons. $\boldsymbol{A}$ : oulline of ulnar bone. Trichrome staining.

\section{Figure 7.5}

Three ulnar Pacinian corpuscles between ulnar periosteum (q.a) and flexor digitorum communis muscle ( $\$$ ).

Trichrome staining.

\section{Figure 7.6}

Three radial Pacinian corpuseles situated near radial periosteum ( $\mathrm{q} . \mathrm{b})$. The tendon of pronator teres muscle (-) , the pronator quadratus muscle $(\star)$ and a part of the interosseous membrane $(p)$ are present.

Trichrome staining.

Figure 7.7

Detail of figure 7.6. Trichrome staining. 
Since the superficial antebrachial nerve plexus also contains F.I.F.-positive fibers (see chapter 5), a contribution from this type of axon may be assumed.

Another difference between olecranal and outer ulnar periosteum and the rest of the periosteal layers might be responsible for the poor innervation pattern of the latter. We observed that the more deeply situated periosteum and connective tissue in the region apparently are less accessible for the acetylcholinesterase incubation medium. In spite of several efforts it appeared to be impossible to stain the evidently present Pacinian corpuscles either in situ or in fragments of the periosteum taken out. We cannot give a plausible explanation for this phenomenon.

In the description of the occurrence of GTO"s in the considered region (chapter 6) it has been noted that no GTO's occur at the periosteal muscle compartment walls, with one exception: GTO's as well as (rare) muscle spindles are connected with the radial periosteal connective tissue that constitutes the SUP muscle compartment.

Large clusters of Pacinian corpuscles in loose areolar interosseous connective tissue have been also described by others (Barker, 1962, 1974; Zelena, 1982, 1984; Kanatani et al., 1986) but the localisation of lamellated corpuscles of this size in an environment of collagenous connective tissue, as in the ulnar and radial clusters, is rather exceptional. This finding is in contrast to the observation of other authors (a.o. Gardner 1950; Polacek, 1966; Halata et al., 1984, 1985; Strasmann et al., 1987) who state that the larger type of lamellated corpuscle (100 $\mu \mathrm{m}$ ) is connected with loose connective tissue environment and that lamellated corpuscles are smaller in densely fibrous environment. Sometimes a few Pacinian corpuscles of this size are described near the periosteal attachment of "tendons of origin" of some muscles (Swett and Eldred, 1960a; Richmond and Stuart, 1985). Like in our material they are located outside the muscle compartment in the loose connective tissue surrounding the tendon of origin.

Pressure and/or deformation of the capsular lamellae of the Pacinian corpuscle are thought to form the main stimulus for this rapidly adapting sensory ending, though the exact mechanism that transduces these external stimuli to electrofysiological activity of the nerve ending is yet unknown. It is hypothesized that deformation between the osseous tissue and the adjoining mass of the flexor muscles (e.g. pronator quadratus muscle) forms a possible stimulus for the ulnar and radial cluster. This might occur during (isometric as well as auxotonic) contraction of those muscles and/or by displacement of the foreleg bones actively or passively resisted by those muscles. Movements of the antebrachial bones may also lead to squeezing of the corpuscles between the bones and the attached regular dense collagenous connective tissue layers. This could hold for the intermuscular septal layer between the extensor and flexor carpi ulnaris muscles and the ulna (ulnar cluster), or for the tendon of the pronator teres muscle and the radius (radial cluster). This latter phenomenon might also be evoked by contraction of antagonist muscles like the supinator muscle. The interosseal cluster thus could react to movements (rotations) of the neck of the radial bone. At the level of the central nervous system squeezing, rolling and/or deformation of those corpuscles could serve as part of the information necessary to perceive movements of the bones of the foreleg. The relatively large size, combined with the phenomenon of clustering of the receptors, possibly guarantees the relatively large range or sphere of sensory activity required. This confirms the notion that morphogical substrate for perception of movements and/or induced stresses in a given joint region, has not necessarily to be situated near that joint or even in that region. 


\subsection{Conclusions}

1 The periosteal connective tissue layers that constitute the muscle compartment walls of the antebrachial extensor muscles, are relatively poor in substrate of proprioception. The presence of noci-mechano-sensitive free nerve endings is assumed.

2 The radial periosteum to which muscle fascicles of the supinator muscle insert, is the only periosteal layer in the lateral antebrachial region to which encapsulated mechanoreceptors are attached (i.e. GTO's and some muscle spindles).

3 The periosteal connective tissue at the flexor side of the foreleg bones is well-equipped with Pacinian corpuscles.

4 Presumably the organization of those Pacinian corpuscles enables the perception of movements of the foreleg bones (also induced by action of antebrachial extensor muscles) and stresses conveyed via the elbow joint. 



\section{FINAL DISCUSSION AND GENERAL CONCLUSIONS}

In the concept of the spatial organization of the muscular and connective tissue in a given joint region in man, as proposed by Van Mameren and Drukker (1984), muscular and regular dense collagenous connective tissue structures do not function in parallel in the maintenance of joint stability and integrity, but as functional tissue units in series with each other and the skeletal elements. In vivo those collagenous connective tissue structures are strained during movements of the skeletal parts induced and led by tension (alterations) in muscular tissue.

Therefore the concept on which the description of mechanoreceptive substrate is usually based - as being distributed and functioning in muscular structures next to articular structures - should be reevaluated. In this study information has been gathered about the localisation of various types of possible proprioceptive substrate in relation to the above mentioned functional tissue units.

For this purpose, several hypotheses have been formulated and their implications tested in the lateral cubital region of the rat. This region has been chosen as model because most insight into such functional tissue units has been gained from studies in the corresponding region in man (v.Mameren, 1981, 1983; Drukker et al., 1983a-c; v.Mameren and Drukker, 1984).

First hypothesis to be tested was that in the rat the architecture (spatial organization) of the muscular tissue components in relation to the components of regular dense collagenous connective tissue is similar to that in man. The description of the epicondylar and olecranal muscle/connective tissue units in which fractions of muscular tissue are organized in series with a multilayered apparatus of regular dense collagenous connective tissue constituted by the proximal extensions of muscle compartment walls, has confirmed this. The second hypothesis to be tested was that a spatial correlation exists between the morphological substrate of proprioception and the demonstrated architecture of muscular and collagenous connective tissue.

Starting from the idea that in particular regular dense collagenous connective tissue structures in series with muscular tissue convey stresses (v.Mameren, 1981; v.Mameren and Drukker, 1984), we have subsequently questioned whether mechanoreceptive substrate could be found within the above mentioned apparatus. Except for free nerve endings - with putative mechanonociceptive quality - no mechanosensitive substrate was found within the connective tissue structures concerned.

However, other types of mechanoreceptors are found mainly at the transitional areas between the various components of the regular dense collagenous connective tissue apparatus and adjacent connective tissue or adjoining (in-series) muscular tissue. A common denominator of these areas is, that deformation can occur, which indeed forms the main stimulus for such sensory endings. Therefore these areas may be considered strategic for such substrate.

In consequence of the identification of an in-series organization of muscular tissue and regular dense collagenous connective tissue (distally mainly tendons and proximally compartment walls), attached to skeletal parts (periosteal attachment), three types of configuration of mechanoreceptors can be identified, successively consisting of: - muscle spindles, Golgi tendon organs, free nerve endings and lamellated corpuscles found in areas between muscular and collagenous connective tissue. This configuration coincides with the conventional muscle-tendon-spectrum of sensory nerve endings (Stilwell, 1957a, 1957b; Barker, 1974; v.Düring et al. 1984; Andres et al., 1985). 
- lamellated corpuscles and free nerve endings in areas where regular dense collagenous connective tissue adjoins reticular connective tissue. This configuration mainly coincides with the spectrum of sensory nerve endings usually indicated as articular receptors (Polacek, 1966; Freeman and Wyke, 1967a, 1967b; Halata et al., 1974, 1975).

- only free nerve endings in the transition to the skeletal attachment. This configuration coincides with the endotenonial spectrum of sensory nerve endings (v.Düring et al., 1984; Andres et al., $1985,1987)$.

In the above mentioned configurations Ruffini corpuscles are not indicated. GTO's and Ruffini corpuscles are considered to be the same receptor type presenting gradual differences depending on the texture of the surrounding tissue (Andrews, 1954; Halata et al., 1985; Strasmann et al., 1987).

It has been found that the actual appearance of mechanoreceptive substrate in a given muscular tissue/connective tissue/skeletal tissue continuity presents mixtures or varieties of those configurations correlated to the architecture of the area in which they occur. So it may be stated that the quartet muscle spindle - GTO/Ruffini corpuscle - lamellated corpuscle - free nerve ending represents the complete spectrum of mechanoreceptors in a joint region. In this way the three types of so-called capsular (or joint) receptors - free nerve ending, Ruffini corpuscle and lamellated (or Pacini) corpuscle - (Polacek, 1966) are combined with the three main types of so-called muscle receptors - muscle spindle, GTO and lamellated corpuscle - (Barker, 1974).

Complementary to the above mentioned configurations of mechanorecptors, the actual presence of muscle spindles and GTO's in muscular tissue can be summarized as folllows:

- Muscle spindles and GTO's are mostly concentrated in areas of muscular tissue directly intermediating distal and proximal regular dense collagenous connective tissue structures (i.e. distally ten- dons, proximally compartment walls).

- If distal and proximal regular dense collagenous connective tissue structures are situated at relatively large distance from each other, the receptors accordingly form small elongated zones segregated from surrounding extrafusal fibers. The muscle spindle zone as a whole is organized in series with the relatively small muscle-connective tissue transition area where related GTO's occur (distally and/or proximally).

- If the distance between distal and proximal regular dense collagenous connective tissue structures is relatively short both structures being situated more in parallel with each other - , the spindles run obliquelly in parallel to each other in a relatively broad muscular area bridging a short distance. Individual GTO's occur in direct one to one relation to individual spindles in a relatively broad area of muscle/connective tissue transition. The extrafusal fibers are more or less equally distributed between them.

- Muscle portions which do not link two regular dense collagenous connective tissue structures but which attach directly to periosteal tissue, tend to be devoid of muscle spindles.

Accordingly we concieve the basic organizational principle of mechanoreceptors of a muscular area not as muscle zones equipped with muscle spindles but as muscular tissue/connective tissue zones equipped with muscle spindles and GTO's, to be indicated as "monitor muscle spindle/GTO zones".

In the case of the alignment of a proximal and distal unit, such zones appear as a GTO/muscle spindle/GTO zone intermediate between a distal and a proximal regular dense collagenous connective tissue structure.

The description of the periarticular collagenous connective tissue as situated in series with contractile elements, has led to the definition of the dynamic ligament. Afferent nerve fibers reach the related mech- 
anoreceptive substrate from the superficial. side of the structure, which feature is generally described as characteristic of capsular or ligamentous innervation. The related collagenous connective tissue component itself is devoid of mechanoreceptors, but they occur at its boundaries. The foregoing makes clear that such "ligaments" are to be considered particular types of muscle/connective tissue transitions.

We conclude that in principle an in-series unit of muscular tissue/regular dense collagenous connective tissue layer/skeletal element equipped with mechanosensitive substrate at the transitional areas between the various tissue components, constitutes the basic unit of the spatial organization of the substrate of proprioception. Such a unit may occur as a muscle fraction in series with a muscle compartment wall that is shared with the muscular tissue of an adjacent muscle. It may also appear as a muscle compartment wall with muscle fascicles inserting unilaterally and with afferent nerve fibers reaching the related mechanoreceptors from the outer side (dynamic ligament). It may be concluded that the concept of inseries organization of muscular tissue and periarticular regular dense collagenous connective tissue has produced valid i.e. verifiable presumptions about the spatial distribution of mechanoreceptors in the locomotor apparatus. The recognition of an ordening principle for the substrate of proprioception makes it appropriate to reconsider a number of data which thus far have been assembled and discussed in the light of the muscle as the functional entity functioning in parallel with articular structures. These are:

- The classification into muscle and joint receptors as the morphological substrate of joint position sense.

- Receptor distribution in the muscular fraction of the locomotor apparatus including quantitative parameters regarding this distribution.

- The concept of "kinesiological monitor muscles".

- The functional partioning of muscles.
Usually it is assumed that so-called joint receptors signal the extremes of joint position (Burgess and Clark, 1969; Grigg and Greenspan, 1977; Tracey, 1979, 1980; Grigg et al., 1982; Ferrell et al., 1986, 1987; Baxendale and Ferrell, 1987) whereas muscle afferents function as full-range receptors signalling steady joint angle and position (Millar, 1975; Rossi and Grigg, 1982; Rossi and Rossi, 1985). The definition of joint versus muscle receptors depends also on the anatomical criteria by which (peri)articular connective tissue structures are defined. Most collagenous fibers of the proximal connective tissue apparatus are in series with muscular tissue and only a few actually cross between the skeletal parts. Therefore an anatomical basis for distinguishing muscle and joint receptors does not exist. For instance the mechanosensitive substrate at the transition of the supinator septum with adjoining tissue, fits with a substrate appropriate for a dynamic ligament capable of signalling stresses in various positions of the joint rather than with a substrate only gathering information about stresses in this tissue in extreme joint positions only.

Also the notion of several authors that muscular activity may effect on recordings from so-called joint afferents in the absence of joint movement (Skoglund, 1956; Millar, 1973; Clark, 1975; Grigg, 1975; Baxendale and Ferrell, 1983; Ferrell, 1985) or that "kinaesthetic acuity" is restored by tension of the muscles acting upon that joint (Ferrell and Smith, 1987; Ferrell, 1988), may be considered to be in line with the concept proposed here. Connective tissue layers are strained by joint movement as well as by activity of the muscular tissue with which they are in series.

That articular nerves are found to contain so-called muscle afferents from adjoining muscles (Clark and Burgess, 1975; Grigg, 1975; McIntyre et al., 1978; Rossi and Grigg, 1982; Rossi, 1983; Rossi and Rossi, 1985), is consistent with the concept proposed here. The demonstrated plexus of afferent nerves in the joint region concerned, contain afferents from sensory nerve endings situated in 
muscle/connective tissue transitions. The fact that a similar nervous substrate described by Wilson and Lee $(1983,1986)$ and Lee and Wilson (1985a) indeed appears to be active during the complete range of joint movement, is considered to be in line with the concept of the "dynamic ligament". In this concept "articular" not necessarily implies "only dischargeable by stretch of capsular connective tissue", which statement holds for the sensory nerve ending as well as for the articular nerve from which a recording is being made.

If the number of mechanoreceptors is calculated - per weight or per volume - the outcome not only depends on the number of receptors but also on the extension, the volume or magnitude of the unit concerned. This again is determined by one's conceptual issue how to define entities in the locomotor apparatus. In the model proposed here, neither individual muscles nor ligaments are the functional entities to which receptor distribution in the considered joint region should be related.

Comparing the quantitative data on the occurrence of muscle spindles and GTO's in the considered region with the outcome of the three-dimensional study of the architecture of those receptors, confirms that parameters per muscle fail to express the spatial organization of those teceptors: muscles with similar respectively different densities exhibit different respectively similar distribution patterns. Similar considerations are valid for parameters as (absolute and relative) receptor volumes. This is because quantifying receptors per muscle or per connective tissue structure ignores the functional architectural continuity that apparently exists in the various tissue elements of the locomotor apparatus functioning while maintaining joint integrity.

Consequently, concepts like that of the existence of "kinesiological monitor muscles" (Peck et al $, 1984,1988$ ) - based on the assumption of the existence of muscles rich and muscles poor in muscle spindles (and GTO's) - are challenged by the outcome of this study. A broad layer of collagenous con- nective tissue organized in series with relatively many short muscle fibers may be assumed to be an area where forces are transmitted over a large transition zone (a broad "line of pull") which requires an adequate number of receptors in that zone. For instance in the case of the SUP muscle this results in a receptor rich muscle, since the muscle/connective tissue unit here nearly completely coincides with the muscle concerned. In the case of the ECR muscle a relatively small and narrow zone of muscular tissue fits to bridge the proximal and distal stress-conveying collagenous connective tissue layers, resulting in a muscle with low receptor density. If receptor distribution in muscles is considered starting from the proposed concept of "monitor muscle/connective tissue in-series units", the variance in receptor density in various muscles becomes understandable in terms of architecture of muscullar and regular dense collagenous connective tissue.

Some authors have postulated that the "line of pull" of a given muscle is a preferential area for muscle spindle-rich zones correlated with $\mathrm{S}$ (low) $\mathrm{O}$ (xydative) extrafusal fiber distribution (Meyer-Lohmann et al., 1974; Gonyea and Ericson, 1977; Maier, 1979; Galvas and Gonyea, 1980; Cameron et al., 1981). A regional study as performed here, reestablishes the concept of "line of pull" as organization principle for the architecture of muscle spindles and GTO"s. The described monitor muscle spindle/GTO zones coincide with extrafusal fiber areas bridging between the proximal and distal force transmitting collagenous connective tissue structures and represent a regional (transmuscular) pattern of "lines of pull". However, this organization pattern coincides with muscle/connective tissue inseries units rather than with muscles as substrate of "lines of pull", since muscles do not represent the architectural units functioning in the conveying of stresses.

Adirect consequence of the proposed concept is that the organization of the morphological substrate of proprioception should be regarded in terms of fractions of muscu- 
lar tissue rather than in terms of muscles. Recent research has made it plausible that also on the level of spinal sensorimotor control no longer muscles should be regarded as the functional entity in the locomotor system. Nelson and Mendell (1978) found that muscle spindle afferents may project to motoneurons of another muscle, thus indicating that spindles and the muscle in which they occur are not strictly linked on the level of motor control. Also the organization principle of neuromuscular muscle compartments - projecting in a topographical organization to the corresponding motor nucleus - (Letbetter, 1974; English and Letbetter, 1982a, 1982b; English and Weeks, 1984; English, 1985) is thought to allow the organism to differentiate muscle activity into activity of muscle parts. This again matches well the task-dependent model of Loeb $(1981,1982,1984)$ i.e. that motor units are not necessarily organized with respect to individual motor nuclei but are organized according to behavioral tasks. In such concepts physiologically defined tasks not only have their neuro-anatomical correlate, but also a neuromuscular one in which muscle compartments must be involved. In this model a so-called task group contribution is defined as an impulse to maintain (against gravity) or change momentum of the limb. In locomotion, a given muscle"s velocity can be seen more appropriately as the result rather than as the cause of the necessary skeletal movement.

To regard the locomotor apparatus as being built up by architectural units of muscular tissue in series with collagenous connective tissue is more consistent with such trans- or supramuscular models than the concept in which muscles function as the entities that maintain joint integrity.

It is concluded that in vivo the activity of a mechanoreceptor is not only defined by its functional properties, but also by its architectural environment. If Abrahams (1982) and Richmond and Bakker (1982) state that the topography of mechanoreceptors provides a "subtle comparative function in the process of sensory coding of muscle events", they raise the important issue of the spatial distribution of receptors in the process of proprioception. To this the notion should be added that the architecture of the muscular and connective tissue to which receptor distribution is related, plays a significant role in the coding of the proprioceptive information that is provided. 


\section{Conclusions}

1 The principle or basic unit in the architecture of the morphological substrate of proprioception is the in-series muscular tissue/connective tissue/skeletal tissue unit with mechanoreceptive substrate at the transitions between the various tissues involved. In muscular tissue zones intermediate between proximal and distal regular dense collagenous connective tissue structures, this results in the appearance of "monitor GTO/muscle spindle/GTO zones".

2 The usual distinction between joint receptors and muscle receptors is not valid in the concept in which muscular and collagenous connective tissue (structures) function in series while maintaining joint integrity and stability. In vivo those connective tissue structures are strained during movements of the skeletal parts induced and led by tension (alterations) in muscular tissue.

3 The morphological substrate of proprioception in the lateral cubital region of the rat is concentrated in those areas where - based on the description of the architecture of the muscular and connective tissue - the conveying of tensile stresses over the elbow joint is expected to take place.

4 A mutual relation exists between structure (and function) of the mechanoreceptors and the architecture of the muscular and regular dense collagenous connective tissue. Both are instrumental in the coding of proprioceptive information to the CNS. 


\section{Further studies}

In this study the spatial relation between the architecture of the muscular and connective tissue and the organization of the morphological substrate of proprioception has been studied by means of descriptive methods. Functional significance of the proven relation had to be based on interpretation of the topographical features. To define the functional role of the architecture of the regular dense collagenous connective tissue in the sensory coding of proprioceptive information, several (experimental) studies need to be carried out.

The occurrence and distribution of the mechanoreceptive substrate in the rat should be compared to the situation in the homologous region of man. The hypotheses brought forward about the functional relation between mechanoreceptor distribution and architecture of muscular and comnective tissue, may then be applied to a region in which, moreover, the role of the architecture in the transmission of forces is known (v.Mameren, 1981, 1983; Drukker et al., $1983 \mathrm{a}-\mathrm{c}$, v. Mameren and Drukker, 1984).

In the rat neurophysiological recordings could be carried out to establish the role of the demonstrated receptors in the process of joint position and joint movement sense. This would meet the condition stated by Nade et al. (1987) that conclusions about the role in proprioception of periarticular receptors should be based on single unit recordings in which the peripheral connection of each fiber is anatomically identified, including architectural relations and tissue texture. Such recordings could be done either directly from the two plexuses decribed or from their afferent nerve branches to determine the activity of type III and type IV fibers. The activity of those afferent nerve fibers could be registered during various conditions of action - active (electrophysiologically induced) or passive (stretch) - of the muscular tissue organized in series with regullar dense collagenous connective tissue structures. If the mechanosensitive substrate attached to those connective tissue structures, as revealed by this study, proves to react to mechanical activity of the muscular tissue inserted to that connective tissue, this could be regarded as a confirmation of the in-series model as described here for those "muscle/comnective tissue monitor units". It might even be possible to record the electrophysiological activity of the afferent fibers from the mechanoreceptors related to the supinator septum in various positions or various activities of the foreleg or the supinator muscle. In this way it could be elucidated under what conditions those mechanoreceptors are triggered. For instance: in what joint position and with what muscle contracted or relaxed:

The concept of "neuromuscular compartmentalization" as proposed by Weeks and English (1985) and others, could be verified and tested in the antebrachial extensor region of the rat. The neuromuscular organization of the described "muscle/connective tissue monitor zones" could be studied in relation to the described "muscle/connective tissue units" and muscle topography, on the level of the spinal cord. Extensive experiments with retrograde tracing techniques could result in a projection map of the dorsal root ganglion as well as of the spinal cord in relation to the spinal topology of the alpha- and gamma-neurons (Mense, 1988). The question could be raised what role the architecture of muscular and connective tissue plays during development of the morphological substrate of proprioception. The relation between receptor distribution on the one hand and extrafusal fiber type, nerve distribution, line of pull and connective tissue architecture on the other hand is evident, but still post or propter of this relation remains questionable. A method to elucidate the nature of this relation could be found in studying the effects of experimental changes in the balance of forces during development e.g. by intrauterine tenotomy. The "induction" of muscle spindles and Golgi tendon organs in the rat occurs before the 15 th day of prenatal development (Milburn, 1973, 1984; Zelena, 1957). Inactivation of muscles by means of de-efferentia- 
tion and tenotorny (Zelena, 1957, 1963; Soukup and Zelena, 1977b) carried out in the period from the 17 th day p.c. till the second postnatal day of development, alters measures, shape and structure, (Hnik et al., 1971), but not the number of the muscle spindles and Golgi tendon organs in hindlimb muscles of the rat. Changes in the distribution pattern of the mechanoreceptive substrate that possibly result from such experimental changes in the local mechanical relations, has not yet been studied.

Pilot experiments carried out in our institute (v.d.Wal and v.Dongen, 1986; v.d.Wal and Drukker, 1987) reveal that it is possible to change the architecture of the muscular and connective tissue by means of intrauterine tenotomy on the 18 th p.c. allowing the animal to survive till young adulthood ( 12 weeks). Tenotomized distal extensor muscles establish a new distal insertion on the foreleg bones resulting in new architectural relations between the muscular tissue and the adjoining proximal connective tissue. The spatial distribution of muscle spindles and Golgi tendon organs in such altered mechanical conditions could be described in its relation to the connective tissue, not only within the tenotomized muscle but explicitly in the context of the regional architecture. 


\section{CHAPTER 9}

\section{REFERENCES}

Abrahams, V.C., 1982, Neck muscle proprioception and motor control. In: Garlick, D. (ed.), Proprioception, posture and emotion: $103-120$, Kensington N.S.W., University of New South Wales - Comm. in postgraduate medical education.

Alnaes, E., 1967, Static and dynamic properties of Golgi tendon organs in the anterior tibial and soleus muscles of the cat, Acta Physiol. Scand. 70: $176-178$.

Andres, K.H., and Düring, M. von, 1972, Morphology of cutaneous receptors. In: Iggo, A. (ed.), Handbook of sensory physiology, Vol. II, Somatosensory system: $3-28$, Springer Verlag, Berlin, Heidelberg, New York.

Andres, K.H., Düring, M. von, and Schmidt, R.F., 1985, Sensory innervation of the Achilles tendon by group III and IV afferent fibers, Anat. Emb. 172: 145 - 156.

Andres, K.H., von Düring, M. von, Muszynski, K, and Schmidt, R.F ${ }^{\prime}, 1987$, Nerve fibres and their terminals of the dura mater encephali of the rat, Anat. Emb. 175: $289-301$.

Andrew, B.L., 1954, The sensory innervation of the medial ligament of the knee joint, J. Physiol. 123: 241 - 250.

Arendt, K.W., and Asmussen, G., 1974, Die Anzahl und die Verteilung von Muskelspindeln in M. Triceps Surae der Ratte, Anat. Anz. 136: $207-216$.

Aro, H., Eerola, E., and Aho, A.J., 1985, Development of non-unions in the rat fibula after removal of periosteal neural mechanoreceptors, Clin. Orthop. Rel. Res. 199: $292-299$.
Bakker, G.J., and Richmond, F.J.R., 1981 , Two types of muscle spindles in cat neck muscles: a histochemical study of intrafusal fiber composition, J. Neurophysiol. 45: 973 $-986$.

Bakker, D.A. and Richmond, F.J.R., 1982, Muscle spindle complexes in muscles around upper cervical vertebrae in the cat, J. Neurophysiol. 48: $62-74$.

Baljet, B. and Drukker, J., 1975, An acetylcholinesterase method for in toto staining of peripheral nerves ${ }_{»}$ Stain Techn. 50: 31-36.

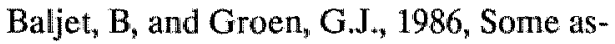
pects of the peripheral nervous system in the human fetus as revealed by the acetylcholinesterase in toto staining method, Acta Histochem. Suppl. 32: 69 - 75.

Banks, R., and Stacey, M., 1988, Quantitative studies on Mammalian muscle spindles and their sensory innervation. In: Hnik, P. et al. (eds.), Mechanoreceptors, Development, Structure and Function: 263 - 269, Plenum Press, New York and London

Barker, D., 1962, The structure and distribution of muscle receptors. In: Barker, D. (ed.), Symposium on Muscle Receptors: 227 - 240, Hong Kong University Press, Hong Kong.

Barker, D. 1974, The morphology of muscle receptors. In: Barker, D., Hunt, C.C., and McIntyre, A.K. (eds.), Handbook of Sensory Physiology, Vol.III/2: Muscle receptors: 2 - 190, Springer Verlag, BerlinNew York.

Barker, D., and Chin, N.K., 1960, The number and distribution of muscle spindles in certain muscles of the cat, J. Anat. 94: 473 486. 
Barker, D., and Ip, M.C., 1961, A study of single and tandem types of muscle-spindle in the cat, Proc. Roy. Soc. B.154: $377-397$.

Baxendale, R.H., and Ferrell, W.R., 1983 , Discharge characteristics of the elbow joint nerve of the cat, Brain Res. $261: 195-203$.

Baxendale, R.H. and Ferrell, W.R., 1987, Disturbance of proprioception at the human knee resulting from acute joint distension, J. Physiol. 392: 60P.

Beursgens, J.P.W.M. Mameren, H. van and Drukker, J., 1987, A computer-aided reconstruction technique in anatomical research and teaching, Acta Anat. 130: 11.

Binder, M.D., Kroin, J.S., Moore, G.P., Stauffer, E.K., and Stuart, D.G., 1976, Correlation analysis of muscle spindle responses to single motor unit contractions, $J$. Physiol. 257: 325 - 336.

Binder, M.D., and Stuart, D.G., 1980 , Motor unit-muscle receptors interactions: Design features of the neuromuscular control system. In: Desmedt, I. (ed.), Prog. in Clin. Neurophysiol. 8.: 72 - 98, Karger, Basel.

Binder, M.D., and Osborn, C.E., 1985, Interactions between motor units and Golgi tendon organs in the tibialis posterior muscle of the cat, J. Physiol. 364: $199-215$.

Botterman, B.R., Binder, M.D., and Stuart, D.G., 1978, Functional anatomy of the association between motor units and muscle receptors, Amer. Zool. 18: 135-152.

Bout, R.G., 1987, Neuroanatomical circuits for proprioceptive and motor control of feeding movements in the mallard (Anas platyrhynchos L.), Thesis, University of Leiden, The Netherlands.

Boyd, I.A., 1954, The histological structure of the receptors of the knee joint of the cat correlated with their physiological re- sponse, I. Physiol. 124: 476-488.

Boyd, I.A., and Davey, M.R., 1968, Composition of Peripheral Nerves, E \& S Livingstone Ltd., Edinburgh.

Bridgman, C.F., Eldred, E., and Eldred B., 1962, Distribution and structure of muscle spindles in the extensor digitorum brevis of the cat, Anat. Rec. 143: 219 - 227.

Bridgman, C.F., 1968 , The structure of tendon organs in the cat: a proposed mechanism for responding to muscle tension, Anat. Rec. 162: 209 -220.

Bridgman, C.F., 1970, Comparisons in structure of tendon organs in the rat, cat and man, J. Comp. Neurol. 138: 369 - 372.

Brodal, A. 1981, Neurological Anatomy in relation to clinical medicine, $3 \mathrm{rd}$. ed., Oxford University Press, Oxford, New York.

Burg, $E_{n}, 1988$, De perifere verbindingen van zenuwplexus in de distale voorpoot van de rat met het CZS (Peripheral projection of nervous plexuses in the antebrachial region of the rat to the CNS), Internal Report D1281, University of Limburg, The Netherlands.

Burgess, P.R., and Clarke, F.J., 1969, Characteristics of knee joint receptors in the cat, J. Physiol. 203: 317 - 335.

Burgess, P.R., and Perl, E.R., 1973, Cutaneous mechanoreceptors and nociceptors. In: Iggo, A. (ed.), Handbook of Sensory Physiology, Vol. II, Somatosensory System: $29-78$, Springer Verlag, Berlin, Heidelberg, New York.

Burke, R.E., 1981, Motor units: anatomy, physiology, and functional organization. In: Brooks, V.B. (ed.), Handbook of Physiology, Section I: The nervous system, Vol. II, Motor Control, part I: 345 - 422, American Physiological Society, Bethesda. 
Burke, R.E., Levine, D.N., Tsairis, P., and Zajac, R.E., 1973, Physiological types and histochemical profiles in motor units of the cat gastrocnemius, J. Physiol. 234: 723 - 748.

Cameron, W.E., Binder, M.D., Botterman, B.R., Reinking, R.M., and Stuart, D.G., 1981, "Sensory partitioning" of cat medial gastrocnemius muscle by its muscle spindles and tendon organs, J. Neurophysiol. 46: 32 - 47 .

Campbell, 1971, Operative orthopaedics, C.B. Mosby Company, Saint Louis.

Chiasson, R.B., 1980, Laboratory Anatomy of the white rat, 4th ed., Wm. C. Brown Comp., Dubuque (Iowa),

Chin, N.K., Cope, M. and Pang, M., 1962, Number and distribution of spindle capsules in seven hindlimb muscles of the cat. In: Barker, D. (ed.), Symposium on Muscle Receptors: 241 - 248, Hong Kong University Press, Hong Kong.

Christ, B., Jacob, H.J., Jacob, M., and Wachtler, F., 1983, On the origin, distribution and determination of avian limb mesenchymall cells. In : Limb development and regeneration. Part B: 281 - 291, A.R. Liss Inc., New York.

Christ, B., and Jacob, H.J., 1986, Morphogenese, Musterbildung und Zellmigration als Teilprozesse der Extremitätenentwicklung bei Amniotenembryonen. Eine Synopsis experimenteller Befunde, Verh. Anat. Ges. 80: 115 - 126.

Clark, F.J., 1975, Information signalled by sensory fibers in the medial articular nerve, J. Neurophysiol. 38: 1464 - 1472.

Clark, F.J., and Burgess, P.R., 1975, Slowly adapting receptors in the cat knee joint: can they signal joint angle?, J. Neurophysiol. 38 : 1448 - 1463.

Crago, P.E., Houk, J.C., and Rymer, W.Z.,
1982, Sampling of total muscle force by tendon organs, J. Neurophysiol. 47: 1069 - 1083 .

Cross, M.J., and McCloskey, D.I., 1973, Position sense following surgical removal of joints in man, Brain. Res. 55: 443 - 445 .

Devanandan, M.S., Ghosh, S., and John, K.T., 1983, A quantitative study of muscle spindles and tendon organs in some intrinsic muscles of the hand in the bonnet monkey (Macaca radiata), Anat. Rec. 207: 263 266.

Drukker, J., Mameren, H. van, and Wal, J.C. van der, 1983a, The functional anatomy of structures guiding tensile and compressive loads in the human elbow region, Proc. NATO Advanced Study Institute 151, Lissabon.

Drukker, J., Mameren, H. van, and Wal, J.C. van der, 1983b, Connective tissue structures in the cubital region of man and rat. Their role in guidance of forces and their role as a substrate for propriocepsis, J. Anat. 137: 432 .

Drukker, J., Mameren, H. van, and Wal, J.C. van der, 1983c, A description of the gross anatomy (with some functional implications) of connective tissue structures in the cubital region of man and rat, Anat. Anz. 153: 269 .

Drury, R.A.B., and Wallington, E.A., 1980, Holmes' (1947) method for axons. In: Carleton's Histological Technique, 5th ed.: 360 -362 , Oxford University Press, Oxford.

Düring, M. von, 1988, Topographie und feinstrukturelle Analyse von Endigungen dünner markhaltiger und markloser Afferenzen in M. Gastrocnemius/M. Soleus der Katze, Proc. Symposium The Primary Afferent Neuron, Zürich, 1988, Anat. Anz: in press. 
Düring, M. von, Andres, K.H., and Schmidt, R.F., 1984, Ultrastructure of fine afferent terminations in muscle and tendon of the cat. In: Hamann, W., and Iggo, A. (eds.), Sensory receptor mechanisms: 15 23, World Scient. Publ. Co. Singapore.

Eklund, G., and Skoglund, S., 1960, On the specificity of the Ruffini like joint receptors, Acta Phsyiol. Scand. 49: 184 - 191.

Eldred, E., Bridgman, C.F., Swett, J.E., and Eldred, B., 1962, Quantitative comparisons of muscle receptors in cat's medial gastrocnemius, soleus, and extensor digitorum brevis muscles. In: Barker, D. (ed.), Symposium on Muscle Receptors: 207 - 213, Hong Kong University Press, Hong Kong.

English, W.A., 1985, Limbs vs. Jaws: Can They Be Compared?, Amer. Zool. 25: 351 363.

English, A.W., and Letbetter, W.D., 1982a, Anatomy and innervation patterns of cat lateral gastrocnemius and plantaris muscles, Amer. J. Anat. 164: 67 - 77.

English, A.W., and Letbetter, W.D., 1982b, A histochemical analysis of identified compartments in cat lateral gastrocnemius muscle, Anat. Rec. 204: 123 - 130.

English, A.W., and Weeks, O.I., 1984, Compartmentalization of single muscle units in cat lateral gastrocnemius, Exp. Brain Res. 56: 361 - 368.

Erikson, P.O, and Thornell, L.E, 1987, Relation to extrafusal fiber-type composition in muscle-spindle structure and location in the human masseter muscle, Arch. Oral Biol. 32: 483 - 491 .

Falck, B., Hillarp, N.A., Thieme, G., and Thorp, A., 1962, Fluorescence of catecholamnines and related compounds condensed with formaldehyd, J. Histochem. Cytochem. 10: 348 - 354.
Ferrell, W.R., 1980, The adequacy of stretch receptors in the cat knee joint for signalling joint angle throughout a full range of movement, J. Physiol. 299: 85 - 99.

Ferrell, W.R., 1985, The response of slowly adapting mechanoreceptors in the cat knee joint to tetanic contraction of hindlimb muscles, Quart. J. Exp. Physiol. 70: 337 345.

Ferrell, W.R., 1988, Discharge characteristics of joint receptors in relation to their proprioceptive role. In: Hnik, P. et al. (eds.), Mechanoreceptors, Development, Structure, and Function: 383 - 388, Plenum Press, New York and London.

Ferrell, W.R., Nade S., and Newbold, P.J., 1986, The inter-relation of neural discharge, intra-articular pressure and joint angle in the knee of the dog, J. Physiol. 373: 353 365 .

Ferrell, W.R. and Smith, A., 1987, The effect of digital nerve block on position sense at the proximal interphalangeal joint of the human index finger, Brain Research 425: $369-371$.

Ferrell, W.R., Gandevia, S.C., and McCloskey, D.I., 1987, The role of joint receptors in human kinaesthesis when intramuscular receptors cannot contribute, J. Physiol. 386: 63 - 71 .

Freeman, M.A.R., Dean, M.R.E. and Hanham, J.W.F. 1965, The etiology and prevention of functional instability of the foot, J. of Bone and Joint Surg. 47B: 678.

Freeman, M.A.R. and Wyke, B.D., 1967a, The innervation of the ankle joint. An anatomical and histological study in the cat, Acta Anat. 68: 321 - 333 .

Freeman, M.A.R. and Wyke, B.D., 1967b, The innervation of the knee joint. An anatomical and histological study in the cat, J. of Anat. 101: 505 - 532. 
Freeman, M.A.R, and Wyke, B.D. $1967 \mathrm{c}$, Articular reflexes at the ankle joint: an electro-myographic study of normal and abnormal influences of ankle-joint mechanoreceptors upon reflex activity in the leg muscles, Brit. J. Surg. 54: $990-1001$.

Fukami, Y., 1981, Responses of isolated Golgi tendon organs of the cat to muscle contraction and electrical stimulation, $\mathfrak{J}$. Physiol. 318: $429-443$.

Galvas, P.E., and Gonyea, W.J., 1980, Motor-end-plate and nerve distribution in a histochemically compartmentalized pennate muscle in the cat, Am. J. Anat. 159: 147 $-156$.

Gandevia, S.C., 1983, Psychophysical and electrophysiological evidence for the cortical projection of muscle afferents in man. In: Proc. Australian Physiological and Pharmacological Society 14:241 - 259 .

Gans, C., 1982, Fiber architecture and muscle function, Exer. Sport Sci. Rev. 11: $160-207$.

Gans, C., and Bock, W.J., 1965, The functional significance of muscle architecture A theoretical analysis, Ergebn. Anat. Entwicklgesch. 38: $115-142$.

Gardner, E., 1948, The innervation of the elbow joint, Anat. Rec. 102: 161 - 173.

Gardner, E., 1950, Physiology of movable joints, Physiol. Rev. 30: 127 - 176.

Goldfinger, M.D., and Fukami, Y., 1982, Distribution, density and size of muscle receptors in cat tail dorsolateral muscles, J.Anat. 135: 371 - 384.

Gonyea, W.J., and Ericson, G.C., 1977, Morphological and histochemical organization of the flexor carpi radialis muscle in the cat, Am. J. Anat. 148: 329 - 344.

Goodwin, G.M., McCloskey, D.I., and
Matthews, P.B.C., 1972, The contribution of muscle afferents to kinaesthesia shown by vibration induced illusions of movement and by the effect of paralysing joint afferents, Brain 95: 705 - 748.

Greene, E.Ch., 1959, Anatomy of the rat, 2nd ed., Hafner Publishing Company, New York.

Gregory, J.E., and Proske, U., 1979, The response of Golgi tendon organs to stimulation of different combinations of motor units, J. Physiol. 295: 251 - 262.

Gregory, J.E., Morgan, D.L., and Proske, U., 1986, The discharge of cat tendon organs during unloading contractions, Exp. Brain Res. 61: 222 - 226 .

Grigg, P., 1975, Mechanical factors influencing response of joint afferent neurons from cat knee, J. Neurophysiol. 38: 1473 1484.

Grigg, P., 1976, Response of joint afferent neurons in cat medial articular nerve to active and passive movements of the knee, Brain Res. 118: 482 - 485.

Grigg, P., Finerman, G.A., and Riley, L.H., 1973, Joint-position sense after total hip replacement, Am. J. Bone Jt. Surg. 55: 1016 1025.

Grigg, P., and Greenspan, B.J., 1977, Response of primate joint afferent neurons to mechanical stimulation of knee joint, J. Neurophysiol. 40: 1 - 8 .

Grigg, P., Hoffman, A.H., and Fogarly, K.E., 1982, Properties of Golgi-Mazzoni afferents in cat knee joint capsule, as revealed by mechanical studies of isolated joint capsule, J. Neurophysiol. 47: 31 - 40.

Grigg, P., and Hoffman, A.H., 1982, Properties of Ruffini afferents revealed by stress analysis of isolated sections of the knee capsule, J. Neurophysiol.. 47: 41 - 54. 
Grigg, P., and Hoffman, A.H., 1984, Ruffini mechanoreceptors in isolated joint capsule: responses correlated with strain energy density, Somatosens. Res. 2: $149-162$.

Grim, M., 1972, On the problem of irregular distribution of muscle spindles, Folia Morphol. 20: 119-120.

Groen, 1986, Contributions to the anatomy of the peripheral autonomic nervous system, Thesis, University of Amsterdam, The Netherlands.

Groen, G.J., Baljet, B., and Drukker, J., 1988, The innervation of the spinall dura mater: anatomy and clinical implications, Acta Neurochír. 92: 39 - 46.

Hagbarth, K.E., and Wohlfart, G., 1952, The number of muscle spindles in certain muscles in the cat in relation to the composition of the muscle nerves, Acta Anat. 15: $85-104$.

Halata, Z., 1977, The ultrastructure of the sensory nerve endings in the articular capsule of the knee joint of the domestic cat (Ruffini corpuscles and Pacinian corpuscles), J. Anat. 124: 717 - 729.

Halata, $Z_{\text {., }}$ and Munger, B.L., 1983, The sensory innervation of the primate facial skin, II. Vermillion border, Brain Res. Rev. 5: 81 - 107.

Halata, Z., Badalamente, M.A., Dee, R., and Propper, M., 1984, Ultrastructure of sensory nerve endings in monkey (Macaca fascicularis) knee joint capsule, J. Orthop. Res. 2: 169 - 176.

Halata Z., Rettig, T. and Schulze, W., 1985 , The ultrastructure of sensory nerve endings in the human knee joint capsule, Anat. Embryol. 172:265-275.

Halata, Z, and Strasmann, Th., 1988, Die LItrastruktur der Mechanorezeptoren in Muskulo-skelettal System einiger Saüger,
Marsupialier und Vögel, Anat. Anz.: in press.

Hebel, R. and Stromberg, M.W., 1986, Anatomy and Embryology of the Laboratory rat, Wörthsee Biomed. Comp.

Heppelman, B., Messlinger, K., and Neiss, W.F., 1988, Ultrastruktur un Rekonstruktion von Freien Nervenendigungen im Kniegelenk der Katze, Anat. Anz.: in press.

Hnik, P., and Zelena, J., 1961, Atypical spindles in reinnervated rat muscles, $\mathrm{J}$. Embryol. Exp. Morph. 9: 456 - 467.

Hnik, P., Beranek, R., Vyklicky, L., and Zelena, J., 1963, Sensory outflow from chronically tenotomized muscles, Physiol. Bohemoslov. 12: 23 - 29.

Hohmann, E.L., Elde, R.P., Rysavy, J.A., Einzig, S., and Gebhard, R.L., 1986, Innervation of periosteum and bone by sympathetic vasoactive intestinal peptide-containing nerve fibers, Science 232: 868 - 871 .

Holt, S.J., Hobbiger, E.E., and Pawan, G.L.S., 1959, Preservation of integrity of rat tissues for cytochemical staining purposes, J. Biophys. Biochem. Cytol. 7: 383 - 386 .

Hömig, J.R., 1970, Die Anatomie des aktiven Bewegungsapparates der Albinoratte (Mus rattus norvegicus albinus), Inaug.Diss der Tierärtzlichen Fakultät, München.

Houk, J.C., and Henneman, E., 1967, Responses of Golgi tendon organs to active contractions of the soleus muscle of the cat, J. Neurophysiol. 30: 466 - 481.

Hunt, C.C., 1974, The physiology of muscle receptors. In: Hunt, C.C. (ed.), Handbook of Sensory Physiology, Vol. III, part 2, Muscle Receptors: 191 - 234. Springer Verlag, Berlin, New York.

Iggo, A., 1985, Sensory receptors in the skin of mammals and their sensory functions, 
Rev. Neurol. 141: $599-613$.

Jacob, H.J., and Christ, B., 1980, On the formation of muscular pattern in the chick limb. In: Merker, H.J. et al. (eds.), Teratology of the limbs: $89-97$, Walter de Gruyter and $\mathrm{Co}$, Berlin, New York.

Kanatani, Y., Hirohata, K., and Umetani, $T ., 1986$, An autoradiographic study on the distribution of sensory nerve endings in the knee joint of the rat, J. Jpn. Orthop. Ass. 60: $1283-1292$.

Kaneff, A., 1959, Beitrag zur Morphologie und Ausbildung des M. ext. digitorum lateralis bei einigen fünffingrigen Säugern, Morphol. Jahrb. 100: 115 - 130.

Kaneff, A., 1960, Beitrag zur Morphologie des M. Extensor digitorum profundus bei manchen fünffingrigen Säugern, Morph. Jahrb. 100: 648 - 665 .

Karnowsky, M.J., and Roots, L., 1964, A "direct-coloring" thiocholine method for cholinesterases, J. Histochem. Cytochem. 12: $219-221$.

Kruger, L., Perl, E.R., and Sedivec, M.J., 1981 , Fine structure of myelinated mechanical nociceptor endings in cat hairy skin, $\mathbf{J}$. Comp. Neurol. 198: 137 - 154.

Laczko, J. and Levai, G., 1975, A simple differential staining method for semithin sections of ossifying cartilage and bone tissue embedded in epoxy resin, Mikroskopie 31: 1 - 4 .

Landsmeer, J.M.F., 1955, Anatomical and functional investigations of the articulations of the human fingers, Acta Anat. 25: 1 - 69.

Landsmeer, J.M.F., 1976, Atlas of Anatomy of the hand, Churchill Livingstone, New York.

Langford, L.A., and Schmidt, R.F., 1983, Afferent and efferent axons in the medial and posterior articular nerves of the cat, Anat. Rec. 206: 71 - 78 .

Lataster, L.M.A. and Mameren, H. van, 1983, Eine Methode zur Einbettung von Aufhellungspräparaten in Kunstharz, Der Präparator 29: 165 - 172.

Lataster, L.M.A., Rensema, J.W., Mameren, H. van and Drukker, J., 1984, Transverse sections of the elbow region in man, made into transparancies and embedded in plastic in a self study module, Anat. Rec. 210: 541 - 547.

Lee, H.B., and Wilson, A.S., 1985a, Fibre analysis following experimental denervation of the anterior aspect of the knee, $J$. Anat. 143: 242.

Lee, H.B., and Wilson, A.S., 1985b, A quantitative elucidation of the innervation of the anterior apparatus of the knee in the rat, Proceedings XIIth International Anatomical Congress, London.

Lennartson, B., 1980a, The occurrence of muscle spindles in the masticatory muscles. A methodological study of different staining techniques, J. Anat. 130: 127 - 130.

Lennartson, $B_{*}, 1980 b$, Number and distribution of muscle spindles in the masticatory muscles of the rat, J. Anat. 130: 279 288 .

Letbetter, W.D., 1974, Influence of intramuscular nerve branching on motor unit organization, Anat. Rec. 178: 402.

Loeb, G.E., 1981, Somatosensory unit input to the spinal cord during normal walking, Canadian J. of Physiol. and Pharmacol. 59: $627-635$.

Loeb, G.E., 1982, Task groups - A proposed functional unit for motor control, Abstr. Soc. Neurosci. 8: 272.7. 
Loeb, G.E, 1984, The control and responses of mammalian muscle spindles during normally executed motor tasks, Exer. Sport Sci. Rev. 12: 157 - 203

Lojda, Z., Gossrau, R., Schiebler, T.H., 1976, Enzymhistochemische Methoden: 54 - 60, Sptinger Verlag, Berlin, Heidelberg, New York.

Luft, J.H., 1961, Improvements in epoxy resin embedding methods, J. Biophys. Biochem. Cytol. 9: 409 - 414.

Lund, J.P., Richmond, F.J.R., Touloumis, C., Patry, Y., and Lamarre, Y., 1978, The distribution of Golgi tendon organs and muscle spindles in masseter and temporalis mucles in the cat, Neurosc. 3: $259-270$.

Maier, A., 1979, Occurence and distribution of muscle spindles in masticatory and suprahyoid muscles of the rat, Am. J. Anat. 155: 483 - 506.

Malinovsky, L., 1986, Classification of sensory nerve endings in vertebrates brought up to date, Folia Morphol. 34: 261 - 264.

Malinowsky, L, and Pac, L., 1982, Morphology of sensory corpuscles in mammals, Acta Fac. Med. Univ. Brun. 79: 5 - 219.

Mameren, $\mathrm{H}$. van, 1981, Muscle insertions around the humero-radial joint, Acta Morph. Neerl..Scand. 19: 90-91.

Mameren, H. van, 1983, Reaction forces in a model of the human elbow joint, Anat. Anz. 152: $327-328$.

Mameren, H. van, and Wal, J.C. van der, 1983, Comparison of the organisation of the connective tissue in relation with muscle and nerve tissue in the cubital region in man and in the rat, Acta Morphol. Neerl.Scand. 21: 169.

Mameren, H. van, and Drukker, J., 1984, A functional anatomical basis of injuries to the ligamentum and other soft tissues around the elbow joint: Transmission of tensile and compressive loads, Int. J. Sports Med. 5 (suppl.): $88-92$.

Mameren, H. van, Groenewegen, W. and Rensema, H., 1984, A computerized drawing method to make representations of the collagenous connective tissue structures in situ around the elbow joint, Acta Morph. Neerl_-Scand. 22: 253.

Mameren, H. van, Lataster, A., Rensema, H. and Drukker, J., 1985, The use of modern imaging techniques (CT-scanning and NMR) in the study of the locomotor apparatus, Acta Morph. Neerl.-Scand. 23: 247 . 258 .

Marchand, R, Bridgman, C.F, Shumpert, E. and Eldred, E., 1971, Association of terdon organs with spindles in muscles of the cat's leg, Anat. Rec. 169: 23 - 32.

Matthews, P.B.C., 1972, Mammalian muscle receptors and their central a ctions, Edward Arnold, London.

Matthews, P.B.C., 1981, Evolving views on the internal operation and functional role of the muscle spindle, J. Physiol. 320: 1 - 30 .

Matthews, P.B.C., 1982, Where does Sherrington's "muscular sense" originate? Muscles, joints, corollary discharges?, Ann. Rev. Neurosci. 5: 189 - 218.

McCloskey, D.I., 1978, Kinesthetic sensibility, Physiol. Rev. 58: $763-820$.

McIntyre, A.K., Proske, U., and Tracey, D.J., 1978, Afferent fibres from muscle receptors in the posterior nerve of cat's knee joint, Exp. Brain Res. 33: 415 - 427.

Mense, S., 1988, Morphologischen Untersuchungen an physiologisch identifizierten primärafferenten Neuronen, Proc. Symposium The Primary Afferent Neuron, Zürich, 1988, Anat. Anz.: in press. 
Mense, S., and Meyer, $\mathbb{H}_{\text {., }}$ 1981, Response properties of group III and IV receptors in the Achilles tendon of the cat, Pflüg. Arch. 389: R25.

Mense, S., Craig, A.D., Lehmann-Willenbrock, E., and Meyer, H., 1985, Neurobiology of small-diameter afferent fibers from deep tissues. In: Rowe, M.J., and Willis, W.D. (eds.), Development, Organization and Processing Somatosensory Pathways, Allan Liss, New York.

Mense, S., and Meyer, H., 1985, Different types of slowly conducting afferent units in cat skeletal muscle and tendon, J. Physiol. 363: 403 - 417 .

Merrilees, N.C.R., 1962, Some observations on the fine structure of a Golgi tendon organ of the rat. In: Barker, D. (ed.), Symposium on Muscle Receptors: 199 - 206, Hong Kong University Press, Hong Kong.

Meyer-Lohmann, J., Riebold, W., and Robrecht, D., 1974, Mechanical influences of the extrafusal muscle on the static behavior of deefferented primary muscle spindle ending in cat, Pflügers Archiv. 352: 267 - 278 .

Milburn, A., 1973, The early development of muscle spindles in the rat. J. Cell Sci., 12: $175-195$.

Milburn, A., 1984, Stages in development of cat muscle spindle, J. Embryol. Exp. Morph. 82: 177 - 216.

Millar, J., 1973, Joint afferent fibres responding to muscle stretch, vibration and contraction, Brain Res. 63: 380 - 383.

Millar, J, 1975, Flexion-extension sensitivity of elbow joint afferents in cat, Exp. Brain Res. 24: 209 - 214.

Millar, J., 1979, Convergence of joint, cutaneous, and muscle afferents onto cuneate neurons in the cat, Brain Res. 175: 347 - 350.
Miller, M.R., and Kasahara, M., 1963, Observations on the innervation of human long bones, Anat. Rec. 145: 13 - 20.

Munger, B.L, and Halata, Z., 1983, The sensory innervation of primate facial skin, I. Hairy skin, Brain Res. Rev. 5: 45 - 80.

Nade, S., Newbold, P.J., and Straface, S.F., 1987, The effects of direction and acceleration of movement of the knee joint of the dog on medial articular nerve discharge, $J$. Physiol. 388: 505 - 519 .

Nelson, S.G., and Mendell,L.M., 1978, Projection of single knee flexor la fibers to homonymous and heteronymous motoneurons, J. Neurophysiol. 41: 778 - 787.

Nirschl, R.P. and Pettrone, F.A., 1979, Tennis elbow, the surgical treatment of lateral epicondylitis, J. Bone and Joint Surg. 61A: $832-839$.

Novotny, V., 1973, Relation between receptor kind and afferent fiber diameter in knee-joint capsule in the cat, Acta Anat. 86: $436-450$.

O'Connor, B.L. and McConnaughey, J.S. 1978, The structure and innervation of cat knee menisci, and their relation to a "Sensory hypothesis" of meniscal function, Am.J. Anat. 153: 431 - 442.

O'Connor, B.L., and Gonzales, J., 1979, Mechanoreceptors of the medial collateral ligament of the cat knee joint, J. Anat. 129: $719-729$.

Pearse, A.G.E., 1968, Histochemistry, Theoretical and applied, 3rd. ed., Vol. I: 577, Churchill, London.

Peck, D., Buxton, D.F., and Nitz, A.J., 1984, A comparison of spindle concentrations in large and small muscles acting in parallel combinations, J. Morph. 180: 243 - 252 
Peck, D., Buxton, D.F., and Nitz, A.J., 1988, A proposed mechanoreceptor role for the small redundant muscles which act in parallel with large prime-movers. In: Hnik, P. et al. (eds.), Mechanoreceptors, Development, Structure, and Function: 377 - 382, Plenum Press, New York and London.

Peters, G., 1988, Tools for the measurement of stress and strain fields in soft tissue (application to the elbow joint), Thesis, University of Limburg" Maastricht, The Netherlands.

Polacek, P., 1966, Receptors of the joints. Their structure, wariability and classification, Acta Fac. Med. Univ. Brunensis 23: 9 $-107$.

Post, H., Goldberg, V.M. and Larrey, R., 1978 , Extensor fasciotomy for tennis elbow, Clin. Orthop. Rel. Res. 135: 179 - 182.

Prochazka, A., Stephens, J.A., and Wand, P., 1979, Muscle spindlle discharge in normal and obstructed movements, J. Physiol. 287: $57-66$.

Proske, U., 1979, The Golgi tendon organ, TINS 2: $7-8$.

Proske, U, and Gregory, J.E., 1980, The discharge rate: tension relation of Golgi tendon organs, Neurosci. Lett. 16: 287-290.

Reynolds, E.S., 1963, The use of lead citrate at high $\mathrm{pH}$ as an electron-opaque stain in electron microscopy, J. Cell Biol. 17: 208 -212 .

Richmond, F.J.R., Anstee, G.C.B., Sherwin, E.A., and Abrahams, V.C., 1976, Motor and sensory fibres of neck muscles in the cat, Can. J. Phys. Pharm. 54: 294 - 304.

Richmond, F.J.R., and Abrahams, V.C., 1975, Morphology and distribution of muscle spindles in dorsal muscles of the cat neck, J. Neurophysiol. 38: 1322 -1339
Richmond, F.J.R., and Abrahams, V.C., 1979, What are the proprioreceptors of the neck? In: Granit, R., and Pompeiano, O. (eds.), Reflex controll of posture and movement, Progr. Brain Res. 50: 245 - 254.

Richmond, F.J.R., and Bakker, D.A., 1982, Anatomical organization and sensory receptor content of soft tissues surrounding upper cervical vertebrae in the cat, J. Neurophysiol. 48: 49 - 61 .

Richmond, F.J.R., and Stuart, D.G., 1985, Distribution of sensory receptors in the flexor carpi radialis muscle of the cat, $\mathrm{J}$. Morph. 183: 1 - 13.

Richmond, F.J.R., Bakker, G.J., Bakker, D.A., and Stacey, M.J., 1986, The innervation of tandem muscle spindles in the cat neck, J. Comp. Neurol. 245: 483 - 497.

Roddeman, D.G., Drukker, J., Oomens, C.W.J., and Janssen, J.D., 1987a, The wrin-

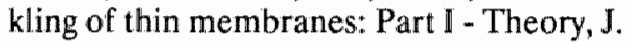
App. Mechan. 109: 884 - 887.

Roddeman, D.G., Drukker, J., Oomens, C.W.J., and Janssen, J.D., 1987b, The wrinkling of thin membranes: Part II - Numerical Analysis, J. App. Mechan. 109: 888 - 892.

Roddeman, D.G., 1988, Force transmission in wrinkled membranes. A numeric tool to study connective tissue structures. Thesis, Technical University, Eindhoven, The Netherlands.

Romeis, B., 1968, Mikroskopische Technik, 16th ed.: 174 (par. 703), R. Oldenbourg Verlag, München-Wien.

Rosser, B.W.C, and George, J.C., 1985, An exceptionally high density of muscle spindles in a slow tonic pigeon muscle, Anat. Rec. 212: $118-122$

Rossi, A., 1983, Joint receptors, kinaesthesia and position sense: a role as yet undefined, Rev. Neurobiol. 29: 42 - 49 . 
Rossi, A. and Grigg, P., 1982, Characteristics of hip joint mechanoreceptors in the cat, I. Neurophysiol. 47: 1029 - 1042.

Rossi, A., and Rossi, B., 1985, Characteristics of the receptors in the isolated capsule of the hip in the cat, Int. Orthopaed. 9: 123 $-127$.

Sathian, $\mathbb{K}$, and Devanandan, M.S., 1983, Receptors of metacarpophalangeal joints: a histological study in the bonnet monkey and man, J. Anat. 137: $601-613$.

Schaible, H.G., and Schmidt, R.F., 1983a, Responses of fine medial articular nerve afferents to passive movements of knee joint, J. Neurophysiol. 49: 1118 - 1126.

Schaible, H.G., and Schmidt, R.F., 1983b, Activation of group III and IV sensory units in medial articular nerve by mechanical stimulation of the knee joint, J. Neurophysiol. 49 :. 35 - 44 .

Schoultz, T.W., and Swett, J.E., 1972, The fine structure of the Golgi tendon organ, J. Neurocyt. 1: $1-26$.

Schoultz T.W., and Swett J.E. ,1974, Ultrastructural organization of sensory fibers innervating the Golgi tendon organs, Anat Rec 179: $147-162$.

Scott, J.J.A, and Young, H., 1987, The number and distribution of muscle spindles and tendon organs in the peroneal muscles of the cat, J. Anat. 151: $143-155$.

Skoglund, S. 1956, Anatomical and physiological studies of knee joint innervation in the cat, Acta Phys. Scand. 36, Suppl. 124: 1 $-101$.

Skoglund, S. 1973, Joint receptors and kinaesthesis. In: Iggo, A. (ed.), Handbook of Sensory Physiology, Vol. II: 111 - 136, Springer Verlag, Berlin, Heidelberg, New York.
Soukup, $T, 1983$, The number, distribution and size of Golgi tendon organs in developing and adult rat muscles, Physiol. Boh. Slov. 32: $211-224$.

Soukup, $T$, and Zelena, J, $1977 \mathrm{a}$, The number and size of Golgi tendon organs in rat muscles during postnatal development, Folia Morphol. 25: $79-82$.

Soukup, T. and Zelena, J., $1977 \mathrm{~b}$, The development of Golgi tendon organs. J. Neurocyt. $6: 171-194$.

Soukup, T., and Zelena, J., 1985, Structure of tendon organs of the rat after neonatal de-efferentiation, Cell. "Tissue Res. 241:229 -236 .

Spaethe, A., 1984, Eine Modifikation der Silbermethode nach Richardson für die Axonfärbung in Paraffinschnitten, Anat. Anz. 78: $101-102$.

Spalteholz, W., 1914, Über das Durchsichtig machen von menschlichen und tierischen Präparaten und seine theoretische Bedingungen, Hirzel, Leipzig.

Spielmann, J.M., and Stauffer, E.K., 1986, Morphological observations of motor units connected in-series to Golgi tendon organs, J. Neurophysiol. 55: 147 - 162 .

Spray, D.C. 1986, Cutaneous temperature receptors, Ann. Rev. Physiol. 48: 625 - 638.

Stephens, J.A., Reinking, R.M., and Stuart, D.G., 1975, Tendon organs of cat medial gastrocnemius: response to active and passive forces as a function of muscle length, J. Neurophysiol. $38: 1217-1231$.

Stilwell, D.L. J $r_{n}, 1957 \mathrm{a}$, The innervation of tendons and aponeuroses, Am.J.of Anat. 100: $289-317$.

Stilwell, D.L. Jr, 1957b, The innervation of deep structures of the foot, Am. J. Anat. 101: $59-73$. 
Stilwell, D.L. Jr., 1957c, The innervation of deep structures of the hand, Am. J. Anat. 101: 75 - 99.

Strasmann, Th., Halata, $Z_{x}$, and Saw Kin Loo, 1987, Topography and ultrastructure of sensory nerve endings in the joint capsules of the Kowari (Dasyuroides byrnei), an Australian marsupial, Anat. Embryol. 176: $1-12$.

Strasmann, Th., and Halata, Z., 1988, Topography of mechanoreceptors in the connective tissue of the elbow joint region in Monodelphis domestica, a laboratory marsupial. In: Hnik, P. et al. (eds.), Mechanoreceptors, Development, Structure, and Function: 331 - 336, Plenum Press, New York and London.

Stuart, D.G., Mosher, C.G., and Gerlach, R.L., 1972, Properties and central connections of Golgi tendon organs with special reference to locomotion. In: Banker, B.Q. (ed.), Research in muscle development and the muscle spindle, Int. Congress Series No. 240, Excerpta medica.

Swett, J.E., and Eldred, E., 1960a, Distribution and numbers of stretch receptors in medial gastrocnemius and soleus muscles of the cat, Anat. Rec. 137: 453-460.

Swett, J.E., and Eldred, Ew, 1960b, Comparison in structure of stretch receptors in medial gastrocnemius and soleus muscle of the cat. Anat.Rec. 137: 461-473.

Thompson, J., 1970, Parallel spindle systems in the small muscles of the rat tail, J. Physiol. 211: 781 - 789 .

Thurston, "T.J., 1982, Distribution of nerves in long bones as shown by silver impregnation, J. Anat. 134: $219-227$.

Tinkelenberg, J., 1979, Graphic reconstructions, Microanatomy with a pencil, $J$. Audiovis. Media Med. 2: 102 -106.
Tracey, D., 1978, Joint receptors - changing ideas, TINS 1: $63-65$.

Tracey, D.J., 1979, Characteristics of wrist joint receptors in the cat, Exp. Brain Res. 34: 165 - 176 .

Tracey, D., 1980, Joint receptors and the control of movement, TINS 3: $253-255$.

Voorhoeve, P.E., (red.), 1978, Leerboek der neurophysiologie. Elsevier, Amsterdam.

Voss, H., 1956, Zahl und Anordnung der Muskelnspindeln in den oberen Zungenbeinmuskeln, in $\mathrm{m}$. Trapezius und $\mathrm{m}$. Latissimus dorsi, Anat. Anz. 103: 443 - 447.

Voss, H., 1958, Zahl und Anordnung der Muskelspindeln in den unteren Zungenbeinmuskeln, dem $\mathrm{m}$. Sternocleidomastoideus und den Mauch- und tiefen Nackmuskeln, Anat. Anz. 105: 265 - 275.

Voss, H., 1971, Tabelle der absoluten und relativen Muskelspindelzahlen der menschlichen Skelettmuskulatur, Anat. Anz. 129: $562-572$.

Weeks, O.I., and English, A.W., 1985, Compartmentalization of the cat lateral gastrocnemius motor nucleus, J. Comp. Neurol. $235: 255-267$.

Wei, J.Y., Simon, J., Randic, M., and Burgess, P.R., 1986, Joint angle signalling by muscle spindle receptors, Brain Res. 370 : $108-118$.

Weijs, W.A., 1973, Morphology of the muscles of mastication in the albino rat, Rattus Norvegicus (Berkenhout, 1769), Acta Morphol. Neerl.-Scand. 11: 321 - 340.

Williams, P.L., and Warwick, R. (eds.), 1980, Gray's Anatomy, 36th ed., Churchill Livingstone, Edinburgh.

Wilson, A.S., and Lee, H.B., 1983, Innerv- 
ation of the knee joint, J. Anat. 136: 649.

Wilson, A.S., and Lee, H.B., 1986, Hypothesis relevant to defective position sense in a damaged knee, J. Neurol. Neurosurgery and Psychiatry 49: 1462 - 1464.

Wohlfart, G., and Henriksson, K.G., 1960 , Observations on the distribution, number and innervation of Golgi musculo-tendinous organs, Acta Anat. 41: 192 - 204.

Woittiez, R.D., Huijing, P.A., and Rozendal, R.H., 1983, Influence of muscle architecture on the length-force diagram of mammalian muscle, Pfluegers Arch. 399: $275-279$.

Wood, L., and Ferrell, W.R., 1985, Fluid compartmentation and articular mechanoreceptor discharge in the cat knee joint, Quart. J. Exp. Physioll. 70: 329 - 335.

Wyke, B.D., 1967, The neurollogy of joints, Ann. Royal Coll. Surgeons Engl. 41: 25 - 50.

Wyke, B., 1979, Neurology of cervical spimal joints, Physiotherapy 65: $72-76$.

Yellin, H., 1969, A histochemical study of muscle spindles and their relationship to extrafusal fibre types in the rat, Am. J. Anat. 125: 31 - 46.

Zelena, J., 1957, The morphogenetic influence of innervation on the ontogenetic development of muscle spindles, J. Embryol. Exp. Morph. 5: 283-292.

Zelena, J., 1963, Development of muscle receptors after tenotomy, Phys. Bohemoslovenica 12: $30-36$.

Zelena, J., 1982, Survival of Pacinian corpuscles after denervation in adult rats, Cell Tissue Res. 224: 673 - 683.

Zelena, J., 1984, The effect of long-term denervation on the ultrastructure of Pacinian corpuscles in the cat, Cell Tissue Res. $238: 387-394$.

Zelena, J., and Soukup, T., 1979, The development of Giolgi tendon organs, J. Neurocytol. 6: $171-194$.

Zellena, J., and Soukup, T., 1983, The inseries and in-parallel components in rat hindlimb tendon organs, Neuroscience 9: $899-910$.

Zenker, W., Die afferente Innervation des m. Sternomastoideus der Ratte, Proc. Symposium The Primary Afferent Neuron, Zürich, 1988, Anat. Anz.: in press.

Zweers, G.A., 1974, Structure, movement and myography of the feeding apparatus of the mallard (Anas platyrhynchos L.). A study in functional anatomy, Neth. J. Zool. 24: $323-467$. 
Strasmann, Th, Wal, J.C. van der, Halata, Z., and Drukker, J., 1988, Functional topography and ultrastructure of periarticular mechanoreceptors in the lateral elbow region of the rat, Acta Anatomica: in press.

Wall, J.C. van der, Drukker, J., and Mameren, H. van, 1984, The organisation of the connective tissue in relation with the muscle and nerve tissue in the lateral cubital region in the rat, Anat. Anz. 156: 631 632.

Wal, J.C. van der, and Drukker J., 1986, The organization of nervous tissue elements in relation with the architecture of the connective and muscle tissue in the lateral cubital region of the rat, Acta Morphol. Neerl.Scand. 24: $147-148$.

Wal, J.C. van der, and Dongen, J. van, 1986, Intrauterine tenotomy in rat - A model for studying the spatial organization of the morphological substrate of propriocepsis, Proc. 27th Dutch Federation Meeting, april 1986: 432 (W12).

Wal, J.C. van der, and Drukker, J., 1987, Das morphologische Substrat der Propriozepsis im lateralen Ellenbogengebiet der Ratte, Anat. Anz. 163: 194.

Wal, J.C. van der, Strasmann, Th., Drukker, J., and Halata, $Z_{n}, 1987$, The occurrence of sensory nerve endings in the lateral cubital region of the rat in relation to the architecture of the connective tissue, Acta Anat. 13: 94.
Wal, J.C. van der, and Drukker, J., 1988, The occurrence of muscle spindles in relation to the architecture of the connective tissue in the lateral cubital region of the rat. In: Hnik, P. et al. (eds.), Mechanoreceptors, Development, Structure, and Function: 345 -346, Plenum Press, New York and London.

Wal, J.C. van der, Strasmann, Th., Drukker, J., and Halata, Z., 1988, Sensory nerve endings in the deep lateral cubital region: a topographical and ultrastructural study in the rat. In: Hnik, P. et al. (eds.), Mechanoreceptors, Development, Structure, and Function: 337 - 344, Plenum Press, New York and London.

Wal, J.C. van der, Strasmann, Th., Drukker, J., and Halata, Z., 1988, The occurrence of sensory nerve endings in the connective tissue in the deep lateral cubital region of the rat, Anat. Anz. 164: in press.

Wal, J.C., van der, and Drukker, J., 1988, The occurrence and distribution of muscle spindles in the lateral cubital region of the rat, Anat. Anz. 164: in press.

Wal, J.C., van der, and Drukker, J., 1988, The organization of muscle spindles and Golgi tendon organs in the lateral cubital region of the rat, Acta. Morphol. Neerl.Scand.: in press.

Wal, J.C. van der, Strasmann, Th., Drukker, J. and Halata, Z, 1988, The connective tissue apparatus in the lateral elbow region of the rat as instrument in the quality of centripetal information, Anat. Anz.: in press. 


\section{CHAPTER 10}

\section{SUMMARY}

In the concept of the spatial organization of the muscular and connective tissue in a given joint region in man, as proposed by Van Mameren and Drukker (1984), muscular and regular dense collagenous connective tissue structures do not function in parallel (as ligaments and muscles) in the maintenance of joint stability and integrity, but as functional tissue units in series with each other and the skeletal elements. In vivo those connective tissue structures are strained during movements of the skeletal parts induced and led by tension (alterations) in muscular tissue.

Therefore the concept on which the description of the morphological substrate of proprioception is usually based - as being distributed and functioning in muscular structures next to articular (regular dense collagenous connective tissue) structures should be reevaluated. For this purpose, several hypotheses have been formulated and their implications tested in the lateral cubital region of the rat. This region has been chosen as model because most insight into the aforementioned functional tissue units has been gained from studies in the corresponding region in man (v.Mameren, 1981; Drukker et al., 1983a-c).

It is hypothesized that functional interpretation of the occurrence and spatial distribution of the morphological substrate of proprioception has to be based on the spatial relation of the substrate with the architecture of muscular and regular dense collagenous connective tissue regarded as organized and functioning as one joint stability system.

Prerequisite for testing this hypothesis is:

- an integral description of the architecture of the muscular and connective tissue in a joint area based on the principles mentioned above, combined with:

- a complete description of the threedimensional arrangement of all the possible (and detectable) morphological substrate of proprioception present.

\section{Materials and methods}

For this study not only techniques were demanded that enable histological recognition of the various types of mechanosensitive nerve endings, but also techniques for three-dimensional representation of the architecture of the muscular and connective tissue as well as of the spatial organization of the morphological substrate of proprioception. The materials and methods applied for both purposes are described in chapter 2. All methods have been applied to the forelegs of young adult ( 12 weeks old) white laboratory rats (Lewis strain). Besides standard methods for the mesoscopic, lightand electron-microscopic identification of nerve structures in situ and a method to dissect connective tissue structures, techniques to obtain three-dimensional representations of the afferent nerve fibers and their endings in relation to the constituents of the locomotor apparatus are described in this chapter. Finally methods used for quantification of the occurrence of mechanoreceptors are explained.

\section{The architecture of the muscular and con- nective tissue in the region}

The architecture of the muscular and connective tissue structures as revealed by dissection and by computerized three-dimensional reconstruction based on serial sections of complete forelegs embedded in a polyester resin, is described in chapter 3 . To define the applied descriptive terms, the topography of the locomotor apparatus in the region under consideration has been described first. Then the architecture of the regular dense collagenous connective tissue is described in relation to the architecture 
of the muscular tissue. A complex apparatus of regular dense collagenous connective tissue exists in the proximal part of the region, malnly consisting of the walls of muscle compartments. Those layers converge towards the lateral humeral epicondyle and the olecranon. The majority of the collagenous fibers is interposed between skeletal tissue and muscle fascicles; ligaments as separate entities consisting of collagenous connective tissue running from bone to bone, cannot be discriminated. Instead, muscle/connective tissue units are identified in the proximal lateral cubital region, in which muscular and regular dense collagenous connective tissue are organized in series and that do not coincide with the usual anatomical classification into muscles and ligaments. It is concluded that in the rat the architecture (spatial organization) of the muscular tissue components in relation to the components of regular dense collagenous connective tissue is similar to that in man (i) and that the region may serve as a model to study the relation between the (spatial) organization of the morphollogical substrate of proprioception and the inseries architecture of muscular and connective tissue (ii). The possible role of the found architecture in the maintenance of stability and integrity in the elbow joint is discussed.

\section{Occurrence and spatial distribution of mechanoreceptors}

In chapter 4 quantitative data about the occurrence and distribution of mechanoreceptors are given. This is done in order to compare the substrate under consideration with data available in literature. Moreover, it seemed worthwile to reestimate the usually applied quantitative parameters, in relation to the concept of the in-series organization of muscular and regular dense collagenous connective tissue. The quantitative data mainly concern the occurrence of muscle spindles and Golgi tendon organs (GTO's) in the lateral cubital and antebrachial region; absolute numbers as well as relative numbers per muscle or per collagenous connective tissue structure are provided. The relative number of muscle spindles per muscle is expressed per gram of muscle (spindle density), per gram of muscle related to muscle size (spindle abundance) and per muscle zone (spindle volume). The number of GTO's is expressed per muscle as well as per collagenous connective tissue structure. It is preliminarily concluded that the applied quantitative parameters per muscle fail to express the functional characteristics of a muscle because the spatial distribution of the muscle receptors as substrate for the perception of stresses and joint movements in the region is not taken into consideration.

Starting from the idea that in particular regular dense collagenous connective tissue structures in series with muscular tissue convey stresses, we have subsequently questioned whether mechanosensitive nerve endings could be found within the above mentioned proximal connective tissue apparatus (chapter 5). Specimens of the components of the proximal connective tissue apparatus - in situ as well as taken out - have been studied for the presence of nerve elements. In particular in the outer muscle compartment walls - considered as components of the mentioned connective tissue apparatus plexiformly arranged nerve fascicles are demonstrated. The nerve fascicles terminate in lamellated corpuscles, Golgi tendon organs, free nerve endings and (sometimes) muscle spindles. The latter structures are situated at the transition of the (stress-conveying) regular dense collagenous connective tissue structures with adjacent areolarly organized capsular connective tissue or with muscle fascicles organized in series with the concerned collagenous layers. The demonstrated free nerwe endings show ultra-microscopical features characteristic for mechanosensitive nerve terminals. Similar nerve endings are present within the collagenous connective tissue apparatus at the transitional area with the periosteal connective tissue. The possible functional significance of the demonstrated substrate of 
proprioception is discussed in relation to the architecture of the muscular and connective tissue and the occurrence of stress and strain in the region. It is concluded that the proximal extensions of the muscle compartment walls are well-equipped with mechanosensitive substrate in relation to the assumed extent to which stresses are conveyed via those collagenous layers. There exists no morphological basis for the description of so-called joint receptors being deformed (stimulated) exclusively by strain that is induced passively in articular collagenous connective tissue structures e.g. by displacement of the articulating bones.

The results of our investigations into occurrence and distribution of mechanosensitive terminals in the complementary constituent of the locomotor apparatus i.e. the muscular tissue, are given in chapter 6 . This mainly concerns the three-dimensional reconstruction of the spatial distribution of muscle spindles and (GTO's) in the region. Those receptors are concentrated in areas of muscular tissue situated in-series with distal stress-conveying structures of regular dense collagenous connective tissue (tendons) on the one hand and proximal structures as such (muscle compartment walls) on the other hand i.e. also in areas extended between such structures. This leads to the definition of "monitor muscle/connective tissue units", the topography of which parallels the architecture of the in-series muscle/connective tissue units described. The patterns of distribution of muscle spindles and GTO's are discussed in relation to current concepts regarding receptor distribution. It is concluded that the receptors concerned are concentrated in those areas where the conveying of tensile stresses over the elbow joint is expected to take place (from muscular tissue via regular dense collagenous connective tissue to a skeletal element).

In chapter 7 the muscle compartment walls coinciding with the periosteal lining of the antebrachial bones in combination with adjoining periskeletal connective tissue, have been studied for the occurrence of nerve elements. A rich nerve plexus exists in the periosteum covering the superficial side of the uinar bone; in the rest of the periosteal. layers such a plexus cannot be demonstrated. Encapsulated nerve endings cannot be demonstrated within or near the periosteal connective tissue on the extensor side of the foreleg bones with an exception for some GTO's in the radial periosteum. Clusters of relatively large Pacinian corpuscles occur in the loose connective tissue between the necks of the two antebrachial bones and distally between the periosteal layers of the ulnar and radial bone and adjoining muscular tissue, mainly of the flexor muscles. It is discussed what role the latter receptors could play in the proprioceptive input from the region under consideration.

\section{Final conclusions}

It is summarized and concluded in chapter 8 , that the actual appearance of the morphological substrate of proprioception in a given continuity (unit) of muscular tissue/connective tissue/skeletal tissue presents mixtures or varieties of three characteristic configurations of the quartet: muscle spindle - GTO/Ruffini corpuscle - lamellated corpuscle - free nerve ending. This actual appearance is correlated to the architecture of the muscular and regular dense collagenous connective tissue of the area in which the concerned mechanoreceptors occur. So it may be stated that the quartet mentioned above represents the complete spectrum of mechanoreceptors in a joint region. In this way the three types of so-called capsular (or joint) receptors - Ruffini corpuscle, lamellated (or Pacini) corpuscle and free nerve ending - (Polacek, 1966) are combined with the three main types of so-called muscle receptors - muscle spindle, GTO and lamellated corpuscle - (Barker, 1974). Moreover, we concieve the basic organizational principle of mechanoreceptors of a muscular area not as muscle zones equipped with muscle spindles but as muscular tissue/connective tissue zones equipped 
with muscle spindles and GTO's, to be indicated as "monitor muscle spindle/GTO zones". In the case of the alignement of a proximal and distal muscle/connective tissue unit, such "monitor zones" appear as a GTO/muscle spindle/GTO zone intermediate between a distal and a proximal (stressconveying) regular dense collagenous connective tissue structure.

From this study we conclude that in principle an in-series unit of muscular tissue /regular dense collagenous connective tissue layer/skeletal element equipped with mechanosensitive substrate at the transitional areas between the various tissue components, constitutes the basic unit of the spatial organization of the substrate of proprioception in the locomotor apparatus. Such a unit may occur as a muscle fraction in-series with a muscle compartment wall that is shared with the muscular tissue of an adjacent muscle. It may also appear as a well-developed aponeurotic muscle compartment wall with muscle fascicles inserting unilaterally and with afferent nerve fibers reaching the related mechanoreceptors from the outer side.

The recognition of the ordening principle for the substrate of proprioception resulting from this study, makes it appropriate to reconsider a number of data which thus far have been assembled and discussed in the light of the muscle as the functional entity functioning in parallel with articular collagenous connective tissue structures. It may be concluded that the concept of inseries organization of muscular tissue and periarticular regular dense colllagenous connective tissue has produced valid i.e. verifiable presumptions about the spatial distribution - and its functional implications - of mechanoreceptors in the locomotor apparatus. 


\section{SAMENVATTING}

Rondom een gewricht functioneren spierweefsel en straf collageen bindweefsel bij het handhaven van de samenhang van en stabiliteit in het betreffende gewricht niet parallel (in de vorm van ligamenten en spieren), maar in de vorm van functionele eenheden waarin beide krachtdoorleidende weefseltypen in serie met elkaar en met de skeletelementen zijn georganiseerd (v.Mameren en Drukker, 1984). In vivo worden periarticulaire collagene bindweefselstructuren aangespannen tijdens bewegingen van de articulerende skeletelementen, mede als gevolg en op geleide van (veranderingen in) de spanning van het betreffende spierweefsel.

In dit licht dient het uitgangspunt waarop gewoonlijk de beschrijving van het morfologisch substraat van propriocepsis is gebaseerd - n.l. als zou dit werdeeld zijn over spieren enerzijds en articulaire (straf collagene) bindweefselstructuren anderzijds te worden herbezien. Daartoe zijn enkele hypothesen geformuleerd waarvan de implicaties getoetst zijn in het laterale ellebooggebied van de rat. De keuze voor deze regio als modelgebied is ingegeven door het feit dat inzicht in bouw en functie van bedoelde (spier-/bindweefsel-)eenheden vooral is gebaseerd op studies in de homologe regio bij de mens (v.Mameren, 1981; Drukker et al., 1983a-c).

Als belangrijkste hypothese is gesteld dat de functionale interpretatie van vórrkomen en ruimtelijke verdeling van het morfologisch substraat van propriocepsis gebaseerd dient te zijn op de ruimtelijke relatie van dat substraat met de architectuur van spierweefsel en straf collageen bindweefsel, waarbij ervan uit dient te worden gegaan dat deze laatste zijn georganiseerd als eén systeem voor de handhaving van gewrichtsstabiliteit.

Voorwaarde voor het toetsen van deze hypothese is:

- een integrale beschrijving van de architectuur van spier-en bindweefsel in een gewrichtsregio uitgaande wan de eerder vermelde principes, in combinatie met:

- een beschrijving van de driedimensionale ordening wan mogelijk morfologisch substraat van propriocepsis (voor zover aantoonbaar).

\section{Materiaal en methoden}

Ten behoeve van deze studie waren niet alleen technieken vereist om de verschillende typen mechanosensibele zenuweindigingen histologisch aan te tonen, maar ook technieken om de architectuur van spier-en bindweefsel alsmede de ruimtelijke ordening van het morfologisch substraat van propriocepsis, driedimensionaal te reproduceren. Het materiaal en de methoden die voor deze beide doeleinden zijn aangewend, worden beschreven in hoofdstuk 2 . Alle methoden zijn toegepast op jong volwassen ( 12 weken oud) witte laboratoriumratten (Lewis stam). Behalve mesoscopische, lichtmicroscopische en electronenmicroscopische standaardmethoden om zenuwstructuren in situ aan te tonen en een methode om bindweefselstructuren te prepareren, worden ook de technieken om 3Dreconstructies te vervaardigen van afferente zenuwvezels en bijbehorende eindigingen (in samenhang met de componenten van het bewegingsapparaat) in dit hoofdstuk beschreven. Tenslotte worden de methoden om het vórkomen van mechanoreceptoren te kwantificeren, toegelicht.

De architectuur van het spier- en bindweefsel

De architectuur van spier- en bindweefselstructuren, zoals die met behulp van dissectie en gecomputeriseerde 3D-reconstructie op basis van seriecoupes van complete in plastic ingesloten woorpoten zich tbaar is gemaakt, wordt in hoofdstuk 3 weergegeven. Eerst is de topografie van het houdings- en bewegingsapparaat in de betreffende regio 
aangegeven teneinde de gebruikte terminologie te definiëren en toe te lichten. Vervolgens wordt de architectuur van het straf collagene bindweefsel in relatie met de architectuur van het spierweefsel beschreven. In het proximale deel van de regio is een complex apparaat van straf collagene bindweefsellagen aanwezig, dat voornamelijk bestaat uit de begrenzingen van aanwezige spierkokers. Deze lagen convergeren naar de laterale epicondylus van de humerus en naar het olecranon. Het merendeel van de collagene vezels is uitgespannen tussen botstukken enerzijds en spiervezels anderzijds; ligamenten - gedefiniëerd als afzonderlijke, van bot naar bot lopende, collagene bindweefseleenheden - kunnen niet of nauwelijks worden beschreven. In plaats daarvan worden in de proximale elleboogregio spier/bindweefsel-eenheden onderscheiden, waarin spierweefsel en straf collageen bindweefsel in serie georganiseerd zijn en die niet samenvallen met de gebruikelijke anatomische indeling in spieren en ligamenten. Geconcludeerd wordt dat de ruimtelijke ordening en organisatie wan de spierweefselcomponenten in samenhang met de straf collagene bindweefselcomponenten in de rat overeenkomt met die bij de mens (i) en dat daarom de betreffende regio als model kan dienen om de relatie tussen de ruimtelijke ordening van het morfologisch substraat van propriocepsis en de in-serie architectuur van spier- en bindweefsel, te bestuderen (ii). De mogelijke rol van de aangetoonde architectuur bij het handhaven van de stabiliteit en integriteit van het ellebooggewricht, wordt besproken.

\section{Aanwezigheid en ruimtelijke ordening van mechanoreceptoren in de regio}

In hoofdstuk 4 worden de kwantitatieve gegevens betreflende annwezigheid en verdeling van mechanoreceptoren vermeld. Deze zijn bepaald teneinde het hier bestudeerde substraat te kunnen vergelijken met bestaande literatuur over aantallen receptoren in het houdings- en bewegingsapparaat. Bovendien lijkt het wenselijk om de ge- woonlijk toegepaste kwantitatieve parameters te heroverwegen in het licht van het uitgangspunt dat spierweefsel en straf collageen bindweefsel (als krachtdoorleidende componenten) in serie geschakeld zijn. De kwantitatieve gegevens betreffen voornamelijk het wóórkomen van spierspoelen en peeslichaampjes (GTO's) in het laterale elleboog-en voorpootgebied; zowel absolute aantallen zijn bepaald als aantallen per spier of per collagene bindweefselstructuur. Het relatieve aantal spierspoelen per spier is bepaald per gram spierweefsel (spierspoeldichtheid), per gram spier gecorrigeerd naar spiergrootte (spierspoelrijkdom) alsmede per spierzone (spierspoelvolume). Het aantal GTO's is zowel per spier als per collagene bindweefselstructuur bepaald. Als voorlopige conclusie wordt gesteld dat de toegepaste parameters niet geschikt zijn om de functionele karakteristiek van een spier aan te geven, omdat geen rekening wordt gehouden met de ruimtelijke ordening van de spierreceptoren als het substraat voor de perceptie van spanning, rek en beweging in de betreffende regio.

Uitgaande van de idee dat met name straf collagene bindweefselstructuren die in serie met spierweefsel zijn georganiseerd, krachtdoorleidend zijn, is de vraag gesteld of mechanosensibele zenuweindigingen aanwezig zijn in het hierboven genoemde proximale bindweefselapparaat (hoofdstuk 5). De verschillende componenten van dit bindweefselapparaat zijn-zowel apart als in situ - onderzocht op de aanwezigheid van zenuwweefselelementen. Met name bij de bindweefsellagen die de naar buiten (oppervlakkig) gerichte wanden van de betreffende spierkokers vormen, zijn zenuwnetwerken aangetoond. De betreffende zenuwvezels eindigen in Vater Pacini-achtige (druk)lichaampjes, peeslichaampjes (GTO's), vrije zenuweindigingen en (soms) in spierspoelen. Deze eindigingen liggen in het overgangsgebied tussen enerzijds (krachtdoorleidende) straf collagene bindweefselstructuren en anderzijds aangrenzend losmazig bindweefsel behorende bij het gewrichtskapsel of aanhechtende spier- 
vezels (waarmee de betreffende collagene structuur in serie geschakeld is). De vrije zenuweindigingen blijken ultramicroscopisch kenmerken te vertonen die karakteristiek worden geacht voor mechanosensibele zenuweindigingen. Dergelijke zenuweindigingen zijn ook aangetoond ín het straf collagene bindweefselapparaat, namelijk waar dit continu is met het periostale bindweefsel. De mogelijke functionele betekenis van het betreffende substraat wordt besproken in samenhang met de architectuur van het spier-en bindweefsel en het vóórkomen van spanning en rek in het gebied. Geconcludeerd kan worden dat de proximale wanden van de betreffende spierkokers goed zijn toegerust met mechanosensibel substraat in overeenstemming met de veronderstelde mate waarin deze bindweefsellagen krachtdoorleidend functioneren. Morfologisch bezien is er geen aanleiding te spreken van gewrichtsreceptoren wanneer daarmee receptors bedoeld worden die uitsluitend gedeformeerd (en daarmee gestimuleerd) worden door passieve rek van collagene bindweefselstructuren als gevolg van de verplaatsing van de skeletdelen waartussen deze structuren uitgespannen zouden zijn.

De resultaten van het onderzoek naar aanwezigheid en ruimtelijke verdeling van receptoren in de complementaire component van het houdings- en bewegingsapparaat, namelijk het spierweefsel, worden beschreven in hoofdstuk 6. Het betreft hier voornamelijk de driedimensionale reconstructie van de ruimtelijke verdeling van spierspoelen en peeslichaampjes (GTO's) in het bestudeerde gebied. Deze receptoren zijn geconcentreerd in die spierweefsel-zones die in serie georganiseerd zijn met distale krachtdoorleidende structuren van straf collageen bindweefsel (pezen) of met zulke structuren proximaal (wanden van spierkokers). Dit kan resulteren in spierweefselzones met mechanoreceptoren die tussen dergelijke (proximale en distale) structuren gesitueerd (uitgespannen) zijn. Dit leidt tot de definitie van "monitor-spier-/bindweefseleenheden" waarvan de topografie aansluit bij de architectuur van de eerder genoemde en beschreven in-serie eenheden van spieren bindweefsel. De verdelingspatronen van spierspoelen en peeslichaampjes worden besproken en in verband gebracht met gangbare concepten betreffende de ruimtelijke ordening van deze zintuigen. De conclusie is gewettigd dat de betreffende mechanoreceptoren geconcentreerd zijn in die gebieden waar verwacht mag worden dat de krachtdoorleiding over het ellebooggewricht plaats vindt (van spierweefsel via straf collageen bindweefsel naar botweefsel).

In hoofdstuk 7 wordt het voórkomen beschreven van zenuwweefsel-elementen in het periostale bindweefsel voorzover dit mede de spierkokers van de betreffende extensoren completeert. Plexiform georganiseerde zenuwvezels kunnen alleen in het periostale bindweefsel aan de dorsolaterale zijde van olecranon en ulnaschacht worden aangetoond. In de extensorenregio kunnen geen omkapselde zenuweindigingen worden aangetoond in het periost van de beide botstukken (met uitzondering van enkele GTO's aan het radiale periost). Aan de flexorenzijde zijn relatief grote Paciniforme lichaampjes aanwezig, zowel in het losmazige bindweefsel tussen collum radii en collum ulnae als tussen het collagene bindweefsel van het schachtperiost en aangrenzend spierweefsel (flexoren). De eventuele bijdrage van deze receptoren aan de proprioceptieve input uit de betreffende regio wordt besproken.

\section{Slotconclusies}

In hoofdstuk 8 wordt samenwattend geconcludeerd dat de uiteindelijke verschijningsvorm van het morfologisch substraat van propriocepsis in een bepaalde spierweefsel/bindweefsel/botweefsel-continuiteit op te vatten is als mengvormen of variaties van drie karakteristieke configuraties wan het viertal: spierspoel, lichaampje van Ruffini resp. GTO, Vater Pacini-achtige lichaampje en vrije zenuweindiging. Deze uiteindelijke verschijningsvorm wordt mede bepaald door de architectuur van het spier- 
weefsel en straf collageen bindweefsel in het gebied waar de betreffende mechanoreceptoren aanwezig zijn. Gesteld kan worden dat met bovengenoemd viertall het complete spectrum van mechanoreceptoren in een gewrichtsregio is aangeduid. Aldus worden de drie klassieke zogenaamde kapselreceptoren (of gewrichtsreceptoren) t.w. lichaampje van Ruffini, Vater Pacini-achtig lichaampje en vrije zenuweindiging (Polacek, 1966) gecombineerd met de drie voornaamste zogenaamde spierreceptoren t.w. spierspoel, peeslichaampje (GTO) en Vater Pacini-achtige lichaampje (Barker, 1974).

Bovendien wordt gesteld dat in een spierareaal niet een spierzone toegerust met spierspoelen het basisprincipe van organisatie van mechanoreceptoren vormt, maar een spier-/bindweefselzone toegerust met spierspoelen en GTO's, aan te duiden als "monitor spierspoel/GTO zones". Wanneer een distale en een proximale spier-/bindweefseleenheid direct in elkaars werlengde gesitueerd zijn, krijgen dergelijke "monitor zones" het karakter van een GTO/spierspoel/GTO zone, geschakeld tussen distale en proximale krachtdoorleidende bindweefselstructuren.

Uit ons onderzoek concluderen wij dat de basiseenheid van ruimtelijke ordening van het morfologisch substraat van propriocepsis in het houdings- en bewegingsapparaat wordt gevormd door een in-serie eenheid van een spierweefselzone/straf collagene bindweefsellaag/skeletdeel, toegerust met mechanosensibel substraat gelegen in de overgangszones tussen de verschillende componenten. Zo'n eenheid kan zich manifesteren als een gedeelte van een spier in serie met een spierkokerwand die (qua aanhechtingsgebied) gedeeld wordt met spierweefsel van een aangrenzende spier. Er kan ook sprake zijn van een min of meer aponeurotische spierkokerwand met spiervezels aan één zijde aanhechtend en met afferente zenuwvezels die de betreffende mechanoreceptoren vanaf de andere (dit is "buiten"-) zijde bereiken.

Het ordenend principe in het morfologisch substraat van propriocepsis zoals dat in deze studie wordt onderkend, werpt een ander licht op een aantal gegevens die tot dusverre zijn beschouwd in het licht van de spier als functionele eenheid (parallel aan articulaire collagene bindweefselstructuren functionerend). De conclusie is gewettigd dat het uitgangspunt dat spierweefsel en straf collageen bindweefsel als krachtdoorleidende componenten in serie zijn georganiseerd, een aantal valide (verificeerbare) aannames oplevert ten aanzien van de ruimtelijke ordening van mechanoreceptoren en de functionele implicaties daarvan - in het houdings- en bewegingsapparaat. 


\section{NAWOORD}

Zo is de (empirische) cyclus voorlopig rond. Een ronde langs al diegenen die op een of andere wijze aan de totstandkoming van dit werkstuk hebben bijgedragen, is voor mij niet een verplichting maar een genoegen.

Zeker als ik met jou begin, Els, mijn lieve vrouw en kameraad, maar vooral mijn trouwste "fan" toen het in de hectische topmaanden van dit project wel eens moeilijk leek in de afronding te blijven geloven. De uiterlijke en professionele steun van anderen moet het afleggen tegen de stille en trouwe morele steun wan jou. Mér dan wie ook besef(te) jij wat dit proefschrift voor mij in mijn biografie (wel en niet) betekent.

Ook van jullie, Maarten en Miriam van der Wal, mocht ik veel morele en praktische steun ontvangen. Niet in het minst omdat jullie me geholpen hebben om ook in het reine te komen met een noodzakelijkerwijze well erg magere vervulling van de "rol" als jullie vader gedurende het afgelopen jaar. Dat laatste geldt ook, op hun manier, voor jullie zusters Esther en Thea. Grote dank ben ik verschuldigd aan mijn promotor Prof. Dr. J. Drukker. Beste Jan, het is vooral door jouw inzet dat breedsprakigheid en "wolligheid" werd omgezet in exactheid en bondigheid. Aan jou heb ik in belangrijke mate te danken dat ik in Limburg heb gevonden wat ik destijds óók zocht: een gedegen wetenschappelijke vorming. Ik stel het op prijs dat je me daarbij de ruimte liet om binnen de marges van geld en middelen een eigen lijn in het onderzoek uit te zetten. Dat ik met jou regelmatig heb kunnen uitwisselen over de wetenschapstheoretische aspecten van morfologie en morfogenese, beschouw ik als een grote verrijking die veel verder reikt dan dit proefschrift. Dat geldt zeker ook voor de motiverende invloed die van je uit ging (en gaat) om naast goed onderzoek ook goed onderwijs in de humane anatomie en embryologie te verzorgen.

Beste Henk, jou te moeten bedanken als mijn co-promotor Dr. H. van Mameren, past nauwelijks bij hetgeen jij voor mij en voor dit proefschrift hebt betekent. Ik beschouw het als een groot goed dat je me de gelegenheid hebt gegeven om (in mijn eigen tempol) mee te groeien in de belangrijke innoverende concepten betreffende bouw en functie van het houdingsen bewegingsapparaat, die je met zoveel vuur en verve te berde brengt. Op de jou zo eigen manier heb je in al die jaren voortdurend mijn vraagstellingen en conclusies becommentariëerd en aangescherpt. Dat is onmisbaar geweest. Voor het met VBC-nauwkeurigheid corrigeren van de laatste drukproeven, ben ik je dankbaar. De avond dat we het "frame" van hoofdstuk 8 "in elkaar timmerden" is een dierbare herinnering en kenmerkend voor onze wijze van samenwerken. Niet enkel in de wetenschappelijke dieptepunten ben je er geweest om méé te denken en zaken op een rij te zetten, als vriend was je ook aanwezig wanneer het op het persoonlijke vlak mistig werd en optimaal functioneren moeilijk werd.

Dit onderzoek vindt zijn fundament in een grote hoeveelheid histotechnisch werk waaraan door velen is bijgedragen. Aan de ondersteuning door Mw. N. Rijskamp is de eerste aanzet van dit onderzoek grotendeels te danken. Veel technieken zijn in dle nog prille infrastructuur van onze vakgroep (destijds nog capaciteitsgroep) met jouw hulp, Norma, tot stand gekomen. Mw C. Consten en P. van Dijk namen daarna de histotechnische fakkel over. Het vele tel- en meetwerk dat schuil gaat achter menig tabel in dit proefschrift, is door jullie, beste Carla en Paul, met grote inzet en nauwgezetheid volvoerd. Van jou, Carla, is het vele Acetylcholinesterase in toto werk wel bijzonder vermeldenswaard. En ook in het 3D-reconstructie monnikenwerk ben je in al die jaren een trouwe en onmisbare medewerker geweest. Zonder al dat werk was het uiteindelijke resultaat ondenkbaar geweest.

Een belangrijk onderdeel van het onderzoek werd gevormd door de plastic inbeddingstechniek, aan de ontwikkeling waarwan vooral een bijdrage werd geleverd door Drs. A. Lataster. Maar meer dan dat, beste Arno, wil ik je bedanken voor het médenken bij het zoeken naar 
oplossingen voor de problemen die zich bij de 3D-reconstructie voordeden.

Ein wichtiger Beitrag zu dieser Thesis ist auch geliefert von Herrn Professor Z. Halata, Direktor der Abteilung für Funktionelle Anatomie des Anatomischen Institutes der Universitătsklinik Eppendorf in Hamburg (BRD). Sehr gute Erinnerungen habe Ich an die Gastfreundlichkeit und Unterstützung die Sie und Ihre Mitarbeiter mir gegeben haben während die beide Arbeitsperioden in Ihre Abteilung. Ohne die Erweiterung, die Sie mir auf der Ebene der EM-Mikroskopie geboten haben, wäre das Resultat nie so komplett gewesen. Das gilt auch für die Hilfe von Herrn. Th. Strasmann des gleichnämigen Institutes. Lieber Thomas, mit dir zusammen zu arbeiten war nicht allein fruchtbar und lehrsam, aber hat uns beiden auch viel Spass gemacht und mich sehr inspiriert. Wir haben uns sehr gut mit einander verstanden, gerade auch in nicht-wissenschaftliche Sachen.

J. van Dongen, experimenteel microchirurg van de vakgroep Heelkunde, wil ik bedanken voor de hulp bij het ontwikkelen van de intrauteriene tenotomie. Al moeten de directe resultaten van deze experimentele ingrepen in de toekomst nog hun neerslag vinden in een publikatie, wil ik toch hier van jouw grote steun melding maken, Johan. Ik heb veel van je geleerd. Een uitgebalanceerde dier-experimentele techniek is het resultaat.

De fraaie vormgeving van het proefschrift is goeddeels te danken aan de morfologisch vormgever van de vakgroep $H$. Rensema. Maar meer nog dan dat, beste Hans, is veel van het tot stand gekomen onderzoeksresultaat te danken aan jouw adviezen en de door jou nauwgezet uitgevoerde grafische drie-dimensionale reconstructies, die immers zo'n belangrijk bestanddeel van dit onderzoek vormden. Ik wil je vooral bedanken voor de momenten dat je die grote precisie en inzet volhield waar ik het wel eens voor "gezien" meende te kunnen houden: bijna altijd bleek je terecht volhardend te zijn. Vooral in de laatste fase van definitieve vormgeving heb je bergen werk verzet: het fraaie grafische resultaat van dit proefschrift was zonder jouw enorme inzet niet tot stand gekomen.

De benodigde computertechnische ondersteuning werd geleverd door J. Beursgens. Mede door jou, Jacques, veranderde ik van computer-scepticus in een dankbaar en enthousiast toepasser van allerlei fraaie programmatuur die door jou is ontwikkeld. Vooral het gegeven dat je nooit moe werd mij weer eens uitleg van zaken te geven, is een niet onbelangrijke factor voor het uiteindelijke resultaat. Je bijdrage aan de lay-out in de laatste fase is bijzonder waardevol geweest.

Mw. M. Drukker-Boxman wil ik bedanken voor het corrigeren van de tekst. Het was een hele opgave, Mia, om van "mijn" Engels verantwoord English te maken.

Ook de studenten die als stagiaire een bijdrage leverden aan dit onderzoek - A. van Loosbroek, W. van Kuyk, L. Boerboom en E. Burg - wil ik bedanken. Speciaal aan de bijdrage van Drs. E Burg heb ik veel te danken, niet in de laatste plaats de fraaie fotografie van de AChEase in toto preparaten. Beste Erna, het vele werk dat je in korte tijd verrichtte aangaande de innervatie van het bindweefsel, vormt een waardevolle bijdrage in het geheel van dit proefschrift.

Graag wil ik ook de morele steun vermelden die ik mocht ondervinden van G.H. van der Bie, huisarts te Zeist, voormalig collega aan het Anatomisch-Embryologisch Laboratorium te Utrecht. Door jou, beste Guus, is destijds mijn inspiratie voor de humane anatomie en embryologie in hoge mate aangewakkerd. En ook later, zij het op afstand, heb je me herhaaldelijk gemotiveerd om mij ook in wetenschappelijke zin met dit boeiende vakgebied uiteen te blijven zetten, ook als het paradigma me wel eens wat "krap" zat.

Ik sluit af met mw. E. Terwindt-Rouwenhorst, de "andere" Els. Je verzette een enorme berg werk door alle benodigde rattepoten te snijden, te tapen, te kleuren, op te plakken en in te sluiten. Ik wil je bedanken voor de nauwgezetheid waarmee je dat hebt gedaan, inclusief het grote aantal pilotstudies dat is verricht en voor de mate waarin je hebt mégedacht. 
En zo komt ook deze cirkel van Els tot Els rond. Wie een rangorde zoekt, zal die net zo vergeefs zoeken als het begin-en eindpunt van de cirkel. Dat geldt zeker ook voor de empirische cyclus waarvan dit proefschrift de voorlopige afsluiting vormt: er zijn gelukkig meer vragen ontstaan dan er zijn beantwoord.

Het gaat dus (hopelijk) verder.... 
, 


\section{CURRICULUM VITAE}

De schrijver van dit proefschrift werd op 17 februari 1947 geboren te Maarsseveen en volgde van 1959 tot 1965 middelbaar onderwijs aan het Christelijk Gymnasium te Utrecht. Na het behalen van het Gymnasium- diploma en van een colloquium doctum (1966) studeerde hij Geneeskunde aan de Rijksuniversiteit Utrecht, welke studie in 1973 werd afgesloten met het artsexamen. Van 1971 tot 1979 is hij werkzaam geweest als wetenschappelijk medewerker aan het Laboratorium voor medische Anatomie en Embryologie (Prof. Dr. W.J. van Doorenmaalen) van de Rijksuniversiteit Utrecht. Sedert 1979 is hij verbonden aan de vakgroep Anatomie/Embryologie (Prof. Dr. J. Drukker) van de Rijksuniversiteit Limburg, thans als universitair docent. In het kader van dit onderzoek werd tweemaal (1986 en 1987) gedurende enkele weken een werkbezoek gebracht aan het Anatomisch Instituut van de Universiteit van Hamburg (Prof. Dr. Med. Z. Halata) mede mogelijk gemaakt door de financiële steun van de Nederlandse organisatie voor zuiver-wetenschappelijk onderzoek Z.W.O. 


\section{LEGEND OF ABBREVIATIONS AND SYMBOLS AS USED IN TEXT AND FIGURES}

$\begin{array}{ll}\text { Symbol } & \begin{array}{l}\text { Abbre- } \\ \text { viation } \\ \text { (figures) }\end{array}\end{array} \quad$ NAME OF THE STRUCTURE

\section{MUSCULAR TISSUE STRUCTURES}

ECU

\section{SUPERFICIAL EXTENSOR MUSCLES}

Extensor carpi ulnaris muscle

ECU.uln.

epicondyle (humeral head)

EDL

Part of ECU mainly attached to the ulna (ulnar head)

EDC

Extensor digitorum lateralis muscle

ECR

Extensor digitorum communis muscle

ECR.br.

Extensor carpi radialis muscle

\section{5}

ECR.lo.

Extensor carpi radialis brevis muscle

Extensor carpi radialis longus muscle

DEEP EXTENSOR MUSCLES

EDP Extensor digiti primi muscle

EDP.uln. Part of EDP attached to the ulnar bone (ulnar head)

EDP.rad. Part of EDP attached to the radial bone (radial head)

EI

SUP

Extensor indicis muscle

Supinator muscle

TR

\section{OTHER EXTENSOR MUSCLES}

Triceps muscle

TR.lo.

TR.lat.

Long head of triceps muscle (caput longum)

TR.med.

ANC

BIC

BRA

FLEX

Lateral head of triceps muscle (caput laterale)

Medial head of triceps muscle (caput mediale)

Anconeus muscle

FLEXOR MUSCLES

Biceps brachii muscle

Brachialis muscle

Antebrachial flexor muscles

\section{CONNECTIVE TISSUE STRUCTURES}

a

a.a

a.b

a.c

$\mathrm{b}$

c

d ecu/edl ecu/edl.u

ecu/edl.1 ecu/edl.i edl/edc edclecr ext.fas.
Layers between ECU and EDL muscles

Part of ecu/edl to which muscle fascicles of ECU and ANC insert - including floor layer of ECU compartment Part of ecu/edl to which muscle fascicles of EDL insert Intramuscular distal prolongation of ecu/edl.u Intermuscular layer (septum) between EDL and EDC Intermuscular layer (septum) between EDC and ECR Superficial antebrachial (fascial) layer constituted by outer compartment walls of the superficial extensor muscles (and of the triceps muscle) 
d.a ret.ol. Part of ext.fas. constituted by outer compartment walls

(tr.fas.) of the lateral and medial head of the triceps muscle

(lateral olecranal retinaculum)

e s.s.

Supinator septum - connective tissue layer, part of the outer wall of the supinator muscle compartment

e.e s.s.im

Intramuscular extension of supinator septum

f l.c.uln.

Ulnar division of lateral collateral conective tissue layer

l.c.rad.

Radial division of lateral collateral connective tissue layer

$\mathrm{g}$

d.c.com.

Deep common connective tissue layer formed by proximal fusion of s.s., l.c.uln. and l.crad.

k ct.com.

Common layer formed by proximal fusion of d.c.com. with compartment walls of the superficial extensor muscles

$\mathrm{m}$

edp/ei.

Connective tissue layer (septum) between EDP and EI

n

zo.areol.

zo.int. superficial side of d.c.com.

0

Intermediate zone of connective tissue between the distal edge of os.sup. $(=\mathrm{D})$ and the proximal border of the supinator muscular tissue mass

p m.i.

Interosseous membrane

q.a

q.b

per.uln.

Periosteal layer of the ulnar bone

per.rad.

Periosteal layer of the radial bone

t.*

Tendon of * (follows abbreviation or symbol of muscle)

\section{OSSEOUS STRUCTURES}

A

A.A

A.B

A.C

A.D

B

B.A.

B.B.

C

C.A

C.B

C.C

D

I

II

III

IV hum.

cap.hum. tr.hum.

ep.lat.

cr.sup.

uln.

ol.uln.

cr.uln.

rad.

tub.rad.

cap.rad.

col.rad.

os.sup.
Humeral bone (Humerus)

Humeral capitulum (Capitulum humeri)

Humeral trochlea (Trochlea humeri)

Lateral humeral epicondyle (Epicondylus lateralis)

Lateral supracondylar crest of humerus (Crista supracondylaris)

Ulnar bone (Ulna)

Olecranal process (Olecranon)

Ulnar crest (dorsolateral ridge on ulnar shaft and olecranon)

Radial bone (Radius)

Radial tuberosity (Tuberositas radii)

Head of Radial bone (Caput radii)

Neck of Radial bone (Collum radii)

Supinator (sesamoid) bone in d.c.com. (Os supinatoris)

\section{NERVOUS STRUCTURES}

Pl.supf. Nerve plexus in ext.fas. "Plexus superficialis"

Pl.prof. Nerve plexus in zo.areol. "Plexus profundus"

N.Rad. Radial nerve (n. radialis)

R.prof. : Deep branch of Radial nerve (r.profundus) 